\title{
ANION EXCHANGE MEMBRANE DESIGN FOR
}

\author{
REVERSE ELECTRODIALYSIS
}

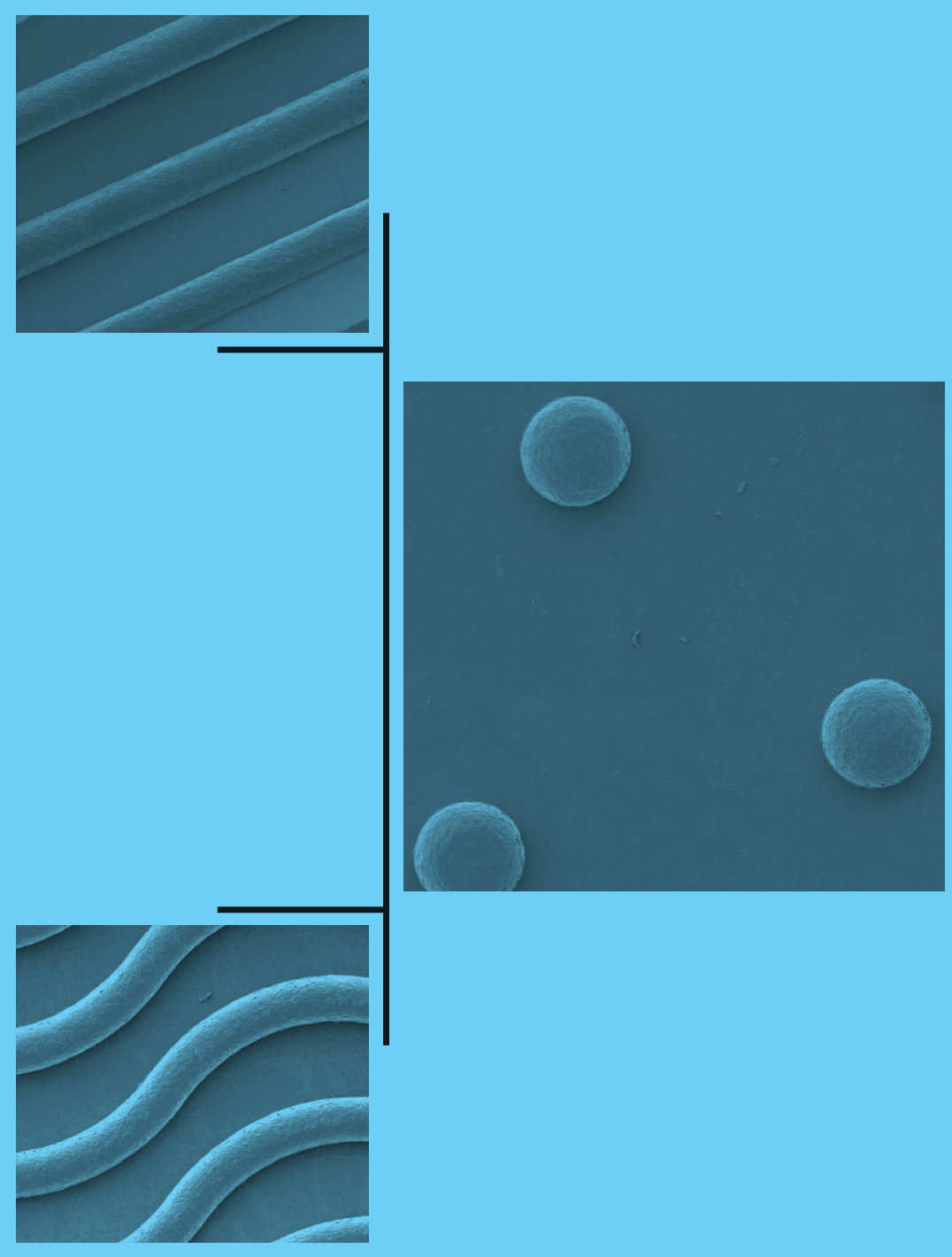

ENVER GÜLER 


\section{ANION EXCHANGE MEMBRANE DESIGN FOR REVERSE ELECTRODIALYSIS}


This research is supported by the TTIW cooperation framework of Wetsus, centre of excellence for sustainable water technology (www.wetsus.nl). Wetsus is funded by the Dutch Ministry of Economic Affairs (IOP-TTI), the European Community (European Fund for Regional Development and Seventh Framework Programme), Northern Netherlands Provinces (Peaks in the Delta), the city of Leeuwarden and the Province of Fryslân. Alliander, Eneco Energy, Fuji Film, Landustrie, Magneto Special Anodes, A. Hak and MAST Carbon of the research theme "Blue Energy" are acknowledged for the financial support.

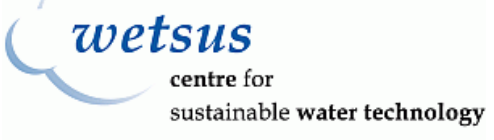

\section{Promotion committee}

Prof. Dr. Ir. D.C. Nijmeijer (promotor)

Dr. B.L. Mojet

Prof. Dr. J.F.J. Engbersen

Prof. Dr. N. Kabay

Prof. Dr. L.C. Rietveld

Dr. Ir. H.V.M. Hamelers

Prof. Dr. G. van der Steenhoven (chairman)
University of Twente

University of Twente

University of Twente

Ege University

Delft University of Technology

Wetsus

University of Twente

Cover design by E. Güler

Front cover: Micro-structured membrane surfaces designed for RED

Back cover: Ion transport between ion exchange membranes in RED stack

\section{Anion exchange membrane design for reverse electrodialysis}

ISBN: 978-90-365-3570-0

DOI: $10.3990 / 9789036535700$

URL: http://dx.doi.org/10.3990/1.9789036535700

Printed by Gildeprint Drukkerij, Enschede, The Netherlands

(C) 2013 Enver Güler, Enschede, The Netherlands 


\title{
ANION EXCHANGE MEMBRANE DESIGN FOR REVERSE ELECTRODIALYSIS
}

\author{
DISSERTATION
}

to obtain

the degree of doctor at the University of Twente, on the authority of the rector magnificus,

Prof. Dr. H. Brinksma

on account of the decision of the graduation committee,

to be publicly defended

on Friday the $31^{\text {st }}$ of January 2014 at 16:45

by

\section{Enver Güler}

born on February 22 $2^{\text {nd }}, 1984$

in Kardzhali, Bulgaria 
This thesis has been approved by:

Prof. Dr. Ir. D.C. Nijmeijer (promotor) 
to my parents Naciye and Ali Güler for all the support, love and encouragement...

"Life is your art. An open, aware heart is your camera. A oneness with your world is your film. Your bright eyes and easy smile is your museum."

A.E. Adams 


\section{CONTENTS}

Chapter 1. Introduction

1.1 Climate change and World`s energy dependence

1.2 Salinity gradient energy

1.3 Reverse electrodialysis process 6

$\begin{array}{ll}1.4 \text { Ion exchange membranes } & 10\end{array}$

1.5 Anion exchange membranes - preparation routes and design for RED 12

1.6 Scope and outline of the thesis 14

1.7 References 16

Chapter 2. Tailor-made anion exchange membrane fabrication for reverse electrodialysis - Tuning membrane properties 19

2.1 Introduction

2.2 Experimental 24

2.2.1 Materials 24

2.2.2 Preparation of homogeneous anion exchange membranes 25

2.2.2.1 Preparation of the casting solution 25

2.2.2.2 Synthesis of quaternized PECH 25

2.2.3 Characterization of AEMs 27

$\begin{array}{ll}\text { 2.2.3.1 SEM } & 27\end{array}$

$\begin{array}{ll}2.2 .3 .2 \text { FTIR } & 27\end{array}$

2.2.3.3 Area resistance 28

2.2.3.4 Permselectivity 28

2.2.3.5 Ion exchange capacity 28

2.2.3.6 Swelling degree $\quad 29$

$\begin{array}{ll}2.2 .3 .7 \text { Fixed-charge density } & 29\end{array}$

2.2.4 RED performance 30

2.2.4.1 The RED stack $\quad 30$

2.2.4.2 Feed water $\quad 30$

2.2.4.3 Electrochemical measurements 30

2.3 Results and discussion $\quad 31$

2.3.1 Characterization of PECH membranes 31

2.3.1.1 Morphology of PECH anion exchange membranes 31

2.3.1.2 FTIR 31

2.3.1.3 Effect of blend ratio on membrane properties 32

2.3.1.4 Effect of excess diamine ratio on the membrane properties 34

2.3.1.5 Effect of charge density on the membrane properties 36

2.3.2 Performance of PECH membranes in RED 38

2.3.2.1 Membrane performance in RED 38

2.3.2.2 Effect of film thickness on membrane performance in RED 40 
2.4 Conclusions $\quad 41$

2.5 Acknowledgements 42

2.6 References 43

Chapter 3. Performance-determining membrane properties $\quad 47$

3.1 Introduction $\quad 49$

3.2 Experimental $\quad 51$

3.2.1 Materials $\quad 51$

3.2.2 Preparation of IEMs 51

3.2.2.1 Synthesis of PECH anion exchange membranes $\quad 51$

3.2.2.2 Synthesis of SPEEK cation exchange membranes 52

3.2.3 Characterization of IEMs $\quad 52$

3.2.4 RED performance $\quad 54$

3.2.4.1 RED setup $\quad 54$

3.2.4.2 Experimental power density $\quad 55$

3.2.4.3 Theoretical power density 55

3.2.4.4 Multiple linear regression (MLR) modeling and analysis of variance $\begin{array}{ll}\text { (ANOVA) } & 57\end{array}$

$\begin{array}{ll}3.3 \text { Results and discussion } & 57\end{array}$

$\begin{array}{ll}\text { 3.3.1 Membrane characteristics } & 57\end{array}$

3.3.1.1 Characterization of IEMs $\quad 57$

3.3.1.2 Effect of thickness on area resistance and permselectivity $\quad 59$

3.3.1.3 Effect of IEC and SD on area resistance and permselectivity 60

3.3.1.4 Effect of charge density on permselectivity and area resistance $\quad 61$

$\begin{array}{lll}\text { 3.3.2 RED performance } & 63\end{array}$

3.3.2.1 Power density in relation to membrane permselectivity and area resistance 63

3.3.2.2 Experimental power density in RED $\quad 65$

3.3.2.3 Multiple linear regression (MLR) and ANOVA analysis 68

3.4 Conclusions $\quad 73$

$\begin{array}{ll}3.5 \text { Acknowledgements } & 74\end{array}$

$\begin{array}{ll}3.6 \text { Nomenclature } & 74\end{array}$

$\begin{array}{ll}3.7 \text { References } & 76\end{array}$

Chapter 4. Monovalent-ion-selective membranes - Fabrication and $\begin{array}{ll}\text { characterization } & 79\end{array}$

$\begin{array}{ll}4.1 \text { Introduction } & 81\end{array}$

$\begin{array}{ll}4.2 \text { Theory } & 84\end{array}$

4.2.1 Transport numbers 84

4.2.2 Experimental and theoretical power density $\quad 85$

4.2.3 Current-voltage (I-V) relations and surface homogeneity $\quad 86$

4.2.4 Transition time for fouling determination 88 


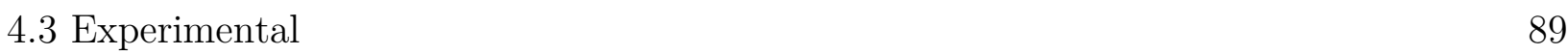

4.3.1 Materials $\quad 89$

4.3.2 Monovalent-ion-selective membranes 90

$\begin{array}{ll}\text { 4.3.3 Characterization of surface properties } & 92\end{array}$

4.3.3.1 SEM-EDX analysis $\quad 92$

$\begin{array}{ll}\text { 4.3.3.2 XPS analysis } & 92\end{array}$

$\begin{array}{ll}\text { 4.3.3.3 Water contact angle } & 92\end{array}$

4.3.3.4 Surface roughness 93

4.3.4 Electrochemical characterization $\quad 93$

4.3.4.1 Current-voltage curves (I-V) and limiting current density (LCD) 93

4.3.4.2 Transport numbers 94

4.3.5 Evaluation of antifouling potential $\quad 94$

$\begin{array}{ll}\text { 4.3.6 RED performance } & 95\end{array}$

4.3.6.1 RED setup $\quad 95$

4.3.6.2 Experimental and theoretical power density 96

$\begin{array}{ll}4.4 \text { Results and discussion } & 96\end{array}$

$\begin{array}{ll}\text { 4.4.1 Membrane preparation } & 96\end{array}$

4.4.2 Characterization of membrane surface $\quad 97$

$\begin{array}{ll}\text { 4.4.2.1 SEM-EDX analysis } & 97\end{array}$

$\begin{array}{lr}\text { 4.4.2.2 XPS analysis } & 99\end{array}$

4.4.2.3 Water contact angle 102

4.4.2.4 Surface roughness 103

$\begin{array}{ll}4.4 .3 \text { Electrochemical characterization } & 104\end{array}$

4.4.3.1 Current-voltage (I-V) curves and limiting current density (LCD) 104

$\begin{array}{ll}\text { 4.4.3.2 Transport numbers } & 108\end{array}$

4.4.4 Evaluation of antifouling potential $\quad 110$

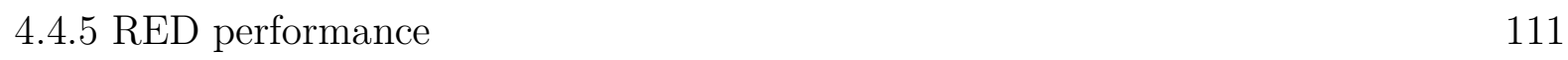

$\begin{array}{ll}4.5 \text { Conclusions } & 114\end{array}$

4.6 Acknowledgements 115

$\begin{array}{ll}4.7 \text { Nomenclature } & 115\end{array}$

4.8 References 116

Chapter 5. Micro-structured membranes - Design and characterization 121

5.1 Introduction 123

5.2 Experimental $\quad 127$

$\begin{array}{ll}5.2 .1 \text { Materials } & 127\end{array}$

5.2.2 Preparation of tailor-made anion exchange membranes $\quad 128$

$\begin{array}{ll}\text { 5.2.2.1 Preparation of flat membranes } & 128\end{array}$

5.2.2.2 Preparation of structured membranes 128

5.2.3 Membrane characterization $\quad 130$

5.2.3.1 SEM 130 
5.2.3.2 Area resistance

5.2.3.3 Permselectivity 131

5.2.4 RED performance 131

5.2.4.1 Flow distribution 131

5.2.4.2 RED setup 132

5.2.4.3 Power density 134

5.3 Results and discussion $\quad 135$

5.3.1 Membrane preparation $\quad 135$

$\begin{array}{ll}\text { 5.3.2 Membrane characterization } & 136\end{array}$

5.3.2.1 SEM 136

5.3.2.2 Area resistance and permselectivity 137

$\begin{array}{ll}\text { 5.3.3. RED performance } & 138\end{array}$

5.3.3.1 Flow distribution 138

$\begin{array}{ll}\text { 5.3.3.2 Gross power density } & 139\end{array}$

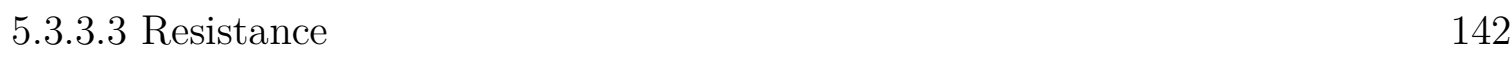

5.3.3.4 Pumping power 144

$\begin{array}{ll}\text { 5.3.3.5 Net power density } & 147\end{array}$

5.4 Conclusions 148

5.5 Acknowledgements 149

$\begin{array}{ll}5.6 \text { Nomenclature } & 149\end{array}$

5.7 References 150

Chapter 6. General conclusions and outlook 153

6.1 General conclusions $\quad 155$

$\begin{array}{ll}6.2 \text { Outlook } & 158\end{array}$

6.2.1 Further development of RED membranes and alternative routes for $\begin{array}{ll}\text { production } & 158\end{array}$

6.2.2 Hydrodynamics and stack design 160

$\begin{array}{ll}6.3 \text { References } & 162\end{array}$

Summary 163

$\begin{array}{ll}\text { Samenvatting } & 165\end{array}$

$\begin{array}{lr}\text { About the author } & 169\end{array}$

$\begin{array}{ll}\text { Acknowledgements } & 173\end{array}$ 


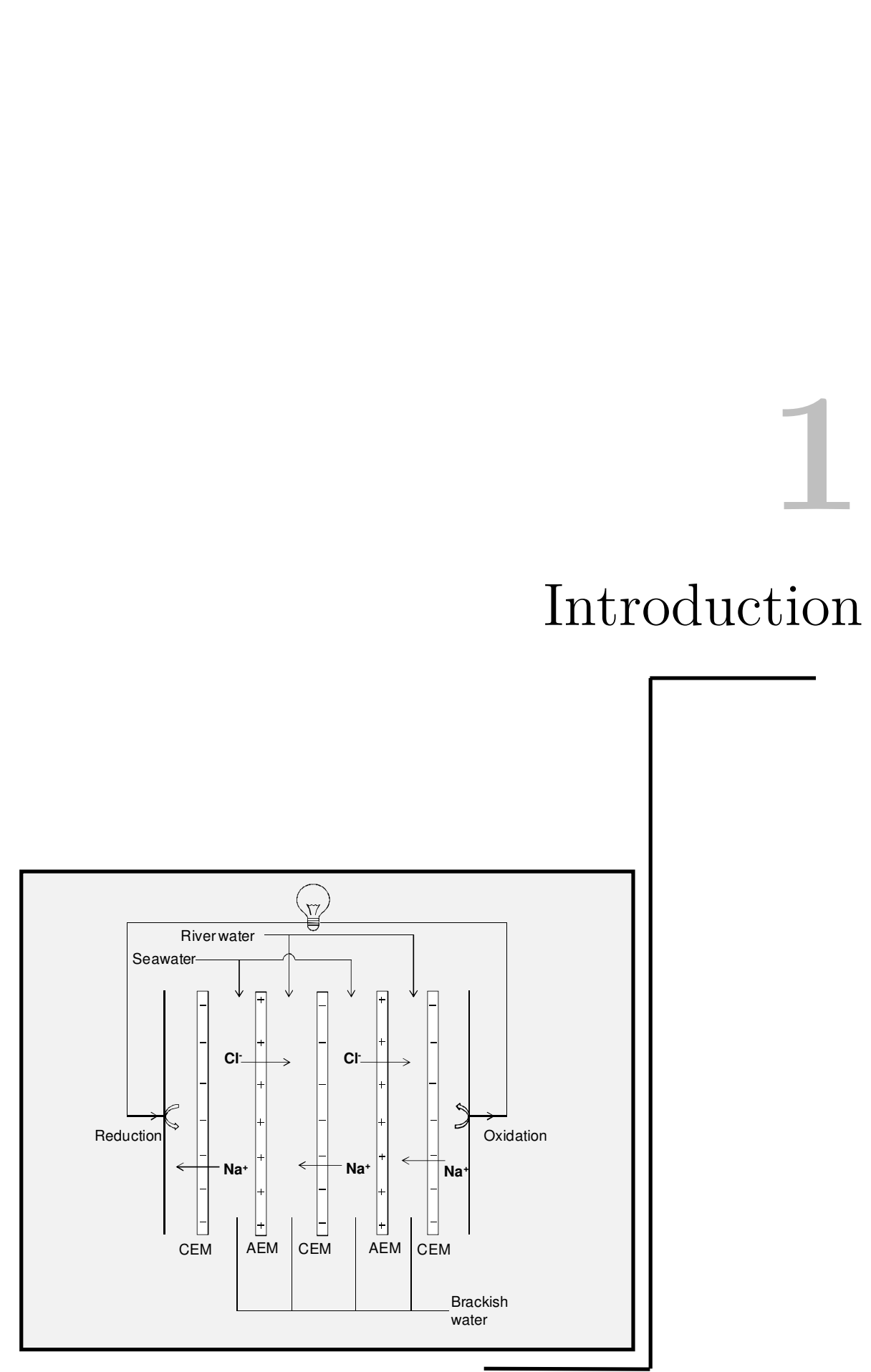


\begin{abstract}
The aim of this research is to investigate the design and development of a reverse electrodialysis process with a strong focus on anion exchange membrane preparation, characterization and modification in relation to the RED process performance. This chapter discusses the global potential of salinity gradient energy, its concept and basic principles and gives a basic introduction in ion exchange membranes, more specifically anion exchange membranes. At the end, the scope and outline of this thesis are presented.
\end{abstract}




\subsection{Climate change and World`s energy dependence}

The Earth`s climate has changed throughout history. The report of the Intergovernmental Panel on Climate Change (IPCC) showed that this change is of particular significance and that it is very likely human-induced [1]. Over the last 50 years, human activities -particularly burning of fossil fuels- have released huge quantities of carbon dioxide and other greenhouse gases to affect the global climate. The atmospheric concentration of carbon dioxide has increased by more than $30 \%$ since pre-industrial times, trapping more heat in the lower atmosphere [2]. Moreover, it is a fact that global sea level has risen about $17 \mathrm{~cm}$ in the last century, and the rate in the last decade is nearly double that of the last century [3]. In addition, the climate model projections by the IPCC indicate that during the $21^{\text {st }}$ century the global surface temperature is likely to rise further 1.1 to $6.4{ }^{\circ} \mathrm{C}$ compared to the years 1980-1999 [4].

Considering all these environmental impacts and global climate change, the need for renewable, environmental-friendly energy is widely realized and huge efforts to extract energy and/or convert it into useful forms are being implemented globally. Well-known 'green energy' sources including solar, wind, biomass, ocean thermal, wave and tidal have been already taken into account to meet the energy needs.

In December 1997, in Kyoto, Japan, more than 150 industrialized nations agreed to reduce their greenhouse gas emissions, as part of an international agreement on climate change called the Kyoto Protocol. Since the Kyoto protocol and the report of the IPCC on carbon capture and storage, there is an emerging need to reduce the emission of $\mathrm{CO}_{2}$ to the atmosphere [5]. The Kyoto protocol introduced in 1997 is crucial since it was confirmed by the countries which cover more than half of the global greenhouse gas emissions [6]. In addition, the European Union (EU) agreed to achieve some targets, so-called '20-20-20` targets, which set three key objectives for 2020 compared to the 1990 levels [7]:

- A 20\% reduction in EU greenhouse gas emissions compared to 1990 levels;

- Raising the share of EU energy consumption produced from renewable sources to $20 \%$;

- A $20 \%$ improvement in the EU's energy efficiency.

In principle, three alternative strategies can be proposed to reduce the $\mathrm{CO}_{2}$ emissions which are 1) the reduction of the energy consumption, 2) the efficient use of energy sources, and 3) the use of alternative energy sources with reduced or no $\mathrm{CO}_{2}$ emission. 
Thus, these strategies promote the establishment of sustainable energy alternatives, and come along with quite some challenges.

The huge risk of climate change associated with the use of fossil fuels makes the supply of sufficient energy increasingly difficult. At the same time, global warming, increasing fuel prices and depletion of fossil fuel stocks forces the developments in the direction of alternative energy sources. Considering also that the energy sector is by far $(\sim 50 \%)$ the largest contributor to the worldwide emissions of $\mathrm{CO}_{2}$ and poses a significant potential for the worldwide reduction of $\mathrm{CO}_{2}$ emissions, the use of alternative energy sources has become a must-follow strategy to reduce the negative impacts of global warming [8]. The share of renewable energy in the EU energy mix has risen steadily to some $10 \%$ of the gross final energy consumption in 2008. In 2009, $62 \%$ of newly installed electricity generation capacity in the EU was from renewable sources, mainly wind and solar. Despite accounting for one-fifth of the world's energy use, the EU continues to have less influence on international energy markets than its economic weight would suggest [9]. Global energy markets are becoming tighter and there is still a huge gap to meet those energy policy aims. Until now, only $7 \%$ of the primary energy consumption is covered by the use of renewable energy sources. When EU's commitment to cover $20 \%$ share of renewable sources is considered, the huge open field for sustainable power generation technologies is once more obvious.

\subsection{Salinity gradient energy}

Due to the depletion of fossil fuel sources, increasing oil prices and emissions of $\mathrm{CO}_{2}$, energy harvesting from renewable sources have received significant attention [10]. Oceans and surface waters contribute to these types of energy such as thermal, waves and tidal power. Perhaps less well-known is salinity gradient energy, which is the energy available from mixing of two aqueous solutions of different salinities, such as seawater and river water. Salinity gradient energy has been estimated to be the second largest marine-based energy source, with a total estimated global potential for power production of about 2.4-2.6 TW, which exceeds the global electricity demand for 2011 (2.3 TW) [11-14]. It is a clean (no emissions of $\mathrm{CO}_{2}, \mathrm{SO}_{2}$, or $\mathrm{NO}_{\mathrm{x}}$ ), sustainable technology that generates energy by mixing of water streams with different salinity. Salinity gradient power can be utilized worldwide in specific locations where salt solutions of different salinity mix, for instance, where river water flows into the sea, or where industrial brine is discharged. 
The theoretically available amount of energy obtainable from the controlled mixing of a concentrated salt solution and a diluted salt solution can be calculated from the Gibbs free energy, where the total amount of energy available from $1 \mathrm{~m}^{3}$ of a concentrated and $1 \mathrm{~m}^{3}$ of diluted salt solution can be determined from the Gibbs energy of the system after mixing, subtracted by the Gibbs energy before mixing [10, 15-16]:

$\Delta \mathrm{G}_{\mathrm{mix}}=\mathrm{G}_{\mathrm{b}}-\left(\mathrm{G}_{\mathrm{c}}-\mathrm{G}_{\mathrm{d}}\right)$

where $\Delta \mathrm{G}_{\mathrm{mix}}$ is the free energy of mixing $\left(\mathrm{J} \cdot \mathrm{mol}^{-1}\right), \Delta \mathrm{G}_{\mathrm{b}}$ is the Gibbs energy of the mixture, the brackish water $\left(\mathrm{J} \cdot \mathrm{mol}^{-1}\right), \mathrm{G}_{\mathrm{c}}$ is the Gibbs energy of the concentrated salt solution (e.g. seawater) $\left(\mathrm{J} \cdot \mathrm{mol}^{-1}\right)$ and $\mathrm{G}_{\mathrm{d}}$ is the Gibbs energy of the diluted salt solution (e.g. river water) $\left(\mathrm{J} \cdot \mathrm{mol}^{-1}\right)$.

The Gibbs energy of an ideal solution is the sum of chemical potentials of the individual chemical components present in that solution:

$\mathrm{G}=\sum \mu_{\mathrm{i}} \mathrm{n}_{\mathrm{i}}$

In this equation, $\mathrm{G}$ is the Gibbs energy of the system $\left(\mathrm{J} \cdot \mathrm{mol}^{-1}\right), \mu_{i}$ is the chemical potential of component $i$ in the solution $\left(J \cdot \mathrm{mol}^{-1}\right)$, and $n_{i}$ is the number of moles of component $\mathrm{i}$ in the solution. The chemical potential of the component $i$ in an ideal solution can be simplified when no pressure change or charge transport is considered upon mixing of a concentrated and a diluted salt solution:

$\mu_{\mathrm{i}}=\mu_{\mathrm{i}}^{0}+\mathrm{RT} \ln \mathrm{x}_{\mathrm{i}}$

where $\mu_{\mathrm{i}}^{0}$ is the molar free energy under standard conditions $\left(\mathrm{J} \cdot \mathrm{mol}^{-1}\right), \mathrm{R}$ is the universal gas constant $\left(8.314 \mathrm{~J} \cdot(\mathrm{mol} \cdot \mathrm{K})^{-1}\right), \mathrm{T}$ is the absolute temperature $(\mathrm{K}), \mathrm{x}_{\mathrm{i}}$ is the mol fraction of component i. When Equation (1.3) is substituted in Equation (1.1) and $\mathrm{n}$ is replaced by solution concentration $\mathrm{c}\left(\mathrm{mol} \cdot \mathrm{m}^{-3}\right)$ and volume $\mathrm{V}\left(\mathrm{m}^{3}\right)$, the final Gibbs free energy of mixing can be described as follows:

$\Delta \mathrm{G}_{\text {mix }}=\sum_{\mathrm{i}}\left[\mathrm{c}_{\mathrm{i} . \mathrm{c}} \mathrm{V}_{\mathrm{c}} \mathrm{RT} \ln \left(\mathrm{x}_{\mathrm{i}, \mathrm{c}}\right)+\mathrm{c}_{\mathrm{i} . \mathrm{d}} \mathrm{V}_{\mathrm{d}} \mathrm{RT} \ln \left(\mathrm{x}_{\mathrm{i}, \mathrm{d}}\right)-\mathrm{c}_{\mathrm{i} . \mathrm{b}} \mathrm{V}_{\mathrm{b}} \mathrm{RT} \ln \left(\mathrm{x}_{\mathrm{i}, \mathrm{b}}\right)\right]$

With Equation (1.4) the theoretical available amount of energy from the mixing of two solutions can be calculated, and thus the theoretical amount of energy from salinity 
gradients can be determined. For example, the theoretical amount of energy from mixing of $1 \mathrm{~m}^{3}$ seawater $(0.5 \mathrm{M} \mathrm{NaCl})$ and $1 \mathrm{~m}^{3}$ river water $(0.01 \mathrm{M} \mathrm{NaCl})$ at a temperature of $293 \mathrm{~K}$ is $1.4 \mathrm{MJ}$.

However, in practice, the chemistry of seawater and river water is much more complex as it does not consist of only pure sodium chloride. When this is combined with other factors such as mass transfer limitations, pressure drop, and other limitations such as resources availability, only a part of this theoretical energy can be recovered, but still it is a huge renewable energy source.

While several methods do exist for the extraction of salinity gradient energy, there are two most widely studied techniques based on selective membranes (i.e. the media where the mixing is limited to one of the components, either the solvent, water or solutes, dissolved salts): pressure retarded osmosis (PRO) and reverse electrodialysis (RED). PRO is the opposite version of a commercially mature membrane process, reverse osmosis (RO), whereas RED is the opposite version of conventional electrodialysis (ED). PRO is the technology where two solutions of different salinity are brought into contact by a semi-permeable membrane that only allows the transport of the solvent (water) and retains the solute (dissolved salts). In PRO, an external device a so-called turbine is used for energy conversion [17-18]. In RED, ion selective membranes are used to allow selective transport of ions in the solution only. The charge transport is directly converted into electrical energy at two electrodes in the system.

Each technology has its own field of application: RED is considered to be more attractive for power generation using river and seawater, whereas PRO seems to be more beneficial for power generation using concentrated saline brines [14]. Although the costs for ED membranes (which have been widely used for RED) are about 2-3 times higher than for RO membranes, the installed costs are probably in the same order of magnitude since high pressure equipment and external turbine are required for PRO. In addition, PRO requires large amounts of water transported through the membrane, thus making the process more dependent on fouling limitations.

\subsection{Reverse electrodialysis process}

The use of RED as a technology to extract electricity from salinity gradients was first recognized in the early 1950`s when Pattle constructed a small stack that produced a maximum electromotive force of 3.1 Volts [19-20]. This approach was further 
developed in the late 1970`s by Weinstein and Leitz [12] and later by Lacey [21]. Today, the RED process developed such that it may be combined with hybrid systems such as with the seawater desalination systems [22], the pressure retarded osmosis [23], and the microbial power cell [24]. In a reverse electrodialysis system for power generation from salinity gradients, a number of cells are stacked between a cathode and an anode (Figure 1.1). The stack is similar to that of conventional electrodialysis [25-27], however, the compartments between the membranes are alternately filled with a concentrated salt solution and a dilute salt solution. These solutions with different salinity are brought into contact through an alternating series of anion exchange membranes (AEM) and cation exchange membranes (CEM) [28-31]. The ion exchange membranes inside the stack are separated by spacers consisting of a non-conductive fabric. The spacer net prevents the membranes from touching each other and direct the flow. At the same time however, they reduce the active membrane area available for ionic transfer because of the non-conducting character of the spacers, which is undesired. In the stack, anions migrate through the AEM towards the anode and cations move through the CEM towards the cathode. The driving force of this ionic migration is the difference in chemical potential between both solutions, e.g. seawater and river water; thus the direction of the ionic migration is from the concentrated solution to the diluted solution for a sodium chloride solution. The salinity gradient results in a potential difference (e.g. about $80 \mathrm{mV}$ for seawater and river water) over each membrane, the so-called membrane potential. The sum of the potential differences over each membrane is the electric potential difference between the outer compartments of the membrane stack. At the electrodes redox reactions occur to convert this electrochemical potential directly into electricity. As a redox pair, often a homogeneous $\mathrm{K}_{4} \mathrm{Fe}(\mathrm{CN})_{6} / \mathrm{K}_{3} \mathrm{Fe}(\mathrm{CN})_{6}$ redox system can be chosen, because it does not cause net chemical reactions and therefore the power losses are low. The iron(III) complex is reduced at the cathode and the iron(II) complex is reoxidized at the anode:

$$
\mathrm{Fe}(\mathrm{CN})_{6}^{3-}+\mathrm{e} \leftrightarrow \mathrm{Fe}(\mathrm{CN})_{6}^{4-}
$$

To maintain electroneutrality, electrons migrate from anode to cathode through an external electrical circuit and power an external load or energy consumer, e.g. a light bulb in Figure 1.1, included in the circuit (Figure 1.1). 


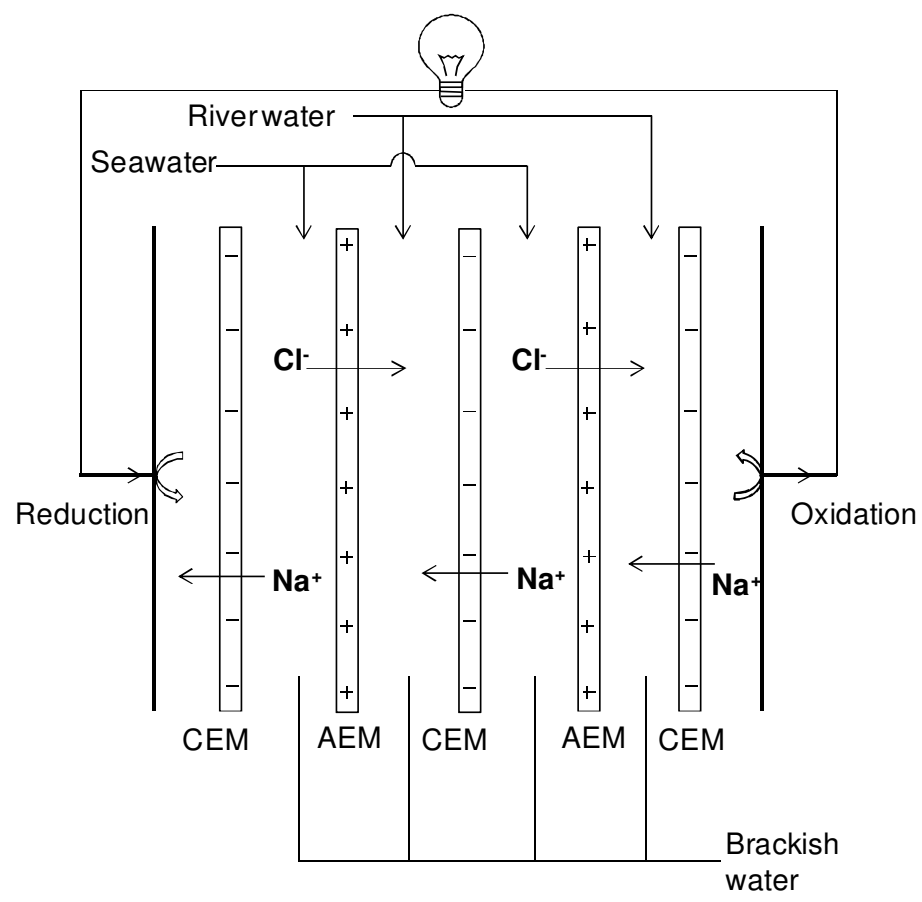

Figure 1.1. Principle of reverse electrodialysis (RED).

The theoretical value of the potential over an ion exchange membrane for an aqueous monovalent ion solution (e.g. $\mathrm{NaCl}$ ) can be calculated using the Nernst equation [21, 32]:

$\Delta \mathrm{V}^{\circ}=\mathrm{N} \frac{2 \alpha \mathrm{RT}}{\mathrm{zF}} \ln \left(\frac{\mathrm{a}_{\mathrm{c}}}{\mathrm{a}_{\mathrm{d}}}\right)$

where $\Delta \mathrm{V}^{\circ}$ is the theoretical stack potential $(\mathrm{V}), \alpha$ is the average membrane permselectivity of an anion and a cation exchange membrane pair (-), $\mathrm{N}$ is the number of membrane cells (-), $\mathrm{R}$ is the gas constant $\left(8.314 \mathrm{~J} \mathrm{~mol}^{-1} \mathrm{~K}^{-1}\right), \mathrm{T}$ is the absolute temperature $(\mathrm{K}), \mathrm{z}$ is the electrochemical valence, $\mathrm{F}$ is the Faraday constant $(96485 \mathrm{C}$ $\left.\mathrm{mol}^{-1}\right), \mathrm{a}_{\mathrm{c}}$ is the activity of the concentrated salt solution $\left(\mathrm{mol} \mathrm{l}^{-1}\right)$ and $\mathrm{a}_{\mathrm{d}}$ is the activity of the diluted salt solution $\left(\mathrm{mol} \mathrm{l}^{-1}\right)$. The power produced is related to the electrochemical potential drop across the membrane, $\Delta \mathrm{V}^{\circ}$, and an external load resistance resulting in:

$\mathrm{W}=\mathrm{I}^{2} \mathrm{R}_{\text {load }}=\frac{\left(\mathrm{V}^{\circ}\right)^{2} \mathrm{R}_{\text {load }}}{\left(\mathrm{R}_{\text {stack }}+\mathrm{R}_{\text {load }}\right)^{2}}$

In this equation, $I$ is the current $(A), R_{\text {load }}$ is the resistance of the load $(\Omega), R_{\text {stack }}$ is the stack resistance $(\Omega)$ and $\mathrm{V}^{\circ}$ is the open stack circuit potential $(\mathrm{V})$. The stack resistance is the sum of the resistances of the anion and cation exchange membranes, 
the feed water compartments (i.e. seawater and river water compartments), the electrodes and their compartments:

$R_{\text {stack }}=\frac{N}{A} \cdot\left(R_{\text {aem }}+R_{\text {cem }}+\frac{d_{c}}{\kappa_{c}}+\frac{d_{d}}{\kappa_{d}}\right)+R_{e l}$

where $\mathrm{A}$ is effective membrane area $\left(\mathrm{m}^{2}\right), \mathrm{R}_{\mathrm{aem}}$ is the anion exchange membrane resistance $\left(\Omega \cdot m^{2}\right), R_{c e m}$ is the cation exchange membrane resistance $\left(\Omega \cdot m^{2}\right), d_{c}$ is the thickness of the concentrated saltwater compartment $(m), d_{d}$ is the thickness of the diluted saltwater compartment $(\mathrm{m}), \boldsymbol{\kappa}_{\mathrm{c}}$ is the conductivity in the concentrated saltwater compartment $\left(\mathrm{S} \cdot \mathrm{m}^{-1}\right), \kappa_{\mathrm{d}}$ is the conductivity in the diluted saltwater compartment $\left(\mathrm{S} \cdot \mathrm{m}^{-1}\right)$ and $\mathrm{R}_{\mathrm{el}}$ is the ohmic resistance of both electrodes and their compartments $(\Omega)$. The maximum power output of the system is obtained when $\mathrm{R}_{\text {load }}$ is equal to the resistance of the stack $\left(\mathrm{R}_{\text {stack }}\right)$. [12, 21, 33]. Thus, the maximum power output can be simplified into:

$\mathrm{W}_{\max }=\frac{\left(\mathrm{V}^{\circ}\right)^{2}}{4 \mathrm{R}_{\text {stack }}}$

Consequently, the power density (power output per unit membrane area, $\mathrm{W}_{\text {gross}}$ ) can be calculated from $\mathrm{W}_{\max }$ :

$\mathrm{W}_{\text {gross }}=\frac{\mathrm{W}_{\max }}{2 \cdot \mathrm{A} \cdot \mathrm{N}}$

where $W_{\text {gross }}$ is the maximum gross power density $\left(\mathrm{W} \cdot \mathrm{m}^{-2}\right), \mathrm{W}_{\max }$ is maximum power output (W), A is effective area of a single membrane $\left(\mathrm{m}^{2}\right)$ and $\mathrm{N}$ is number of membrane cells.

The main dominating membrane related factors in the maximum power density in a RED stack are the membrane permselectivity (which affects the membrane potential, Equation (1.6)), the membrane resistance and the resistance of the river water compartments (which affect mainly the stack resistance, Equation (1.8)) [12, 21, 34]. Thus, it is realized that ion exchange membrane properties play a significant role in determining the RED performance. 


\subsection{Ion exchange membranes}

A general definition of a membrane is a selective barrier that separates and/or contacts two adjacent phases and allows or promotes the exchange of matter, between the phases [27]. When these barriers carry charged groups, more specifically, it is called ion exchange membrane. There are two types of ion exchange membranes: (1) cation exchange membranes which contain negatively charged groups fixed to the polymer matrix; and (2) anion exchange membranes which contain positively charged groups fixed to the polymer matrix. In a cation exchange membrane, transport of cations is allowed whereas anions are retained because of their charge, which is the same as that of the fixed charges in the polymer matrix. In anion exchange membranes, all cations are more or less excluded since the fixed charges are positive in the polymer matrix. Anion exchange membranes have the capability to carry anions (i.e. which are referred as counter-ions) only while cations (co-ions) are retained (Figure 1.2).

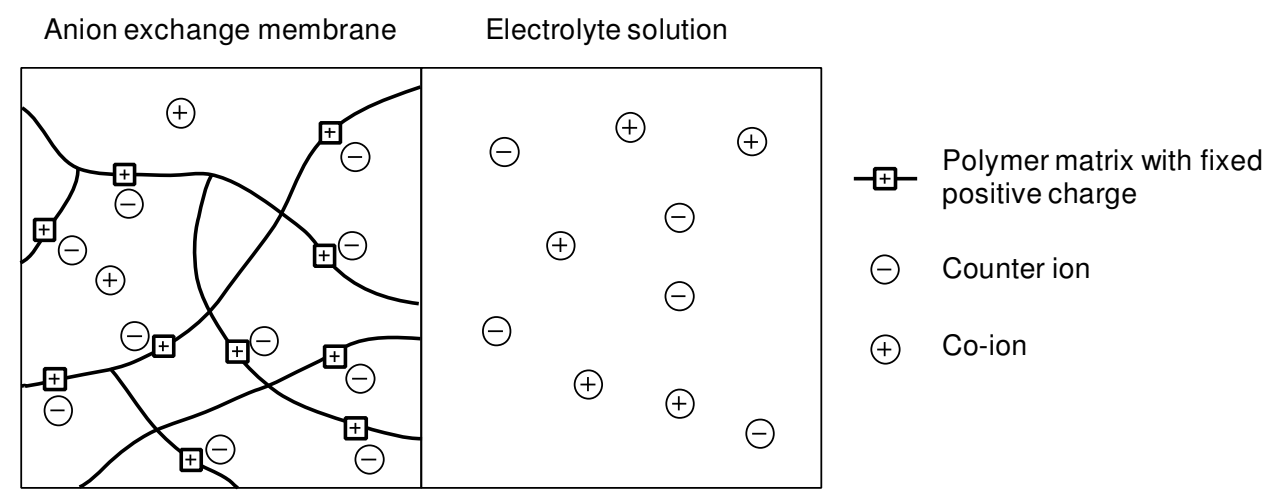

Figure 1.2. Principle of ionic separation by an anion exchange membrane.

In principle, only counterions are able to permeate, while co-ions are excluded by the fixed charges. This principle was first explained by Donnan exclusion [26]. In an electrolyte solution, the current is carried by both ions (Figure 1.2). However, cations and anions usually carry different proportions of the overall current. In ion exchange membranes, the current is carried preferentially by counter ions, e.g. negative ions in the case of anion exchange membranes (Figure 1.2). The transport number quantifies the fraction of the charge carried by that specific ions and is expressed as [27]:

$\mathrm{t}_{\mathrm{i}}=\frac{\left|\mathrm{z}_{\mathrm{i}}\right| \mathrm{J}_{\mathrm{i}}}{\sum_{\mathrm{j}}\left|\mathrm{z}_{\mathrm{j}}\right| \mathrm{J}_{\mathrm{j}}}$

where $t_{i}$ is the transport number of the component $i, J_{i}$ is its flux, and $z_{i}$ its valence, the subscript $\mathrm{j}$ refers to all ions involved in the charge transport. The transport 
number $t_{i}$ indicates the fraction of the total current that is carried by the ion $i$. The transport number of the counterions can be quite different. In principle, the concentration of the counterions is similar to that of the fixed charges of the membrane. However, the mobility of the ions in the membrane mainly depends on steric effects such as the hydration radius and the membrane chemistry (e.g. the crosslinking density of the membrane). As a general rule, the counter ions with a higher valence and a smaller hydrated radius have a higher permeability in an ion exchange membrane than ions with lower valence and larger hydrated radius [26]. The selectivity of the membrane can be considered as the flux of a specific component relative to that of the other component through the membrane under a given driving force. In other words, it is defined as the membrane`s capability to discriminate between anions and cations.

The membrane properties play an important role in electrodialytic processes such as electrodialysis, diffusion dialysis, membrane capacitive deionization and Donnan dialysis. Recently, energy generating ion exchange membrane applications have gained lots of attention as well, for instance, reverse electrodialysis, microbial fuel cells or fuel cells [20, 35-38]. The existing commercial membranes are mainly developed for the electrodialysis applications, but do not specifically meet the requirements for RED. For instance, currently available membranes usually contain a reinforcing material to provide mechanical stability and they are usually relatively thick. Therefore, current ion exchange membranes are overdesigned for the RED applications. However, the performance of the membranes does have an important effect on the overall performance of a RED system as well. Requirements that ion exchange membranes in a RED system have to fulfill are [26, 39]:

- high permselectivity, i.e. ion exchange membrane should have a permselectivity of more than $95 \%$.

- low electrical resistance, i.e. ion exchange membranes should have an area resistance of maximum $3 \Omega \cdot \mathrm{cm}^{2}$.

- a good mechanical and form stability, i.e. the membranes should be mechanically strong enough to construct a RED stack, as thin as possible to have low area resistance, have a low degree of swelling or shrinking in transition from dilute to concentrated ionic solutions.

- a reasonable chemical stability, i.e. no special requirements for chemical stability due to mild membrane environment e.g. seawater and river water. Lifetime should be at least 5 years.

- low cost, i.e. the membranes should be as cheap as $2 € / \mathrm{m}^{2}$. 
It is often challenging to optimize these membrane characteristics for reverse electrodialysis since these properties have counteracting effects in general. For instance, highly crosslinked membranes with high permselectivity might have also high area resistance (which is not desired). Thus, it is of significant importance to design ion exchange membranes especially tailored for to obtain high performance in RED.

\subsection{Anion exchange membranes - preparation routes and design for RED}

Further improvement towards economically viable power production requires the development of ion exchange membranes especially designed and developed for RED. A large community of polymer chemists deals with the development of cation-exchange membranes, but the research on anion exchange membranes is limited. Although several routes are available for the preparation of cation exchange membranes, the possibilities for high-performance anion exchange membranes (AEMs) are not broad. Therefore, development and preparation of AEMs is of special importance for a successful RED operation. The conventional process to prepare AEMs requires several steps such as `polymerization-choloromethylation-amination` [40], and in most cases, after those steps, a post processing so-called crosslinking stage, is required to provide membranes with desired properties, such as mechanical stability and controlled swelling. The process is not very environmentally friendly and requires extensive safety and health precautions. That makes the fabrication of anion exchange membranes more complicated than that of cation exchange membranes. Moreover, it is usually a challenge to optimize the membrane properties. At the same time, permselectivities of commercial anion exchange membranes are in general lower than those of cation exchange membranes. This drawback can be attributed to the higher swelling degree of AEMs, thus limiting the applicability in RED on a commercial scale [34].

Homogeneous types of ion exchange membranes (i.e. membranes with essentially the same structural and transport properties throughout its complete thickness) usually work better for reverse electrodialysis since they offer a homogenous fixed-ion distribution over the entire polymer matrix, and usually they have relatively low area resistances compared to heterogeneous membranes [29].

A homogenous anion exchange membrane can be obtained by several routes as follows $[26,41]$ : 
- Polymerization of mixtures of reactants (e.g. styrene, chloromethylstyrene, vinylpyridine, divinylbenzene) that can polymerize by additional polymerization. At least one of the monomers should contain an anionic moiety. Besides that, one of the reactants is usually a cross-linking agent to provide the control of the solubility of the films in water;

- Casting films from a solution of a mixture of an inert polymer, a functionalized polymer and an amine compound, then evaporating the solvent;

- Introduction of anionic moieties into a polymer chain such as polysulfone or polyphenylene oxide, followed by dissolving the polymer and casting it into a film;

- Introduction of anionic moieties into preformed films by techniques such as imbibing styrene into polyethylene films, polymerizing the imbibed monomer, followed by chloromethylation and amination. A crosslinking agent can also be added to control swelling of the ion exchange component. Other similar techniques, such as graft polymerization of imbibing monomers, have been used to attach functional groups onto molecular chains of preformed polymeric films.

- Preparation of pre-functionalized monomers and their subsequent polymerization.

Most commercially available anion exchange membranes have quaternary ammonium groups as ion exchange membranes [42]. These membranes may be prepared, for instance, by the reaction of trimethylamine with a copolymer membrane prepared from chloromethylstyrene and divinylbenzene or by alkylation with the alkyl halide of a copolymer membrane prepared from vinylpyridine and divinyl benzene. The following reaction scheme shows the schematic representation of the reaction of a positively charged quaternary amine group into a preformed polymer by a chloromethylation procedure followed by an amination with a tertiary amine [26]:

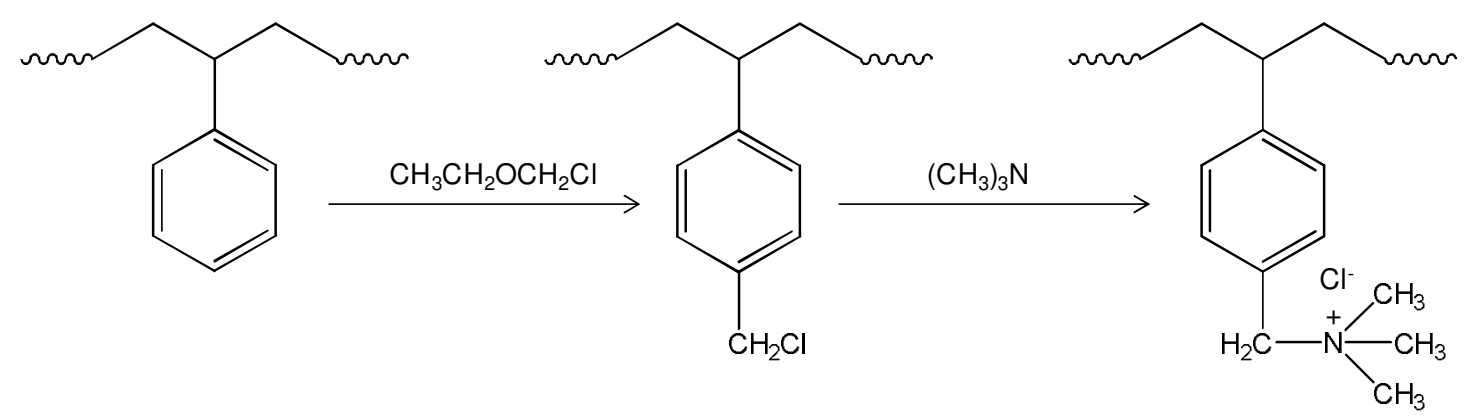

Figure 1.3. Typical reaction scheme of chloromethylation and amination to obtain homogenous anion exchange membrane [26]. 
The membrane structures and their preparation described above are only basic examples as there are many variations in the preparation methods to obtain anion exchange membranes. The most crucial point is to compromise the desired membrane properties for high performance with the criteria for commercial and environmental relevance.

From an environmental point of view, a severe drawback that is difficult to eliminate, is the use of toxic chemicals like chloromethyl methyl ether which are polluting and carcinogenic. There are several methods proposed to eliminate the direct use of chloromethyl methyl ether. Employment of chloromethyl ethyl ether instead of chloromethyl methyl ether is one these methods [43]. Chloromethyl ethyl ether is less volatile, thus gas poisoning is reduced. Another method is the direct employment of monomers or polymers containing nitrogen, such as vinyl pyridine compounds (e.g. 2methyl-5-vinyl pyridine, 2-vinyl pyridine or 4-vinyl pyridine). These monomers can also be crosslinked with diethylbenzene. Then quaternization can be employed, for instance, by the use of iodoethane [43]. The chloromethyl methyl ether can also be avoided by directly grafting vinylbenzylchloride onto solid polymer films or by copolymerizing with other monomers such as divinylbenzene followed by the simple amination reaction to form anion exchange membranes [44].

\subsection{Scope and outline of the thesis}

The main focus of this thesis is the design, characterization and application of tailormade anion exchange membranes in a RED system to generate electricity.

Chapter 2 describes the fabrication of anion exchange membranes produced by a solvent evaporation technique. Polyepichlorohydrin (PECH) is used as active membrane material. Fabrication parameters such as blending ratio of a supporting inert polymer, excess crosslinker ratio, and film thickness are varied in order to observe their effects on membrane properties, such as area resistance and permselectivity. This chapter explores, to the best of our knowledge, for the first time, the applicability of tailor-made ion-exchange membranes in RED to generate power from salinity gradients.

Chapter 3 focuses on the membrane properties, e.g. area resistance and permselectivity, which determine the performance in RED. Several previous papers studied some of those effects in general and to a little extend, but without any clear directions or conclusions. This chapter studies these relationships very systematically 
and based on real experimental data. Based on the results, the highest RED performance was obtained by the stack built with tailor-made anion and cation exchange membranes in which their properties have been tuned specifically for RED. A statistical sensitivity analysis is performed, which investigates the dominating membrane properties contributing to RED performance. In addition, a simple model is developed which provides a better understanding on the dominant performancedetermining membrane properties in RED.

The application of RED in practice requires the use of natural seawater and river water. The presence of multivalent ions reduces the performance in RED. Thus, ion exchange membranes with monovalent ion selectivity are proposed to overcome this limitation. Chapter 4 presents the fabrication of such monovalent ion selective anion exchange membranes for RED. UV irradiation is introduced as a versatile method to fabricate such membranes. Surface properties of the produced membranes are characterized, and their antifouling potential is investigated. Applicability and performance of the designed monovalent ion selective membranes in a real RED stack is also performed.

In Chapter 5, tailor-made micro-structured anion exchange membranes made from the membrane material discussed in Chapter $\mathbf{2}$ are investigated in order to eliminate the use of non-conductive spacers, which reduce the RED performance. Different membrane geometries are designed and characterized. In particular, stack resistance, hydraulic pressure drop and flow distributions are investigated to relate these parameters to the RED performance.

Finally, Chapter 6 presents a summary of the main conclusions of the thesis followed by an outlook and suggestions for future work on ion exchange membranes. 


\subsection{References}

[1] IPCC, Climate Change 2007: The Physical Science Basis, Summary for Policymakers, 2007.

[2] http://www.who.int/.

[3] J.A. Church, N.J. White, A 20th century acceleration in global sea-level rise, Geophysical Research Letters, 33 (2006) L01602.

[4] Global Climate Projections, in: IPCC Fourth Assessment Report: Climate Change 2007, 2007.

[5] K. Nijmeijer, S. Metz, Chapter 5 Salinity Gradient Energy, in: C.E. Isabel, I.S. Andrea (Eds.) Sustainability Science and Engineering, Elsevier, 2010, pp. 95-139.

[6] United Nations Framework Convention on Climate Change, Kyoto Protocol, in, 1998.

[7] European Commission`s Second Strategic Energy Review, 2008.

[8] S.R. Reijerkerk, Polyether based block copolymer membranes for $\mathrm{CO}_{2}$ separation, in, University of Twente, Enschede, 2010.

[9] Energy 2020, A strategy for competitive, sustainable and secure energy, in, Brussels, 2010.

[10] J.W. Post, H.V.M. Hamelers, C.J.N. Buisman, Energy recovery from controlled mixing salt and fresh water with a reverse electrodialysis system, Environmental Science and Technology, 42 (2008) 5785-5790.

[11] EIA, International Energy Outlook 2010, in, Washington DC, 2010.

[12] J.N. Weinstein, F.B. Leitz, Electric power from differences in salinity: The dialytic battery, Science, 191 (1976) 557-559.

[13] G.L. Wick, W.R. Schmitt, Prospects for renewable energy from the sea, Marine Technology Society Journal, 11 (1977) 16-21.

[14] J.W. Post, J. Veerman, H.V.M. Hamelers, G.J.W. Euverink, S.J. Metz, K. Nymeijer, C.J.N. Buisman, Salinity-gradient power: Evaluation of pressure-retarded osmosis and reverse electrodialysis, Journal of Membrane Science, 288 (2007) 218-230.

[15] J. Veerman, J.W. Post, M. Saakes, S.J. Metz, G.J. Harmsen, Reducing power losses caused by ionic shortcut currents in reverse electrodialysis stacks by a validated model, Journal of Membrane Science, 310 (2008) 418-430.

[16] J. Veerman, M. Saakes, S.J. Metz, G.J. Harmsen, Reverse electrodialysis: Performance of a stack with 50 cells on the mixing of sea and river water, Journal of Membrane Science, 327 (2009) 136-144.

[17] S. Loeb, Production of energy from concentrated brines by pressure-retarded osmosis : I. Preliminary technical and economic correlations, Journal of Membrane Science, 1 (1976) 49-63.

[18] K. Gerstandt, K.V. Peinemann, S.E. Skilhagen, T. Thorsen, T. Holt, Membrane processes in energy supply for an osmotic power plant, Desalination, 224 (2008) 64-70.

[19] G.Z. Ramon, B.J. Feinberg, E.M.V. Hoek, Membrane-based production of salinity-gradient power, Energy \& Environmental Science, 4 (2011) 4423-4434.

[20] R.E. Pattle, Production of electric power by mixing fresh and salt water in the hydroelectric pile, Nature, 174 (1954) 660-660.

[21] R.E. Lacey, Energy by reverse electrodialysis, Ocean Engineering, 7 (1980) 1-47.

[22] E. Brauns, Towards a worldwide sustainable and simultaneous large-scale production of renewable energy and potable water through salinity gradient power by combining reversed electrodialysis and solar power?, Desalination, 219 (2008) 312-323.

[23] A. Achilli, T.Y. Cath, A.E. Childress, Power generation with pressure retarded osmosis: An experimental and theoretical investigation, Journal of Membrane Science, 343 (2009) 42-52. 
[24] R.D. Cusick, Y. Kim, B.E. Logan, Energy capture from thermolytic solutions in microbial reverseelectrodialysis cells, Science, 335 (2012) 1474-1477.

[25] M. Mulder, Basic principles of membrane technology, Kluwer Academic Publishers, Dordrecht, 1996.

[26] H. Strathmann, Membrane science and technology ion-exchange membrane separation Processes, 1 ed., Elsevier, 2004.

[27] H. Strathmann, L. Giorno, E. Drioli, An introduction to membrane science and Technology, CNRServizio Pubblicazioni, 2006.

[28] E. Güler, R. Elizen, D.A. Vermaas, M. Saakes, K. Nijmeijer, Performance-determining membrane properties in reverse electrodialysis, Journal of Membrane Science, 446 (2013) 266-276.

[29] E. Guler, Y. Zhang, M. Saakes, K. Nijmeijer, Tailor-made anion-exchange membranes for salinity gradient power generation using reverse electrodialysis, ChemSusChem, 5 (2012) 2262-2270.

[30] D.A. Vermaas, E. Guler, M. Saakes, K. Nijmeijer, Theoretical power density from salinity gradients using reverse electrodialysis, Energy Procedia, 20 (2012) 170-184.

[31] D.A. Vermaas, D. Kunteng, M. Saakes, K. Nijmeijer, Fouling in reverse electrodialysis under natural conditions, Water Research, 47 (2013) 1289-1298.

[32] J. Jagur-Grodzinski, R. Kramer, Novel process for direct conversion of free energy of mixing into electric power, Industrial \& Engineering Chemistry Process Design and Development, 25 (1986) 443-449.

[33] F. Suda, T. Matsuo, D. Ushioda, Transient changes in the power output from the concentration difference cell (dialytic battery) between seawater and river water, Energy, 32 (2007) 165-173.

[34] P. Długołęcki, K. Nymeijer, S. Metz, M. Wessling, Current status of ion exchange membranes for power generation from salinity gradients, Journal of Membrane Science, 319 (2008) 214-222.

[35] R.A. Rozendal, H.V.M. Hamelers, C.J.N. Buisman, Effects of Membrane Cation Transport on pH and Microbial Fuel Cell Performancet, Environmental Science \& Technology, 40 (2006) 5206-5211.

[36] S. Feng, Y. Shang, X. Xie, Y. Wang, J. Xu, Synthesis and characterization of crosslinked sulfonated poly(arylene ether sulfone) membranes for DMFC applications, Journal of Membrane Science, 335 (2009) 13-20.

[37] B.E. Logan, B. Hamelers, R. Rozendal, U. Schröder, J. Keller, S. Freguia, P. Aelterman, W. Verstraete, K. Rabaey, Microbial Fuel Cells: Methodology and Technology†, Environmental Science \& Technology, 40 (2006) 5181-5192.

[38] C. Sollogoub, A. Guinault, C. Bonnebat, M. Bennjima, L. Akrour, J.F. Fauvarque, L. Ogier, Formation and characterization of crosslinked membranes for alkaline fuel cells, Journal of Membrane Science, 335 (2009) 37-42.

[39] J.W. Post, Blue energy: electricity production from salinity gradients by reverse electrodialysis, in, Wageningen University, Wageningen, 2009.

[40] X. Tongwen, Y. Weihua, Fundamental studies of a new series of anion exchange membranes: membrane preparation and characterization, Journal of Membrane Science, 190 (2001) 159-166.

[41] E.N. Komkova, D.F. Stamatialis, H. Strathmann, M. Wessling, Anion-exchange membranes containing diamines: preparation and stability in alkaline solution, Journal of Membrane Science, 244 (2004) 25-34.

[42] T. Sata, Ion exchange membranes : preparation, characterization, modification and application, Royal Society of Chemistry, Cambridge, 2004.

[43] L. Zongqing, L. Jianwu, Research on elimination of chloromethylation in preparation on anionexchange, Desalination, 56 (1985) 421-430. 
[44] H. Herman, R.C.T. Slade, J.R. Varcoe, The radiation-grafting of vinylbenzyl chloride onto poly(hexafluoropropylene-co-tetrafluoroethylene) films with subsequent conversion to alkaline anionexchange membranes: optimisation of the experimental conditions and characterisation, Journal of Membrane Science, 218 (2003) 147-163. 


\section{Tailor-made anion-exchange membrane fabrication for reverse electrodialysis - Tuning membrane properties}

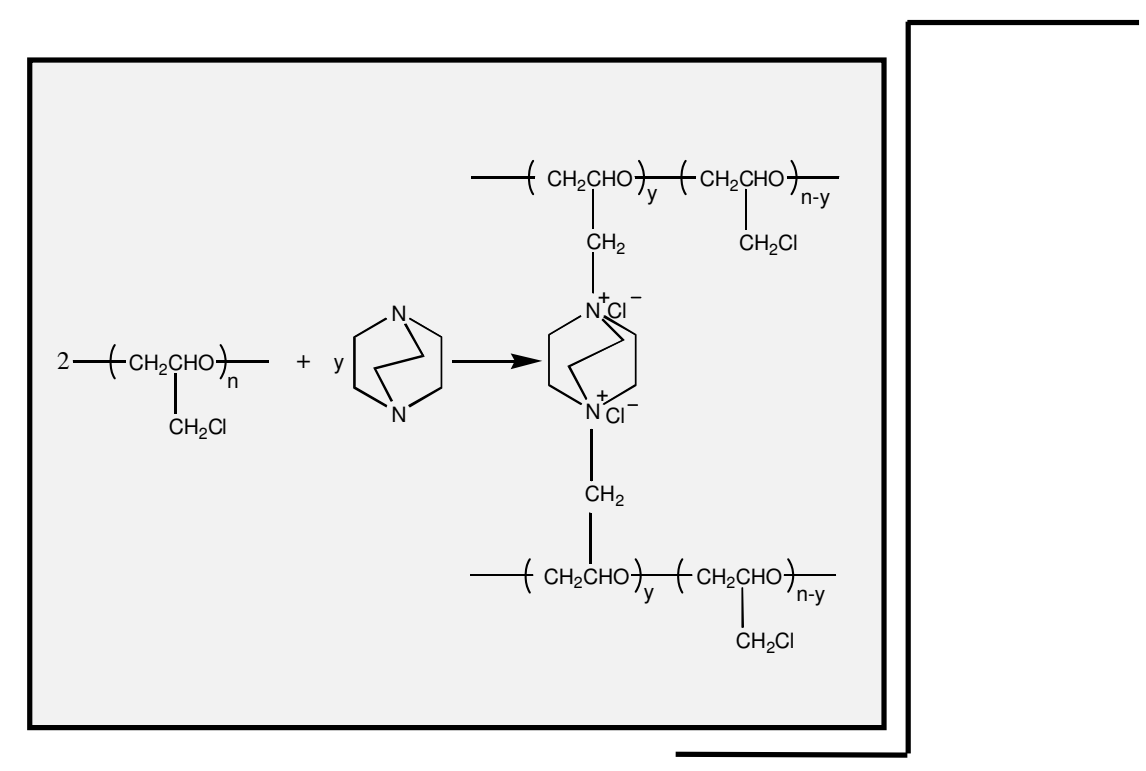

This chapter has been published as:

E. Guler, Y. Zhang, M. Saakes, K. Nijmeijer, Tailor-made anion-exchange membranes for salinity gradient power generation using reverse electrodialysis. ChemSusChem (2012), 5, 2262- 2270. 


\begin{abstract}
Reverse electrodialysis (RED) or blue energy is a non-polluting, sustainable technology for generating power from the mixing of solutions with different salinity, i.e. seawater and river water. A concentrated salt solution (e.g. seawater) and a diluted salt solution (e.g. river water) are brought into contact through an alternating series of polymeric anion exchange membranes (AEM) and cation exchange membranes (CEM), which are either selective for anions or cations. Currently available ion exchange membranes are not optimized for RED, while successful RED operation notably depends on the used ion exchange membranes. In the current work, we designed such ion exchange membranes and for the first time, we show the performance of tailormade membranes in RED. More specifically we focus on the development of anion exchange membranes (AEMs) as these are much more complex to prepare. Here we propose a safe and more environmentally friendly method and used halogenated polyethers such as polyepichlorohydrin (PECH) as starting material. A tertiary diamine (1,4-diazabicyclo[2.2.2] octane, DABCO) was used to introduce the ion exchange groups by amination and for simultaneous cross-linking of the polymer membrane. Area resistances of the series of membranes ranged from 0.82 to 2.05 $\Omega \cdot \mathrm{cm}^{2}$ and permselectivities from 87 to $90 \%$. For the first time we showed that tailormade ion exchange membranes can be applied in RED. Depending on the properties and especially the membrane thickness, application of these membranes in RED resulted in a high power density of $1.27 \mathrm{~W} / \mathrm{m}^{2}$, which exceeds the power output obtained with the commercially available AMX membranes. This shows the potential of the design of ion exchange membranes for a viable blue energy process.
\end{abstract}




\subsection{Introduction}

Global warming, increasing fuel prices and depletion of fossil fuel stocks have created a growing interest in renewable energy forms. In addition to well-known sustainable energy sources such as solar radiation, wind, biomass, fuel cells, energy generated from the mixing of water solutions of different salinity is also gaining a great deal of attention. This energy is known as salinity gradient energy or blue energy.

A blue energy source exists anywhere fresh water (river water) flows into seawater. According to the literature, $80 \%$ of the current global electricity demand could be covered if all the interfaces where river water flows into ocean water were utilized [1].

Today, two main technologies stand out for electricity extraction from blue energy: pressure-retarded osmosis (PRO) and reverse electrodialysis (RED). Each method has its own advantages and application field. PRO can be used for the mixing of more concentrated brines with diluted solutions. For RED, it is beneficial to use slightly brackish water as the dilute stream [2]. RED may also be preferable for extracting energy from the mixing of seawater and river water, since it produces a higher power density for lower salinity gradients [3].

When fresh water and saline water mix, energy is released. In RED (Figure 2.1), anion and cation exchange membranes are installed in an alternating pattern, forming a RED stack. Seawater and river water are continuously fed to the RED stack, the streams separated by the membranes. Due to the chemical potential difference between the solutions, cations transfer in the direction of a cathode and anions in the direction of an anode.

This charge transfer is converted to electron transfer by oxidation and reduction reactions at the electrodes. Subsequently, electrons travel from anode to cathode, producing an electric current [3-7].

The feasibility of RED, as for many other membrane processes, mainly depends on membranes characteristics and their prices. One challenge is to increase the availability of these membranes at reduced costs $\left(<2 € / \mathrm{m}^{2}\right)$ [8]. Furthermore, certain membrane characteristics, such as a high permselectivity and low electrical resistance, are required for high power outputs in RED [4]. The currently available commercial membranes are mainly developed for application in electrodialysis (ED), but do not meet the requirements for RED. For example, ED ion exchange membranes usually contain a reinforcing material to enhance mechanical stability, and/or they are rather 
thick with thicknesses in the range of 100 to $250 \mu \mathrm{m}$ [9]. This high level of robustness of ion exchange membranes is especially relevant for application ED due to the more severe conditions in $\mathrm{ED}$ (e.g. high and low $\mathrm{pH}$, high current densities). In RED however, conditions are relatively mild. Current ion exchange membranes are overdesigned for use in RED. The current high level of mechanical strength is not required for RED. Consequently, membranes designed for RED can be much thinner, do not need reinforcement and need less mechanical robustness to withstand the conditions in the RED stack [8]. Such heterogeneous membranes have a higher resistance than homogeneous membranes due to their structure [10-11]. Both aspects result in not only high electrical resistance and consequently low power outputs in RED, but also makes them more expensive. Although some heterogeneous commercial membranes are available at very low prices $\left(<4 € / \mathrm{m}^{2}\right)$, low-resistance ion exchange membranes still have high prices of $80 € / \mathrm{m}^{2}$ or more [12]. The development of thinner, low resistance membranes, without compromising the permselectivity or the mechanical stability, is essential to increase the power output obtainable in RED.

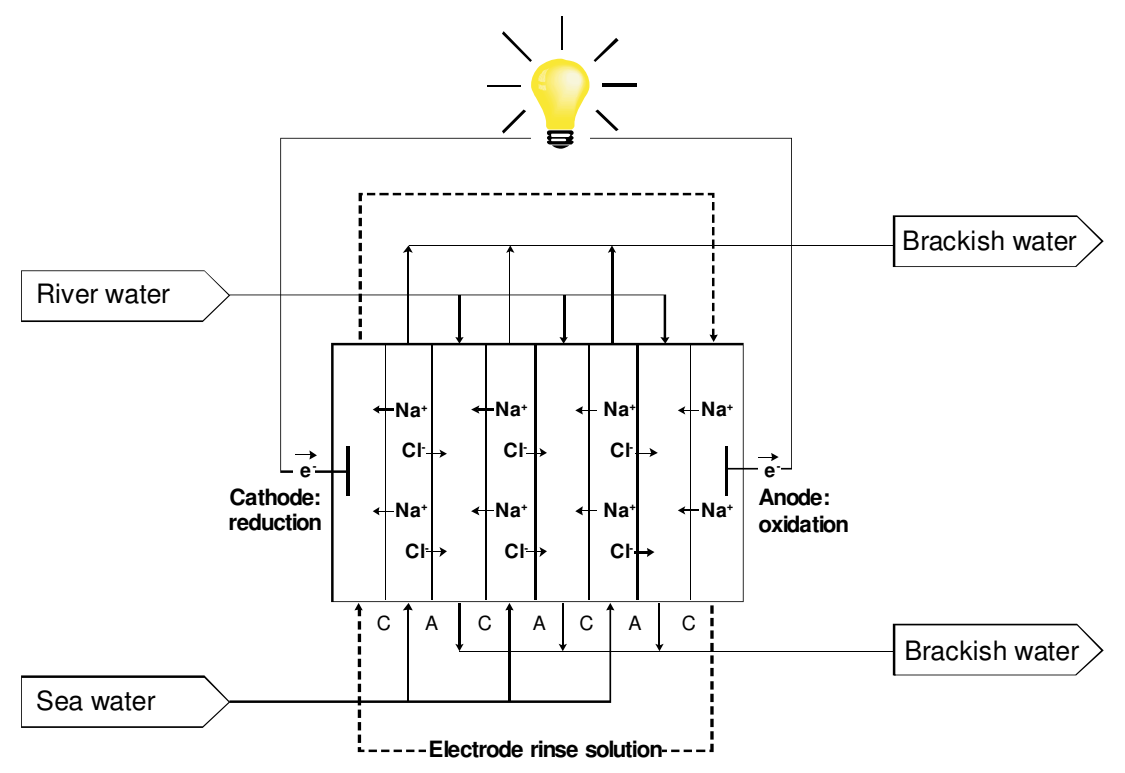

Figure 2.1. Schematic representation of a reverse electrodialysis stack. C: a cation exchange membrane and $\mathrm{A}$ : an anion exchange membrane.

Many researchers have investigated the power density of a RED stack using standard commercial membranes [12-19]. Audinos [13] was one of the first who systematically investigated the effect of ion exchange membranes on the power output in RED. Recently, Długołęcki et al. [4] focused on the effect of electrochemical properties of the membranes and presented a theoretical model for the power density regarding these properties. Veerman et al. [17] compared different commercial membranes and obtained a power density of $1.2 \mathrm{~W} / \mathrm{m}^{2}$ for Fumasep (FAD and FKD) and Selemion 
(AMV and CMV) membranes. In these studies, no systematic approach of the effect of membrane properties on the total RED performance was taken, since the manufacturer data available for commercial membranes do not offer sufficient information on the membrane properties relevant for RED.

The charge density of the membrane, which is the amount of ion exchange functionalities per water uptake of the membrane, is the major parameter that affects its ion permselectivity (the ability of the membrane to discriminate between the anions $\left(\mathrm{Cl}^{-}\right)$and cations $\left(\mathrm{Na}^{+}\right)$) and its electrical resistance. Although there is no straightforward relationship between these properties, membranes with a high fixedcharge density usually have a high ion permselectivity, meaning effective co-ion exclusion (cations in the case of anion exchange membranes and anions in the case of cation exchange membranes) [4]. It is a challenge to optimize these membrane properties like ion exchange capacity, resistance, permselectivity, thickness, swelling degree, etc. since they often have a counteracting effect on the performance characteristics. For example, membranes with a relatively low electrical resistance usually have a low permselectivity, which is undesirable [20]. At the same time, permselectivities of commercial anion exchange membranes are usually lower than those of cation exchange membranes. This is due to the higher swelling degree of anion exchange membranes, which reduces the effective fixed-charge density in anion exchange membranes, thus limiting the applicability of RED on a commercial scale [4].

The development of AEMs has seen much progress in recent decades, especially for fuel cell applications. Polysulfone membranes with very low swelling degrees with high mechanical strength were widely prepared by chemical grafting [21-26]. Varcoe and Slade and coworkers performed a significant amount of studies in alkaline anion exchange membranes (AAEMs) including mixed fluorocarbon/hydrocarbon materials with promising hydroxide conductivities and high chemical stabilities [27-31]. Jung et al. [32] were able to make similar membranes with small water uptakes in the field. AAEMs having good mechanical strength and negligible swelling have been successfully made using polymerization and utilization of dicyclopentadiene crosslinkers [33]. In addition, Cornelius et al. [34] has recently reported a novel AAEM that employs a poly(phenylene) backbone, which exhibits good mechanical and electrochemical properties.

The conventional way to prepare AEMs usually requires many steps like polymerization, chloromethylation, amination and cross-linking. Among these, especially the chloromethylation reaction is not easy to handle, and requires the use of chloromethyl methyl ether, which is highly toxic and carcinogenic. In this study we 
have developed a method for the design and preparation of anion exchange membranes for application in RED. We adopted the elastomer polyepichlorohydrin (PECH), which has inherent chloromethyl groups, as polymer matrix (Figure 2.2), so that the chloromethylation reaction could be avoided. In addition, the use of a tertiary diamine, e.g. 1,4-diazabicyclo[2.2.2] octane (DABCO), introduces the positively charged groups into the polymer matrix and at the same time, produces cross-linking. When prepared using only these components, the membranes are brittle in water due to their high degree of swelling because of the high ion exchange capacity of the membrane [35]. Guo et al. [36] reported PECH membranes using a porous PTFE support which increased mechanical strength and stability. Recently, Wright [37] succeeded in making membrane electrode assemblies using hydrophilic PECH membranes for fuel cell applications. Altmeier [38] used the inert polymer polyacrylonitrile (PAN) to give mechanical strength to PECH membranes to be used as acid blocker membranes in ED.

To tailor the properties of our PECH membranes for RED, we follow the strategy proposed by Altmeier and use PAN as an inert polymer to enhance the mechanical stability of the membranes. Differently from the patent study, for safer working conditions, we preferred using dimethyl sulfoxide (DMSO) rather than dimethylformamide (DMF) to dissolve the polymers in the casting solution. In addition to that, mass ratios of the polymers and the aminating agent were varied for the optimum properties of the membranes. In particular, we investigated the effect of chemical composition on the membrane's electrochemical properties by varying the number of active, charged groups, and the amounts of the inert polymer (PAN) and diamine (DABCO). We benchmarked these properties with commercially available membranes and further examined the effects of membrane thickness in a RED stack and its impact on power density. To our knowledge, this is the first time that the performance of RED using tailor made membranes has been reported.

\subsection{Experimental}

\subsubsection{Materials}

For the preparation of the anion exchange membranes, we used polyepichlorohydrin (EPICHLOMER H, 37 wt \% chlorine content, Daiso Co., Ltd) as the active polymer, polyacrylonitrile (H-PAN, $\mathrm{M}_{\mathrm{w}}=200000 \mathrm{~g} / \mathrm{mol}$, Dolan $\mathrm{GmbH}$ ) as the inert polymer and dimethylsulfoxide (DMSO, for synthesis 99\%, Merck) as the solvent. For 
amination of the polymer, 1,4-diazabicyclo-[2,2,2]-octane (DABCO, 98\%, SigmaAldrich) was used. For the membrane characterization, sodium chloride (99.5\%, AcrosOrganics) and sodium sulfate (99\%, Acros-Organics) were used. For membrane performance evaluation in RED, we used sodium chloride (technical grade, Boom BV), potassium hexacyanoferrate (II) (99\%, Boom BV) and potassium hexacyanoferrate (III) $(99 \%$, Boom BV). All chemicals were used without further purification.

\subsubsection{Preparation of homogeneous anion exchange membranes}

\subsubsection{Preparation of the casting solution}

The membranes were formed by solution casting on a glass plate. The membraneforming solution comprises three functional components, i.e. the active polymer polyepichlorohydrin (PECH), the inert polymer polyacrylonitrile (PAN) and the amine component 1,4-diazabicyclo[2.2.2] octane (DABCO), also used for crosslinking.

The active polymer solution was prepared by dissolving $20 \mathrm{~g}$ PECH in $80 \mathrm{~g}$ DMSO; the inert polymer solution was prepared by dissolution of $12 \mathrm{~g}$ PAN in $88 \mathrm{~g}$ DMSO; the aminating solution was prepared by dissolution of $12.25 \mathrm{~g}$ DABCO in $88 \mathrm{~g}$ DMSO under stirring at room temperature for a few hours. Subsequently, these three solutions were combined and mixed in a three-neck round-bottomed flask for half an hour at $80^{\circ} \mathrm{C}$.

\subsubsection{Synthesis of quaternized PECH}

The amination reaction was performed according to Figure 2.2. PECH membranes were prepared at different compositions by varying the amount of active polymer, inert polymer and diamine. Before the synthesis, a pre-reaction stage was carried out by placing the casting solution in a thermostated silicon oil bath at $80^{\circ} \mathrm{C}$ for $30 \mathrm{~min}$. This results in a pre-reaction between $\mathrm{PECH}$ and $\mathrm{DABCO}$ without crosslinking of the $\mathrm{PECH}$ polymer, and limits the evaporation of DABCO during amination [38]. 


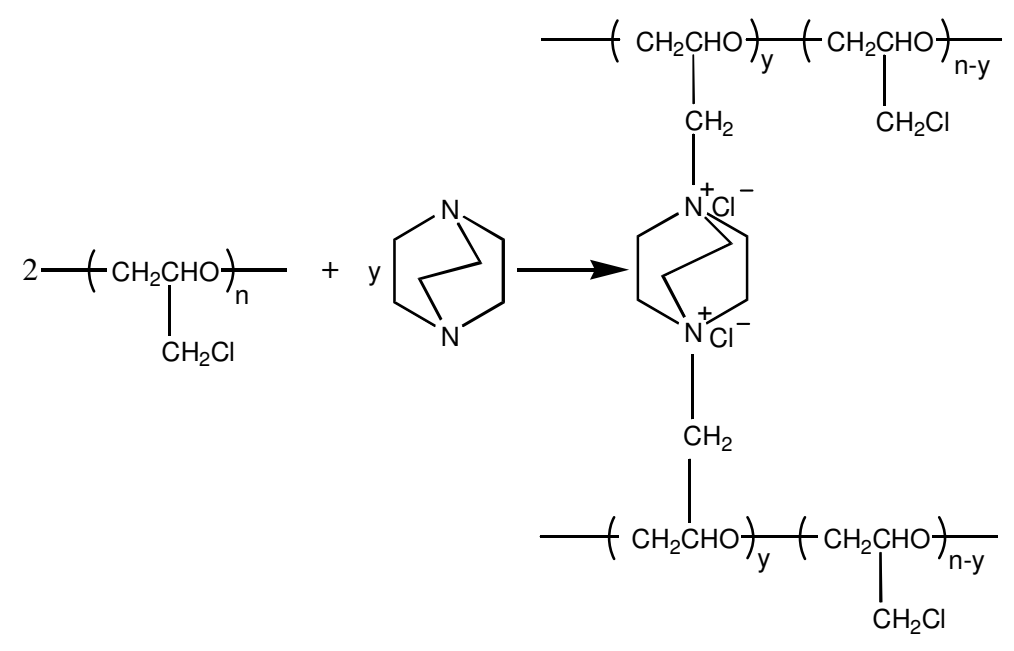

Figure 2.2. Reaction mechanism of amination-crosslinking of PECH polymers [37, 39].

After taking the clear casting solution from the silicon oil bath, a syringe was used to spread a specific amount of this solution over a glass plate which was subsequently covered to prevent further evaporation of DABCO during amination. The sealed glass box was then placed into an oven and heated for $2 \mathrm{~h}$ at $110^{\circ} \mathrm{C}$, during which amination and cross-linking took place. Next, the seals were removed from the glass box to allow evaporation of residual solvent at $130^{\circ} \mathrm{C}$ for $30 \mathrm{~min}$. After cooling the glass box with the polymer film, the film was soaked in $0.5 \mathrm{M} \mathrm{NaCl}$ solution. After a few minutes, the film could be peeled off from the glass substrate and stored in $0.5 \mathrm{M} \mathrm{NaCl}$ solution. The thickness of the obtained membranes was measured with a digital screw micrometer as 33, 77 and $130 \mu \mathrm{m}$.

The amount of PAN added to the casting solution ( $\mathrm{m}_{\mathrm{PAN}} \mathrm{g}$ polymer) was varied to obtain different blend ratios of membrane containing specific amounts of the active, anion exchange polymer PECH ( $\mathrm{m}_{\mathrm{PECH}}$, g polymer), as specified in detail hereafter. The blend ratio $\sigma$ is defined as the mass ratio of $\mathrm{PECH}$ over PAN:

$$
\sigma=\frac{\mathrm{m}_{\mathrm{PECH}}}{\mathrm{m}_{\mathrm{PAN}}}
$$

For amination and cross-linking, DABCO was added to the casting solution in order to react with the chloromethyl groups of $\mathrm{PECH}$ to introduce the specific positive charge required for ion exchange. The excess diamine ratio $v$ represents the molar ratio of the amine component $\mathrm{DABCO}\left(\mathrm{m}^{\mathrm{d}}, \mathrm{mmol} / \mathrm{g}\right.$ diamine $)$ over the chloromethyl groups in $\mathrm{PECH}\left(\mathrm{m}^{\mathrm{p}}, \mathrm{mmol} / \mathrm{g}-\mathrm{CH}_{2} \mathrm{Cl}\right)$ : 
$v=\frac{m^{\mathrm{d}}}{\mathrm{m}^{\mathrm{p}}}$

To produce membranes with a low electrical resistance and high permselectivity, an excess of tertiary diamine is required due to the limited access to the chloromethyl groups [40]. The amination of these functional groups is strongly dependent on parameters such as polymer type, polymer solution concentration, mobility of the polymer chain and the type of diamine [40]. Blend ratio and excess diamine ratio are polymer solution properties rather than membrane properties. We will later describe how these two parameters affect membrane properties and performance in RED operation.

Two series of PECH membranes were prepared having various blend or excess diamine ratios. For the various blend ratios $(0.100,0.208,0.260,0.333,0.417,0.622,0.833$ and 1.042), the amount of PAN was varied and all other parameters were kept constant. For the various excess diamine ratios $(2.63,3.41,4.20,5.23,6.27$ and 7.31 ), the amount of DABCO was varied. For each composition, at least two membrane samples were prepared from the same casting solution. All prepared PECH membranes were mechanically stable and transparent with a yellowish color.

\subsubsection{Characterization of AEMs}

\subsubsection{SEM}

Samples for SEM were prepared by freezing the membrane films in liquid nitrogen and cutting them manually to obtain cross-sections. Samples were kept in a vacuum oven at $30^{\circ} \mathrm{C}$ overnight and were subsequently coated with a thin layer of gold using a Balzers Union SCD 040 sputtering device. Membranes were examined using a Jeol JSM-5600 LV Scanning Electron Microscope.

\subsubsection{FTIR}

The chemical structures of the PECH membranes were analyzed by Fourier transform infrared spectroscopy (FTIR) using an ALPHA FT-IR Spectrometer (Bruker Optics Inc., Germany). The measurements were performed using an attenuated total reflectance (ATR) attachment. Dry and clean membrane samples were pressed onto the crystal, without any further sample preparation. 


\subsubsection{Area resistance}

A six-compartment cell made from plexiglass was used to determine the area resistance of the membranes using a $0.5 \mathrm{M} \mathrm{NaCl}$ solution [41]. The voltage drop over the membrane was recorded for the applied current density. Two runs were performed: one with and one without the membrane under investigation (blank run). The resistance was given by the slope of the plot of the current density versus the potential difference. The final membrane area resistance was determined by subtracting the resistance measured in the blank run from the resistance measured in the run with the membrane under investigation.

\subsubsection{Permselectivity}

The permselectivity is a measure for how well the membrane under investigation can discriminate between the anions $\left(\mathrm{Cl}^{-}\right)$and cations $\left(\mathrm{Na}^{+}\right)$. Static potential measurements were carried out to determine the apparent permselectivity $\left(\alpha^{\mathrm{ap}}\right)$ of the membrane under investigation [42]. The set-up consisted of two compartments separated by the membrane under investigation. Solutions of $0.1 \mathrm{M} \mathrm{NaCl}$ and $0.5 \mathrm{M}$ $\mathrm{NaCl}$ were recirculated along the sides of the test membrane. Two reference electrodes were used to measure the potential over the membrane. The experimental potential was monitored with an external potentiostat. The permselectivity was calculated from the ratio of the experimental potential over the theoretical potential for an ideal $100 \%$ permselective membrane, as shown in Equation (2.3):

$$
\alpha^{\mathrm{ap}}=\frac{\Delta \mathrm{V}_{\text {measured }}}{\Delta \mathrm{V}_{\text {theoretical }}} \times 100 \%
$$

Here, $\Delta \mathrm{V}_{\text {measured }}$ is the measured membrane potential $(\mathrm{V})$ and $\Delta \mathrm{V}_{\text {theoretical }}$ is the theoretical membrane potential $(\mathrm{V})$. The theoretical membrane potential, which is the membrane potential for a $100 \%$ permselective membrane, was calculated as $37.91 \mathrm{mV}$ from the Nernst equation.

\subsubsection{Ion exchange capacity}

The ion exchange capacity (IEC) of the membranes, which is the amount of charged groups in the membrane, was measured using a titration method [43]. A specific mass of membrane in the wet state was brought into $\mathrm{Cl}^{-}$form by soaking in $3 \mathrm{M} \mathrm{NaCl}$ solution for at least $15 \mathrm{~h}$. After the membrane was rinsed with demineralised water, it 
was soaked in a $1.5 \mathrm{M} \mathrm{Na} \mathrm{SO}_{4}$ solution for $3 \mathrm{~h}$ to undergo ion exchange (i.e. replacement of $\mathrm{Cl}^{-}$by $\mathrm{SO}_{4}{ }^{2-}$. The solution containing released $\mathrm{Cl}^{-}$was titrated with a $0.1 \mathrm{M} \mathrm{AgNO}_{3}$ solution. The IEC values (mmol/g dry membrane) can be calculated via the following relationship:

$$
\mathrm{IEC}=\frac{\mathrm{V}_{\mathrm{AgNO}_{3}}}{\mathrm{~W}_{\text {dry }}} \times \mathrm{C}_{\mathrm{AgNO}_{3}}
$$

Here, $\mathrm{V}_{\mathrm{AgNO}}$ is the volume of $\mathrm{AgNO}_{3}$ solution used, $\mathrm{W}_{\text {dry }}$ is the mass of the dried membrane and $\mathrm{C}_{\mathrm{AgNO}}$ is the concentration of the solution.

\subsubsection{Swelling degree}

The swelling degree indicates the water content of the membranes when exposed to water. To determine the swelling degree, the anion exchange membranes were immersed in demineralized water for at least $24 \mathrm{~h}$. After taking the membrane out of the water and removing the water from the surface of the membrane, the membrane was weighed immediately. Then the wet membrane was subsequently dried at $30^{\circ} \mathrm{C}$ in a vacuum oven until a constant dry weight was achieved. The swelling degree SD (g $\mathrm{H}_{2} \mathrm{O} / \mathrm{g}$ dry membrane) can be calculated by the following equation: [20]

$$
\mathrm{SD}=\frac{\mathrm{m}_{\text {wet }}-\mathrm{m}_{\text {dry }}}{\mathrm{m}_{\text {dry }}} \times 100 \%
$$

Here, $\mathrm{m}_{\text {wet }}$ and $\mathrm{m}_{\text {dry }}$ are the mass $(\mathrm{g})$ of the wet and the dry membrane, respectively.

\subsubsection{Fixed-charge density}

The fixed-charge density, expressed in mmol fixed charge groups per gram of water in the membrane, was determined from the ratio of IEC over the swelling degree of the membrane (Equation (2.6)) [4]:

$\mathrm{C}_{\text {fix }}=\frac{\text { IEC }}{\mathrm{SD}}$

Here, $\mathrm{C}_{\text {fix }}$ is the fixed-charge density $\left(\mathrm{mmol} / \mathrm{g} \mathrm{H} \mathrm{H}_{2} \mathrm{O}\right)$, IEC is the ion exchange capacity ( $\mathrm{mmol} / \mathrm{g}$ dry membrane) and $S D$ is the swelling degree, $\left(\mathrm{m}_{\text {wet }}-\mathrm{m}_{\text {dry }}\right) / \mathrm{m}_{\text {dry }},\left(\mathrm{g} \mathrm{H}_{2} \mathrm{O} / \mathrm{g}\right.$ dry membrane). 


\subsubsection{RED performance}

\subsubsection{The RED stack}

The RED performance of the tailor-made membranes was evaluated in a RED stack previously described [44]. In this study, five pairs of anion and cation exchange membranes were installed between two endplates, each of them equipped with titanium mesh end electrodes with dimensions of $10 \mathrm{~cm} \mathrm{x} 10 \mathrm{~cm}$, coated with Ru-Ir mixed metal oxides (Magneto Special Anodes, The Netherlands). A sixth cation exchange membrane was used to prevent the transfer of negatively charged iron complexes into the stack. The electrode compartments contained a solution of $\mathrm{NaCl}$ $(0.25 \mathrm{M})$ with $\mathrm{K}_{4} \mathrm{Fe}(\mathrm{CN})_{6}(0.05 \mathrm{M})$ and $\mathrm{K}_{3} \mathrm{Fe}(\mathrm{CN})_{6}(0.05 \mathrm{M})$. The electrolyte was pumped through the anode and cathode compartments at a flow rate of $300 \mathrm{ml} / \mathrm{min}$.

The cell width (intermembrane distance) of $200 \mu \mathrm{m}$ was maintained by the use of a polyamide woven spacer (Nitex 03-300/51, Sefar). The porosity and open area of this spacer are $67 \%$ and $51 \%$, respectively. Around the spacer, a silicon gasket (Specialty Silicone Fabricators, USA) was placed to seal the water compartments. The membranes, gaskets and spacers were cut into proper shape with a punch and a press.

\subsubsection{Feed water}

Model seawater $(0.507 \mathrm{M})$ and river water $(0.017 \mathrm{M})$ were prepared by dissolving technical grade $\mathrm{NaCl}$ (technical grade BOOM BV, The Netherlands) in demineralized water. These feed waters were pumped through the stack at flow rates of $0.67,1.67$ and $3.33 \mathrm{~cm}^{3} / \mathrm{s}$. For the delivery of seawater and river water, peristaltic pumps (Masterflex, Cole Palmer) were used. Temperature was controlled at $298 \pm 1 \mathrm{~K}$ for all experiments by means of a thermostated water bath (Colora thermostat WK16).

\subsubsection{Electrochemical measurements}

The performance of the membranes was evaluated using an Ivium potentiostat (Ivium Technologies, Eindhoven, The Netherlands) in the chronopotentiometry mode. At each flow rate, 20 current steps $\left(0,2,4 \ldots 40 \mathrm{~A} / \mathrm{m}^{2}\right)$ for 30 seconds each were applied. All measurements were performed at least three times. From the measured voltage (E)current (I) curves, the gross power output was calculated as the maximum of the product from E and I. The gross power output was corrected by subtracting the power output of a blank run using only one cation exchange membrane in the stack. Then, 
the power output was converted into power density by dividing the power output by the total membrane area $\left(\mathrm{W} / \mathrm{m}^{2}\right)$.

\subsection{Results and discussion}

\subsubsection{Characterization of PECH membranes}

\subsubsection{Morphology of PECH anion exchange membranes}

SEM was used to investigate the morphology of the prepared PECH anion exchange membranes.

SEM images of the cross-section of $77-\mu$ m-thick membranes after solvent evaporation at magnifications of 250x (a) and 2000x (b) are shown in Figure 2.3, in which a clear dense structure without pores can be recognized. Similar membrane morphologies were observed for membranes with thicknesses of $33 \mu \mathrm{m}$ and $130 \mu \mathrm{m}$.

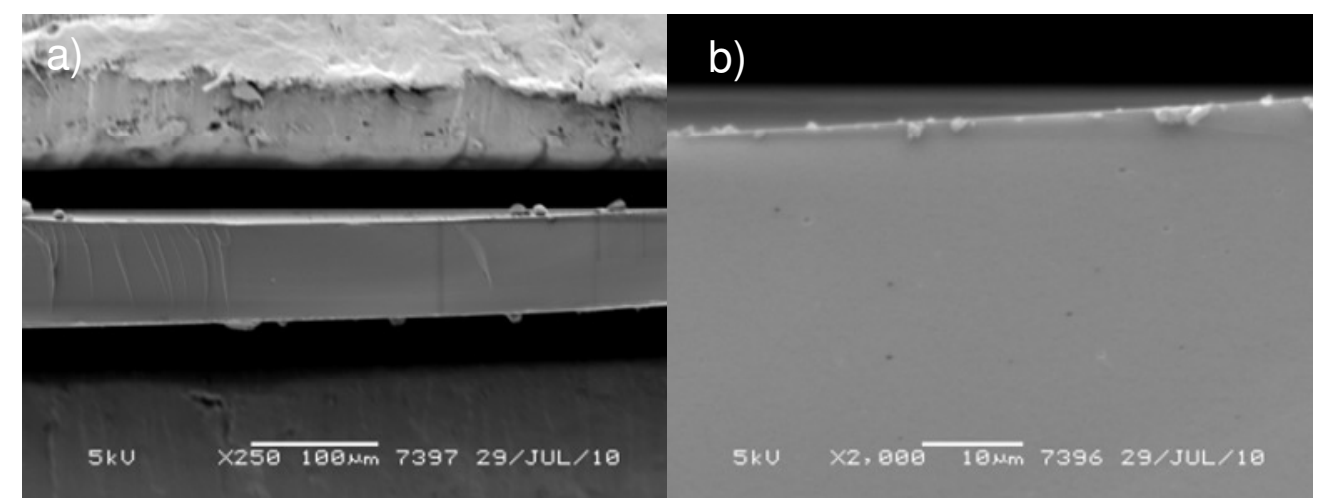

Figure 2.3. Cross section of the dense PECH membrane obtained after solvent evaporation; (a) magnification: 250x; (b) magnification: 2000x.

\subsubsection{FTIR}

To confirm the quaternization of the PECH polymer, FTIR was employed. Figure 2.4 displays the FTIR spectra of a) pure PECH, b) pure PAN, c) PECH/PAN and d) and e) quaternized PECH (QPECH)/PAN with blend ratios of 0.333 and 0.208 respectively. Figures 2.4a and 2.4b show the FTIR spectra for pure PECH and PAN films, respectively. When these two polymers are blended, an intense peak at $2240 \mathrm{~cm}^{-}$ ${ }^{1}$, representing the nitrile group $(-\mathrm{C} \equiv \mathrm{N})$ of the inert polymer PAN, can also be seen in Figures 2.4b-e. Compared with PECH (Figure 2.4a), two new peaks at 1640 and 3400 
$\mathrm{cm}^{-1}$ are visible in the spectrum of QPECH/PAN with blend ratios of 0.333 (Figure 2.4d) and 0.208 (Figure 2.4e). The former is associated with the C-N group and the latter belongs to the O-H group. Overall, the results indicate successful introduction of the quaternized ammonium [40] and blending of the active polymer PECH with the inert polymer PAN.

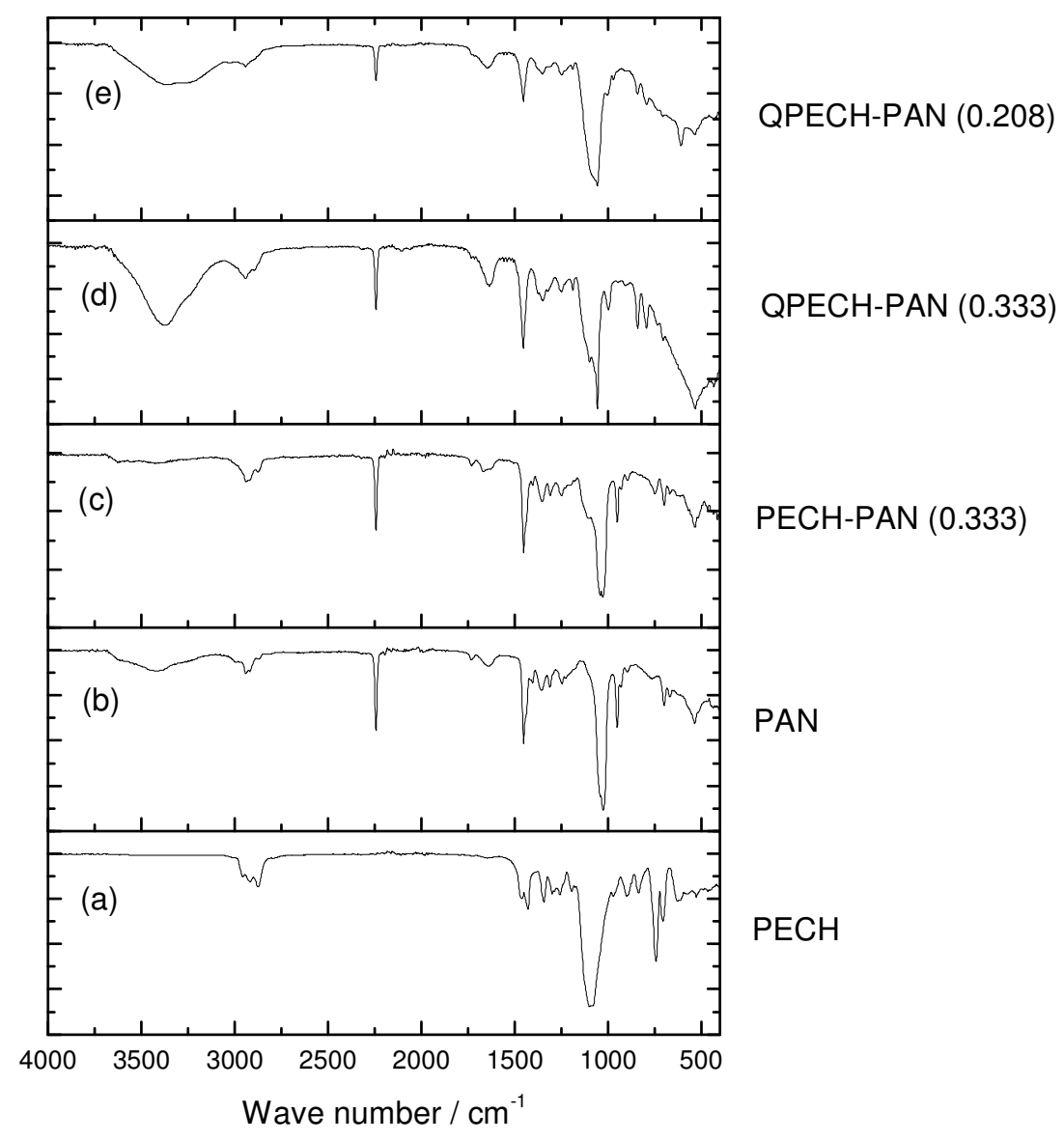

Figure 2.4. FTIR spectra of membranes for (a) PECH, (b) PAN, (c) PECH-PAN, (d) QPECH-PAN with a blend ratio of 0.333 , (e) QPECH-PAN with a blend ratio of 0.208 .

\subsubsection{Effect of blend ratio on membrane properties}

The PECH membranes were blended with PAN at blend ratios $\sigma\left(\mathrm{m}_{\mathrm{PECH}} / \mathrm{m}_{\mathrm{PAN}}\right)$ ranging from 0.100 to 1.040 (more details on the determination of blend ratio can be found in the experimental part). Figure 2.5 shows the effect of blend ratio on the ion exchange capacity (IEC) and swelling degree of the prepared membranes. With increasing blend ratio, the proportion of active polymer PECH, increases. This results in a higher IEC, as there are more charged groups present in the polymer. The highest 
IEC obtained was $2.8 \mathrm{mmol} / \mathrm{g}_{\text {dry }}$ for the membrane with the highest blend ratio $(\sigma=$ $1.04)$.

A higher IEC improves the ion conductive character of the polymer. On the other hand, the higher ionic charge in the membrane leads to an increase in the hydrophilic nature of the membrane. Consequently, the membranes swell more. Nevertheless, although the membranes with IECs higher than 2.3 exhibited a high degree of swelling, they maintained their excellent mechanical stability and strength.

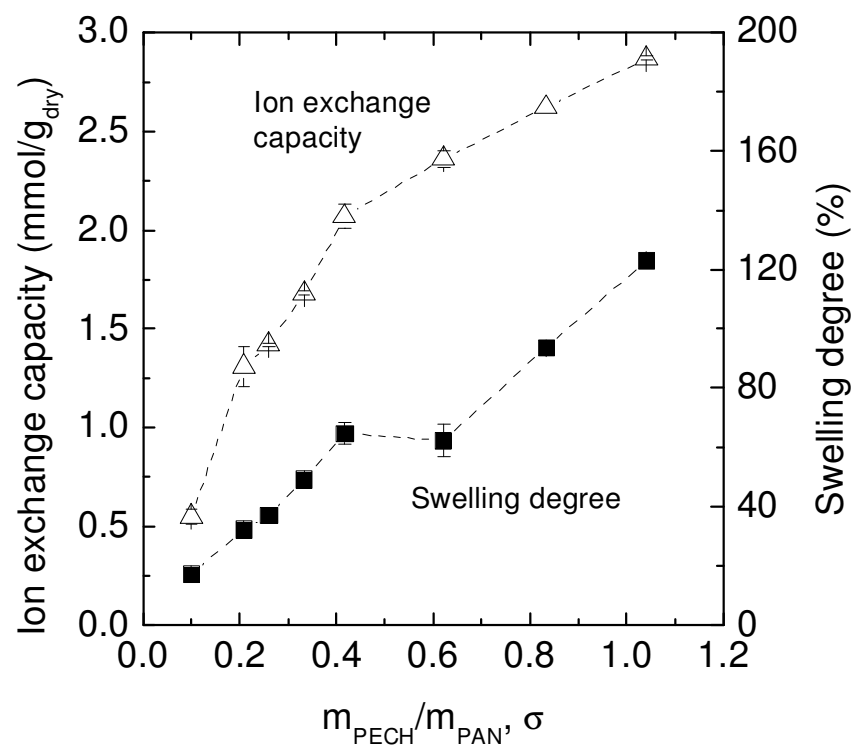

Figure 2.5. Ion exchange capacity and swelling properties of PECH membranes as a function of $\mathrm{m}_{\mathrm{PECH}} / \mathrm{m}_{\mathrm{PAN}}$.

Figure 2.6 presents the area resistance and permselectivity of the developed PECH anion exchange membranes as a function of blend ratio. The area resistance exhibited a decreasing trend with increasing blend ratio, and did not change significantly for blend ratios above 0.333 . We found area resistances of less than $1 \Omega \cdot \mathrm{cm}^{2}$. The PECH membrane with a blend ratio of 0.333 showed a resistance of only $0.94 \Omega \cdot \mathrm{cm}^{2}$, which is desirable for use in a RED stack [8]. The low area resistances are a consequence of a high level of amination. At higher blend ratios, the amount of the active polymer is higher, leading to higher amounts of functional chloromethyl groups to be aminated. The permselectivity of the membranes decreased with increasing blend ratio. This was due to the increasing degree of swelling with increasing blend ratio (Figure 2.4). 


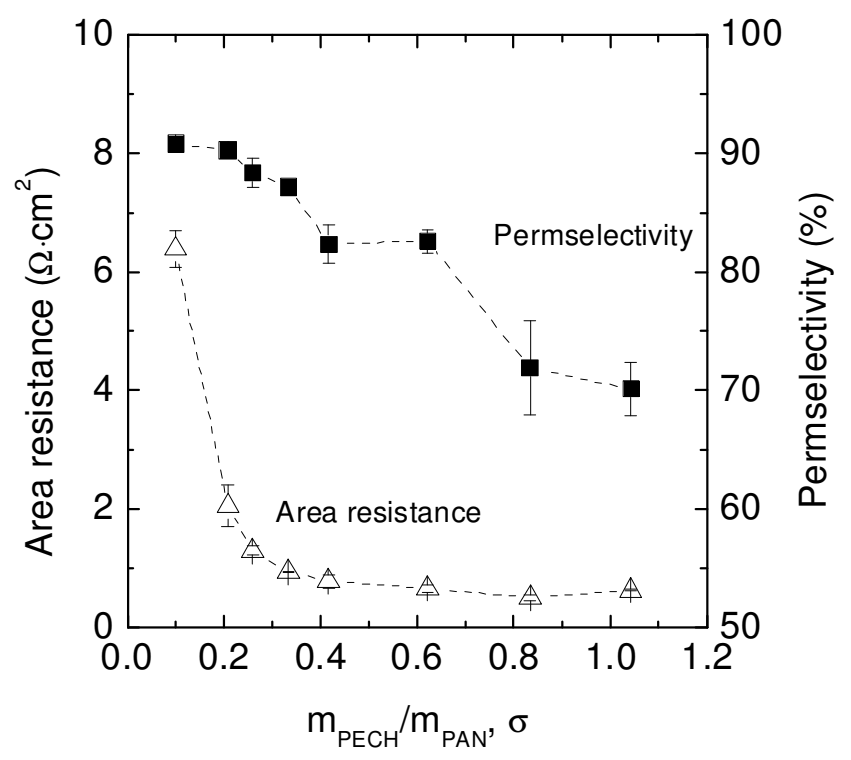

Figure 2.6. Area resistance and permselectivity properties of PECH membranes as a function of $\mathrm{m}_{\text {PECH }} / \mathrm{m}_{\text {PAN }}$.

\subsubsection{Effect of excess diamine ratio on the membrane properties}

The excess diamine ratio $v$ represents the molar ratio of the amine component DABCO over the chloromethyl groups in PECH (more details on the excess diamine ratio can be found in the experimental part). Various amounts of diamine (DABCO) were added to the $\mathrm{PECH} / \mathrm{PAN}$ solution, with the value of $v$ ranging from 2.63 to 7.31 signifying a significant excess of diamine. (In Equation (2.2), when $v$ is equal to 0.5, the amount of tertiary amine groups on the diamine and the amount of chloromethyl groups of PECH are equal). Such an excess of diamine is usually added to the casting solution to enhance the amination of chloromethyl groups in the active polymer PECH.

Because we used a significant amount of diamine, the effect of the amount of diamine on the membrane properties is very limited. Only at lower values of $v$ (up to approx. 4.2) a small increase in ion exchange capacity, swelling degree and permselectivity and a corresponding small decrease in area resistance were observed (Figure 2.7-2.8). At higher values of $v$, these parameters where almost independent of the excess diamine ratio. This is probably due to the amination of all possible chloromethyl groups of the polymer being reached at an excess diamine ratio of 4.2. These results are in good agreement with the data reported by Komkova et al. [40] for chloromethylated 
polysulfone membranes and by Hao et al. [45] for solvent-resistant anion exchange membranes.

In general, as the ion exchange capacity increases, the hydrophilicity of the membranes increases which leads to a decrease in mechanical stability [46-47]. Cross-linking of the polymer is one of the alternative ways to increase the mechanical stability of the membrane. As we used in all cases a significant excess amount of crosslinker, we did not carry out a quantitative analysis of the degree of cross-linking in our membranes. All membranes prepared exhibited excellent free-standing properties without any use of reinforcing material. This shows the advantage of simultaneous amination and crosslinking, which can improve the mechanical properties during functionalization of the polymer.

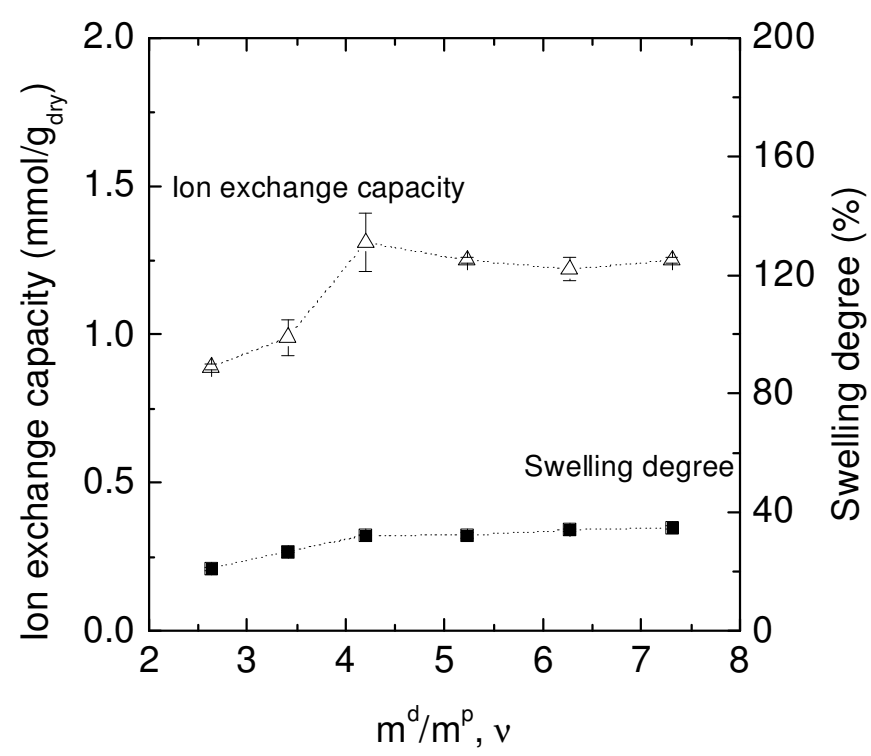

Figure 2.7. Ion exchange capacity and swelling properties of PECH membranes as a function of $\mathrm{m}^{\mathrm{d}} / \mathrm{m}^{\mathrm{p}}$. 


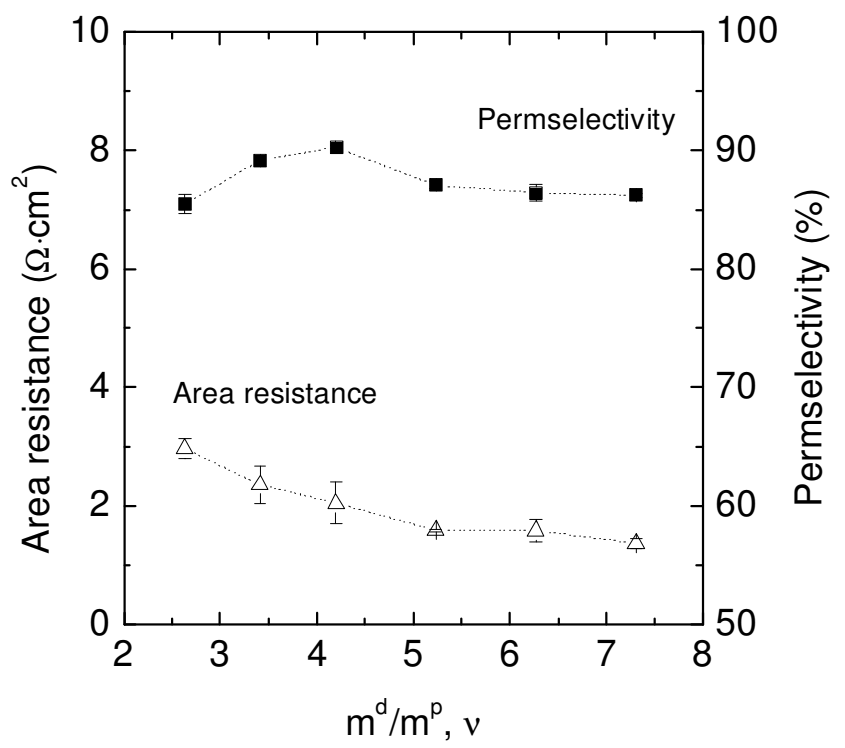

Figure 2.8. Area resistance and permselectivity properties of $\mathrm{PECH}$ membranes as a function of $\mathrm{m}^{\mathrm{d}} / \mathrm{m}^{\mathrm{p}}$.

\subsubsection{Effect of charge density on the membrane properties}

The charge density of the membrane is one of the most important factors that determine its ion permselectivity and its area resistance. Equation 2.6 defines the fixed-charge density as the amount of fixed ionic charges per water content of the membrane. Therefore, co-ion exclusion will be more effective if the IEC is high and the membrane swells less, i.e. at a high fixed-charge density.

Figure 2.9 shows the membrane permselectivity and area resistance as a function of the fixed-charge density of the membrane for all anion exchange membranes prepared.

As expected, the membrane permselectivity increases with increasing charge density. The higher the charge density, the stronger the exclusion of co-ions. According to Figure 2.9, surprisingly the membranes with a higher charge density seem to have a slightly higher membrane resistance as well. Although we do not understand the exact nature behind this, we assume this may stem from differences in the degree of crosslinking of the different membranes. Crosslinking reduces the swelling and thus increases the charge density, but apparently at the same time, it also increases the resistance more than expected. Długołecki et al. [4] investigated the relationship between permselectivity, membrane area resistance and charge density for commercial membranes, and observed the same for anion exchange membranes. At the same time, 
they showed that cation exchange membranes in general have higher charge densities and higher area resistances as a result of their high degree of cross-linking.

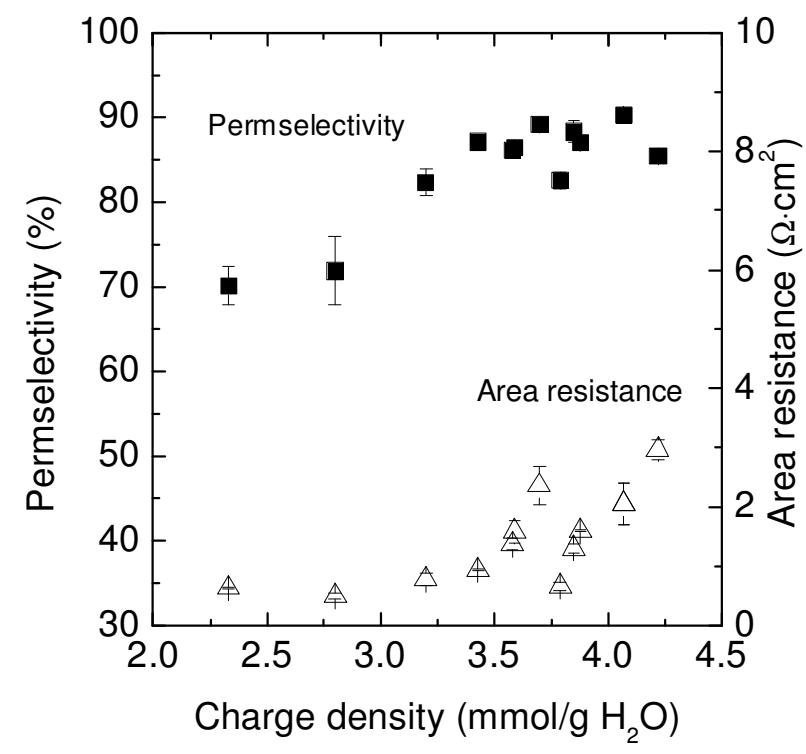

Figure 2.9. Membrane permselectivity and area resistance as a function of charge density.

From the results of Figures 2.5-2.9, we selected the best anion exchange membranes, those having low area resistances and high permselectivities, for performance evaluation in RED (Table 2.1). Table 2.1 also gives the characteristics of the Neosepta AMX membrane. To enable a fair comparison between the commercial AMX membrane and the tailor-made PECH membranes, PECH membranes were prepared at a similar thickness $(130 \mu \mathrm{m})$ as that of the Neosepta AMX membranes $(134 \mu \mathrm{m})$. As can be seen in Table 2.1, the area resistance of the PECH B-3 membrane is lower than that of the AMX membrane. However, the PECH B-3 membrane swells more than the AMX membrane due to its high IEC, resulting in a lower fixed-charge density. Hence, the PECH B-3 membrane is slightly less permselective than the AMX membrane. 
Table 2.1. Characteristics of membranes used for RED performance evaluation.

\begin{tabular}{lccccccc}
\hline Membrane & $\sigma^{[a]}$ & $\begin{array}{c}\delta^{[\mathrm{b}]} \\
{[\mu \mathrm{m}]}\end{array}$ & $\begin{array}{c}\alpha^{[\mathrm{c}]} \\
{[\%]}\end{array}$ & $\begin{array}{c}\mathrm{AR}^{[\mathrm{d}]} \\
{\left[\Omega \cdot \mathrm{cm}^{2}\right]}\end{array}$ & $\begin{array}{c}\mathrm{IEC}^{[\mathrm{e}]} \\
{\left[\mathrm{mmol} \mathrm{g}{ }^{-1} \mathrm{dry}\right]}\end{array}$ & $\begin{array}{c}\mathrm{SD}^{[\mathrm{f}]} \\
{[\%]}\end{array}$ & $\begin{array}{c}\mathrm{CD}^{[\mathrm{g}]} \\
{\left[\mathrm{mmol} \mathrm{g}^{-1} \mathrm{H}_{2} \mathrm{O}\right]}\end{array}$ \\
\hline PECH A & 0.208 & 77 & $90.3 \pm 0.11$ & $2.05 \pm 0.36$ & $1.31 \pm 0.10$ & $32.2 \pm 0.16$ & 4.1 \\
PECH B-1 & 0.333 & 33 & $86.5 \pm 0.71$ & $0.82 \pm 0.01$ & $1.68 \pm 0.01$ & $49.0 \pm 0.85$ & 3.4 \\
PECH B-2 & 0.333 & 77 & $87.2 \pm 0.00$ & $0.94 \pm 0.01$ & $1.68 \pm 0.01$ & $49.0 \pm 0.85$ & 3.4 \\
PECH B-3 & 0.333 & 130 & $87.0 \pm 0.01$ & $1.32 \pm 0.16$ & $1.68 \pm 0.04$ & $49.1 \pm 0.21$ & 3.4 \\
PECH C & 0.417 & 77 & $79.2 \pm 0.90$ & $1.14 \pm 0.05$ & $1.88 \pm 0.01$ & $53.5 \pm 0.20$ & 3.5 \\
AMX & - & 134 & $90.0 \pm 0.80$ & $2.35 \pm 0.05$ & $1.40 \pm 0.04$ & $26.0 \pm 0.20$ & 5.4 \\
CMX & - & 158 & $95.0 \pm 0.00$ & $3.00 \pm 0.01$ & $1.62 \pm 0.04$ & $18.0 \pm 0.20$ & 9.0 \\
\hline
\end{tabular}

[a] Blend ratio. [b] Thickness. [c] Permselectivity. [d] Area resistance. [e] Ion exchange capacity. [f] Swelling degree. [g] Charge density.

Table 2.1 also shows that IEC, an intrinsic membrane property, does not depend on the thickness of the membrane. We also found that the swelling degree did not differ between membranes with different thicknesses (PECH B-1, PECH B-2 and PECH B3). These membranes, therefore, have a similar fixed-charge density and permselectivity. Among our tailor-made PECH membranes, PECH A has the lowest degree of swelling resulting in the highest fixed-charge density and the highest permselectivity. However, this membrane also has the highest area resistance due to its lowest IEC.

\subsubsection{Performance of PECH membranes in RED}

\subsubsection{Membrane performance in RED}

Herein, we show for the first time the performance of a RED stack using tailor-made membranes. As a starting point, in order to compare the RED performance of PECH membranes with that of AMX membranes, PECH B-3 membranes were prepared at a blend ratio of 0.333 and a similar thickness as Neosepta AMX membranes (around 130 $\mu \mathrm{m})$. The RED stack was initially equipped with Neosepta CMX and AMX membranes, and the AMX membranes were later replaced with our PECH B-3 membranes to enable a comparison. As expected, the power output increases with increasing flow rate due to reduced boundary layer effects. Figure 2.10 shows that the tailor-made PECH-3 membrane exhibited a similar RED performance as the AMX 
membrane at a feed flow rate of $3.33 \mathrm{~cm}^{3} / \mathrm{s}$, but performed less well at lower flow rates. This is most probably due to the fact that the PECH B-3 membrane has a lower area resistance and a slightly lower permselectivity than the AMX membrane (see Table 2.1). The result was very promising, as the membrane investigated was not specifically optimized for application in RED.

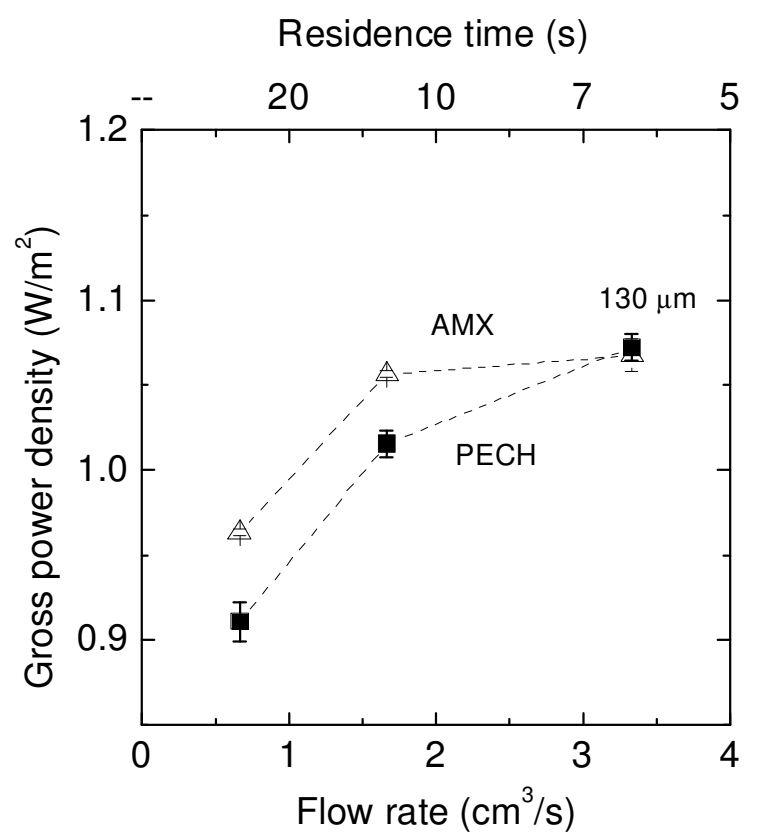

Figure 2.10. Comparison of RED performance of the tailor-made PECH membrane and the commercial AMX membrane. Cation exchange membrane: CMX.

Because the best membranes were obtained for $v=4.2$, we selected membranes with that excess diamine ratio, but with various blend ratios for testing in RED. Figure 2.11 shows the power output of these membranes as a function of the blend ratio.

The best-performing membrane, PECH B-2, has a blend ratio of 0.333 and power densities up to $1.2 \mathrm{~W} / \mathrm{m}^{2}$ can be obtained using a spacer thickness of $200 \mu \mathrm{m}$. The PECH B-2 membrane has the lowest resistance $\left(0.94 \Omega \cdot \mathrm{cm}^{2}\right)$ and a reasonably high permselectivity of $87.2 \%$ as compared to the other membranes. The optimum in blend ratio with respect to power output may be the result of the fact that polymer properties influence the different membrane parameters (e.g. permselectivity, resistance, ion exchange capacity, swelling degree, etc.). All together these parameters determine the final power density obtainable for a specific membrane. At this stage with the current data it is not possible yet to identify the dominant membrane characteristics that determine the final RED performance. This requires a much more systematic and 
extended study using different membrane types, which is outside the scope of the present work.

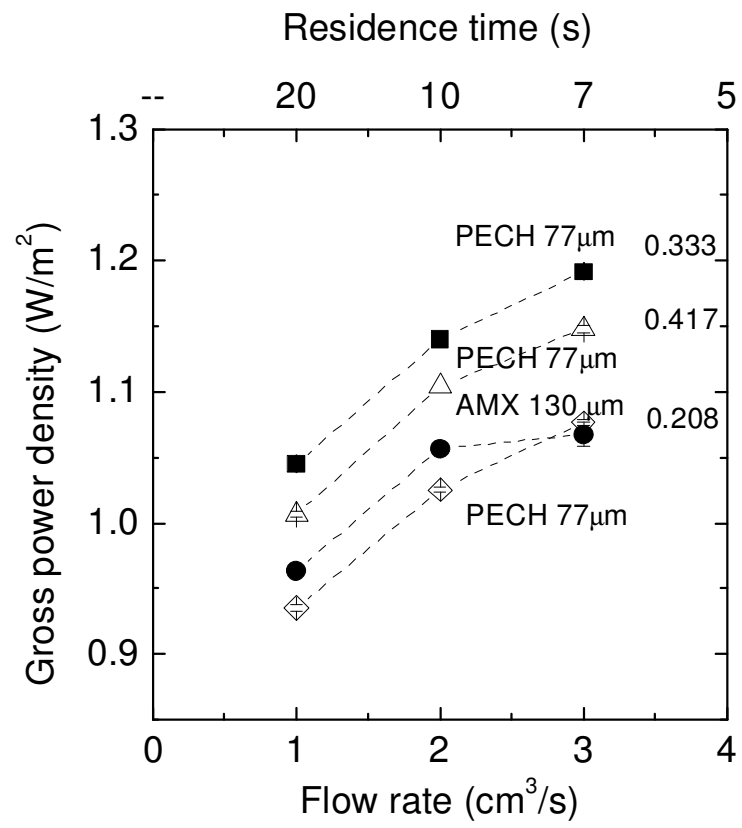

Figure 2.11. Practically obtainable gross stack power density determined of tailor-made PECH membranes as a function of the flow rate for different blend ratios ( CMX/PECH B-2; $\triangle \mathrm{CMX} / \mathrm{PECH}$ C; $\bullet$ CMX/AMX; $\diamond$ CMX/PECH A). Cation exchange membrane: CMX. The performance of the AMX membrane is shown for comparison.

\subsubsection{Effect of film thickness on membrane performance in RED}

The membrane that gives the highest power density was the one with a blend ratio of 0.333. Membrane thickness has a significant effect on the membrane performance. Table 2.1 shows the decreasing trend in area resistance with decreasing membrane thickness. At the same time, ion exchange capacity and swelling degree did not change significantly with membrane thickness, resulting in an equivalent permselectivity. Figure 2.12 shows the effect of the membrane thickness on the power output obtainable in RED. 


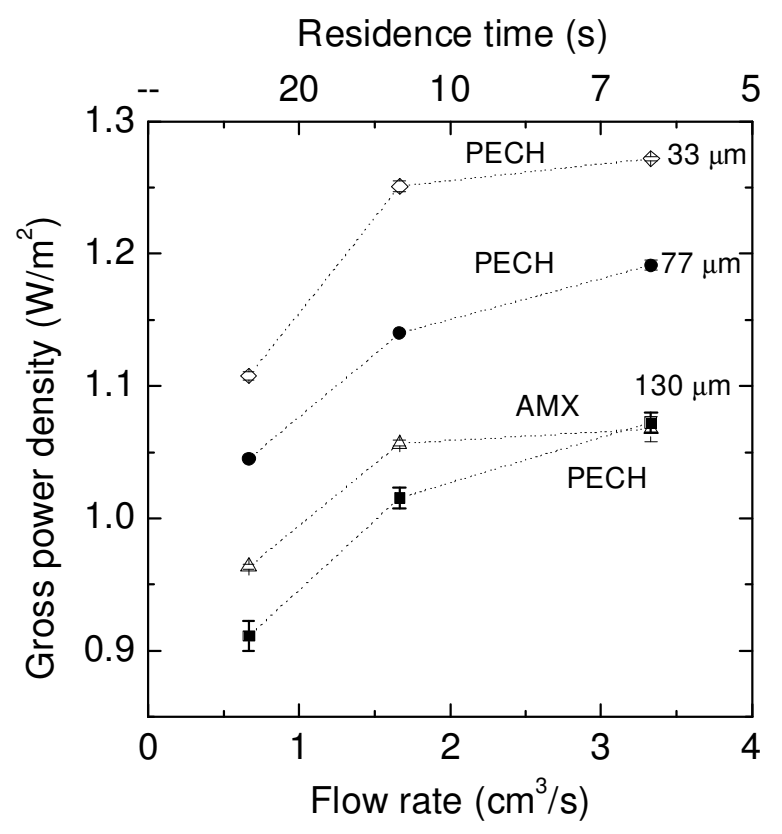

Figure 2.12. Practically obtained gross power density as a function of the flow rate for PECH membranes with various thicknesses. Cation exchange membrane: CMX. The values obtained for the AMX membrane are shown as a reference.

Figure 2.12 reveals that the power output is strongly dependent on membrane thickness. The thinner the membrane, the better the performance, resulting in the highest power density of $1.27 \mathrm{~W} / \mathrm{m}^{2}$ for the thinnest membrane $(33 \mu \mathrm{m})$, with the lowest area resistance $\left(0.82 \Omega \cdot \mathrm{cm}^{2}\right)$. This is the first time that we achieve such high power density and at the same time use tailor-made anion exchange membranes. When the membrane thickness is increased to $77 \mu \mathrm{m}$, a $6 \%$ gross power density reduction is observed. The lowest power density is obtained by using a membrane with a thickness of $130 \mu \mathrm{m}$. In order to produce even higher power densities, even thinner anion exchange membranes could be investigated, while at the same time also the cation exchange membrane properties could be considered as a method to further increase the power output.

\subsection{Conclusions}

For the first time we have shown the performance of a reverse electrodialysis (RED) stack using tailor-made anion exchange membranes. Anion exchange membranes were prepared in a more environmentally friendly and safer way than via the conventional method, using the elastomer polyepichlorohydrin $(\mathrm{PECH})$, which has inherent chloromethyl groups, as polymer matrix. A tertiary diamine $(1,4$ - 
diazabicyclo[2.2.2] octane, DABCO) was used to introduce the ion exchange groups by amination and for simultaneous cross-linking of the polymer membrane. Area resistance, permselectivity, swelling degree and ion exchange capacity of these PECH membranes were investigated for various PECH and diamine concentrations; area resistances ranged from 0.82 to $2.05 \Omega \cdot \mathrm{cm}^{2}$ and permselectivities from 87 to $90 \%$. For the first time we showed that tailor-made ion exchange membranes can be applied in RED for the generation of power from the mixing of sea and river water. Although PECH membranes performed slightly less well at the same thickness as the AMX membranes, playing with the chemistry and the thickness of the membranes enables us to improve the power density. Depending on the properties and especially the membrane thickness, application of these membranes in RED resulted in a high power density of $1.27 \mathrm{~W} / \mathrm{m}^{2}$, which exceeds the power output obtained with the commercially available AMX membranes. This shows the potential of the design of ion exchange membranes for a viable Blue Energy process.

\subsection{Acknowledgements}

This work was performed within the TTIW cooperation framework of Wetsus, centre of excellence for sustainable water technology (www.wetsus.nl). Wetsus is funded by the Dutch Ministry of Economic Affairs. The authors like to thank Alliander, Eneco Energy, FrisiaZout, Fuji Film, Landustrie, Magneto Special Anodes, A. Hak and MAST Carbon of the research theme "Blue Energy" for fruitful discussions and financial support. 


\subsection{References}

[1] EIA, International energy outlook 2009, in, Office of integrated analysis and forecasting, Department of energy, Washington D.C., 2009.

[2] G.Z. Ramon, B.J. Feinberg, E.M.V. Hoek, Membrane-based production of salinity-gradient power, Energy and Environmental Science, 4 (2011) 4423-4434.

[3] J.W. Post, J. Veerman, H.V.M. Hamelers, G.J.W. Euverink, S.J. Metz, K. Nymeijer, C.J.N. Buisman, Salinity-gradient power: Evaluation of pressure-retarded osmosis and reverse electrodialysis, Journal of Membrane Science, 288 (2007) 218-230.

[4] P. Długołecki, K. Nymeijer, S. Metz, M. Wessling, Current status of ion exchange membranes for power generation from salinity gradients, Journal of Membrane Science, 319 (2008) 214-222.

[5] B. E, Salinity gradient power by reverse electrodialysis: effect of model parameters on electrical power output, Desalination, 237 (2009) 378-391.

[6] R.E. Lacey, Energy by reverse electrodialysis, Ocean Engineering, 7 (1980) 1-47.

[7] J.W. Post, H.V.M. Hamelers, C.J.N. Buisman, Energy recovery from controlled mixing salt and fresh water with a reverse electrodialysis system, Environmental Science and Technology, 42 (2008) 57855790 .

[8] J.W. Post, C.H. Goeting, J. Valk, S. Goinga, J. Veerman, H.V.M. Hamelers, P.J.F.M. Hack, Towards implementation of reverse electrodialysis for power generation from salinity gradients, Desalination and Water Treatment, 16 (2010) 182-193.

[9] E. Middelman, Balster, Jörg Henning, WO/2008/095509, Reinforced ion-exchange membrane comprised of a support, and laminated thereon, a polymeric film, in, 2008.

[10] P.V. Vyas, B.G. Shah, G.S. Trivedi, P. Ray, S.K. Adhikary, R. Rangarajan, Characterization of heterogeneous anion-exchange membrane, Journal of Membrane Science, 187 (2001) 39-46.

[11] M. Yukio, Structure of ion exchange membranes, Journal of Membrane Science, 49 (1990) 121-144.

[12] M. Turek, B. Bandura, Renewable energy by reverse electrodialysis, Desalination, 205 (2007) 67-74.

[13] R. Audinos, Electrodialyse inverse. Etude de l'energie electrique obtenue a partir de deux solutions de salinites differentes, Journal of Power Sources, 10 (1983) 203-217.

[14] J. Jagur-Grodzinski, R. Kramer, Novel process for direct conversion of free energy of mixing into electric power, Industrial \& Engineering Chemistry Process Design and Development, 25 (1986) 443-449.

[15] R.E. Pattle, Electricity from fresh and salt water-without fuel, Chem. Proc. Eng., 35 (1954) 351354 .

[16] F. Suda, T. Matsuo, D. Ushioda, Transient changes in the power output from the concentration difference cell (dialytic battery) between seawater and river water, Energy, 32 (2007) 165-173.

[17] J. Veerman, R.M. de Jong, M. Saakes, S.J. Metz, G.J. Harmsen, Reverse electrodialysis: Comparison of six commercial membrane pairs on the thermodynamic efficiency and power density, Journal of Membrane Science, 343 (2009) 7-15.

[18] J. Veerman, J.W. Post, M. Saakes, S.J. Metz, G.J. Harmsen, Reducing power losses caused by ionic shortcut currents in reverse electrodialysis stacks by a validated model, Journal of Membrane Science, 310 (2008) 418-430.

[19] J.N. Weinstein, F.B.J.W. Leitz, Electric power from differences in salinity: the dialytic battery, Science, 191 (1976) 557-559. 
[20] F.G. Wilhelm, I.G.M. Pünt, N.F.A. Van Der Vegt, H. Strathmann, M. Wessling, Cation permeable membranes from blends of sulfonated poly(ether ether ketone) and poly(ether sulfone), Journal of Membrane Science, 199 (2002) 167-176.

[21] J.-S. Park, S.-H. Park, S.-D. Yim, Y.-G. Yoon, W.-Y. Lee, C.-S. Kim, Performance of solid alkaline fuel cells employing anion-exchange membranes, Journal of Power Sources, 178 (2008) 620-626.

[22] J. Pan, Y. Li, L. Zhuang, J. Lu, Self-crosslinked alkaline polymer electrolyte exceptionally stable at 90 [degree]C, Chemical Communications, 46 (2010) 8597-8599.

[23] J. Zhou, M. Unlu, J.A. Vega, P.A. Kohl, Anionic polysulfone ionomers and membranes containing fluorenyl groups for anionic fuel cells, Journal of Power Sources, 190 (2009) 285-292.

[24] G. Wang, Y. Weng, D. Chu, R. Chen, D. Xie, Developing a polysulfone-based alkaline anion exchange membrane for improved ionic conductivity, Journal of Membrane Science, 332 (2009) 63-68.

[25] M.R. Hibbs, M.A. Hickner, T.M. Alam, S.K. McIntyre, C.H. Fujimoto, C.J. Cornelius, Transport properties of hydroxide and proton conducting membranes, Chemistry of Materials, 20 (2008) 2566-2573.

[26] J. Pan, C. Chen, L. Zhuang, J. Lu, Designing Advanced Alkaline Polymer Electrolytes for Fuel Cell Applications, Accounts of Chemical Research, 45 (2011) 473-481.

[27] J.R. Varcoe, R.C.T. Slade, E. Lam How Yee, S.D. Poynton, D.J. Driscoll, D.C. Apperley, Poly(ethylene-co-tetrafluoroethylene)-derived radiation-grafted anion-exchange membrane with properties specifically tailored for application in metal-cation-free alkaline polymer electrolyte fuel cells, Chemistry of Materials, 19 (2007) 2686-2693.

[28] J.R. Varcoe, R.C.T. Slade, An electron-beam-grafted ETFE alkaline anion-exchange membrane in metal-cation-free solid-state alkaline fuel cells, Electrochemistry Communications, 8 (2006) 839-843.

[29] J.R. Varcoe, R.C.T. Slade, E.L.H. Yee, S.D. Poynton, D.J. Driscoll, Investigations into the ex situ methanol, ethanol and ethylene glycol permeabilities of alkaline polymer electrolyte membranes, Journal of Power Sources, 173 (2007) 194-199.

[30] J.R. Varcoe, Investigations of the ex situ ionic conductivities at $30^{\circ} \mathrm{C}$ of metal-cation-free quaternary ammonium alkaline anion-exchange membranes in static atmospheres of different relative humidities, Physical Chemistry Chemical Physics, 9 (2007) 1479-1486.

[31] R.C.T. Slade, J.R. Varcoe, Investigations of conductivity in FEP-based radiation-grafted alkaline anion-exchange membranes, Solid State Ionics, 176 (2005) 585-597.

[32] M.-s.J. Jung, C.G. Arges, V. Ramani, A perfluorinated anion exchange membrane with a 1,4dimethylpiperazinium cation, Journal of Materials Chemistry, 21 (2011) 6158-6160.

[33] T.J. Clark, N.J. Robertson, H.A. Kostalik Iv, E.B. Lobkovsky, P.F. Mutolo, H.c.D. Abruña, G.W. Coates, A Ring-Opening Metathesis Polymerization Route to Alkaline Anion Exchange Membranes: Development of Hydroxide-Conducting Thin Films from an Ammonium-Functionalized Monomer, Journal of the American Chemical Society, 131 (2009) 12888-12889.

[34] M.R. Hibbs, C.H. Fujimoto, C.J. Cornelius, Synthesis and Characterization of Poly(phenylene)Based Anion Exchange Membranes for Alkaline Fuel Cells, Macromolecules, 42 (2009) 8316-8321.

[35] C. Sollogoub, A. Guinault, C. Bonnebat, M. Bennjima, L. Akrour, J.F. Fauvarque, L. Ogier, Formation and characterization of crosslinked membranes for alkaline fuel cells, Journal of Membrane Science, 335 (2009) 37-42.

[36] T.Y. Guo, Q.H. Zeng, C.H. Zhao, Q.L. Liu, A.M. Zhu, I. Broadwell, Quaternized polyepichlorohydrin/PTFE composite anion exchange membranes for direct methanol alkaline fuel cells, Journal of Membrane Science, 371 (2011) 268-275.

[37] S. Wright, 2475148, Hydrophilic Polymer Membranes, in, United States, 2011. 
[38] P. Altmeier, 5746917, Strongly alkaline anion exchange membranes and process for producing the same, in, United States, 1998.

[39] B.A. Bolto, M.B. Jackson, Polyamine ion-exchange resins from polyepichlorohydrin: Resins with improved resistance to oxidation, Reactive Polymers, Ion Exchangers, Sorbents, 2 (1984) 209-222.

[40] E.N. Komkova, D.F. Stamatialis, H. Strathmann, M. Wessling, Anion-exchange membranes containing diamines: preparation and stability in alkaline solution, Journal of Membrane Science, 244 (2004) 25-34.

[41] J.J. Krol, M. Wessling, H. Strathmann, Chronopotentiometry and overlimiting ion transport through monopolar ion exchange membranes, Journal of Membrane Science, 162 (1999) 155-164.

[42] B. Bauer, H. Strathmann, F. Effenberger, Anion-exchange membranes with improved alkaline stability, Desalination, 79 (1990) 125-144.

[43] Chapter 3 Preparation and characterization of ion-exchange membranes, in: S. Heiner (Ed.) Membrane Science and Technology, Elsevier, 2004, pp. 89-146.

[44] P. Długołęcki, A. Gambier, K. Nijmeijer, M. Wessling, Practical potential of reverse electrodialysis as process for sustainable energy generation, Environmental Science and Technology, 43 (2009) 68886894.

[45] J.H. Hao, C. Chen, L. Li, L. Yu, W. Jiang, Preparation of solvent-resistant anion-exchange membranes, Desalination, 129 (2000) 15-22.

[46] X. Tongwen, F.F. Zha, Fundamental studies on a new series of anion exchange membranes: effect of simultaneous amination-crosslinking processes on membranes ion-exchange capacity and dimensional stability, Journal of Membrane Science, 199 (2002) 203-210.

[47] G.-J. Hwang, H. Ohya, Preparation of anion-exchange membrane based on block copolymers: Part 1. Amination of the chloromethylated copolymers, Journal of Membrane Science, 140 (1998) 195-203. 
Chapter 2. 


\section{Performance-determining membrane properties in reverse electrodialysis}

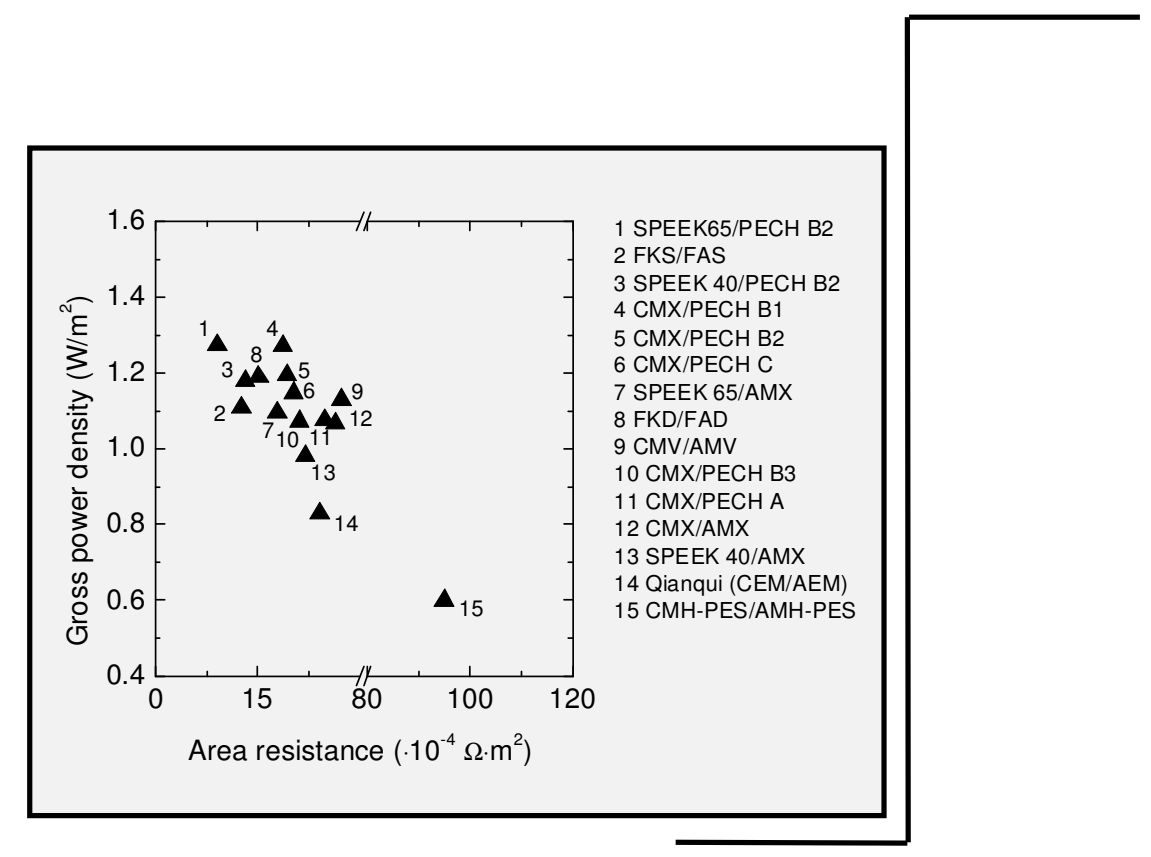

This chapter has been published as:

E. Guler, R. Elizen, D. A. Vermaas, M. Saakes, K. Nijmeijer, Performance-determining membrane properties in reverse electrodialysis. Journal of Membrane Science (2013), 446, 266-276. 


\begin{abstract}
Ion exchange membranes are core elements in reverse electrodialysis (RED), a process that can generate electricity from salinity gradients. The electrochemical and physical properties of these membranes are RED performance-determining factors. Although several studies regarding the optimization and modeling of membrane properties for RED have been performed, conclusions based on real experimental data of the relationship between physicochemical membrane bulk properties and power density (power output per unit membrane area) are still lacking. In this work, we studied bulk membrane properties of both a series of commercially available membranes and tailor made membranes and correlated these to experimental RED performance data. We successfully constructed the RED stack completely built with tailor-made membranes, made of polyetheretherketone (SPEEK) as cation-exchanging material and polyepichlorohydrin $(\mathrm{PECH})$ as anion-exchanging material. We obtained the highest gross power density when using only tailor-made membranes because of their significantly reduced membrane resistance. Using the experimental data, we developed a model based on multiple linear regression for gross power density which provides a better understanding on the dominant performance-determining membrane properties in RED to generate power from salinity gradients. The results set the directions towards tailoring ion exchange membranes for RED applications and show that emphasis should be especially on the development of low resistance membranes, whereas further increase of the permselectivity only has a limited effect.
\end{abstract}




\subsection{Introduction}

The development of renewable energy forms has become paramount to mankind in view of the ongoing depletion of fossil fuels, their environmental aspects and rising prices, in combination with increasing energy demands. Recently, using the salinity difference between seawater and river water has been recognized as a vital alternative to generate energy.

Reverse electrodialysis (RED) is one of the membrane processes that can convert the salinity differences between saltwater and freshwater into electrical power. A typical RED membrane stack consists of an alternating series of cation exchange membranes (CEMs) and anion exchange membranes (AEMs) situated between two electrodes. The chemical potential difference between these two solutions causes ions to migrate from the saltwater stream to the freshwater stream. The electrodes at both ends facilitate redox reactions that generate an electrical current (Figure 3.1).

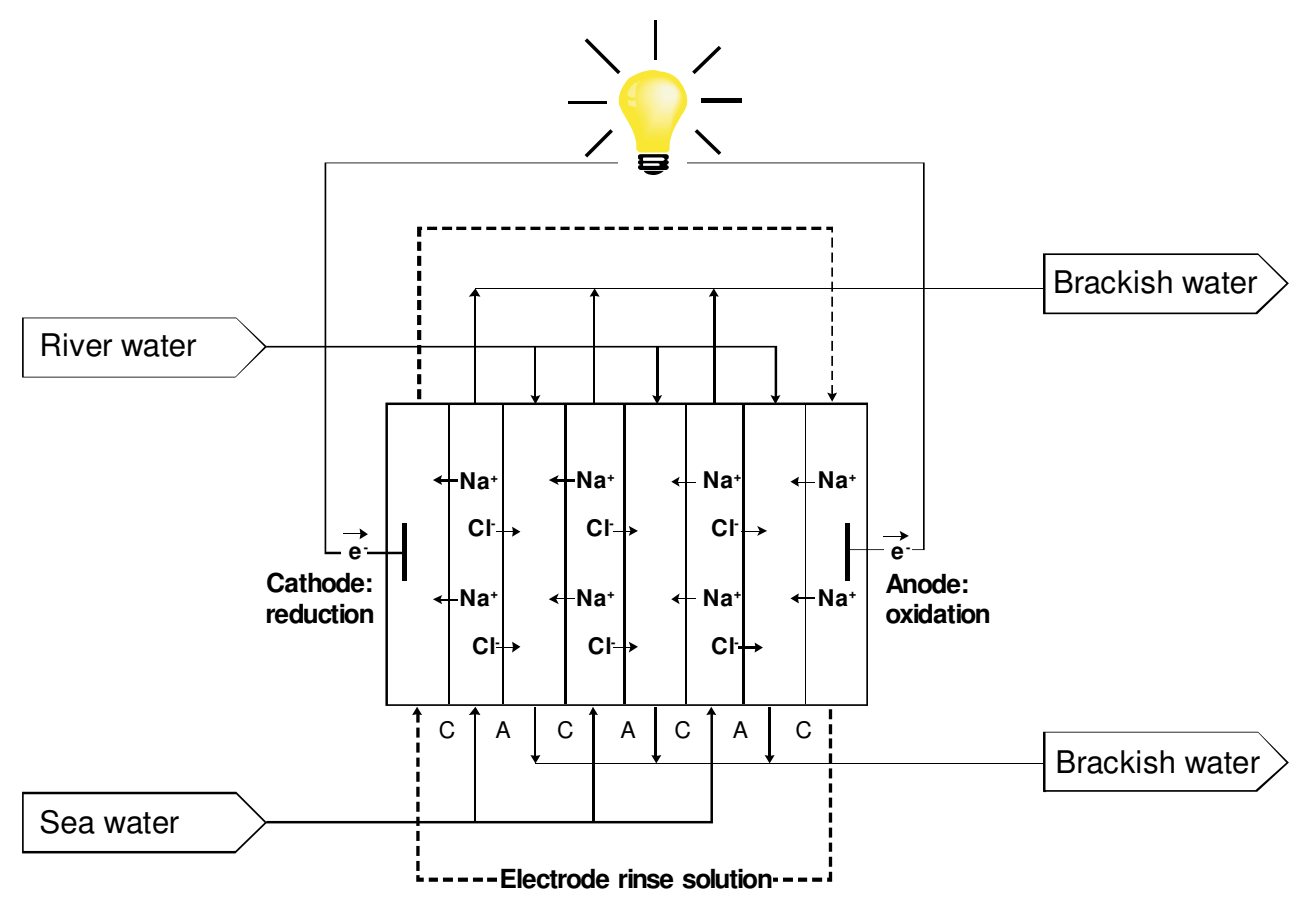

Figure 3.1. Schematic representation of a reverse electrodialysis stack. C: a cation exchange membrane and $\mathrm{A}$ : an anion exchange membrane.

Ion exchange membranes (IEMs) are successfully applied in water treatment and power generation [1], and in various other processes such as electrodialysis [2-9], desalination [10-22], and gas separation [23-26]. Over the past decades, the use of IEMs progressed from laboratory scale to industrial application in for example fuel cells [2728]. As IEMs are the key elements of any RED process, special attention must be paid 
to their characteristics. Membrane properties can be divided into physicochemical ones (e.g. thickness and swelling degree) and electrochemical ones (e.g. area resistance, permselectivity and charge density). Many researchers have tested commercial membranes in RED to generate power [29-31] and the literature reports the effects of parameters such as membrane type [30-32], spacer thickness [33], electrode systems [34-36] and flow rates on power production [33, 37-38]. Optimization of the power output involving operating parameters such as current density, more concentrated salt streams, stack resistance and membrane geometry has also been the topic of analyses and model calculations [39-40]. Patil et al. proposed that shunt currents and the membrane area occupied by the spacer mesh are main factors [39]. Recently, Vermaas et al. demonstrated that reducing membrane resistance and cell length could be an effective way to improve the power density in RED [40]. Fujii et al. worked on optimization of a RED stack with tailor-made poly(vinyl alcohol) (PVA) based ion exchange membranes obtaining a power density of $0.4 \mathrm{~W} / \mathrm{m}^{2}$ [41]. It is well known that electrochemical properties of the membranes (charge density, area resistance and permselectivity) each have a significant effect on RED performance. However, which membrane property is the main performance-determining factor is still under discussion. Previously, some authors investigating these properties focusing on the area resistance of the membranes $[30,33,40,42]$, but especially the effects of permselectivity in combination with area resistance in RED using tailor-made membranes has not been analyzed yet.

Most membrane properties have counteracting effects on performance. For instance, while it may be straightforward to prepare IEMs with a low area resistance by increasing the relative amount of active polymer containing a functional group, such membranes also have a loose mechanical structure and generally low permselectivity. The mechanical stability of the membranes could be improved by increasing the amount of cross-links in the polymer matrix. This would result in improved permselectivity, but area resistance would also become more pronounced which is not desired [43]. Therefore, membrane designers have to find a compromise between permselectivity and area resistance. That makes it crucial to determine which membrane properties are performance-determining in specific RED conditions and requires a systematic experimental approach.

In the work presented here, various tailor-made AEMs and CEMs were prepared. A complete RED stack was built by using only tailor-made IEMs (sulfonated polyetheretherketone or SPEEK and polyepichlorohydrin or PECH). The RED performance of these membranes was compared with the performance of commercially 
available IEMs having various electrochemical and physical properties. Homogeneous and heterogeneous membranes were evaluated in artificial seawater and river water conditions. Bulk membrane properties - e.g. area resistance, permselectivity, and charge density - were investigated and correlations between these properties and power density were analyzed with the aid of linear models and sensitivity analysis in order to determine the contribution of each of these membrane properties on power density.

\subsection{Experimental}

\subsubsection{Materials}

For the preparation of tailor-made AEMs, the elastomer polyepichlorohydrin (PECH, EPICHLOMER H, 37 wt\% chlorine content, Daiso Co. Ltd, Japan) was used as the active polymer. Polyacrylonitrile $\left(\mathrm{H}-\mathrm{PAN}, \mathrm{M}_{\mathrm{w}}=200,000 \mathrm{~g} / \mathrm{mol}\right.$, Dolan $\mathrm{GmbH}$, Germany) was chosen as an inert supporting polymer. Dimethyl sulfoxide (DMSO, 99\%, Merck) was used as solvent and a tertiary diamine (DABCO, 98\%, SigmaAldrich) was used for amination.

For the preparation of tailor-made CEMs, sulfonated polyetheretherketone (SPEEK, supplied by Fumatech, Germany) was used. The sulfonation degrees, which are a measure of the amount of sulfonic acid groups per repeating unit, were $65 \%$ and $40 \%$. N-methyl-2-pyrrolidon (NMP, Acros Organics, Belgium) was used as a solvent.

Sodium chloride (99.5\%, Acros Organics) and sodium sulfate (99\%, Acros Organics) were used for membrane resistance measurements. $\mathrm{AgNO}_{3}(0.1 \mathrm{~N}$, Merck) and $\mathrm{NaOH}$ (0.1N, Sigma-Aldrich) were used for ion exchange capacity measurements. For RED performance characterization, sodium chloride (technical grade, Boom BV, the Netherlands), potassium hexacyanoferrate(II) (99\%, Boom BV) and potassium hexacyanoferrate(III) (99\%, Boom BV) were used. All chemicals were used without further purification.

\subsubsection{Preparation of IEMs}

\subsubsection{Synthesis of PECH anion exchange membranes}

PECH anion exchange membranes were prepared by a solvent evaporation technique as described in previous work [32]. The membrane-forming solution (comprising PECH, 
PAN and DABCO) was cast onto a glass plate. After thermal curing (for $2 \mathrm{~h}$ at $110^{\circ} \mathrm{C}$ ) and solvent evaporation (for $30 \mathrm{~min}$ at $130^{\circ} \mathrm{C}$ ) in a thermostated oven, the polymer film was soaked in $0.5 \mathrm{M} \mathrm{NaCl}$ solution to release the membrane from the glass plate. The membranes were then stored in aqueous $\mathrm{NaCl}(0.5 \mathrm{M})$ till further use. PECH membranes were prepared at different blend ratios (0.208, 0.333 and 0.417), which is the mass ratio of PECH (active polymer providing the ion exchange groups) over PAN (inert polymer providing mechanical stability) and at different thicknesses (33, 77 and $130 \mu \mathrm{m})$. The thickness of the membranes was determined with a digital screw micrometer (Mitutoyo 293-240, Mitutoyo Co., Japan).

\subsubsection{Synthesis of SPEEK cation exchange membranes}

SPEEK with a sulfonation degree of 65\% (SPEEK65) was dissolved in 20 wt\% NMP overnight at ambient temperature and upon stirring. SPEEK with a sulfonation degree of $40 \%$ (SPEEK40) was dissolved in $10 \mathrm{wt} \%$ NMP upon stirring and heating up to 50 ${ }^{\circ} \mathrm{C}$ overnight. After that, the casting solution was cooled down. Subsequently membranes were cast on a clean glass plate. A casting knife with a slit width of 0.5 $\mathrm{mm}$ was used resulting in an average thickness of $70 \mu \mathrm{m}$ for SPEEK65 and an average thickness of $55 \mu \mathrm{m}$ for SPEEK40 membranes. After casting, the solvent was evaporated under nitrogen atmosphere, first 4 days at room temperature, followed by 14 days at $60{ }^{\circ} \mathrm{C}$. Next, the films were immersed in ultrapure water to separate the film from the glass plate. Finally the membranes were washed for 3 days with ultrapure water, which was replaced several times, after which the membranes were stored in a $0.5 \mathrm{M} \mathrm{NaCl}$ solution until use.

\subsubsection{Characterization of IEMs}

Tailor-made IEMs as prepared as described above and several commercially available IEMs were investigated. The latter included homogeneous as well as heterogeneous (containing ion exchange particles in non-conductive polymer binder) IEMs. We characterized electrochemical properties by determining the IEMs' area resistance, permselectivity, swelling degree and charge density according to procedures described elsewhere [32].

The area resistance $(R)$ is the resistance of the membrane and an important parameter determining the energy generating performance in RED. From an engineering point of view, the unit of membrane resistance is usually referred to as $\Omega \cdot \mathrm{cm}^{2}$ or $\Omega \cdot \mathrm{m}^{2}$. It is usually dependent on the ion exchange capacity and the mobility of the ions within the 
membrane matrix. Moreover it is affected by the temperature. In this work, it was measured by using a six-compartment cell with $\mathrm{NaCl}(0.5 \mathrm{M})$ as the test solution and $\mathrm{Na}_{2} \mathrm{SO}_{4}(0.5 \mathrm{M})$ as the electrolyte solution under direct current (DC). With an external potentiostat (Ivium Technologies, the Netherlands), the applied current density and voltage were measured with the membrane under investigation and without a membrane (blank) to determine the area resistance. The net area resistance was calculated from the difference between the slopes of the current-voltage curves for these two measurements. At least two runs were performed for each membrane.

The permselectivity of the membranes is defined as the flux of a specific component relative to the mass flux through the membrane under a given driving force. The permselectivity of an ion exchange membrane is a measure for how well the membrane under investigation can discriminate between the anions (e.g. $\mathrm{Cl}^{-}$) and the cations (e.g. $\mathrm{Na}^{+}$). In this study, it was determined by using a two-compartment cell. Solutions of $0.1 \mathrm{M} \mathrm{NaCl}$ and $0.5 \mathrm{M} \mathrm{NaCl}$ (99.5\%, Acros Organics) were recirculated on each side of the membrane. Two reference calomel electrodes were used to measure the potential over the membrane; the experimental potential was monitored with an external potentiostat. The permselectivity $(\alpha)$ was calculated from the ratio of the experimental potential $\left(\Delta \mathrm{V}_{\text {measured }}\right)$ over the theoretical potential $\left(\Delta \mathrm{V}_{\text {theoretical }}\right)$ for a $100 \%$ permselective membrane:

$\alpha=\frac{\Delta \mathrm{V}_{\text {measured }}}{\Delta \mathrm{V}_{\text {theoretical }}} \mathrm{x} 100 \%$

The swelling degree (SD) indicates the water content of the membranes. It is calculated from the difference in weight of a wet membrane and a dried membrane. The wet membrane was equilibrated in ultrapure water for at least 24 hours before it was patted dry with a tissue and the weight was recorded $\left(\mathrm{m}_{\mathrm{wet}}\right)$. The dry weight of the membrane $\left(\mathrm{m}_{\text {dry }}\right)$ was determined after at least 24 hours in a vacuum oven. The swelling degree of a membrane, in weight percent, is calculated following the next formula:

$\mathrm{SD}=\frac{\mathrm{m}_{\mathrm{wet}}-\mathrm{m}_{\mathrm{dry}}}{\mathrm{m}_{\mathrm{dry}}} \times 100 \%$

The ion exchange capacity (IEC) of the membranes is a crucial factor, which affects almost all other membrane properties. It is defined as the number of milli-equivalents of ion exchange groups included in $1 \mathrm{~g}$ of a dry membrane (meq·(g dry membrane $\left.)^{-1}\right)$. It was determined by titration. The AEMs were first immersed in $3 \mathrm{M} \mathrm{NaCl}(99.5 \%$, 
Acros Organics) overnight and at room temperature, to bring them in $\mathrm{Cl}^{-}$form. Then, they were rinsed with ultrapure water. The chlorine ions were then replaced by sulfate ions by immersing the membranes in a $1.5 \mathrm{M} \mathrm{Na}_{2} \mathrm{SO}_{4}$ solution for 3 hours. The solution was refreshed every hour and the three solutions containing the released chlorine ions were combined to obtain the titration solution. The collected $\mathrm{Na}_{2} \mathrm{SO}_{4}$ solution was titrated with a $0.100 \mathrm{M} \mathrm{AgNO}$ solution and the required volume of $\mathrm{AgNO}_{3}$ as recorded. The membrane samples were then dried in a vacuum oven at $30{ }^{\circ} \mathrm{C}$ for 24 hours to reach a constant weight, $\mathrm{m}_{\text {dry }}$, to allow calculation of the IEC with the aid of the following formula:

$\operatorname{IEC}\left[\frac{\mathrm{mmol}}{\mathrm{g} \text { dry membrane }}\right]=\frac{\mathrm{V}_{\mathrm{AgNO}_{3}}}{\mathrm{~m}_{\mathrm{dry}}}\left[\frac{\mathrm{ml}}{\mathrm{g}}\right] \cdot \mathrm{C}_{\mathrm{AgNO}_{3}}\left[\frac{\mathrm{mmol}}{\mathrm{ml}}\right]$

The CEMs were initially immersed in $1 \mathrm{M} \mathrm{HCl}$ for at least 12 hours at room temperature, then rinsed in ultrapure water. Subsequently, CEMs were immersed in a $2 \mathrm{M} \mathrm{NaCl}$ solution for 3 hours, and the titration was conducted with $0.100 \mathrm{M} \mathrm{NaOH}$. These CEMs were dried similarly as the AEMs and the IEC was then calculated with formula (Equation 3.4). All IEC measurements were performed in duplicate.

IEC $\left[\frac{\mathrm{mmol}}{\mathrm{g} \text { dry membrane }}\right]=\frac{\mathrm{V}_{\mathrm{NaOH}}}{\mathrm{m}_{\mathrm{dry}}}\left[\frac{\mathrm{ml}}{\mathrm{g}}\right] \cdot \mathrm{C}_{\mathrm{NaOH}}\left[\frac{\mathrm{mmol}}{\mathrm{ml}}\right]$

If the IEC and the swelling degree of a membrane are known, the fixed charge density (CD) can also be calculated. The fixed charge density represents the amount of fixed charge groups per gram of water in the membrane. The following formula expresses the fixed charge density $\left(\mathrm{mmol} / \mathrm{gH}_{2} \mathrm{O}\right)$ :

$\mathrm{CD}=\frac{\mathrm{IEC}}{\mathrm{SD}}\left[\frac{\mathrm{mmol}}{\mathrm{g}_{\mathrm{H}_{2} \mathrm{O}}}\right]$

\subsubsection{RED performance}

\subsubsection{RED setup}

For evaluation of the membrane performance in RED, we used a PMMA stack (STT Products BV, Tolbert, the Netherlands) containing 2 Ti electrodes (mesh 1.0, $10 \mathrm{~cm} \mathrm{x}$ $10 \mathrm{~cm}$ ) coated with Ir/Ru (Magneto Special Anodes BV, the Netherlands). The stack with membranes also contained silicone gaskets of $200 \mu \mathrm{m}$ (Specialty Silicone Fabricators, USA), and non-conductive spacers (Sefar, Nitex 03-300/51, Switzerland). 
The stack was placed in a thermostated oven (Fisher Scientific) at $25{ }^{\circ} \mathrm{C}$ to control the temperature.

Technical grade $\mathrm{NaCl}$ and demineralized water were used to prepare artificial seawater $(0.513 \mathrm{M} \mathrm{NaCl})$ and artificial river water $(0.017 \mathrm{M} \mathrm{NaCl})$. The salinity of these feed solutions was measured with a conductivity meter (WTW, Germany). The feed solutions were pumped through the RED stack by peristaltic pumps (Masterflex, Cole Palmer) and measurements at different flow rates were performed (40, 100, 200 $\mathrm{ml} / \mathrm{min}$ ). During measurements, the electrolyte solution containing $0.05 \mathrm{M}$ potassium hexacyanoferrate (II), 0.05 M potassium hexacyanoferrate (III) and $0.25 \mathrm{M} \mathrm{NaCl}$ were pumped through the electrode compartment at $300 \mathrm{ml} / \mathrm{min}$.

\subsubsection{Experimental power density}

Power density measurements were carried out with an external potentiostat (Ivium Technologies, the Netherlands) and a chronopotentiometric method as described elsewhere [32]. The feed waters flow in a continuous-flow mode through the system without any recycle loop. Prior to each the measurement, it takes about $30 \mathrm{~min}$. to achieve stable operation. At each flow rate, 20 current steps $\left(0,2,4 \ldots 40 \mathrm{~A} / \mathrm{m}^{2}\right)$ of 30 seconds each were applied. All measurements were performed at least three times.

The gross power output was calculated from the maximum of the product of the voltage (E) and the current (I). Next, this gross power output was corrected by subtracting the value resulting from a blank run with only one CEM in the stack. The power density was subsequently derived by dividing gross power output by total membrane area.

\subsubsection{Theoretical power density}

A theoretical model can be used to estimate the theoretical power density [30, 44]. The potential difference created by the salinity gradient as given by the Nernst equation is referred to as the open circuit voltage $\left(\mathrm{E}_{\mathrm{OCV}}\right)$ :

$\mathrm{E}_{\mathrm{OCV}}=\mathrm{N} \frac{2 \alpha \mathrm{RT}}{{ }_{\mathrm{zF}}} \ln \left(\frac{\mathrm{a}_{\mathrm{c}}}{\mathrm{a}_{\mathrm{d}}}\right)$

where $\alpha$ is the average membrane permselectivity of an anion and a cation exchange membrane pair (-), $\mathrm{N}$ is the number of membrane cells (-), $\mathrm{R}$ is the gas constant (8.314 $\mathrm{J} \mathrm{mol}^{-1} \mathrm{~K}^{-1}$ ), $\mathrm{T}$ is the absolute temperature $(\mathrm{K}), \mathrm{z}$ is the electrochemical valence, $\mathrm{F}$ is 
the Faraday constant $\left(96,485 \mathrm{C} \mathrm{mol}^{-1}\right), \mathrm{a}_{\mathrm{c}}$ is the activity of the concentrated salt solution $\left(\mathrm{mol} \mathrm{l} \mathrm{l}^{-1}\right.$ ) and $\mathrm{a}_{\mathrm{d}}$ is the activity of the diluted salt solution (mol l-1). The activities were approximated by the multiplication of the activity coefficient (-) of $\mathrm{NaCl}$ and the molar concentration $\left(\mathrm{mol} \mathrm{l}^{-1}\right)$ of the solutions.

Neglecting the non-ohmic resistances, i.e. the sum of boundary layer resistance (due to concentration polarization) and the resistance due to the change of the concentration of bulk solution, the stack resistance can be defined as [30]:

$R_{\text {stack }}=\frac{N}{A} \cdot\left(R_{\text {aem }}+R_{\text {cem }}+\frac{d_{c}}{\kappa_{c}}+\frac{d_{d}}{\kappa_{d}}\right)+R_{e l}$

where $\mathrm{A}$ is effective membrane area $\left(\mathrm{m}^{2}\right), \mathrm{R}_{\mathrm{aem}}$ is the anion exchange membrane resistance $\left(\Omega \cdot \mathrm{m}^{2}\right), \mathrm{R}_{\text {cem }}$ is the cation exchange membrane resistance $\left(\Omega \cdot \mathrm{m}^{2}\right), \mathrm{d}_{\mathrm{c}}$ is the thickness of the concentrated saltwater compartment $(\mathrm{m}), \mathrm{d}_{\mathrm{d}}$ is the thickness of the diluted saltwater compartment $(\mathrm{m}), \kappa_{\mathrm{c}}$ is the conductivity in the concentrated saltwater compartment $\left(\mathrm{S} \mathrm{m}^{-1}\right), \kappa_{\mathrm{d}}$ is the conductivity in the diluted saltwater compartment $\left(\mathrm{S} \mathrm{m}^{-1}\right)$ and $\mathrm{R}_{\mathrm{el}}$ is the ohmic resistance of both electrodes and their compartments $(\Omega)$. In this work, the resistance of electrodes and its compartments is assumed to be negligible as its contribution to the whole stack resistance is relatively low compared to other resistances such as river water compartment and membrane resiatnces. Therefore, $R_{e l}$ is not quantified individually and not included in the theoretical power density data that will be presented later.

The maximum power output using $R_{\text {stack }}$ and $E_{O C V}$ can subsequently be expressed as $[30,42]$ :

$\mathrm{P}_{\max }=\frac{\left(\mathrm{E}_{\mathrm{OCV}}\right)^{2}}{4 \mathrm{R}_{\mathrm{stack}}}$

Then, the maximum power output can be easily extended by substituting E $_{\mathrm{OCv}}$ in Equation 3.8 by Equation 3.6:

$\mathrm{P}_{\max }=\frac{\alpha^{2}}{\mathrm{R}_{\mathrm{stack}}} \cdot\left[\frac{\mathrm{NRT}}{{ }_{\mathrm{zF}}} \ln \left(\frac{\mathrm{a}_{\mathrm{c}}}{\mathrm{a}_{\mathrm{d}}}\right)\right]^{2}$

In this equation, gross power density is a function of the square of membrane permselectivity $\alpha^{2}$ and stack resistance $R_{\text {stack }}$. 
Consequently, the power density (power output per unit membrane area, $\mathrm{P}_{\text {gross }}$ ) can be calculated from $\mathrm{P}_{\max }$ :

$\mathrm{P}_{\text {gross }}=\frac{\mathrm{P}_{\max }}{2 \cdot \mathrm{A} \cdot \mathrm{N}}$

where $\mathrm{P}_{\text {gross }}$ is the maximum gross power density $\left(\mathrm{W} \mathrm{m}^{-2}\right), \mathrm{P}_{\max }$ is maximum power output $(\mathrm{W})$, A is effective area of single membrane $\left(\mathrm{m}^{2}\right)$ and $\mathrm{N}$ is number of membrane cells $(-)$.

\subsubsection{Multiple linear regression (MLR) modeling and analysis of variance (ANOVA)}

A statistical modeling technique was applied to find the correlation between membrane properties and RED performance in terms of power density. The best fit of the data was investigated to estimate the power density for specific membrane properties. A statistical sensitivity analysis (ANOVA) was carried out to assess the effects and the respective contributions of the parameters (membrane properties, e.g. area resistance and permselectivity) on the power density $\left(\mathrm{P}_{\text {gross }}\right)$ in a RED system. The data were processed with the aid of the Analysis ToolPak add-in of the Microsoft Excel spreadsheet.

\subsection{Results and discussion}

\subsubsection{Membrane characteristics}

\subsubsection{Characterization of IEMS}

A variety of commercially available membranes as well as tailor-made membranes (SPEEK and PECH) was characterized to gain insight in their electrochemical and physical properties (Table 3.1). Depending on membrane type, IEMs may have different film thicknesses i.e. they can be relatively thick such as Ralex membranes $(\sim 700 \mu \mathrm{m})$ or thin such as Fumatech FKS/FAS membranes $(\sim 30 \mu \mathrm{m})$. Fumatech FKS/FAS membranes tested in this work were specially made on demand and had a low thickness to obtain a high power density in RED. Thickness obviously has an important influence on electrochemical properties such as area resistance; the effect of membrane thickness on area resistance will be discussed in detail in the next section. 
In general, we observed lower area resistances for thinner membranes such as the tailor-made PECH and SPEEK membranes and commercial Fumatech FKS and FAS membranes. Permselectivity is another crucial membrane property; it largely depends on the membrane's fixed charge density (CD, ion exchange capacity per water content of the membrane). As expected, we found that the membranes with a higher or moderate IEC but relatively lower swelling degree had a high fixed charged density (>10 meq/gH $\mathrm{g}_{2} \mathrm{O}$ ), e.g. FKS/FAS membranes and CMV/AMV membranes. Swelling behavior obviously plays an important role and so does IEC, which depends on properties such as water content, swelling degree, and area resistance.

Table 3.1. Membrane characteristics.

\begin{tabular}{|c|c|c|c|c|c|c|c|}
\hline Membrane & Manufacturer & $\begin{array}{c}\delta \\
(\mu \mathrm{m})\end{array}$ & $\begin{array}{c}\mathrm{R} \\
\left(\Omega \cdot \mathrm{cm}^{2}\right)\end{array}$ & $\begin{array}{c}\alpha \\
(\%)\end{array}$ & $\begin{array}{l}\mathrm{SD} \\
(\%)\end{array}$ & $\begin{array}{c}\text { IEC } \\
(\mathrm{meq} / \mathrm{g})\end{array}$ & $\begin{array}{c}\mathrm{CD} \\
\left(\mathrm{meq} / \mathrm{gH}_{2} \mathrm{O}\right)\end{array}$ \\
\hline CMX & Tokuyama Co., Japan & 164 & 2.91 & 99.0 & 18.0 & 1.62 & 9.0 \\
\hline CMH-PES & MEGA a.s., Czech Republic & 700 & 11.33 & 94.7 & 31.0 & 2.34 & 7.6 \\
\hline FKS & FumaTech GmbH, Germany & 40 & 1.50 & 94.2 & 13.5 & 1.54 & 11.4 \\
\hline $\begin{array}{l}\text { Qianqiu } \\
(\mathrm{CEM})\end{array}$ & $\begin{array}{l}\text { Hangzhou Qianqiu Industry } \\
\text { Co., China }\end{array}$ & 205 & 1.97 & 82.0 & 33.0 & 1.21 & 3.7 \\
\hline CMV & Asahi Glass Co. Ltd., Japan & 101 & 2.29 & 98.8 & 20.0 & 2.01 & 10.1 \\
\hline FKD & FumaTech GmbH, Germany & 113 & 2.14 & 89.5 & 29.0 & 1.14 & 3.9 \\
\hline SPEEK 65 & Tailor-made & 72 & 1.22 & 89.1 & 35.6 & 1.76 & 4.9 \\
\hline SPEEK 40 & Tailor-made & 53 & 2.05 & 95.3 & 23.0 & 1.23 & 5.3 \\
\hline AMX & Tokuyama Co., Japan & 134 & 2.35 & 90.7 & 16.0 & 1.25 & 7.8 \\
\hline AMH-PES & MEGA a.s., Czech Republic & 714 & 7.66 & 89.3 & 56.0 & 1.97 & 3.5 \\
\hline FAD & FumaTech GmbH, Germany & 74 & 0.89 & 86.0 & 34.0 & 1.42 & 4.2 \\
\hline $\begin{array}{l}\text { Qianqiu } \\
(\mathrm{AEM})\end{array}$ & $\begin{array}{l}\text { Hangzhou Qianqiu Industry } \\
\text { Co., China }\end{array}$ & 294 & 2.85 & 86.3 & 35.0 & 1.33 & 3.8 \\
\hline AMV & Asahi Glass Co. Ltd., Japan & 124 & 3.15 & 87.3 & 17.0 & 1.78 & 10.5 \\
\hline FAS & FumaTech GmbH, Germany & 33 & 1.03 & 89.4 & 8.0 & 1.12 & 14.0 \\
\hline PECH A ${ }^{a}$ & Tailor-made & 77 & 2.05 & 90.3 & 32.2 & 1.31 & 4.1 \\
\hline $\mathrm{PECH} \mathrm{B}^{\mathrm{b}}$ & Tailor-made & 33 & 0.82 & 86.5 & 49.0 & 1.68 & 3.4 \\
\hline $\mathrm{PECH} \mathrm{B2}{ }^{\mathrm{b}}$ & Tailor-made & 77 & 0.94 & 87.2 & 49.0 & 1.68 & 3.4 \\
\hline PECH B3 $^{b}$ & Tailor-made & 130 & 1.32 & 87.0 & 49.1 & 1.68 & 3.4 \\
\hline PECH $\mathrm{C}^{\mathrm{c}}$ & Tailor-made & 77 & 1.14 & 79.2 & 53.5 & 1.88 & 3.5 \\
\hline
\end{tabular}

a: blend ratio 0.208 ; b: blend ratio 0.333 ; c: blend ratio 0.417 ; $\delta$ : wet thickness; R: area resistance; $\alpha$ : permselectivity; SD: swelling degree; IEC: ion exchange capacity; CD: charge density. 


\subsubsection{Effect of thickness on area resistance and permselectivity}

The thickness of an ion exchange membrane plays an important role, as it affects electrochemical properties such as area resistance and permselectivity. In previous work, we obtained low area resistances $\left(<1 \Omega \cdot \mathrm{cm}^{2}\right)$ for relatively thin anion exchange membranes based on PECH [32]. We observed a similar trend for our tailor-made cation exchange membranes (SPEEK) and some commercial membranes (Figure 3.2).

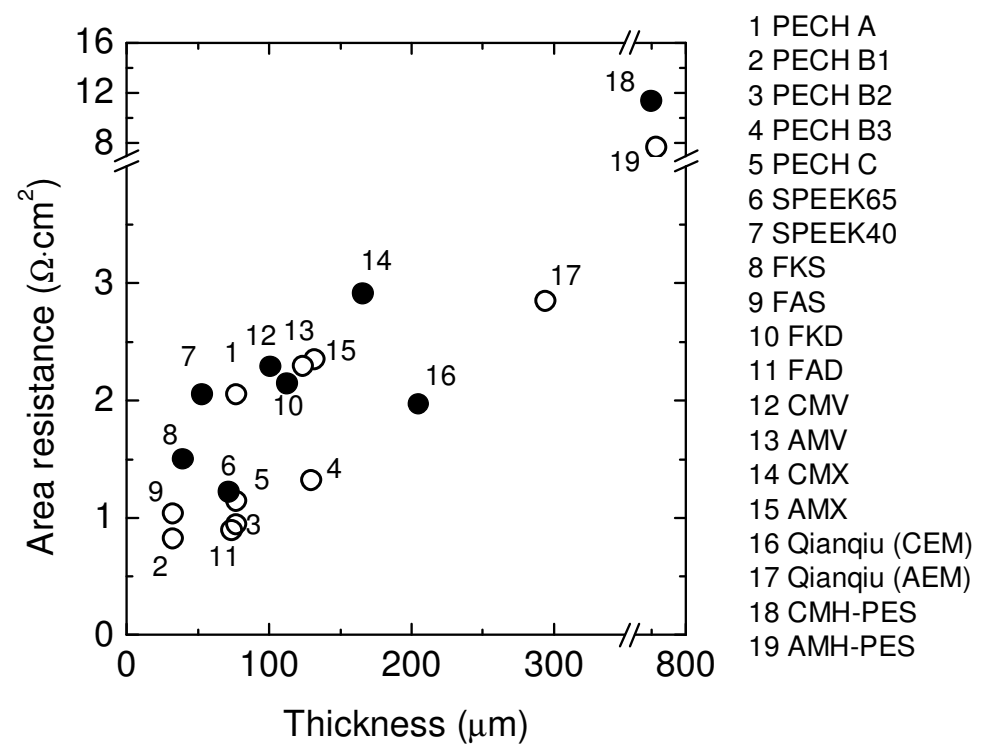

Figure 3.2. Effect of wet membrane thickness on area resistance.

Ion transfer through the membrane becomes faster with decreasing thickness of the conductive medium, i.e. the membrane. Therefore, the use of relatively thin membranes is expected to be advantageous in a RED system. The results show that the area resistance does not extrapolate to zero at zero membrane thickness, even not for tailor-made PECH membranes (Figure 3.2). We expect that this non-ideal behavior can be attributed to surface roughness of the membranes and boundary layer effects occurring in the cell. Due to surface roughness and non-perfect mixing, a boundary layer is introduced in the system. This boundary layer resistance thus contributes as an additional resistance, which is visible as a deviation of a line through the origin in Figure 3.2. However, as we assume this effect to be more or less equal for all membranes investigated, as they are all investigated under the same (mixing) conditions, we can still compare the individual membrane resistances.

IEMs can have similar permselectivities independently of membrane thickness. For instance, PECH B-type membranes (with the same blend ratio of 0.333 ) have different thicknesses but exhibited similar permselectivities of around 87\% (Table 3.1). 
Considering that permselectivity is dependent on IEC and SD, membranes having similar IEC and SD are expected to have similar permselectivities; this is usually the case for membranes with the same chemistry but with different thicknesses, such as the PECH B-type membranes but not by definition valid for membranes with different chemistries. Also Balster et al. found that SPEEK CEMs blended with polyethersulfone (PES) at various thicknesses have the same permselectivity. It was found that IEC and SD did not change significantly with membrane thickness, resulting in the same level of permselectivity [45]. Other previous work reported similar data that are also in good agreement $[32,46]$.

As mentioned earlier, the thickness of the membrane appears to have no effect on the swelling degree as the latter is defined as a relative value (Table 3.1). Membranes with a similar thickness can have a similar swelling degree (e.g. AMX versus AMV), but can also have a different swelling degree (e.g. AMX versus PECH B3). Therefore, only membranes with the same chemical composition can be compared fairly. For instance, the swelling degrees of the thin PECH B-1 membrane and the thick PECH B-3 membrane are similar, namely around 49\%. Izguierdo-Gil et al. studied Nafion membranes with different thicknesses, and observed an increase of IEC with increasing thickness, coinciding with an increasing swelling degree [46]. As we did not observe an increase of IEC with increasing thickness for our PECH membranes, the dependency of the swelling degree on IEC appeared to be more pronounced than the dependency on other membrane properties.

\subsubsection{Effect of IEC and SD on area resistance and permselectivity}

The ion exchange capacity of a membrane represents the quantity of counter ions that can be exchanged in the membrane. Table 3.1 shows that heterogeneous membranes (Ralex CMH-PES/AMH-PES) have a higher IEC than most of the homogenous membranes. They also have a relatively high swelling degree (up to 56\%). It is well known that swelling of an IEM results from the presence of ionic groups (fixed charges) [47-48]. Therefore, membranes with a high swelling degree are expected to have low area resistances. However, a high IEC does not always coincide with a low area resistance, as especially the charge density, more than the ion exchange capacity itself, plays an important role. Ralex membranes (CMH-PES and AMH-PES) have a high IEC but also a reasonable swelling degree resulting in the highest area resistances (7.66-11.33 $\left.\Omega \cdot \mathrm{cm}^{2}\right)$; this is due to the relatively low charge density of these membranes. Also for other commercial membranes, there is no pronounced direct relationship between IEC and resistance (Table 3.1). Therefore, other factors must be considered, 
such as the charge density, the density of the polymer network, the hydrophilic character of the matrix polymer (as swelling degree represent the water content of the membrane) and the morphology of the membrane itself [49].

As discussed in the previous section, permselectivity mainly depends on the fixed charge density, which is a function of both IEC and swelling degree. IEC is not the sole factor that determines permselectivity, as can also be seen in Table 3.1; membranes with a high IEC can have a low permselectivity due to their high degree of swelling (e.g. Ralex AMH-PES). But as long as the swelling of the membranes is controlled, further improvement of IEC might yield higher permselectivities.

\subsubsection{Effect of charge density on permselectivity and area resistance}

As already mentioned, the charge density represents the quantity of counter ions that can be exchanged per unit water content of the membrane and is an important electrochemical property. Basically, the higher the charge density is, the stronger the exclusion of co-ions [50-51]. Therefore, a decrease in co-ion leakage will promote the selective transport of counter ions with increasing charge density, resulting in high permselectivity. In previous work with tailor-made $\mathrm{PECH}$ membranes, we demonstrated that a high charge density generally improves permselectivity whereas we saw no clear impact on area resistance [32]. The apparent lack of correlation between area resistance and charge density in the case of the PECH membranes may be a consequence of having different membrane structures with different degrees of cross-linking [32, 50]. We found a similar behavior of these two properties for commercial ion exchange membranes (Figure 3.3). Nevertheless, the relation between charge density and permselectivity does not show a sharp straight-line correlation but scatters with a slight trend for higher permselectivity when charge density increases. 

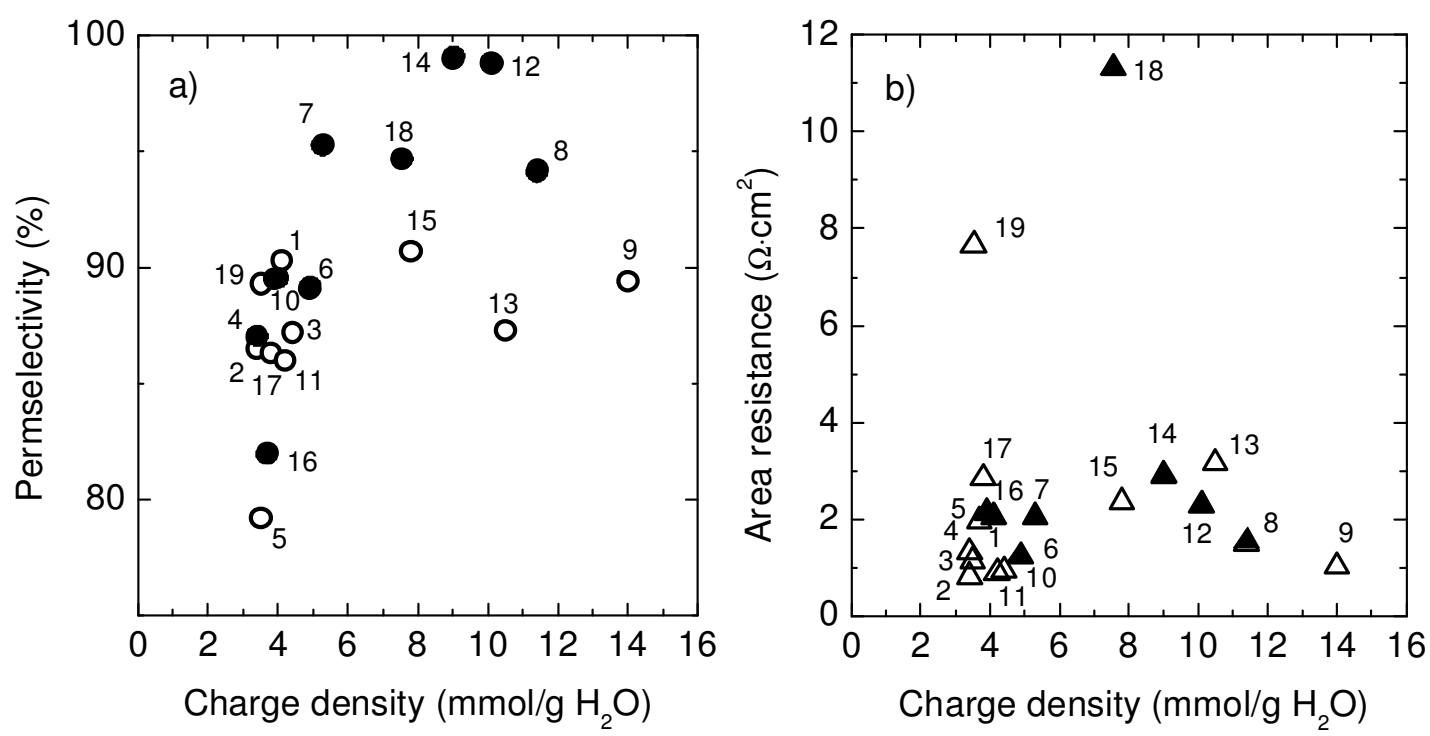

$1 \mathrm{PECH} A$

$2 \mathrm{PECH} B 1$

3 PECH B2

$4 \mathrm{PECH} B 3$

5 PECH C

6 SPEEK65

7 SPEEK40

8 FKS

9 FAS

10 FKD

11 FAD

12 CMV

13 AMV

$14 \mathrm{CMX}$

15 AMX

16 Qianqui (CEM)

17 Qianqui (AEM)

$18 \mathrm{CMH}-\mathrm{PES}$

19 AMH-PES

Figure 3.3. Effect of fixed charge density on membrane permselectivity (a) and resistance (b).

We expected that area resistance would show an increasing trend with increasing fixed charge density. However, we did not observe this in our experiments. Our tailor-made membranes and commercial membranes did not exhibit a straightforward relationship between charge density and area resistance neither (Figure 3.3). The random behavior of area resistance with charge density can be due to several effects. For instance, for some membranes, the repelling forces of fixed charges in the polymer matrix (inhomogeneous fixed charge distribution) may affect the transport of counter ions, which results in higher area resistances, or the degree of cross-linking and chemistry may differ. An increase in the amount of cross-linking reagent in the membranes can lead to high permselectivity (high transport number of counter ions) but high electrical resistance as well $[43,52]$. Other possible reasons for this independent behavior of membrane resistance can be the type of membrane reinforcement 'porosity', membrane roughness or membrane hydrophilicity (depending on membrane surface properties). The investigation of these effects was outside the scope of this work.

Another parameter that could be related to the charge density of the membrane is the area resistance per unit thickness of the membrane $(\Omega \cdot \mathrm{m})$, the so-called specific resistance. Although this property is an intrinsic property, when calculating this using the experimental data of this study, also this value did not show a direct correlation with the membrane fixed charge density due to the possible effects as described above.

For the investigated membranes, the charge densities generally were lower for membranes with a high swelling degree (Table 3.1). For instance, some of our tailormade membranes containing a high amount of active polymer (blend ratio of 0.417 ) 
have significantly higher swelling degrees, such as PECH C, which have an SD of $53.5 \%$. That results in a charge density of $3.5 \mathrm{meq} / \mathrm{g} \mathrm{H}_{2} \mathrm{O}$ only although this membrane has a relatively high IEC, namely $1.88 \mathrm{meq} / \mathrm{g}$. On the other hand, membranes can have relatively low swelling degrees with relatively high IECs. For example, Selemion AMV/CMV and Fumatech FKS/FAS membranes have very low swelling degrees, resulting in high fixed charge densities. Heterogeneous membranes may have a better IEC, but some of them may have high swelling degrees as well. An example is the Ralex AMH-PES membrane, which has ion exchange particles in the binding polymer matrix allowing it to have more ion exchanging fixed charges resulting in a high IEC. The Ralex CMH-PES membrane (the cation exchange type Ralex membrane) has relatively high charge density due to its high IEC combined with low swelling degree.

\subsubsection{RED performance}

\subsubsection{Power density in relation to membrane permselectivity and area resistance}

Permselectivity and area resistance of an IEM are definitely performance-determining factors in RED; they are strongly dependent on the membrane's physicochemical properties such as IEC and swelling degree. Długołęcki et al. also concluded that resistance and permselectivity do play an important role in reverse electrodialysis, but only when thin spacers $(<600 \mu \mathrm{m})$ are used. When thick spacers are used, there are minor differences in power densities for different membrane pairs and the resistance of feed water compartments start to play a larger role in RED than membrane properties [30]. In our work, all tests were performed with a stack with thin spacers (200 $\mu \mathrm{m})$ so that membrane resistance and permselectivity were the key factors that determine RED performance.

Figure 3.4 presents the effect of average permselectivities (a) and total area resistance (b) of the membrane couples on the gross power density obtained in our RED system. 

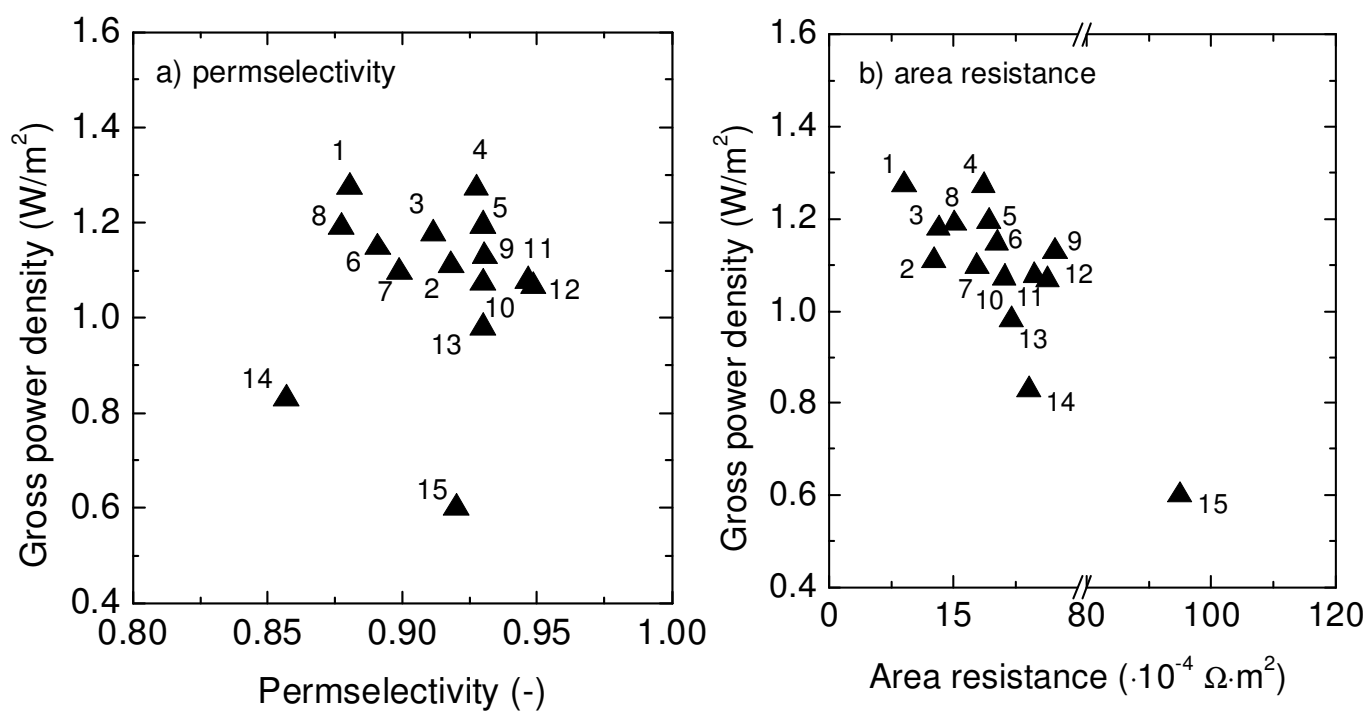

1 SPEEK65/PECH B2 $2 \mathrm{FKS} / \mathrm{FAS}$ 3 SPEEK 40/PECH B2 4 CMX/PECH B1 5 CMX/PECH B2 $6 \mathrm{CMX/PECH} \mathrm{C}$ 7 SPEEK 65/AMX $8 \mathrm{FKD} / \mathrm{FAD}$ $9 \mathrm{CMV} / \mathrm{AMV}$ $10 \mathrm{CMX/PECH} \mathrm{B3}$ $11 \mathrm{CMX/PECH} \mathrm{A}$ 12 CMX/AMX 13 SPEEK 40/AMX 14 Qianqui (CEM/AEM) $15 \mathrm{CMH}$-PES/AMH-PES

Figure 3.4. Effect of average permselectivity (a) and total area resistance (b) of all the membranes (5 AEMs and 5 CEMs) investigated on gross power density in RED.

According to the theoretical equations (Equation 3.9 and 3.10), the permselectivity has a strong impact to the theoretical power density in RED such that the theoretical power density is equal to the square of permselectivity $\left(\mathrm{P}_{\text {gross }} \sim \alpha^{2}\right)$. The same accounts for the area resistance, which determines the power output in an inverse way $\left(\mathrm{P}_{\text {gross }} \sim 1 / \mathrm{R}\right)$. Although permselectivity and resistance of the membrane definitely determine the power output obtainable in RED, the data above do not show these straightforward relationships unambiguously. Despite that, as we will show later, both permselectivity and area resistance are the key parameters that determine the power output, albeit not precisely in the way as predicted by Equation 3.10. Even PECH membranes, which consist of the same polymeric material did not show a direct relationship with gross power density, when coupled with CMX membranes as cation exchange membrane. It is obvious that PECH membranes (PECH B1, B2 and B3) having very similar permselectivity values nevertheless yield different values of power density (Figure 3.4). On the other hand, membrane couples having good permselectivities (around $90 \%$ and more) can have relatively low power densities. For instance, Ralex CMH-PES/AMH-PES membranes have high permselectivity, but also have high area resistances, which is undesirable and results in low power densities (Figure 3.4).

Figure $3.4 \mathrm{~b}$ also shows the effects of area resistance on power density. As expected, there is a trend of decreasing gross power density with increasing membrane resistance. The highest power density is obtained for the membrane couple with the lowest 
average area resistances (SPEEK65/PECH B2), whereas Qianqui and Ralex membranes with very high area resistances performed the worst.

Charge density is a parameter that is closely linked with the permselectivity of the membranes (Figure 3.3). Since permselectivity did not show a straightforward relationship with gross power density (Figure 3.4), and it is strongly dependent on charge density, charge density is expected to show a similar behavior. In addition, charge density is not included in the theoretical power output equation based on the Nernst equation (Equation 3.9). Consequently, membranes with relatively high charge densities do not by definition perform well in RED.

\subsubsection{Experimental power density in RED}

To the best of our knowledge, we managed to build the first complete RED stack using only tailor-made membranes which provides the highest power density. We evaluated our membranes in terms of experimental power output obtainable in RED and compared them with commercially available ones. Although the experimental data showed that the theoretical dependency of the power output on membrane resistance and permselectivity is not as straigthfoward as predicted by the theoretical equation (Equation 3.10), we do calculate these theoretical values based on measured resistances and permselectivities, as comparison of the experimental data with these 'theoretical' ones shows the deviation of ideality of the experimental results. We also evaluated the performance of membrane couples consisting of tailor made and commercially available membranes, i.e. PECH membranes with CMX and SPEEK membranes with AMX. Figure 3.5 shows the performance of some of the membrane couples for different feed flow rates. Table 3.2 shows the RED performance of all membrane pairs evaluated. 


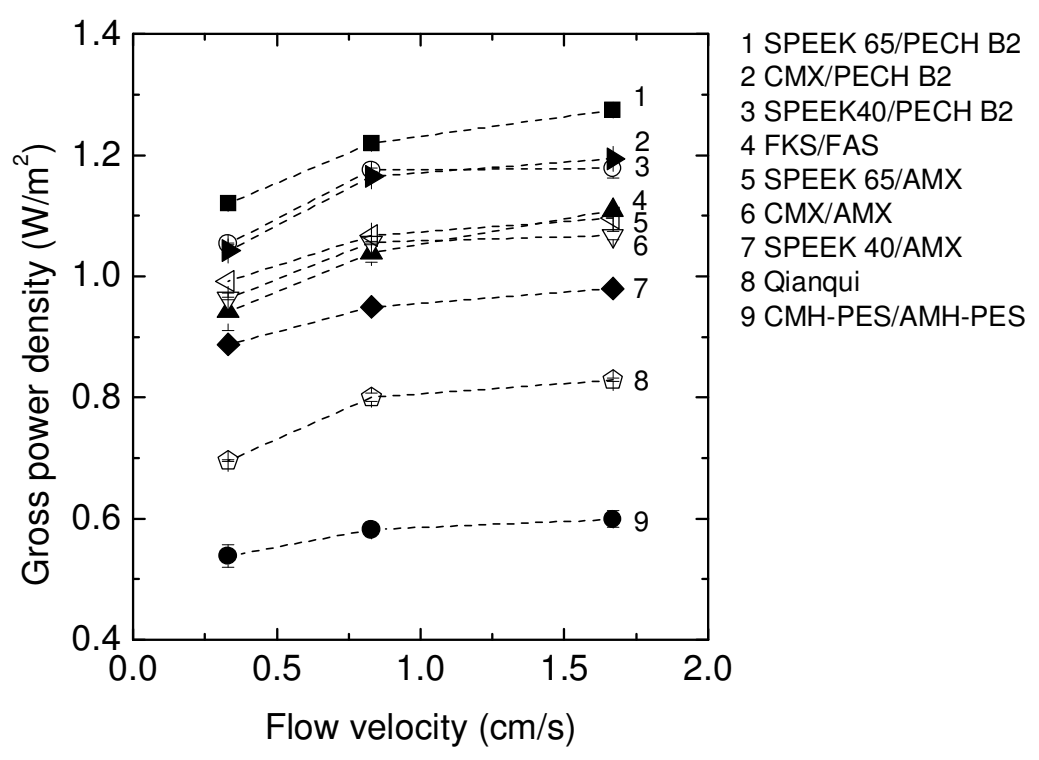

Figure 3.5. Experimental power density obtainable in RED for the different membrane couples investigated as a function of the flow rate (Number of cells: 5; Spacer thickness: $200 \mu \mathrm{m}$ ).

Since all the other membranes were produced to be used in electrodialysis applications, the membrane properties were not optimized specifically for RED. Our tailor-made membranes on the other hand, have excellent electrochemical properties compared with those of other membranes (Table 3.1), resulting in the highest experimental power output. Especially for our PECH membranes, we achieved remarkably low area resistances; this basically counteracts the negative effect of the less advantageous, lower permselectivity for the tailor-made cation exchange membrane SPEEK. The highest gross power density achieved was almost $1.3 \mathrm{~W} / \mathrm{m}^{2}$ with our homogeneous tailor-made membrane pair (SPEEK65 as cation exchange membrane and PECH B2 as anion exchange membrane).

Other homogeneous membranes (without any internal reinforcement) that we used were Fumatech FKS/FAS membranes. They are very thin $(30-40 \mu \mathrm{m})$, but are not easy to handle and it is difficult to build a stack without leakage. They therefore yielded a relatively lower power density $\left(1.02 \mathrm{~W} / \mathrm{m}^{2}\right)$ although the theoretical value was calculated as the highest $\left(2.24 \mathrm{~W} / \mathrm{m}^{2}\right)$ as these membranes have excellent electrochemical properties with low area resistance and high permselectivity (Table 3.1). The other membranes showed relatively small differences between experimental power densities and theoretical values (Table 3.2). 
Table 3.2. Experimental power density $\left(\mathrm{P}_{\text {exp. }}\right)$ and theoretical power density $\left(\mathrm{P}_{\text {theo }}\right)$ as calculated using Equation 3.10 for different membrane couples.

\begin{tabular}{lccc}
\hline Membrane couple & $\begin{array}{c}\mathrm{P}_{\text {exp. }} \\
\left(\mathrm{W} / \mathrm{m}^{2}\right)\end{array}$ & $\begin{array}{c}\mathrm{P}_{\text {calculated }} \\
\left(\mathrm{W} / \mathrm{m}^{2}\right)\end{array}$ & $\begin{array}{c}\text { Ratio } \\
\left(\mathrm{P}_{\text {exp. }} / \mathrm{P}_{\text {theo }}\right)\end{array}$ \\
\hline FKS/ FAS & 1.11 & 2.24 & 0.50 \\
SPEEK40/ PECH B2 & 1.18 & 2.17 & 0.54 \\
SPEEK65/ PECH B2 & 1.28 & 2.31 & 0.55 \\
CMX/PECH B3 & 1.07 & 1.96 & 0.55 \\
SPEEK40/ AMX & 0.98 & 1.79 & 0.55 \\
CMX/ PECH B2 & 1.18 & 2.00 & 0.59 \\
Qianqiu CEM/AEM & 0.83 & 1.39 & 0.59 \\
SPEEK65/ AMX & 1.10 & 1.85 & 0.59 \\
CMX/PECH B1 & 1.27 & 2.08 & 0.61 \\
CMX/PECH A & 1.08 & 1.77 & 0.61 \\
CMX/PECH C & 1.15 & 1.84 & 0.63 \\
CMX/AMX & 1.07 & 1.69 & 0.63 \\
FKD/FAD & 1.19 & 1.90 & 0.63 \\
CMV/AMV & 1.13 & 1.59 & 0.71 \\
Ralex CMH/AMH & 0.60 & 0.64 & 0.93 \\
\hline
\end{tabular}

The membrane pair which performed closest to the theoretical value (Equation 3.10) was found to be the Ralex membrane pair, which had a $\mathrm{P}_{\text {exp. }}$ to $\mathrm{P}_{\text {theo. }}$ ratio of 0.93 . These membranes are the ones with the highest area resistance (Table 3.1). Therefore, it appears that the theoretical power density may be a good approximation for membrane pairs with relatively high area resistances. The reason for this is that any non-ideal effects in the stack (boundary layer effects, concentration changes in the bulk solution, leakage of water compartments, membrane poisoning by electrolyte solutions etc.) do not dominate membrane performance in this case (high area resistance). By contrast, the performance of other relatively good membranes can in some individual cases slightly be hampered by such effects, which is reflected as non ideal behavior and a deviation from the theoretically predicted power outputs. Despite that, as we will show later, both permselectivity and area resistance are the key parameters that determine the power output, albeit not precisely in the way as predicted by Equation 3.10 .

The ratio of $\mathrm{P}_{\text {exp. }}$ to $\mathrm{P}_{\text {theo. }}$ can also be correlated to the apparent shadow effect of the spacers used in the stack. The non-conductive spacers block some parts of the 
membrane area and reduce the power density. Therefore, in practical applications the required membrane area is always larger than the calculated cell pair area. Hence, a shadow factor $\beta$ can be defined as the ratio of calculated membrane area to the one required in practice [53-54]. This relation can be directly attributed to the ratio of $\mathrm{P}_{\exp }$. to $\mathrm{P}_{\text {theo. }}$. Post et al. reported a shadow factor of 0.6 for the stack with $200 \mu \mathrm{m}$ spacers and a value of 0.47 for $500 \mu \mathrm{m}$ spacers built with Neosepta CMS/ACS membranes [53]. These reported values correlate very well to our data in Table 3.2.

\subsubsection{Multiple linear regression (MLR) and ANOVA analysis}

In order to quantify the relationship between membrane bulk properties and the experimental power output obtainable in RED, we performed a multiple linear regression analysis (MLR). To identify the dominant and independent parameters determining the power output, we performed multiple regression analyses to investigate the relative contribution of all membrane properties investigated in this work, on the power output. We concluded that the area resistance and permselectivity are independent variables and the dominant factors regarding the power output. Factors like ion exchange capacity, swelling degree, and membrane thickness are indirectly included, as these do have an effect on resistance and permselectivity (making them dependent variables). Consequently, in the remainder of the work we will focus on these two parameters and their effect on the power output.

The general purpose of multiple regression modeling is to quantify the relationship between several independent variables and a dependent variable. A set of coefficients defines the linear combination of independent variables (e.g. membrane properties) that best describes the dependent output (e.g. power density). The power density for a set of membrane couples (CEM and AEM) would then be calculated as a combination of each membrane property (area resistance, permselectivity) given by the respective coefficients. A multilinear model can be represented as:

$\mathrm{y}=\beta_{0}+\beta_{1} \mathrm{x}_{1}+\beta_{2} \mathrm{x}_{2}+\ldots+\beta_{\mathrm{k}} \mathrm{x}_{\mathrm{k}}+\varepsilon$

where $\mathrm{k}$ is the number of independent variables, $\beta_{1}, . ., \beta_{\mathrm{k}}$ are the regression coefficients of the independent variables $\left(\mathrm{x}_{1}, \mathrm{x}_{2}, . ., \mathrm{x}_{\mathrm{k}}\right), \varepsilon$ is the residue and $\mathrm{y}$ is the dependent variable. Regression coefficients represent the independent contributions of each variable.

However, some of the input variables do not necessarily have to be included in the model. The criterion for including or excluding these variables in the model is the F- 
test, which is a method of analyzing of variance (ANOVA) to investigate whether a variable has a significant influence. The $\mathrm{F}$ value, which is the ratio of the withinsample mean square and the between-sample mean square, is compared with the critical $\mathrm{F}$ value $\left(\mathrm{F}_{\text {crit }}\right)$ for the appropriate numbers of freedom and a confidence interval of $95 \% . \mathrm{F}_{\text {crit }}$ is the highest value of $\mathrm{F}$ that can be obtained without rejecting the null hypothesis. The null hypothesis (no influence) is rejected if $\mathrm{F}>\mathrm{F}_{\text {crit }}$ which means that linear regression is valid and at least one independent variable is linearly related to the dependent variable, y. F is calculated in the following way: First the sum of squares due to error $\left(\mathrm{SS}_{\text {error }}\right)$ is calculated using the following formula:

$\mathrm{SS}_{\text {error }}=\mathrm{SS}_{\mathrm{T}}-\mathrm{SS}_{\text {mean }}-\mathrm{SS}_{\text {factors }}$

where $\mathrm{SS}_{\mathrm{T}}$ is the total number of the squares, $\mathrm{SS}_{\text {mean }}$ is the overall mean squared multiplied by the total number of analysis, and $\mathrm{SS}_{\text {factors }}$ is the sum of squares of all the independent variables. Then the number of degrees of freedom for the error ( $\left.\mathrm{DOF}_{\text {error }}\right)$ is calculated:

$\mathrm{DOF}_{\text {error }}=\mathrm{DOF}_{\mathrm{T}^{-1}}-\sum \mathrm{DOF}_{\text {factors }}$

where $\mathrm{DOF}_{\mathrm{T}}$ is the number of degrees of freedom for the total number of analysis, $\mathrm{DOF}_{\text {factors }}$ is the number of degrees of freedom for each factor. When the sum of the squares due to error and the corresponding degrees of freedom have been calculated, the error variance (i.e. mean square for error, $\mathrm{VAR}_{\text {error }}$ ) and variance ratio (i.e. F) can be calculated as follows:

$\mathrm{VAR}_{\text {error }}=\frac{\mathrm{SS}_{\text {error }}}{\mathrm{DOF}_{\text {error }}}$

and

$\mathrm{F}=\frac{\left(\mathrm{MEAN}_{\text {factor }}\right)^{2}}{\mathrm{VAR}_{\text {error }}}$

where $\mathrm{MEAN}_{\text {factor }}$ is a mean value of the objective function for a given factor. The $\mathrm{F}$ ratio quantifies the influence of each factor (variable) in the model. In general, a value of $\mathrm{F}$ above 4 indicates that the effect of the factor (variable) is significant.

The p-value representing the probability of error also provides evidence such that the null hypothesis is rejected if the p-value is lower than the significance level, 0.05 (for a 
95\% confidence level). This value can be calculated depending on the number of factors and analysis for a system. More information on this method and the details of these calculations can be found elsewhere [55-56]. The results of the regression analysis are summarized in Table 3.3.

Table 3.3. Membrane properties as variables, experimental and theoretical power density and residual values predicted by the MLR method.

\begin{tabular}{clccccc}
\hline No & \multicolumn{1}{c}{ Membranes } & $\begin{array}{c}\mathrm{R} \\
\left(\cdot 10^{-4} \Omega \cdot \mathrm{m}^{2}\right)\end{array}$ & $\begin{array}{c}\alpha \\
(-)\end{array}$ & $\begin{array}{c}\mathrm{P}_{\text {exp. }} \\
\left(\mathrm{W} / \mathrm{m}^{2}\right)\end{array}$ & $\begin{array}{c}\mathrm{P}_{\text {pred. }} \\
\left(\mathrm{W} / \mathrm{m}^{2}\right)\end{array}$ & $\begin{array}{c}\text { Residual } \\
\left(\mathrm{W} / \mathrm{m}^{2}\right)\end{array}$ \\
\hline 1 & SPEEK65/PECH B2 & 9.05 & 0.88 & 1.28 & 1.15 & 0.12 \\
2 & FKS/FAS & 12.65 & 0.92 & 1.11 & 1.18 & -0.07 \\
3 & SPEEK40/PECH B2 & 13.20 & 0.91 & 1.18 & 1.16 & 0.01 \\
4 & CMX/PECH B1 & 18.65 & 0.93 & 1.27 & 1.15 & 0.13 \\
5 & CMX/PECH B2 & 19.25 & 0.93 & 1.19 & 1.14 & 0.05 \\
6 & CMX/PECH C & 20.25 & 0.89 & 1.15 & 1.08 & 0.06 \\
7 & SPEEK65/AMX & 17.85 & 0.90 & 1.10 & 1.11 & -0.02 \\
8 & CMX/PECH B3 & 21.15 & 0.93 & 1.07 & 1.13 & -0.06 \\
9 & CMX/PECH A & 24.80 & 0.95 & 1.08 & 1.12 & -0.05 \\
10 & CMX/AMX & 26.30 & 0.95 & 1.07 & 1.12 & -0.05 \\
11 & SPEEK40/AMX & 22.00 & 0.93 & 0.98 & 1.12 & -0.14 \\
12 & Qianqui CEM/AEM & 24.11 & 0.84 & 0.83 & 0.99 & -0.16 \\
13 & Ralex CMH/AMH & 94.95 & 0.92 & 0.60 & 0.56 & 0.04 \\
14 & FKD/FAD & 15.15 & 0.88 & 1.19 & 1.10 & 0.09 \\
15 & CMV/AMV & 27.20 & 0.93 & 1.13 & 1.09 & 0.04 \\
\hline Total & & & & & 0.09 \\
\hline
\end{tabular}

$\mathrm{R}$ : total membrane resistance in the 5-cell RED stack; $\alpha$ : average permselectivity; $\mathrm{P}_{\text {exp. }}$ : experimental power density; $\mathrm{P}_{\text {pred. }}$ : predicted power density as calculated by the MLR method; Residual $=\mathrm{P}_{\text {exp. }}-\mathrm{P}_{\text {pred. }}$.

A single MLR model was developed using Microsoft Excel software. The selected variables were total area resistance $(R)$ of all the membranes in a stack and the average permselectivity $(\alpha)$ of the two membranes (CEM and AEM) for the fifteen different membrane couples (Table 3.3). We assumed them to be independent membrane properties. SD and IEC generally affect charge density, hence permselectivity, and in addition also membrane thickness has a direct impact on area resistance. The model resulting from the regression analysis describes the gross power density for this set of data as follows:

$\mathrm{P}_{\text {gross }}=0.048-74.855 \cdot \mathrm{R}+1.333 \cdot \alpha$ 
Positive values of the regression coefficients indicate that the factor contributes positively to the value of $\mathrm{P}_{\text {gross }}$, whereas negative values indicate an inverse relationship with $\mathrm{P}_{\text {gross. }}$ As expected, area resistance $(\mathrm{R})$ has a negative effect whereas permselectivity has a positive influence on $\mathrm{P}_{\text {gross }}$. Figure 3.6 displays the plot of this predicted power density $\mathrm{P}_{\text {pred. }}$ versus the experimental power density $\mathrm{P}_{\text {exp. as }}$ determined using the MLR method; Table 3.3 contains the specific data including the residuals values $\left(\mathrm{P}_{\text {exp. }}-\mathrm{P}_{\text {pred. }}\right)$.

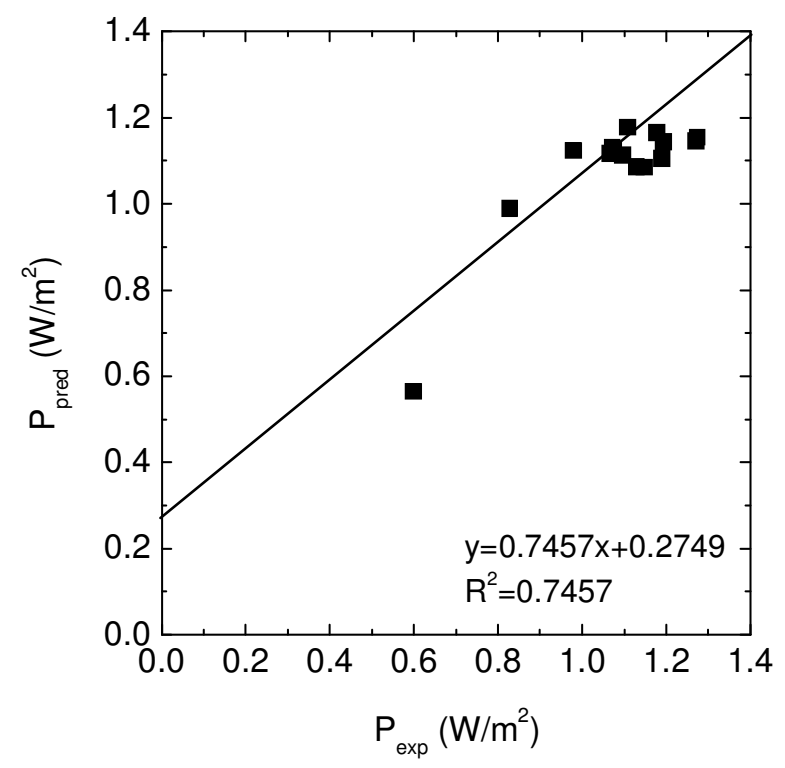

Figure 3.6. Predicted power density $\left(\mathrm{P}_{\text {pred. }}\right.$ ) as estimated from the MLR model vs. the experimentally determined power density $\left(\mathrm{P}_{\text {exp. }}\right)$.

The coefficient of regression $\left(\mathrm{R}^{2}\right)$ has a value of 0.7457 (Figure 3.6), which is relatively low, but reasonable. In addition, the adjusted $\mathrm{R}$ squared value, which corrects for the degrees of freedom and is a representation of the goodness of fit, is also in that range (Table 3.4). In other words, the MLR model using the membrane resistance and permselectivity as variables, allows the prediction of the experimental values of the gross power density obtainable in RED to a reasonable extent. ANOVA was used to determine the factors that influence the power density in RED. Tables 3.4 and 3.5 contain the statistical characteristics of the model and significance of input variables, respectively. 
Table 3.4. ANOVA (analysis of variance) and statistical features of the model.

\begin{tabular}{lccccc}
\hline \multicolumn{1}{c}{ Source } & SS & DOF & VAR & F-ratio & p-value \\
\hline Model & 0.3142 & 2 & 0.1571 & 17.60 & 0.0003 \\
Residual & 0.1072 & 12 & 0.0089 & & \\
\hline
\end{tabular}

$\mathrm{R}$-squared $=0.7457, \mathrm{R}$-squared (adjusted for degrees of freedom) $=0.7033$, standard error $=0.0945, \mathrm{SS}$ : Sum of squares, DOF: degrees of freedom, VAR: Mean square (variance).

The residuals are around zero, which indicates that the distribution does not vary greatly around the fitted line and the sum of squares for error $\left(\mathrm{SS}_{\text {error }}\right)$ is as low as 0.1072. From Table 3.4, it can be concluded that the model is useful and provides a good fit since the p-value (0.0003) is smaller than 0.05 (significance level for $95 \%$ confidence) and the F-ratio (17.60) is greater than 4 (as $\mathrm{F}_{\text {crit }}$ calculated for two membrane parameters - i.e. $\mathrm{R}$ and $\alpha$ - and fifteen membrane couples). In other words, the null hypothesis is rejected and at least one parameter is expected to be significantly related to the power density.

Table 3.5. Model parameters resulting from MLR method.

\begin{tabular}{cccccc}
\hline Parameter & $\begin{array}{c}\text { Estimated } \\
\text { coefficient }\end{array}$ & Standard error & p-value & Lower 95\% & Upper 95\% \\
\hline Intercept & 0.048 & 0.7955 & 0.9529 & -1.685 & 1.781 \\
$\mathrm{R}$ & -74.855 & 12.6760 & 0.0001 & -102.473 & -47.236 \\
$\alpha$ & 1.333 & 0.8766 & 0.1542 & -0.577 & 3.243 \\
\hline
\end{tabular}

R: total area resistance; $\alpha$ : average permselectivity.

As can be seen in Table 3.5, the estimated coefficients and standard errors are given for the corresponding variables. Standard errors (i.e. standard deviations) show how much each variable deviates from its mean value. As expected it shows that the experimental data points for $\mathrm{R}$ change over a wider range, whereas $\alpha$ values are all in the same range as the absolute values. In addition, sensitivity parameters for the intercept are shown, which basically depend on the main variables of interest $(\mathrm{R}$ and $\alpha)$ in the model.

The probability term, the p-value, can also be calculated individually for the main variables $(\mathrm{R}$ and $\alpha$ ) (Table 3.5). That value allows to observe the relative contribution of each parameter in the model. For instance, the p-value for $\mathrm{R}$ is rather small as 0.0001 (i.e. almost zero), indicating that the null hypothesis is rejected. In other words, the effect of this parameter is significant and the correlation of the power density with this parameter is strong. However, the p-value for permselectivity is relatively high 
and even higher than the significance level, 0.05. Hence, permselectivity matters within the model, but the correlation with the power density is weak. This argument can also be concluded from the lower and upper limits of the parameter coefficients, which are the so-called lower 95\% and upper 95\% values, respectively. These are the end points of the confidence intervals for $\mathrm{R}$ and $\alpha$. For permselectivity, these two limits represent both a negative value $(-0.577)$ and a positive value $(+3.243)$ representing that there is neither a significant positive nor a negative effect on $\mathrm{P}_{\text {gross }}$. That also means that permselectivity can vary over a wide range within the confidence interval of $95 \%$ without deteriorating the model equation. Therefore, on the basis of this set of data, it appears that improving the permselectivity of ion exchange membranes for RED would not be that beneficial. On the other hand, the value of these limits (lower 95\% and upper $95 \%$ ) is always negative for the total area resistance $(\mathrm{R})$, for the confidence interval of $95 \%$. Although it seems that the range of these coefficient limits seems to be wider for $\mathrm{R}$ than for $\alpha$, the values should not be considered as absolute values and the quantitative values of area resistance (in $\Omega \cdot \mathrm{m}^{2}$ scale) are relatively lower than the ones for permselectivity, resulting in higher coefficient for R. Consequently, improving ion exchange membranes in terms of area resistance, i.e. producing low-resistance membranes, is a "must-follow" strategy to increase the power density in RED. These interpretations also match our graphical representations of resistance and permselectivity versus power density in Figure 3.4 very well, where area resistance shows a clear inverse correlation with power density, while permselectivity has a less well defined effect.

To quantify the relationship between membrane bulk properties like permselectivity and area resistance and the experimental power output obtainable in RED, we performed this multiple linear regression analysis (MLR). Although the main conclusions are general in nature and applicable to any RED system, the absolute numbers may vary from stack to stack design, as specific stack effects are included in the data. Nevertheless, we think this is a valuable contribution, as this analysis clearly sets the directions for further membrane development to improve the power output obtainable in RED.

\subsection{Conclusions}

This research shows the importance of membrane bulk properties and how these affect RED performance in practice. In addition, we formulated the correlation between these membrane properties and gross power density obtainable in RED based on 
experimental results. We constructed a RED stack built with only tailor-made membranes of which we can tune the properties easily. The performance of such a RED stack exhibited the highest gross power density $\left(1.3 \mathrm{~W} / \mathrm{m}^{2}\right)$ relative to stacks built with commercially available membranes at predefined experimental conditions. Area resistance was found to be correlated to RED power density, whereas permselectivity did not show a straightforward relationship. Statistical analyses (a linear model and a sensitivity study) confirmed this correlation. Consequently, this research shows the directions towards tailoring ion exchange membranes for RED applications.

\subsection{Acknowledgements}

This work was performed in the TTIW cooperation framework of Wetsus, centre of excellence for sustainable water technology (www.wetsus.nl). Wetsus is funded by the Dutch Ministry of Economic Affairs (IOP-TTI), the European Community (European Fund for Regional Development and Seventh Framework Programme), Northern Netherlands Provinces (Peaks in the Delta), the city of Leeuwarden and the Province of Fryslân. The authors would like to thank Alliander, Eneco Energy, Frisia Zout, Fuji Film, Landustrie, Magneto Special Anodes, A. Hak and MAST Carbon of the research theme "Blue Energy" for the productive conversations and the financial support. In addition, the authors thank Joost Veerman for the fruitful discussions.

\subsection{Nomenclature}

$\begin{array}{ll}\text { A } & \text { effective membrane area }\left[\mathrm{m}^{2}\right] \\ \mathrm{a}_{\mathrm{c}} & \text { activity of salt solution }[\mathrm{mol} / \mathrm{l}] \\ \mathrm{a}_{\mathrm{d}} & \text { activity of diluted salt solution }[\mathrm{mol} / \mathrm{l}] \\ \mathrm{C}_{\mathrm{AgNO3}} & \text { concentration of } \mathrm{AgNO}_{3} \text { for titration }[\mathrm{mmol} / \mathrm{ml}] \\ \mathrm{C}_{\mathrm{NaOH}} & \text { concentration of } \mathrm{NaOH} \text { for titration }[\mathrm{mmol} / \mathrm{ml}] \\ \mathrm{CD} & \text { fixed charge density }\left[\mathrm{mmol} / \mathrm{g} \mathrm{H}_{2} \mathrm{O}\right] \\ \mathrm{d}_{\mathrm{c}} & \text { thickness of dilute compartment }[\mathrm{m}] \\ \mathrm{d}_{\mathrm{d}} & \text { thickness of concentrate compartment }[\mathrm{m}] \\ \text { DOF } & \text { degrees of freedom }[-] \\ \mathrm{E}_{\mathrm{OCV}} & \text { open circuit voltage }[\mathrm{V}] \\ \mathrm{F} & \text { F ratio in multiple regression model }[-] \\ \mathrm{F} & \text { Faraday constant }[96485 \mathrm{C} / \text { mol }] \\ \mathrm{F}_{\text {crit }} & \text { critical F ratio in multiple regression model }[-] \\ \text { IEC } & \text { ion exchange capacity }[\text { mmol/g dry membrane }]\end{array}$




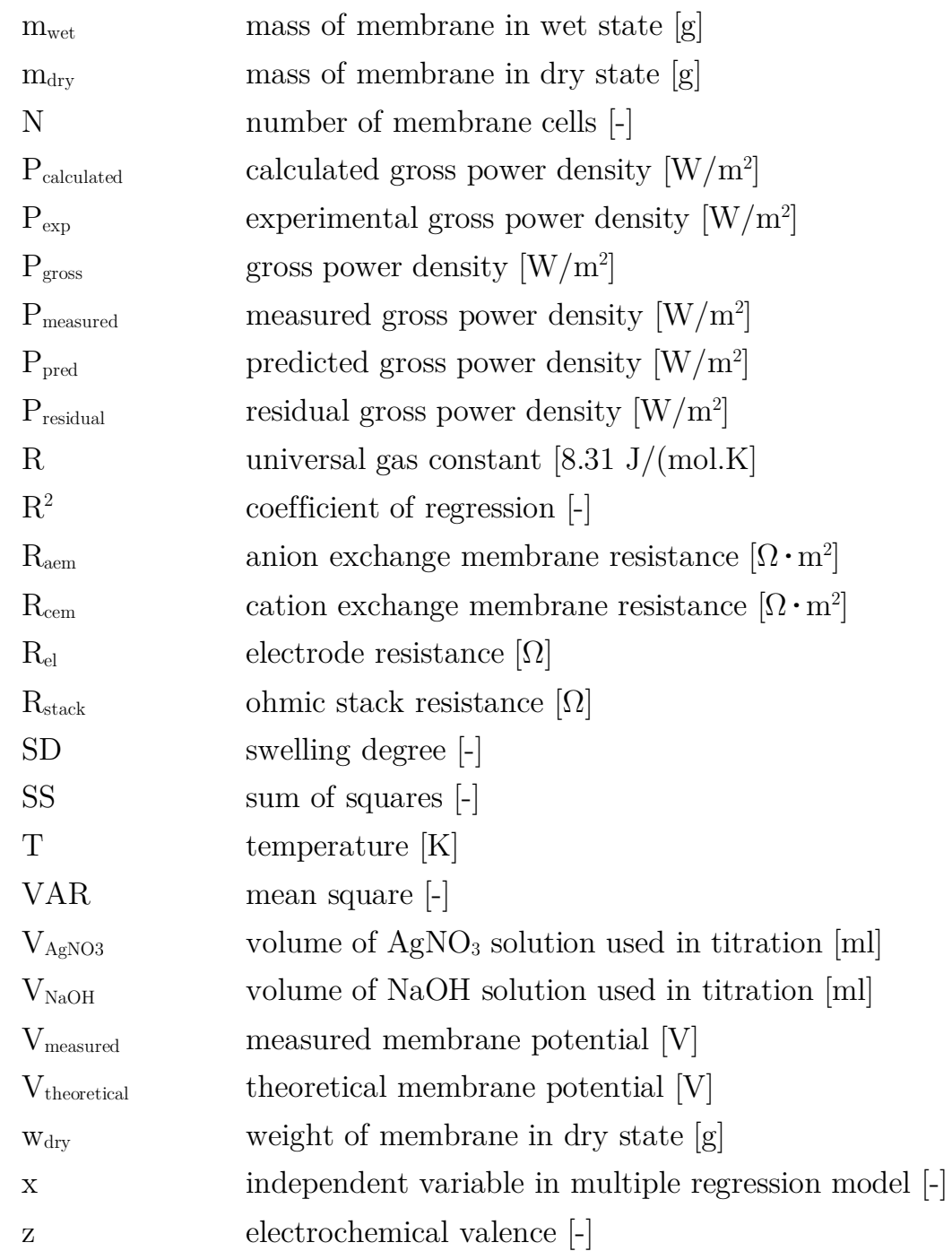

Greek symbols

$\begin{array}{ll}\alpha & \text { membrane permselectivity }[-] \\ \beta & \text { regression coefficient in multiple regression model }[-] \\ \mathrm{K}_{\mathrm{d}} & \text { conductivity of dilute compartment }[\mathrm{S} / \mathrm{m}] \\ \mathrm{K}_{\mathrm{c}} & \text { conductivity of concentrate compartment }[\mathrm{S} / \mathrm{m}] \\ \varepsilon & \text { residue in multiple regression model }[-]\end{array}$




\subsection{References}

[1] T. Xu, Ion exchange membranes: State of their development and perspective, Journal of Membrane Science, 263 (2005) 1-29.

[2] F. Xu, C. Innocent, G. Pourcelly, Electrodialysis with ion exchange membranes in organic media, Separation and Purification Technology, 43 (2005) 17-24.

[3] H. Strathmann, J.J. Krol, H.J. Rapp, G. Eigenberger, Limiting current density and water dissociation in bipolar membranes, Journal of Membrane Science, 125 (1997) 123-142.

[4] G. Saracco, Ionic membrane technologies for the recovery of valuable chemicals from waste waters, Annali di Chimica, 93 (2003) 817-826.

[5] G. Pourcelly, C. Gavach, Electrodialysis water splitting - Applications of electrodialysis with bipolar membranes (EDBM), Handbook on Bipolar Membrane Technology, (2000) 17-46.

[6] M. Kameche, F. Xu, C. Innocent, G. Pourcelly, Electrodialysis in water-ethanol solutions: Application to the acidification of organic salts, Desalination, 154 (2003) 9-15.

[7] C.H. Huang, T.W. Xu, Cleaner production by using electrodialysis in organic or aqueous-organic systems, Trends in Conservation and Recycling of Resources, (2006) 83-97.

[8] C. Huang, T. Xu, Y. Zhang, Y. Xue, G. Chen, Application of electrodialysis to the production of organic acids: State-of-the-art and recent developments, Journal of Membrane Science, 288 (2007) 1-12.

[9] R. Audinos, Ion-exchange membrane processes for clean industrial chemistry, Chemical Engineering and Technology, 20 (1997) 247-258.

[10] Y. Tanaka, R. Ehara, S. Itoi, T. Goto, Ion-exchange membrane electrodialytic salt production using brine discharged from a reverse osmosis seawater desalination plant, Journal of Membrane Science, 222 (2003) 71-86.

[11] Y. Tanaka, Mass transport in a boundary layer and in an ion exchange membrane: Mechanism of concentration polarization and water dissociation, Russian Journal of Electrochemistry, 48 (2012) 665681.

[12] Y. Tanaka, Ion-exchange membrane electrodialysis program and its application to multi-stage continuous saline water desalination, Desalination, 301 (2012) 10-25.

[13] Y. Tanaka, Ion-exchange membrane electrodialysis for saline water desalination and its application to seawater concentration, Industrial and Engineering Chemistry Research, 50 (2011) 7494-7503.

[14] Y. Tanaka, Ion-exchange membrane electrodialysis of saline water and its numerical analysis, Industrial and Engineering Chemistry Research, 50 (2011) 10765-10777.

[15] Y. Tanaka, Simulation of an ion exchange membrane electrodialysis process for continuous saline water desalination, Desalination and Water Treatment, 22 (2010) 271-285.

[16] Y. Oren, I. Rubinstein, C. Linder, G. Saveliev, B. Zaltzman, E. Mirsky, O. Kedem, Modified heterogeneous anion-exchange membranes for desalination of brackish and recycled water, Environmental Engineering Science, 19 (2002) 513-529.

[17] C. Larchet, V.I. Zabolotsky, N. Pismenskaya, V.V. Nikonenko, A. Tskhay, K. Tastanov, G. Pourcelly, Comparison of different ED stack conceptions when applied for drinking water production from brackish waters, Desalination, 222 (2008) 489-496.

[18] E. Korngold, Electrodialysis processes using ion exchange resins between membranes, Desalination, 16 (1975) 225-233. 
[19] C. Klaysom, R. Marschall, S.H. Moon, B.P. Ladewig, G.Q.M. Lu, L. Wang, Preparation of porous composite ion-exchange membranes for desalination application, Journal of Materials Chemistry, 21 (2011) 7401-7409.

[20] Y.J. Kim, J.H. Kim, J.H. Choi, Selective removal of nitrate ions by controlling the applied current in membrane capacitive deionization (MCDI), Journal of Membrane Science, 429 (2013) 52-57.

[21] Y.J. Kim, J.H. Choi, Desalination of brackish water by capacitive deionization system combined with ion-exchange membrane, Applied Chemistry for Engineering, 21 (2010) 87-92.

[22] Y. Kim, B.E. Logan, Microbial desalination cells for energy production and desalination, Desalination, 308 (2013) 122-130.

[23] E.K. Malinovskii, E.G. Sivalov, Sorption and gas-separation properties of perfluorinated ionexchange membranes with respect to water vapour, Zhurnal Prikladnoi Khimii, 65 (1992) 2728-2731.

[24] O.H. LeBlanc Jr, W.J. Ward, S.L. Matson, S.G. Kimura, Facilitated transport in ion-exchange membranes, Journal of Membrane Science, 6 (1980) 339-343.

[25] D. Langevin, M. Pinoche, E. Selegny, M. Metayer, R. Roux, CO2 facilitated transport through functionalized cation-exchange membranes, Journal of Membrane Science, 82 (1993) 51-63.

[26] W.J. Chen, C.R. Martin, Gas-transport properties of sulfonated polystyrenes, Journal of Membrane Science, 95 (1994) 51-61.

[27] O. Savadogo, Emerging membranes for electrochemical systems: Part II. High temperature composite membranes for polymer electrolyte fuel cell (PEFC) applications, Journal of Power Sources, 127 (2004) 135-161.

[28] B. Smitha, S. Sridhar, A.A. Khan, Solid polymer electrolyte membranes for fuel cell applications - A review, Journal of Membrane Science, 259 (2005) 10-26.

[29] R. Audinos, Electrodialyse inverse. Etude de l'energie electrique obtenue a partir de deux solutions de salinites differentes, Journal of Power Sources, 10 (1983) 203-217.

[30] P. Długołecki, K. Nymeijer, S. Metz, M. Wessling, Current status of ion exchange membranes for power generation from salinity gradients, Journal of Membrane Science, 319 (2008) 214-222.

[31] J. Veerman, R.M. de Jong, M. Saakes, S.J. Metz, G.J. Harmsen, Reverse electrodialysis: Comparison of six commercial membrane pairs on the thermodynamic efficiency and power density, Journal of Membrane Science, 343 (2009) 7-15.

[32] E. Guler, Y. Zhang, M. Saakes, K. Nijmeijer, Tailor-Made Anion-Exchange Membranes for Salinity Gradient Power Generation Using Reverse Electrodialysis, ChemSusChem, 5 (2012) 2262-2270.

[33] D.A. Vermaas, M. Saakes, K. Nijmeijer, Doubled power density from salinity gradients at reduced intermembrane distance, Environmental Science and Technology, 45 (2011) 7089-7095.

[34] O.S. Burheim, F. Seland, J.G. Pharoah, S. Kjelstrup, Improved electrode systems for reverse electro-dialysis and electro-dialysis, Desalination, 285 (2012) 147-152.

[35] J. Veerman, M. Saakes, S.J. Metz, G.J. Harmsen, Reverse electrodialysis: Evaluation of suitable electrode systems, Journal of Applied Electrochemistry, 40 (2010) 1461-1474.

[36] D.A. Vermaas, S. Bajracharya, B.B. Sales, M. Saakes, B. Hamelers, K. Nijmeijer, Clean energy generation using capacitive electrodes in reverse electrodialysis, Energy and Environmental Science, 6 (2013) 643-651.

[37] P. Długołecki, P. Ogonowski, S.J. Metz, M. Saakes, K. Nijmeijer, M. Wessling, On the resistances of membrane, diffusion boundary layer and double layer in ion exchange membrane transport, Journal of Membrane Science, 349 (2010) 369-379.

[38] J. Veerman, M. Saakes, S.J. Metz, G.J. Harmsen, Reverse electrodialysis: A validated process model for design and optimization, Chemical Engineering Journal, 166 (2011) 256-268. 
[39] R. Patil, G. Lipscomb, Parametric sensitivity of reverse electrodialysis for electricity production using salinity gradient, in: AIChE Annual Meeting, Minneapolis, MN, 2011.

[40] D.A. Vermaas, E. Guler, M. Saakes, K. Nijmeijer, Theoretical power density from salinity gradients using reverse electrodialysis, Energy Procedia, 20 (2012) 170-184.

[41] S. Fujii, K. Takeichi, M. Higa, Optimization of RED Test Cell for PVA Based Ion-Exchange Membranes, Procedia Engineering, 44 (2012) 1300-1302.

[42] J. Veerman, J.W. Post, M. Saakes, S.J. Metz, G.J. Harmsen, Reducing power losses caused by ionic shortcut currents in reverse electrodialysis stacks by a validated model, Journal of Membrane Science, 310 (2008) 418-430.

[43] T. Sata, Preparation of ion exchange membranes, in: Ion Exchange Membranes: Preparation, Characterization, Modification and Application, The Royal Society of Chemistry, Cambridge, 2004, pp. $35-88$.

[44] J.N. Weinstein, F.B.J.W. Leitz, Electric power from differences in salinity: the dialytic battery, Science, 191 (1976) 557-559.

[45] E. Middelman, Balster, Jörg Henning, WO/2008/095509, Reinforced ion-exchange membrane comprised of a support, and laminated thereon, a polymeric film, in, 2008.

[46] M.A. Izquierdo-Gil, V.M. Barragán, J.P.G. Villaluenga, M.P. Godino, Water uptake and salt transport through Nafion cation-exchange membranes with different thicknesses, Chemical Engineering Science, 72 (2012) 1-9.

[47] M.C. Wijers, M. Jin, M. Wessling, H. Strathmann, Supported liquid membranes modification with sulphonated poly(ether ether ketone). Permeability, selectivity and stability, Journal of Membrane Science, 147 (1998) 117-130.

[48] M. Mulder, Basic principles of membrane technology, (1991).

[49] V.M. Barragán, M.J. Pérez-Haro, Correlations between water uptake and effective fixed charge concentration at high univalent electrolyte concentrations in sulfonated polymer cation-exchange membranes with different morphology, Electrochimica Acta, 56 (2011) 8630-8637.

[50] L. Jones, P.N. Pintauro, H. Tang, Coion exclusion properties of polyphosphazene ion-exchange membranes, Journal of Membrane Science, 162 (1999) 135-143.

[51] A.V. Sokirko, J.A. Manzanares, J. Pellicer, The Permselectivity of Membrane Systems with an Inhomogeneous Distribution of Fixed Charge Groups, Journal of Colloid and Interface Science, 168 (1994) 32-39.

[52] Y. Mizutani, R. Yamane, H. Ihara, H. Motomura, Studies of ion exchange membranes. XVI. The preparation of ion exchange membranes by the "paste method", Bulletin of the Chemical Society of Japan, 36 (1963) 361-366.

[53] J.W. Post, H.V.M. Hamelers, C.J.N. Buisman, Energy Recovery from Controlled Mixing Salt and Fresh Water with a Reverse Electrodialysis System, Environmental Science \& Technology, 42 (2008) 5785-5790.

[54] H. Strathmann, Ion-exchange Membrane Seperation Processes, 9, 1st ed., Elsevier, Amsterdam, 2004.

[55] D.C.M. Raymond H. Myers, G. Geoffrey Vining, Timothy J. Robinson Generalized Linear Models: with Applications in Engineering and the Sciences, 2 ed., John Wiley \& Sons, Inc, New Jersey, 2010.

[56] M. Grujicic, K.M. Chittajallu, Design and optimization of polymer electrolyte membrane (PEM) fuel cells, Applied Surface Science, 227 (2004) 56-72. 


\section{Monovalent-ion-selective membranes - Fabrication and characterization}

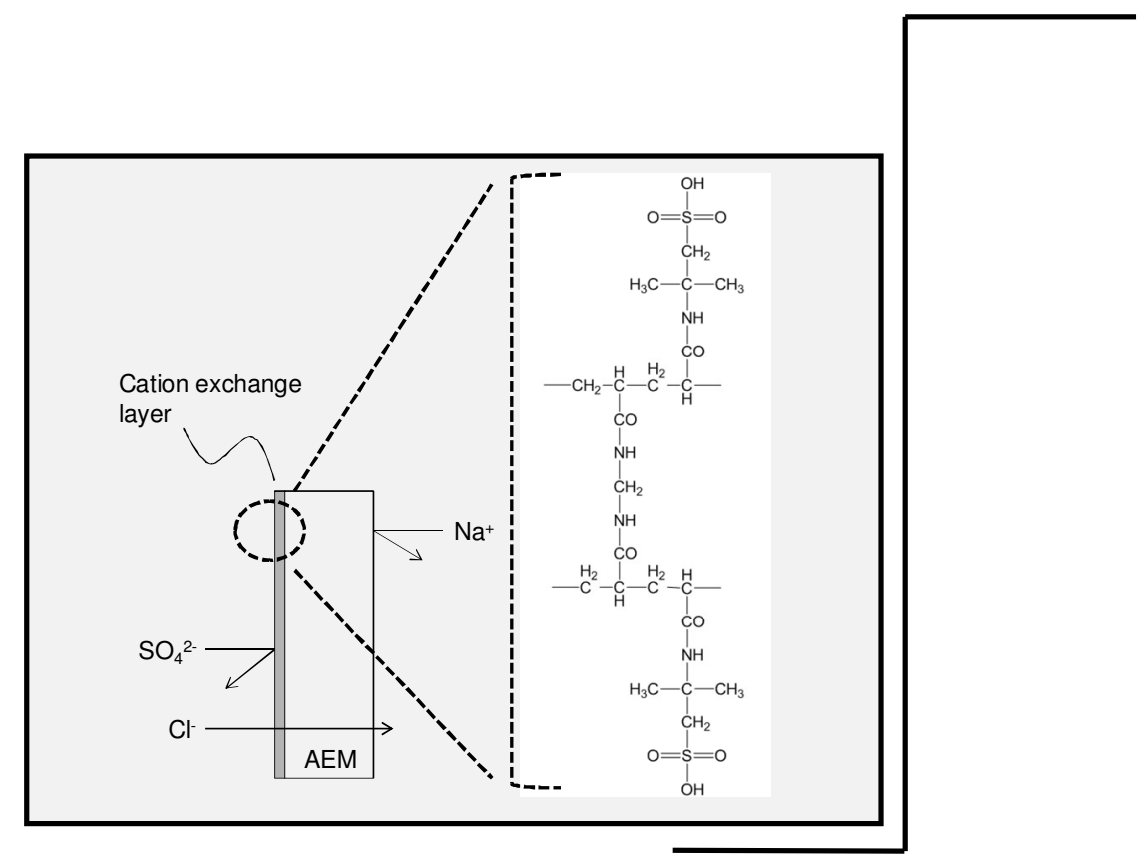

This chapter has been submitted to the Journal of Membrane Science as:

E. Guler, W. van Baak, M. Saakes, K. Nijmeijer, Monovalent-ion-selective membranes for reverse electrodialysis. Journal of Membrane Science (2013). 


\begin{abstract}
Reverse electrodialysis (RED) is a process that can be used to generate energy from salinity gradients. Since its application in practice requires the use of natural seawater and river water, the presence of multivalent ions is inevitable, but this currently limits RED performance. Membranes with selectivity for monovalent ions may overcome this limitation. Standard ion exchange membranes have low monovalent-ion selectivity. We used a single-step and relatively fast method to coat a standard commercial anion exchange membrane to improve its monovalent-ion selectivity. The coating layer was formed by copolymerization of 2-acryloylamido-2-methylpropanesulfonic acid (AMPS) as the active polymer and N,N-methylenebis(acrylamide) (MBA) as the crosslinker, using UV irradiation. The monovalent ion selectivity of the resulting membranes was comparable to that of commercial monovalent-selective membranes. Furthermore, the modified membranes with their negatively charged coating showed increased hydrophilicity and exhibited sufficient antifouling potential against organic foulants. When they were tested in an RED stack, their performance was found to depend especially on the proportion of the divalent ions (sulfate) in the river water stream. However, the use of the currently available monovalent selective membranes was not found to be very effective for obtaining higher gross power densities in RED.
\end{abstract}




\subsection{Introduction}

Global warming and the depletion of fossil fuel sources have resulted in a great deal of attention for energy from renewable sources [1]. Oceans and surface waters have the potential to contribute salinity gradient energy, thermal energy, and energy generated by waves and tidal forces [2]. Of these sustainable energy forms, particularly salinity gradient energy can be considered significant with its theoretical power production potential of 2.4 TW, exceeding the current global electricity consumption [3-4].

One technology for extracting energy from salinity gradients is reverse electrodialysis (RED). In RED, selective ion transport is created via ion-selective membranes. These membranes allow the transport of either anions (i.e. in the case of anion exchange membranes) or cations (i.e. in the case of cation exchange membranes) resulting in a potential difference. The ionic transport is later counterbalanced by electron transport caused by redox reactions at the electrodes. The generated electric current can be utilized in an external electric device.

As the ion exchange membranes are core elements in RED, their performance is vital for efficient energy generation. Besides ions like sodium and chloride, many other ions are naturally present in seawater and river water. The literature on ion exchange membranes indicates that the presence of multivalent ions has a lowering effect on stack voltage and thus on the power density [5-6]. Examples of multivalent ions are magnesium, calcium and sulfate. Multivalent ions - particularly magnesium and sulfate - increase the electrical resistance of the membranes and lower the power output [5]. Moreover, standard-grade ion exchange membranes usually have low selectivity towards such ions, e.g. cation exchange membranes were determined to have very low selectivity towards magnesium [5]. Divalent ions tend to be transported in the direction opposite to their activity gradient (i.e. from the river water compartment to seawater compartment) due to the difference in chemical potential between divalent and monovalent ions. Thus, a divalent ion in a river water compartment is exchanged for two monovalent ions in the seawater compartment reducing the salinity gradient and thus the power density in RED [5]. Therefore, one of the key electrochemical properties of the membranes that determine RED performance is the selectivity for specific ions. In the RED process, such selectivity can be provided by tailor-made ion exchange membranes.

Monovalent-ion-selective membranes have the capability to separate monovalent ions from a solution, e.g. seawater and river water, containing both monovalent and 
multivalent ions. Such relative permselectivity can, for instance, be provided by a very thin layer on the surface of conventional membranes that allows the passage of only monovalent anions (e.g. chloride) while restricting the passage of divalent ions (e.g. sulfate) (Figure 4.1). Such a coating layer can, for instance, carry an opposite charge relative to the membrane, as in Figure 4.1. In addition to providing monovalent-ion selectivity, a membrane modification like this can simultaneously be utilized to control biofouling which is a serious problem not only for RED [4] but also for conventional electrodialysis [7-8].

a)

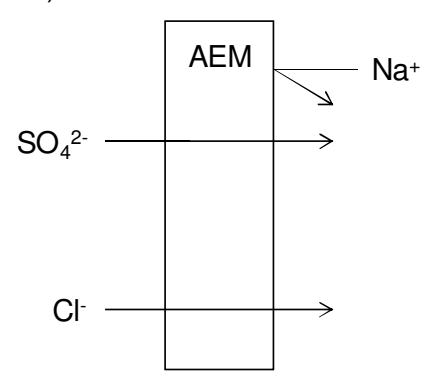

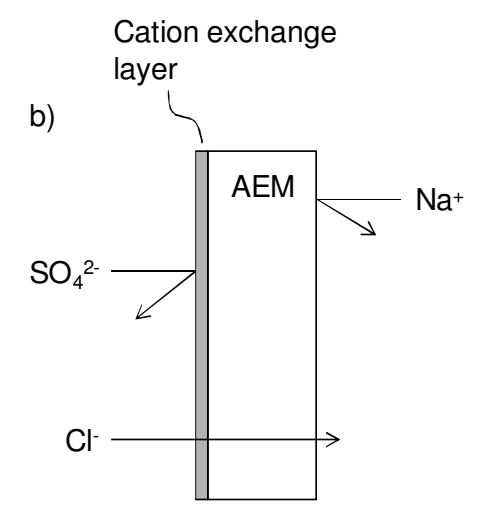

Figure 4.1. Mechanism of monovalent-ion selectivity by integration of a conventional ion exchange membrane (a) with a cation exchange layer (b).

Biofouling, especially for anion exchange membranes, is also considered to be one of the most important limitations for the practical use of the RED process. Organic and colloidal fouling usually involves large negatively charged molecules resulting in fouling specifically on standard anion exchange membranes, which are positively charged [4]. This results in an increase of membrane resistance and a decrease of apparent permselectivity during RED operation with natural waters. Recently, Vermaas et al. investigated fouling in a RED stack using natural seawater and river water, and proposed several strategies to reduce this fouling such as the use of profiled membranes (i.e. spacerless stacks) and switching the current direction [4]. Several other authors studied fouling in electrodialysis, especially for anion exchange membranes [9-14]. To prevent fouling, Grebenyuk et al. suggested using a coating layer with a surfactant containing a sulfonic acid functional group on the membrane surface, which is oppositely charged relative to the membrane bulk material [10]. Combined with the idea of monovalent ion selectivity, this approach, the use of anion exchange membranes with an oppositely charged coating layer, will have benefits in a RED stack as well. 
Another common problem in the application of RED is membrane poisoning. It occurs when electrolyte solutions having a negative charge, such as hexacyanoferrate compounds, penetrate into the bulk of the anion exchange membranes, which are positively charged, and results in decreased RED performance [15]. It can happen not only in the membranes adjacent to the electrode compartments but also in the membranes inside the stack if there is no proper sealing of the membrane cells (leaking gaskets). In addition to anti-fouling properties, a thin negatively charged surface layer to make membranes monovalent-ion-selective also has the potential to prevent membrane poisoning to some extent (via electrostatic repulsion).

Various methodologies for the preparation of anion exchange membranes with monovalent selectivity have already been reported. Sieving of ions by the formation of a highly crosslinked layer was effective in changing the permselectivity between monovalent and divalent ions [16-17]. The thickness of this layer was optimized so as to obtain monovalent-ion selectivity without increasing the electrical resistance. Later, Sata et al. carried out a significant amount of work in this field, such as with condensation-type aromatic amine polymers and formaldehyde on the membrane surface [18], impregnation of ethylene glycols into the membranes [19], and introduction of specific ion exchange groups controlling the hydrophilicity of the base membrane [20-22]. Amara et al. [23-24] and Guesmi et al. [25] worked on the physical adsorption of polyethylenimine (PEI) onto anion exchange membranes, and successfully achieved the separation of anions according to their hydration radii and their sizes. Dey et al. studied PEI functionalization on nanofiltration membranes and achieved a high rejection rate of divalent ions from salt solutions, such as a solute rejection ratio of 1.25 for $\mathrm{NaCl} / \mathrm{Na}_{2} \mathrm{SO}_{4}$ [26]. Layer-by-layer deposition, such as of alternating layers of poly-anions and poly-cations with wash steps in between, was also investigated with the aim to obtain a promising $\mathrm{Cl}^{-} / \mathrm{SO}_{4}{ }^{2-}$ selectivity [27-28]. However, all these studies concerned methods requiring several steps, e.g. layer-by-layer deposition, or a great deal of time, e.g. immersion to achieve physical adsorption. Moreover, none of these studies targeted obtaining specific antifouling properties at the same time.

Previously, the formation of a negatively charged polyelectrolyte layer on the surface of anion exchange membranes was reported to increase permselectivity for monovalent ions [28]. Recently, Mulyati et al. also found that monovalent-anion selectivity can be obtained by the electrostatic repulsion between multivalent anions and a negative surface charge of the membrane, as this repulsion is greater than that between monovalent anions and a negative surface charge [8]. 
In the present paper, we report the development of monovalent-ion-selective membranes by coating commercially available standard grade anion exchange membranes for RED. Photo-polymerization (UV-curing) was performed to create a highly negatively charged layer on the membrane surface by using polyanion 2acryloylamido-2-methylpropanesulfonic acid (AMPS). Contrary to other membrane modification techniques described in the aforementioned literature, we employed a single-step (i.e. casting followed by UV-curing) and relatively fast method. We evaluated the RED performance of these modified membranes in the presence of divalent ions (i.e. sulfate) in terms of power density and their antifouling potential against organic foulants and compared the results to the performance of standard anion exchange membranes and commercially available anion exchange membranes with monovalent ion selectivity.

\subsection{Theory}

\subsubsection{Transport numbers}

To evaluate the monovalent selectivity of membranes, bulk transport numbers of divalent (e.g. sulfate) and monovalent (e.g. chloride) ions in an aqueous salt solution can be determined.

The corresponding ion (A) flux through the membrane $\left(\mathrm{J}_{\mathrm{A}}\right)$ is calculated from the concentration change in time $\left(\frac{\mathrm{dC}_{\mathrm{A}}}{\mathrm{dt}}\right)$ in a dilute electrolyte solution:

$\mathrm{J}_{\mathrm{A}}=\frac{\mathrm{V} \cdot \frac{\mathrm{dC}_{\mathrm{A}}}{\mathrm{dt}}}{\mathrm{A}}$

$\mathrm{V}$ is the volume of the circulated solution $\left(\mathrm{cm}^{3}\right)$ and $\mathrm{A}$ is the membrane area $\left(\mathrm{cm}^{2}\right)$.

To evaluate monovalent-ion selectivity of the membranes, first the current (I) carried by a single ion $(A)$ can be calculated from the concentration change in time $\left(\frac{\mathrm{dC}_{\mathrm{A}}}{\mathrm{dt}}\right)$ in the dilute solution:

$\mathrm{I}_{\mathrm{A}}=\mathrm{F} \cdot \mathrm{V} \cdot \frac{\mathrm{dC}_{\mathrm{A}}}{\mathrm{dt}}$

In this equation, $\mathrm{F}$ is the Faraday constant $\left(96,485 \mathrm{C} \mathrm{mol}^{-1}\right), \mathrm{V}$ is the volume of the circulated solution $\left(\mathrm{cm}^{3}\right), \mathrm{C}$ is concentration $\left.(\mathrm{mol} \mathrm{cm})^{-3}\right)$ and $\mathrm{t}$ is the time $(\mathrm{s})$. The 
transport number of a certain ion $t_{A}$ is defined as the ratio of between the current carried by this ion $\left(\mathrm{I}_{\mathrm{A}}\right)$ and the total current $\left(\mathrm{I}_{\mathrm{A}}\right)$ :

$\mathrm{t}_{\mathrm{A}}=\frac{\mathrm{I}_{\mathrm{A}}}{\mathrm{I}}=\frac{\mathrm{F} \cdot \mathrm{V} \cdot \frac{\mathrm{dC} \mathrm{C}_{\mathrm{A}}}{\mathrm{dt}}}{\mathrm{I}}=\frac{\mathrm{F} \cdot \mathrm{V} \cdot \frac{\mathrm{dC}_{\mathrm{A}}}{\mathrm{dt}}}{\mathrm{i} \cdot \mathrm{A}}$

In this equation, $\mathrm{i}$ is the current density $\left(\mathrm{mA} \mathrm{cm}{ }^{-2}\right)$ and $\mathrm{A}$ is the effective membrane area $\left(\mathrm{cm}^{2}\right)$. Thus, to evaluate the relative permselectivity of the membrane between $\mathrm{A}_{2}$ and $\mathrm{A}_{1}$ ions, the transport number ratio can be determined such that:

$\mathrm{P}_{\mathrm{A}_{1}}^{\mathrm{A}_{2}}=\frac{\mathrm{t}_{\mathrm{A}_{2}} / \mathrm{t}_{\mathrm{A}_{1}}}{\mathrm{C}_{\mathrm{A}_{2}} / \mathrm{C}_{\mathrm{A}_{1}}}$

Here, $t_{A_{2}}$ and $t_{A_{1}}$ denote the transport numbers of $A_{2}$ and $A_{1}$ ions, respectively; $C_{A_{2}}$ and $\mathrm{C}_{\mathrm{A}_{1}}$ are the average concentrations of $\mathrm{A}_{2}$ and $\mathrm{A}_{1}$ ions before and after electrodialysis in the dilute compartment, respectively [20]. In this particular work, $\mathrm{A}_{2}$ may denote sulfate ions and $\mathrm{A}_{1}$ may denote chloride ions.

\subsubsection{Experimental and theoretical power density}

The experimental gross power output can be calculated from the maximum of the product of voltage (E) and current (I). The gross power density is then determined by dividing gross power output by total membrane area $\left(\mathrm{W} \mathrm{m}^{-2}\right)$.

The theoretical gross power density can be calculated based on the values of experimental open-circuit voltage $\left(\mathrm{E}_{\mathrm{OCV}}\right)$, which is the total stack potential with no current applied to the RED stack, and the stack resistance as described earlier [29]. Neglecting the ohmic resistances of electrodes and its compartments, the stack resistance $\left(\mathrm{R}_{\text {stack }}\right)$ can be defined as [30]:

$R_{\text {stack }}=\frac{N}{A} \cdot\left(R_{\text {aem }}+R_{\text {cem }}+\frac{d_{c}}{\kappa_{c}}+\frac{d_{d}}{\kappa_{d}}\right)$

In this equation, $A$ is effective membrane area $\left(\mathrm{m}^{2}\right), \mathrm{R}_{\mathrm{aem}}$ is the anion exchange membrane resistance $\left(\Omega \cdot \mathrm{m}^{2}\right), R_{\text {cem }}$ is the cation exchange membrane resistance $\left(\Omega \cdot \mathrm{m}^{2}\right)$, $d_{c}$ is the thickness of the concentrated saltwater compartment $(m), d_{d}$ is the thickness of the diluted saltwater compartment $(\mathrm{m}), \boldsymbol{\kappa}_{\mathrm{c}}$ is the conductivity in the concentrated saltwater compartment $\left(\mathrm{S} \mathrm{m}^{-1}\right)$, and $\kappa_{\mathrm{d}}$ is the conductivity in the diluted saltwater compartment $\left(\mathrm{S} \mathrm{m}^{-1}\right)$. In this work, analytically measured conductivities of these 
compartments were used and replaced in Equation 4.5 to find the stack resistance in order to have more realistic values of these terms.

The maximum power output using $\mathrm{R}_{\text {stack }}$ and $\mathrm{E}_{\mathrm{OCV}}$ can subsequently be expressed as:

$$
\mathrm{P}_{\max }=\frac{\left(\mathrm{E}_{\mathrm{OCV}}\right)^{2}}{4 \mathrm{R}_{\mathrm{stack}}}
$$

Consequently, the power density (power output per unit membrane area, $\mathrm{P}_{\text {gross }}$ ) can be calculated from $\mathrm{P}_{\max }$ :

$$
\mathrm{P}_{\text {gross }}=\frac{\mathrm{P}_{\max }}{2 \cdot A \cdot \mathrm{N}}
$$

In this equation, $\mathrm{P}_{\text {gross }}$ is the maximum gross power density $\left(\mathrm{W} \mathrm{m}^{-2}\right), \mathrm{P}_{\max }$ is maximum power output $(\mathrm{W}), \mathrm{A}$ is effective area of single membrane $\left(\mathrm{m}^{2}\right)$ and $\mathrm{N}$ is number of membrane cells.

\subsubsection{Current-voltage (I-V) relations and surface homogeneity}

A method frequently used to characterize the transport properties of ion exchange membranes is to study a membrane system's current-voltage (I-V) curves. Monitoring $\mathrm{I}-\mathrm{V}$ curves yields insights about the surface properties of the ion exchange membranes, as they are the performance-determining components of a RED system. On the other hand, ionic transport information above the limiting current region in I-V curves might be of more interest for conventional electrodialysis (ED) applications than for RED since maximum power generation takes place below the overlimiting region in RED with seawater and river water concentrations. Figure 4.2 shows a typical currentvoltage curve for a monopolar ion exchange membrane. 


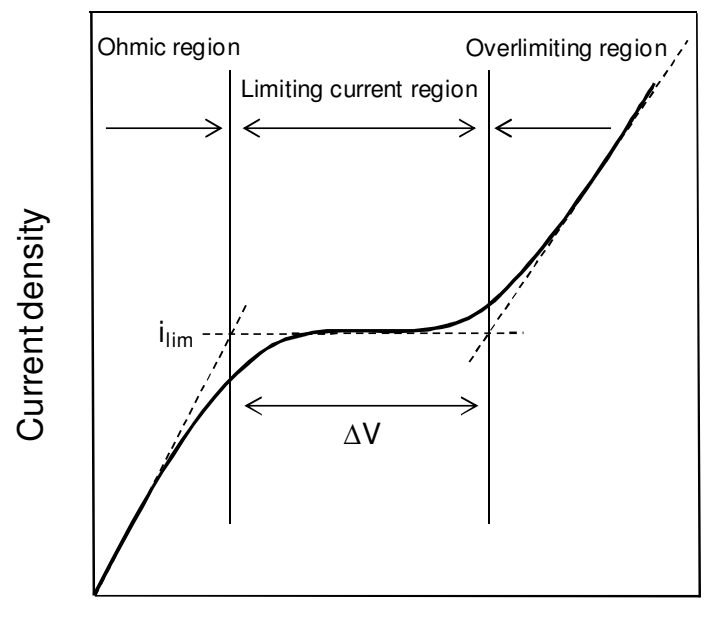

Potential

Figure 4.2. Schematic representation of typical current-voltage curve of ion exchange membranes.

The characteristic curve shows three regions. First, in the ohmic region at lower current densities, ions are available in the diffusion boundary layer of the membrane to transport the current from one compartment to another and there exists a linear relation between voltage and current. Second, this region is followed by the plateau region (i.e. limiting current region) in which the potential increases sharply due to the lack of ions. Due to concentration polarization, ions migrate faster through the membrane than from the bulk solution towards the membrane surface. Thus, the ion concentration at the membrane surface decreases until it reaches zero. The current density that corresponds to this point is called the limiting current density ( $\left.i_{\text {lim }}\right)$. Third, the current plateau is followed by the overlimiting region where water splitting (i.e. production of $\mathrm{H}^{+}$and $\mathrm{OH}^{-}$to transport current) or electroconvection (i.e. mixing of diffusion layer resulting in irregular electric fields) occurs. The plateau length and the onset of the overlimiting region can give information about the conductive heterogeneity of membrane surfaces, and about modifications of the conductivity on membrane surfaces. The theory concerning electroconvection predicts a greater plateau length for membranes with increased surface homogeneity [31]. Electroconvection can be defined as non-gravitational free convection in macroscopic domains of the electrolyte solution, caused by the interactions of a self-consisting electric field with the corresponding space charge [31]. Rubinstein et al. elaborated this theory of flow vortices caused by the mixing of the diffusion layer via surface heterogeneity [32]. According to this concept, the elimination or decrease of surface heterogeneity delays the earlier onset of electroconvection and causes greater plateau lengths in I-V curves. Thus, coating the membrane surface with a conductive thin layer might hinder conductive heterogeneities (effect of funnel, Figure 4.3b) and provide a more stable ionic flow from the electrolyte to the membrane (Figure 4.3a). Shorter plateau lengths 
indicate a less active electroconvective effect, i.e. the smoother the membrane, the longer the plateau.
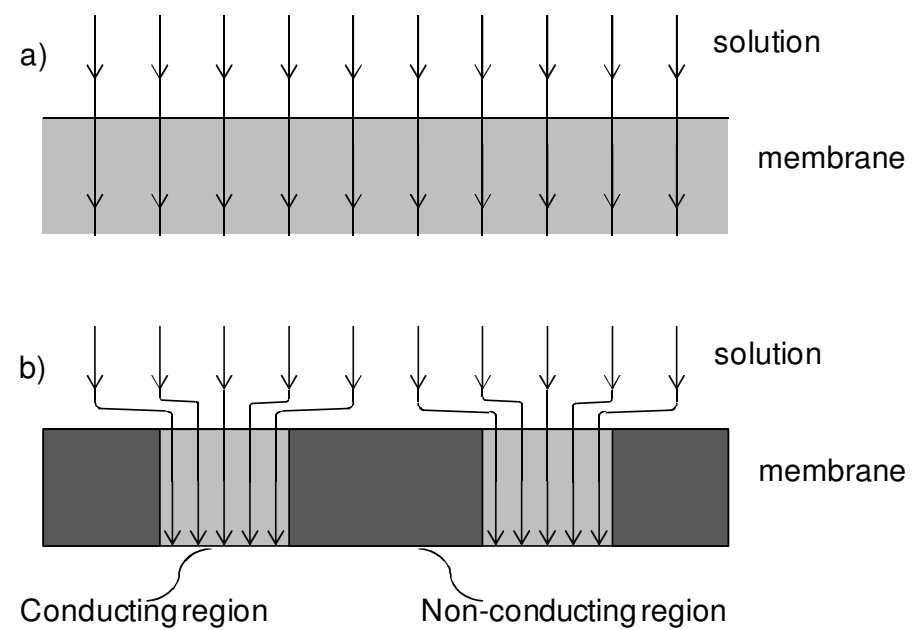

Figure 4.3. Scheme of current line distribution close to a) a homogeneous and b) a heterogeneous membrane surface [31, 33].

Previous research also showed that coating the membrane surface with a conductive thin layer does increase conductive surface homogeneity [31-32]. Rubinstein et al. used a polyvinyl alcohol (PVA) coating layer $(1-2 \mu \mathrm{m})$ on the membrane surface to eliminate the overlimiting conductance [34]. Similarly, Balster et al. used a polyethylenimine (PEI) coating on commercial CMX membranes and observed a noticeable broadening of the plateau (increased length) in the I-V curves [31]. Monitoring I-V curves and determining the plateau length can provide information about the level of homogeneity of the membrane surface [35-37].

\subsubsection{Transition time for fouling determination}

The antifouling potential of ion exchange membranes is an important factor that codetermines RED performance. The membrane potential $(\Delta \mathrm{E}$, potential difference between both sides of the membrane) can be monitored in a single cell (not in a RED stack) over time to investigate fouling. Fouling results in increased area resistance of the membrane, causing $\Delta \mathrm{E}$ to increase in the single cell in which fouling is investigated. First $\Delta \mathrm{E}$ increases gradually, but it increases rapidly after fouling starts to occur. The time elapsed until this rapid increase is called the transition time (Figure 4.4). For membranes with relatively high antifouling properties, this transition time is relatively long. 


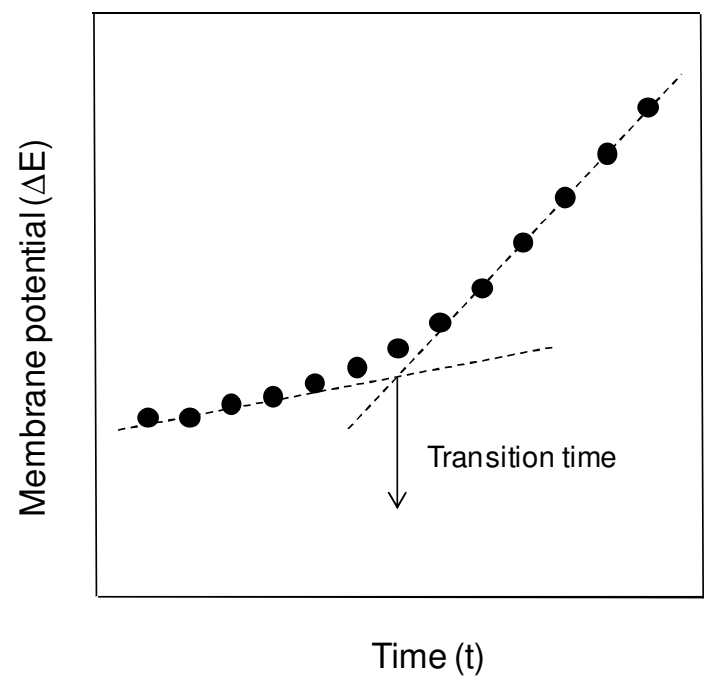

Figure 4.4. Typical graph of membrane potential (potential difference between both sides of the membrane) versus time for the determination of transition time [38].

\subsection{Experimental}

\subsubsection{Materials}

Table 4.1 lists selected properties of the membranes tested in this study. Each membrane is homogenous with non-conductive reinforcement (either PP or PVC). The AMX and ACS membranes have a polymer matrix formed by copolymerization of styrene and divinylbenzene. On the other hand, the commercial Fujifilm membrane (Fuji A) is a standard-grade homogeneous anion exchange membrane without any specific monovalent-ion selectivity or antifouling potential. It has strongly basic anion exchange groups.

Table 4.1. Characteristics of the anion exchange membranes used in this study [39-42].

\begin{tabular}{lllll}
\hline Membrane & Manufacturer & Type & Reinforcing & $\begin{array}{l}\text { Structure } \\
\text { properties }\end{array}$ \\
\hline Fuji A & Fujifilm & Standard grade & PP & - \\
AMX & Tokuyama & Standard grade & PVC & Styrene/DVB \\
ASV (mono) & Asahi Glass & Monovalent-selective & - & - \\
ACS (mono) & Tokuyama & Monovalent-selective & PVC & Styrene/DVB \\
Fuji A-mono & Tailor-made & Monovalent-selective & PP & composite \\
\hline
\end{tabular}

a divinylbenzene. Reinforcing materials: PP: polypropylene; PA: polyamide; PP: polypropylene; PVC: polyvinylchloride. All are homogeneous anion exchange membranes. 
We selected the Fuji A membrane (Fujifilm Manufacturing Europe BV, the Netherlands) to be modified to obtain improved monovalent-ion selectivity and antifouling potential because of its electrochemical properties, as will be discussed later.

For the anionic coating layer, we used 2-acryloylamido-2-methylpropanesulfonic acid (AMPS, Sigma-Aldrich) as polyanion. We used N,N-methylenebis(acrylamide) (MBA, Sigma-Aldrich) as the crosslinking agent to modify both sides of standard-grade Fuji A membranes.

We used 2-hydroxy-2-methyl-1-phenyl-1-propane (Darocure 1173, Ciba Specialty Chemicals) as free-radical photo-initiator, and $\mathrm{LiOH}$ monohydrate (Sigma-Aldrich) as $\mathrm{pH}$ neutralizer to control the high reactivity of AMPS at low $\mathrm{pH}$ values. Milli-Q water (Millipore) and isopropyl alcohol (IPA) (Sigma-Aldrich) were used as solvent for the coating solution.

Neosepta AMX (Tokuyama) is a commercial standard-grade membrane without any specific monovalent-ion selectivity and antifouling properties. On the other hand, Neosepta ACS (Tokuyama) is a commercial monovalent-ion-selective anion exchange membrane prepared by deposition of a highly crosslinked layer on both sides [43]. Selemion ASV (Asahi Glass) is another anion exchange membrane with specific monovalent-ion selectivity [42]. Although some of its chemical structure properties are undeclared, it is known from the literature that this membrane has a highly crosslinked layer similar to the ACS membrane [44].

Sodium chloride (99.5\%, Acros Organics) and sodium sulfate (99\%, Acros Organics) were used for membrane resistance measurements. We chose sodium dodecyl sulfate (SDS, Merck) as a model organic foulant. For RED performance characterization, sodium chloride (technical grade, Boom BV, the Netherlands), potassium hexacyanoferrate(II) (99\%, Boom BV) and potassium hexacyanoferrate(III) (99\%, Boom BV) were used. All chemicals were used without further purification.

\subsubsection{Monovalent-ion-selective membranes}

We prepared the monovalent-ion-selective membranes on the basis of in-situ synthesis of a reactive polymeric layer on the membrane surface [45], preserving the bulk membrane structure. The modified membranes can be considered composite membranes with a functionalized surface. The coating layer containing sulfonic acid groups is formed by acrylamide (AMPS) monomer crosslinked by bis-acrylamide 
(MBA) via UV irradiation and fixed to the solid base membrane material without any chemical grafting. Figure 4.5 shows the reaction scheme. The reaction is a photopolymerization reaction initiated by a free-radical-generating system via active double bonds; MBA functions as the crosslinker that forms the polymer network (Figure 4.5).

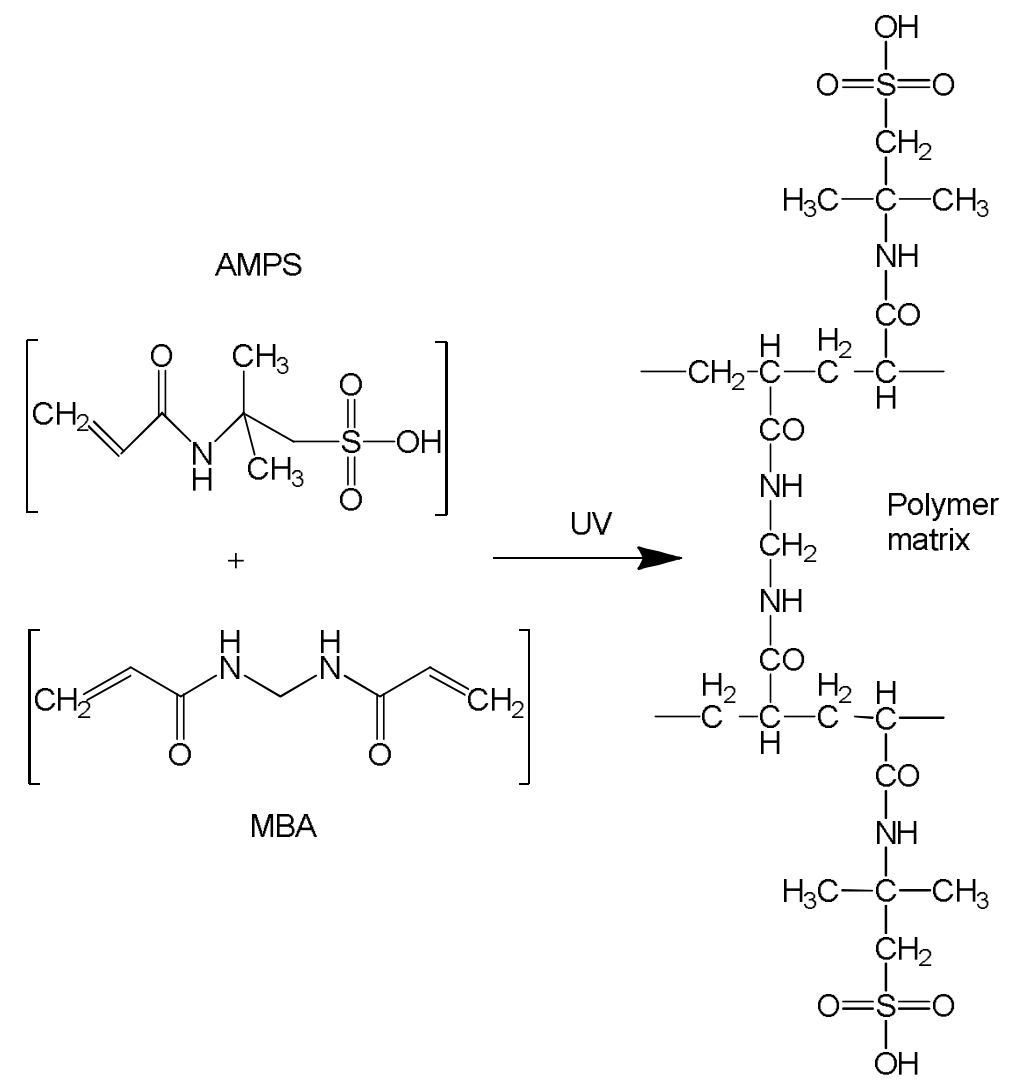

Figure 4.5. Reaction scheme of UV photopolymerization reaction of AMPS and MBA.

The coating solution was prepared by dissolving 5 wt\% AMPS in Milli-Q water/IPA solution followed by addition of $\mathrm{LiOH}$ at small amounts ( $1 \mathrm{wt} \%$ ) at room temperature. Subsequently, crosslinker MBA (2 wt\%) was dissolved in the solution to which freeradical photo-initiator Darocure 1173 (0.5 wt\%) was then added at $65{ }^{\circ} \mathrm{C}$. After a clear solution was obtained, the mixtures were drawn into films by coating them onto airdried Fuji A membranes with a 12 um wire-wound coating bar. The coated Fuji A membranes were then exposed to UV irradiation under a power output of $240 \mathrm{~W} / \mathrm{cm}$. The UV generator was a bench top conveyor system (Heraeus Noblelight Fusion UV Inc., USA), in which UV was emitted by a mercury H-bulb (240-280 nm) working at $100 \%$ intensity and a conveyor speed of $30 \mathrm{~m} / \mathrm{min}$ (single pass) under nitrogen atmosphere. The distance between the UV lamp and the membrane was adjusted to 80 $\mathrm{mm}$. The coated membrane was dried at room temperature for $24 \mathrm{~h}$ and stored in $0.5 \mathrm{M}$ $\mathrm{NaCl}$ until further use. 
In order to make a fair comparison with the commercially available monovalent-ionselective membranes, e.g. the Neosepta ACS membrane, which has a highly crosslinked layer on both sides $[5,46]$, we coated our membranes on both sides as well. We then characterized all membranes and tested them in a RED stack. The coating on the side facing the river water compartment provides the greatest benefit as it prevents the back-transfer of divalent ions against their salinity gradient because of their low chemical potential in this compartment [5]. The coating layer on the river water side, where biofoulants are most densely present, also functions as antifouling in the stack. The coating that faces the seawater compartment helps control fouling as well to some extent, but fouling in the seawater compartment is less severe than in the river water compartment.

\subsubsection{Characterization of surface properties}

\subsubsection{SEM-EDX analysis}

Energy-dispersive X-ray spectrometry (EDX) mapping was performed to determine the morphology and the element distribution of carbon, sulfur, chloride and oxygen on the surface of the membranes. Sulfur mapping is useful as the sulfur originates from the sulfonic acid groups in the coating. Surfaces and cross-sections of the vacuum-dried membranes were analyzed with a JEOL JSM-6330F SEM equipped with EDX detector (X-max, Oxford Instruments) operating at $10 \mathrm{kV}$.

\subsubsection{XPS analysis}

All tested membranes were also subjected to X-ray photo-electron spectroscopy (XPS, Kratos Analytical AMICUS) to confirm the integration of the coating layer and obtain an element analysis for $\mathrm{C}, \mathrm{O}, \mathrm{N}, \mathrm{Cl}$, and $\mathrm{S}$ on the membrane surface. We also quantified the atomic percentage of $\mathrm{N}$ from quaternary ammonium groups. Prior to the analysis, we immersed the membranes in a $3 \mathrm{M} \mathrm{NaCl}$ solution, then rinsed them three times with Milli-Q water. The membranes were allowed to dry in a vacuum oven overnight at $30^{\circ} \mathrm{C}$. The XPS analyses were performed with a surface sensitivity of $1-10$ $\mathrm{nm}[47]$.

\subsubsection{Water contact angle}

Water contact angle measurements (VCA Optima, AST Products INC.) were carried out on the membrane surfaces to determine the hydrophilic properties of the original and modified membranes at room temperature. Before the measurements, the 
membranes were rinsed with Milli-Q water and air-dried overnight. Subsequently, the membranes were further dried for $2 \mathrm{~h}$ in a vacuum oven at $30^{\circ} \mathrm{C}$. The static contact angle measurements were performed by placing $1 \mu \mathrm{L}$ of deionized water onto the membrane surface by a computer-controlled syringe. After $5 \mathrm{~s}$, the contact angle of the water drops was recorded. The measurements were repeated five times for every membrane.

\subsubsection{Surface roughness}

To characterize the surface topology of the membranes, optical interferometry measurements were carried out (Wyko NT9100 Optical Profiler, Veeco USA) on dry membrane samples. In view of the semi-transparency of the membranes, we used black silicon rubber to make replicas of the surface texture of the dry membranes. We measured the depth of the replicas at five different locations. The average values of the surface roughness were calculated as Ra (average mean deviation of the profile).

\subsubsection{Electrochemical characterization}

\subsubsection{Current-voltage curves (I-V) and limiting current density (LCD)}

Current-voltage experiments were carried out in a conventional six-compartment cell (Figure 4.6). To evaluate the homogeneity of the membrane surface, chronopotentiometry was performed with a direct current, a $0.1 \mathrm{M} \mathrm{NaCl}$ solution and a solution mixture of $0.05 \mathrm{M} \mathrm{NaCl} / 0.05 \mathrm{M} \mathrm{Na}_{2} \mathrm{SO}_{4}$. We used a $0.5 \mathrm{M} \mathrm{Na}_{2} \mathrm{SO}_{4}$ solution as electrolyte. The solutions for each compartment were circulated individually at a flow rate of $300 \mathrm{~mL} / \mathrm{min}$, and the temperature was $21 \pm 1^{\circ} \mathrm{C}$. The current was increased step by step (i.e. $0,0.05,0.06, \ldots, 0.35 \mathrm{~A}$ every $30 \mathrm{~s}$ ) via a power supply (Delta Elektronika) and the voltage across the membrane under investigation was measured between Haber-Luggin capillaries with a voltage meter. We plotted the current density versus the voltage over the membrane. The detailed description of the method to investigate limiting current density (i.e. LCD, maximum attainable current density of ions limited by concentration polarization and water splitting) is described in detail elsewhere [48]. 


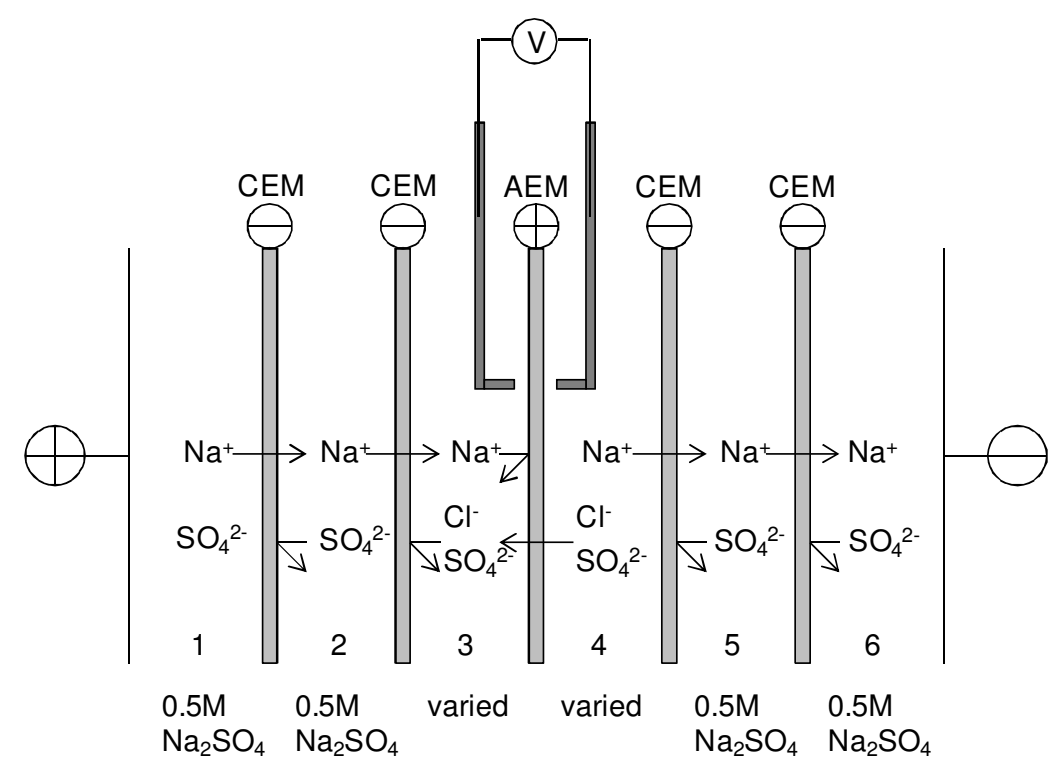

Figure 4.6. Schematic diagram of six-compartment electrolytic cell (AEM = anion exchange membrane, i.e. the membrane under investigation; CEM = cation exchange membrane).

\subsubsection{Transport numbers}

To evaluate the monovalent-ion selectivity of the membranes, bulk transport numbers for the divalent (i.e. sulfate) and monovalent (i.e. chloride) ions were determined. We measured the ionic fluxes of sulfate and chloride through the membranes over time in the same six-compartment cell (Figure 4.6). A solution mixture of $0.05 \mathrm{M} \mathrm{NaCl}$ and $0.05 \mathrm{M} \mathrm{Na}_{2} \mathrm{SO}_{4}$ was used as test solution in compartments 3 and 4 . The applied direct current density was kept constant at $11.4 \mathrm{~mA} / \mathrm{cm}^{2}$ (a total current of $150 \mathrm{~mA}$ ) for each membrane. The solutions for each compartment were circulated individually at a flow rate of $300 \mathrm{~mL} / \mathrm{min}$, and the temperature was $21 \pm 1^{\circ} \mathrm{C}$. Every $20 \mathrm{~min}, 5 \mathrm{~mL}$ of the solution was taken from the dilute (compartment 4) as well as from the concentrate compartment (compartment 3). Ion chromatography (Dionex ICS-5000, Dionex Corp., $\mathrm{CA}$, USA) was used to measure the $\mathrm{Cl}^{-}$and $\mathrm{SO}_{4}{ }^{2-}$ concentrations. The corresponding ion (A) flux through the membrane and the corresponding current in the dilute compartment (compartment 4 in Figure 4.6) were calculated with Equation 4.1 and Equation 4.2, respectively. Once the bulk transport numbers were determined for sulfate and chloride, the relative permselectivity of the membranes (i.e. selectivity of sulfate over chloride) was determined with the aid of Equation 4.4.

\subsubsection{Evaluation of antifouling potential}

The antifouling potential of the modified membrane (Fuji A-mono) and the original membrane (Fuji A) was investigated again using the six-compartment cell shown in 
Figure 4.6. We used a $0.1 \mathrm{M} \mathrm{NaCl}$ solution in the shielding compartments (compartments 2 and 5). A mixture of $0.1 \mathrm{M} \mathrm{NaCl}$ as an electrolyte and $0.00060 \mathrm{M}$ sodium dodecyl sulfate as a foulant was used in compartments 3 and 4 . The applied direct current density was constant at $10 \mathrm{~mA} / \mathrm{cm}^{2}$, providing a total current of 31.4 $\mathrm{mA}$. The solutions for each compartment were circulated individually at a flow rate of $300 \mathrm{~mL} / \mathrm{min}$, and the temperature was $25 \pm 1^{\circ} \mathrm{C}$.

Membrane potential, which is the potential difference between both sides of the membrane, was measured over time to monitor fouling.

\subsubsection{RED performance}

\subsubsection{RED setup}

The performance of the investigated membranes was investigated in a RED stack as previously described [29, 49-50]. We used a PMMA stack (STT Products BV, The Netherlands) containing 2 Ti electrodes (mesh 1.0, $10 \mathrm{~cm}$ x $10 \mathrm{~cm}$ ) coated with $\mathrm{Ir} / \mathrm{Ru}$ (Magneto Special Anodes BV, The Netherlands); Figure 4.7 gives a schematic representation. This stack also contained silicone gaskets of $200 \mu \mathrm{m}$ (Specialty Silicone Fabricators, USA), and non-conductive spacers (Sefar, Nitex 03-300/51, Switzerland). We placed the stack in a thermostated oven kept at $25^{\circ} \mathrm{C}$ (Fisher Scientific).

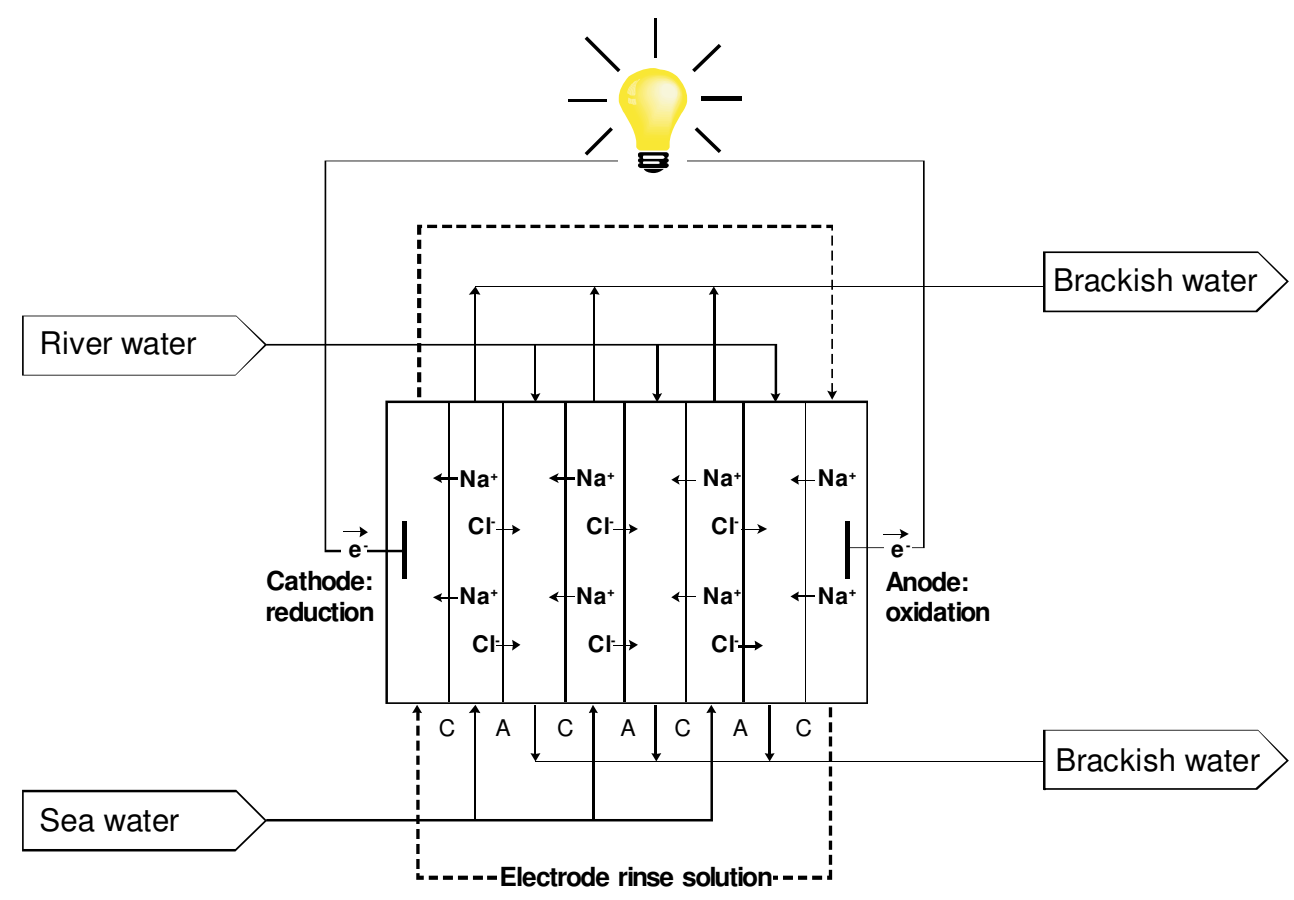

Figure 4.7. Schematic representation of a RED system. 
The feed solutions were artificial seawater (a mixture of $0.45 \mathrm{M} \mathrm{NaCl}$ and $0.05 \mathrm{M}$ $\mathrm{Na}_{2} \mathrm{SO}_{4}$ ) and artificial river water (a mixture of $0.003 \mathrm{M} \mathrm{NaCl}$ and $0.002 \mathrm{M} \mathrm{Na}_{2} \mathrm{SO}_{4}$ [5] and a mixture of $0.012 \mathrm{M} \mathrm{NaCl}$ and $0.002 \mathrm{M} \mathrm{Na}_{2} \mathrm{SO}_{4}$ ), which we prepared with demineralized water. A conductivity meter (WTW, Germany) was used to measure the conductivity of the feed solutions. Peristaltic pumps (Masterflex, Cole Palmer) were used to circulate these feed solutions through the RED stack. During measurements, the electrolyte solution containing $0.05 \mathrm{M}$ potassium hexacyanoferrate (II), $0.05 \mathrm{M}$ potassium hexacyanoferrate (III) and $0.25 \mathrm{M} \mathrm{NaCl}$ were pumped through the electrode compartment at $300 \mathrm{~mL} / \mathrm{min}$. Temperature of these solutions was controlled at $25 \pm 1^{\circ} \mathrm{C}$ during all experiments by means of a thermostated water bath (Colora thermostat WK16).

\subsubsection{Experimental and theoretical power density}

Power density measurements were carried out using a potentiostat (Ivium Technologies, Eindhoven, the Netherlands) and a chronopotentiometry method as described earlier [29]. We corrected the gross power output by subtracting the value of a blank run using only one cation exchange membrane, only installed to prevent undesired effects in the RED stack such as membrane poisoning by hexacyanoferrate compounds in the electrolyte. The theoretical gross power density was calculated (as explained in Section 2.2) and compared to the experimental values.

\subsection{Results and discussion}

\subsubsection{Membrane preparation}

Table 4.2 shows selected properties of the membranes investigated in this study. The Fuji A membrane has a lower area resistance $\left(0.93 \Omega . \mathrm{cm}^{2}\right)$ than the standard-grade AMX membrane and an acceptable permselectivity (89\%). The hydrophilic properties of this membrane (better wettability and adhesion properties, as discussed in more detailed later) allow proper surface modification. Therefore, we selected the Fuji A membrane to be modified toward obtaining improved monovalent-ion selectivity and antifouling potential. 
Table 4.2. Characteristics of the anion exchange membranes investigated in this study [39, 41-42].

\begin{tabular}{lccc}
\hline Membrane $^{\mathrm{a}}$ & $\begin{array}{c}\text { Thickness } \\
(\mu \mathrm{m})\end{array}$ & $\begin{array}{c}\alpha \\
(\%)\end{array}$ & $\begin{array}{c}\mathrm{R} \\
\left(\Omega \cdot \mathrm{cm}^{2}\right)\end{array}$ \\
\hline Fuji A & 123 & $89.0 \pm 0.7$ & $0.93 \pm 0.10$ \\
AMX & 134 & $90.0 \pm 0.8$ & $2.35 \pm 0.05$ \\
Fuji A-mono & 124 & $91.0 \pm 0.8$ & $1.10 \pm 0.10$ \\
ASV (mono) & 110 & $96.0 \pm 0.4$ & $3.07 \pm 0.20$ \\
ACS (mono) & 121 & $94.0 \pm 0.4$ & $4.39 \pm 0.10$ \\
\hline
\end{tabular}

a All membranes investigated are homogenous membranes. ASV, ACS and Fuji A-mono membranes have monovalent-ion selectivity; the other two are standard membranes.

After coating, the obtained Fuji A-mono membranes exhibited a very similar permselectivity and area resistance as the original Fuji A membranes. Owing to the very low thickness of the conductive coating (about $1.5 \mu \mathrm{m}$ ), the area resistance did not change significantly; permselectivity improved very slightly and was comparable to that of the standard AMX membrane. By contrast, commercial monovalent-ionselective membranes (ACS and ASV) have relatively high area resistances due to their highly cross-linked membrane surface structures [43-44]. High area resistance has a detrimental effect on RED performance.

\subsubsection{Characterization of membrane surface}

\subsubsection{SEM-EDX analysis}

Figures 4.8 and 4.9 display the cross-section and surface morphology of the native and coated Fuji A membrane, respectively, including element maps for carbon, sulfur, chloride and oxygen. Figures 4.8a and 4.8c show the original Fuji A membrane before coating. The non-uniform orientation of reinforcement is clearly visible in the crosssections of the membrane. That adds conductive heterogeneity to the membrane as the reinforcement is non-conductive. Figure $4.8 \mathrm{~b}$ and $4.8 \mathrm{~d}$ depict cross-section images of the Fuji A-mono membrane. The coating is hardly visible as it is thin and homogenous, and has a very similar non-porous dense structure as the original membrane material.

Figures 4.8c and 4.8d show EDX mapping for sulfur, overlaid on a cross-section SEM image of (one side of) a native and coated Fuji A membrane, respectively. Red dots indicate sulfur-containing areas. The red dots in the bulk of the original Fuji A 
membrane are due to noise or trace amounts of sulfur (Figure 4.8c). By contrast, the dots are intensely concentrated at the top of the cross-section of the Fuji A-mono membrane (Figure 4.8d); this concentration represents the sulfonic acid functional groups in the coating layer. The coating thickness was determined to be about $1.5 \mu \mathrm{m}$.

Fuji A membranes contain non-woven polypropylene material as reinforcement. The non-conductive fibers of the reinforcement protrude through the bulk membrane. As can be seen, the distribution of sulfur is even in areas with active membrane material, but sulfur is absent in areas with reinforcement material. It means that coating was only successful on active membrane material, not on the non-conductive reinforcement. This is explained by the better wettability and adhesion properties of the active membrane material.
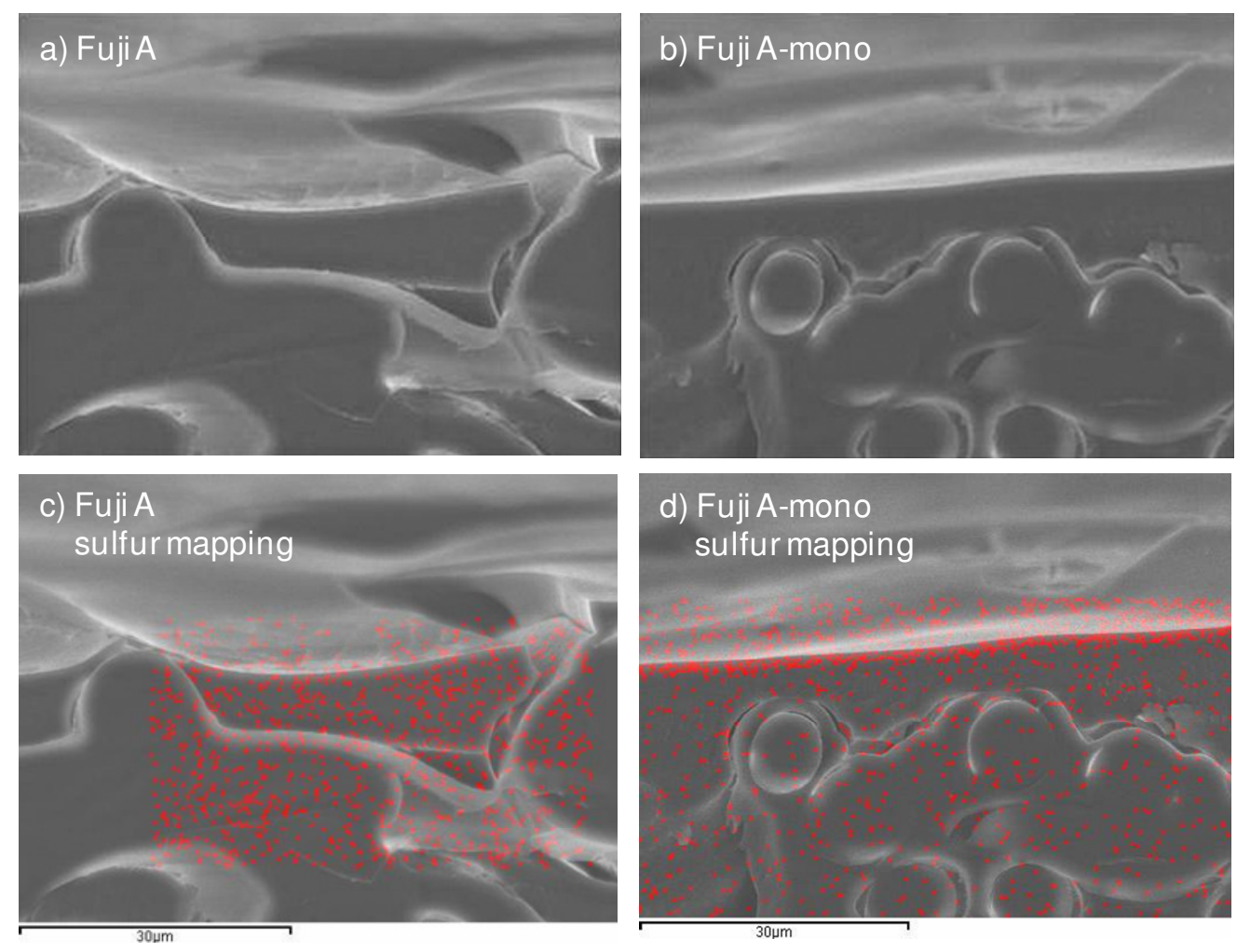

Figure 4.8. EDX sulfur mapping of cross-sections (magnification 2000x): (a) original Fuji A membrane (b) coated Fuji A membrane (= Fuji A-mono) (c) original Fuji A membrane with sulfur mapping (d) coated Fuji A membrane with sulfur mapping (red dots indicating sulfur-containing areas in membrane structure). EDX mapping was performed in only part of the area visible in (c) because the fast-scanning mode was used.

We performed SEM-EDX mapping not only for S but also for C, Cl and O (Figure 4.9) on the Fuji A-mono membrane surface. Figure 4.9a is a surface image of a coated Fuji A membrane (Fuji A-mono). Clearly visible are the polypropylene fibers of the nonwoven reinforcement, which protrude through the membrane, leading to a non-uniform 
surface morphology. The sulfur maps show that sulfur is not homogeneously distributed over the membrane surface; uncoated areas are visible (Figure 4.9b). These uncoated areas can be seen to correspond to locations in which fibers of the reinforcements protrude when Figure $4.9 \mathrm{~b}$ is overlaid on Figure $4.9 \mathrm{a}$, as shown in Figure 4.9c. As in Figure 4.8, the red dots represent sulfur-containing areas on the membrane surface.
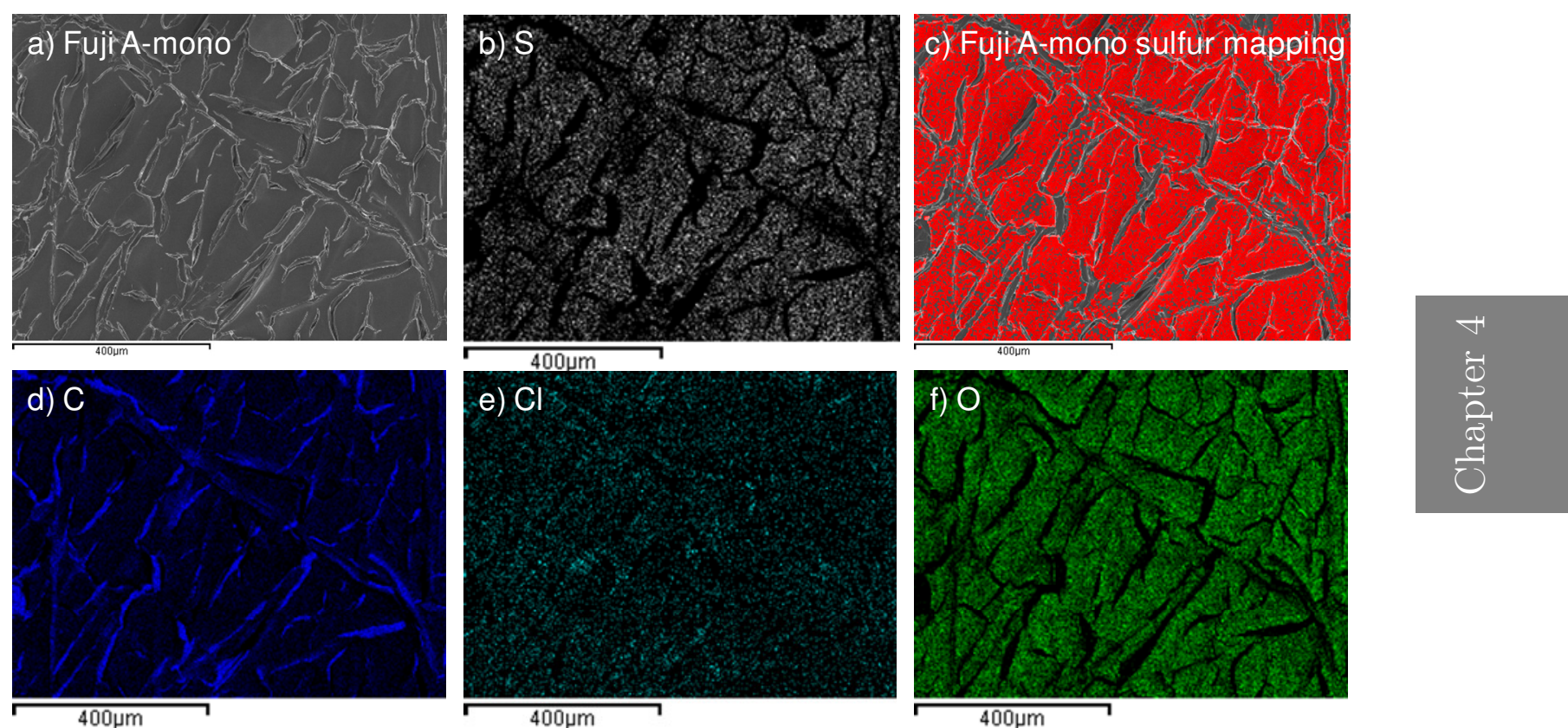

Figure 4.9. EDX element mapping: a) SEM image of Fuji A-mono membrane surface: b) sulfur (S), c) overlay of sulfur map on Fuji A-mono SEM image (red dots representing sulfur-containing areas), d) carbon $(\mathrm{C})$, e) chloride $(\mathrm{Cl})$ and $\mathrm{f}$ ) oxygen $(\mathrm{O})$. The magnification of all the images is $150 \mathrm{x}$.

The uncoated areas in Figure 4.9c coincide with carbon-containing areas (blue) in Figure $4.9 \mathrm{~d}$; the carbon represents the polypropylene material of the membrane reinforcement. The non-homogenous distributions of $\mathrm{Cl}$ and $\mathrm{O}$ coincide with the distribution of $\mathrm{S} ; \mathrm{Cl}$ and $\mathrm{O}$ are also visible only on the active membrane material (Figures $4.9 \mathrm{e}$ and $4.9 \mathrm{f}$ ). $\mathrm{Cl}$ is a counter ion and is therefore only present at trace levels at the surface, as the coating layer is covering the active membrane material. Oxygen, on the other hand, is also present in the coating (AMPS and MBA).

\subsubsection{XPS analysis}

We carried out XPS analysis to investigate the chemical composition and verify the reaction on the membrane surface (up to a depth of $10 \mathrm{~nm}$ [47]). Table 4.3 shows the atomic percentages at the surface of all tested membranes. We determined nitrogen related to the functional groups of the anion exchange membranes $(\mathrm{N}+)$ (quaternary amine) separately from uncharged nitrogen $(\mathrm{N})$ such as nitrogen in secondary amine 
form. The binding energy for the charged $\mathrm{N}+$ group is higher than the binding energy for a non-charged nitrogen functionality [51], leading to a difference of at least $3 \mathrm{eV}$ in XPS spectra. By using peak curve fitting, we separated the regular $\mathrm{N}$ 1s peak and the $\mathrm{N}+$ peak. We also determined atomic percentages of other relevant elements $(\mathrm{C}, \mathrm{O}, \mathrm{Cl}$ and S) (Table 4.3).

Table 4.3. Element composition of membrane surface obtained from XPS analysis.

\begin{tabular}{lccccccc}
\hline \multirow{2}{*}{ Membrane } & \multicolumn{7}{c}{ Element contents (\%) } \\
\cline { 2 - 8 } & $\mathrm{N}+{ }^{\mathrm{a}}$ & $\mathrm{N} 1 \mathrm{~s}^{\mathrm{b}}$ & $\mathrm{Cl} \mathrm{2p}$ & $\mathrm{S} \mathrm{2p}$ & $\mathrm{C} \mathrm{1s}$ & $\mathrm{O} 1 \mathrm{~s}$ & $\mathrm{C} / \mathrm{O}$ \\
\hline Fuji A & 2.2 & 5.3 & 1.6 & 0.38 & 70.8 & 20.0 & 3.5 \\
AMX & 1.1 & 1.8 & 2.2 & 0.54 & 77.0 & 18.0 & 4.3 \\
Fuji A-mono & $<0.2$ & 5.3 & $<0.08$ & 1.75 & 65.1 & 27.9 & 2.3 \\
ACS (mono) & 1.5 & 2.1 & 2.6 & 0.50 & 77.0 & 17.0 & 4.5 \\
ASV (mono) & 0.8 & 1.7 & 1.8 & 0.47 & 75.0 & 21.1 & 3.6 \\
\hline
\end{tabular}

${ }^{\mathrm{a}}$ Nitrogen from quaternary ammonium groups, ${ }^{\mathrm{b}}$ Uncharged nitrogen.

We found that the native Fuji A membrane has a higher surface charge (quaternary ammonium, $\mathrm{N}+$ ) than the other commercial standard-grade membranes (i.e. Neosepta AMX). That is favorable for adherence of oppositely charged polyanions (electrostatic affinity). On the other hand, the surface of the Fuji A membrane surface has a higher percentage of uncharged $\mathrm{N}$ than the standard AMX membrane. That might be because the Fuji A membrane might have some $\mathrm{N}$ containing components in addition to quaternary amines, whereas the AMX membrane lacks these species.

In principle, the number of counter ions (e.g. chloride) is expected to match to the number of functional groups (e.g. quaternary ammonium). Although the percentage quaternary amine in the Fuji A membrane is two times higher than that of the AMX membrane, $\mathrm{Cl}$ as counter ion is slightly lower in the Fuji A membrane than in the AMX membrane. This might be related to the relatively more conductively heterogeneous character of the surface of the native Fuji A membrane. As expected, S is only present in trace amounts, since both membranes are standard-grade membranes without any coating. In addition, the ratio of $\mathrm{C}$ to $\mathrm{O}$ at the membrane surface is lower for the Fuji A membrane than for the AMX membrane. This may be related to the $\mathrm{O}$ content of the acrylamide $\left(\mathrm{C}_{3} \mathrm{H}_{5} \mathrm{NO}\right)$ species present in the Fuji A polymer matrix.

After modification of the Fuji A membrane, the atomic percentage of $\mathrm{N}$ in quaternary ammonium groups $(\mathrm{N}+)$ at the surface was much lower (as the coating contains no quaternary ammonium groups but sulfonic acid groups). Uncharged nitrogen did not 
exhibit a significant change since the coating contains secondary amines from AMPS and MBA.

Obviously, these element data provide information related to the effects and the successfulness of the coating process and confirm the successful integration of the AMPS coating layer on the active groups of the membrane material at the surface.

The surface ratio of $\mathrm{C}$ to $\mathrm{O}$, which is approximately 3.5 for the unmodified Fuji $\mathrm{A}$ membrane, became 2.3 after coating. That might indicate a decrease in the $\mathrm{C}$ amount (i.e. corresponding to a decreasing ratio of $\mathrm{C}$ to $\mathrm{O}$ ) which is mostly related to the $\mathrm{C}$ in the polypropylene filaments of the reinforcement structure. It could indicate that a trace of coating is present in the areas where the reinforcement reaches the surface.

The percentage of carbon atoms differs between the Fuji A-mono membrane and the other monovalent-selective membranes (ACS and ASV). The ratio of $\mathrm{C}$ to $\mathrm{O}$ of the Fuji A-mono membrane is lower than that of the commercial counterparts; the polypropylene reinforcement represents a significant amount of the total carbon present on the surface because this non-woven reinforcement material protrudes through the active membrane material. For the ACS and ASV membranes, the carbon content is generally related to the polymeric membrane material, as the woven support (which is the main reinforcement used in these membranes) is entirely covered by active membrane material. The oxygen content of the Fuji A-mono membrane surface mainly represents the oxygen included in acrylamide $\left(\mathrm{C}_{3} \mathrm{H}_{5} \mathrm{NO}\right)$ and sulfonic acid ($\mathrm{SO}_{3}$ ) groups present in the polymer matrix of the coating. That oxygen might cause the ratio of $\mathrm{C}$ to $\mathrm{O}$ to be smaller than that of the ACS and ASV membranes. It is hard to identify the oxygen-containing compounds of the latter solely on the basis of XPS measurements as insufficient information is available about the composition of these membranes.

The Fuji A-mono membrane carried a lot less quaternary amine $(\mathrm{N}+)$ on the surface than the commercial monovalent-ion-selective ACS and ASV membranes as well as the uncoated Fuji A membrane and the AMX membrane (Table 4.3). The percentage of secondary amine $(\mathrm{N})$ is much lower for the ASV and ACS membranes (as well as the AMX membrane), which is explained by the chemistry of these membranes [42-43].

Because of the coating on the Fuji A-mono membrane, $\mathrm{Cl}$ as counter ion is negligible on the membrane surface relative to the ASV and ACS membranes. Regarding sulfur, the ASV and ACS membranes have only trace amounts of sulfur, whereas the Fuji Amono membrane has more sulfur on the surface, which is attributable to the polyanion 
coating material. This confirms that the monovalent-ion selectivity of the ASV and ACS membranes is not provided by a sulfur-containing polyanion coating but by another technique such as coating with a thin layer that has a high crosslinking density [43].

\subsubsection{Water contact angle}

We carried out water contact angle measurements for all membranes to determine their wettability (Table 4.4). In aqueous applications, the more hydrophilic the membrane surface is, the less prone it is to fouling [8]. It is therefore important to ascertain whether the hydrophilicity of the membranes is changed by our modification to determine its antifouling potential.

Table 4.4. Contact angle measurements.

\begin{tabular}{lc}
\hline Membrane & $\begin{array}{c}\text { Contact angle } \\
\text { (degree) }\end{array}$ \\
\hline Fuji A & $63.6 \pm 1.5$ \\
AMX & $62.8 \pm 4.7$ \\
Fuji A-mono & $23.5 \pm 3.9$ \\
ASV (mono) & $67.1 \pm 2.0$ \\
ACS (mono) & $57.1 \pm 5.7$ \\
\hline
\end{tabular}

The contact angle of the standard Fuji A membrane is very similar to that of the standard Neosepta AMX membrane implying that these membranes have very similar hydrophilic properties (Table 4.4). After modification, the contact angle of the modified membrane (Fuji A-mono) had decreased significantly (from $\sim 64^{\circ}$ to around $\sim 24^{\circ}$; see Table 4.4); this is caused by the increase in the number of ionic groups by the addition of the negatively charged coating layer (sulfonic acid groups). Quaternary ammonium groups might also contribute to the total surface charge; however, this contribution can be estimated as very minor because there is only a trace amount of quaternary amines on the modified membrane surface as determined by XPS (Table 4.3). The strongly decreased wetting angle confirms that, besides monovalent selectivity, the coating also added antifouling potential to the Fuji A membranes. The wettability of the Fuji A-mono membranes is far better than that of the commercial counterparts (ACS and ASV), which are not produced specifically to aim at any antifouling qualities. 


\subsubsection{Surface roughness}

We used optical interferometry techniques to investigate surface roughness. A certain degree of surface roughness can have advantages in RED systems, as surface morphologies that promote mixing at the membrane-solution interface reduce the boundary layer resistance, which usually leads to a higher power density [52-53]. However, this requires roughness being usually at much higher dimensional scales than those observed here. On the other hand, surface roughness is also a component of hydrophilicity and therefore plays a role in fouling. Specifically, colloidal fouling is usually more pronounced on rough membrane surfaces than on membranes with a glossy surface $[11,54]$.

Figure 4.10 displays the average values of surface roughness (Ra, average mean deviation of the profile) as 3D images of the membrane surface morphology (i.e. hilland-valley surface structure) for the original Fuji A membrane, other commercial membranes and our coated membrane (Fuji A-mono). Red areas are areas with positive values, i.e. 'hills' and blue areas represent negative values, i.e. 'valleys'.

It is clear from Figure 4.10 that the standard Fuji A membrane has a higher surface roughness $(\mathrm{Ra}=5.8)$ than the standard AMX membrane $(\mathrm{Ra}=3.1)$. The high surface roughness of the Fuji membrane is mainly related to the uneven distribution of the fibers of the non-woven reinforcement (Figure 4.9). A certain level of roughness might be advantageous for static adhesion of the coating layer; high roughness results in a larger contact area between coating material and membrane surface. The coating might preferentially accumulate in the valleys of rougher surfaces, and have the effect of smoothing the surface.

After the Fuji A membrane was coated, the roughness of the resulting Fuji A-mono membrane was indeed lower because of the smoothing effect of the coating layer. This decrease of roughness of around $2 \mu \mathrm{m}$ might be too small to lead to a recognizable advantage when it comes to fouling prevention. However, this smoothing effect of the coating affects the I-V curves as will be discussed in Section 4.3.1.

The AMX membrane includes patterned spacers, creating relatively wide hills with a smoother surface (Figure 4.10b). Furthermore, the commercially available monovalention-selective membranes (ASV and ACS) have a relatively low surface roughness because of their uniform woven reinforcement when compared with the Fuji A-mono membrane. The highly cross-linked coating layer of these membranes is also expected to contribute to the lower surface roughness. 

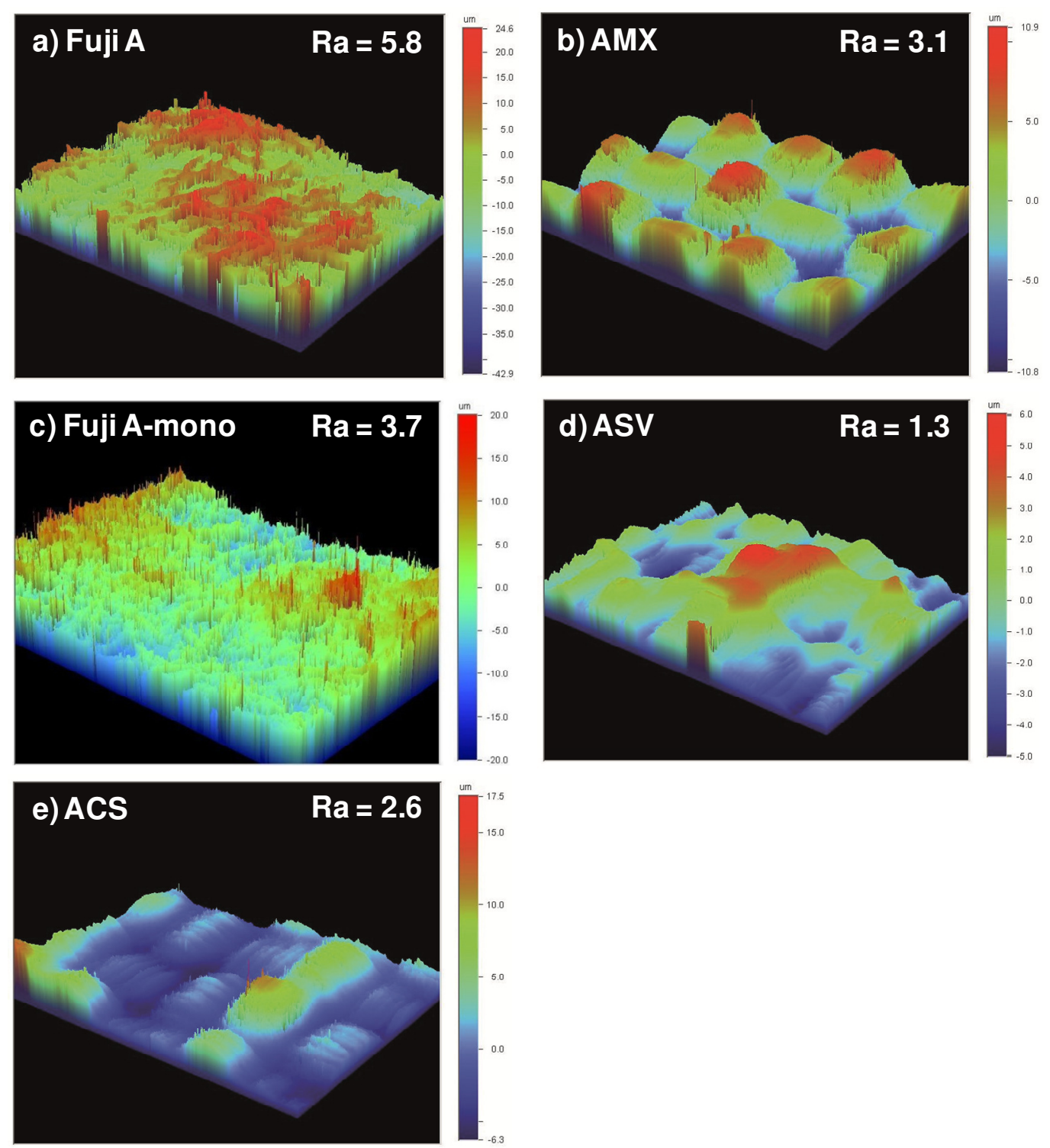

Figure 4.10. Surface roughness for membranes: (a) Fuji A, (b) AMX, (c) Fuji A-mono (d) ASV and (e) ACS; dimensions of the investigated membrane: 1257x942 $\mu \mathrm{m}$.

\subsubsection{Electrochemical characterization}

\subsubsection{Current-voltage (I-V) curves and limiting current density (LCD)}

The investigation of $\mathrm{I}-\mathrm{V}$ behavior of membranes aims generally to obtain information about the surface properties (e.g. ion transport properties, surface homogeneity). In practical RED applications, the maximum power density is obtained far below the limiting current of the ion exchange membranes where undesired effects such as water splitting and concentration polarization do not occur. Therefore, the area above the 
limiting current region in $\mathrm{I}-\mathrm{V}$ curves might be of more interest for conventional electrodialysis (ED) applications than for RED.

We determined the plateau length for each membrane to investigate the homogeneity of the surface (Figure 4.11). Shorter plateau length indicates a less active electroconvective effect, i.e. the smoother the membrane, the longer the plateau. Figure 4.11 shows the I-V relationships of the investigated membranes in a test solution of a) $0.1 \mathrm{M} \mathrm{NaCl}$ and b) a mixture of $0.05 \mathrm{M} \mathrm{NaCl}$ and $0.05 \mathrm{M} \mathrm{Na}_{2} \mathrm{SO}_{4}$ using the sixcompartment cell shown in Figure 4.6.
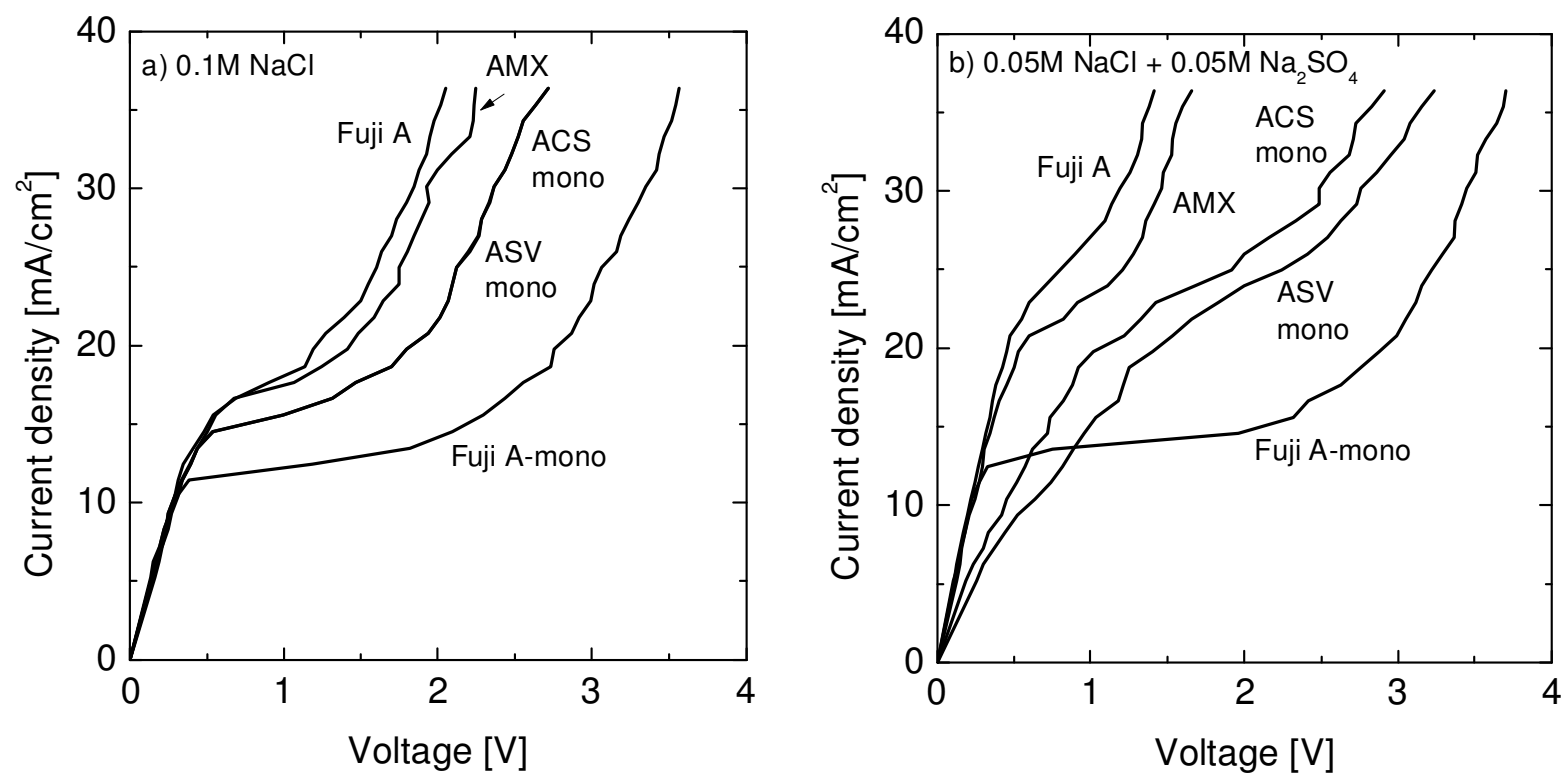

Figure 4.11. $\mathrm{I}-\mathrm{V}$ data of anion exchange membranes in a) $0.1 \mathrm{M} \mathrm{NaCl}$ and b) a mixture of $0.05 \mathrm{M}$ $\mathrm{NaCl}$ and $0.05 \mathrm{M} \mathrm{Na}_{2} \mathrm{SO}_{4}$. Membranes tested: Fuji A (standard) and Fuji A-mono, ASV, ACS, AMX (standard).

Figure $4.11 \mathrm{a}$ presents the $\mathrm{I}-\mathrm{V}$ curves of the membranes in a pure $0.1 \mathrm{M} \mathrm{NaCl}$ solution. The Fuji A membrane has the shortest plateau length indicating enhanced electrotransport of ions resulting in concentration polarization (i.e. the depletion of counter ions at the membrane-solution interface resulting in high membrane potentials) at a lower potential. A shorter plateau length may arise from several causes. One is the conductive heterogeneity, which is basically the non-uniform distribution of the conducting sites of the membrane (i.e. active membrane material). For the Fuji A membrane, the non-uniform distribution of the conducting sites is due to the non-woven inert reinforcement inside the membrane where ionic transport is not possible; this makes the macroscopically homogeneous Fuji A membrane microscopically heterogeneous as shown in Figure 4.3b. The standard-grade AMX 
membrane has a similar I-V curve as the Fuji A membrane, the former having an inert PVC additive inside the membrane material [55] as well as non-conductive reinforcements inside the membrane. These features constitute a microscopically heterogeneous membrane structure leading to hydrodynamic instabilities, thus a short plateau length.

When the Fuji A membrane is coated, its plateau length increases almost threefold (Figure 4.11a) because the coating hides the original membrane surface's heterogeneities. These results are in very good agreement with work by Balster et al. who coated the commercial CMX membrane with the cation polymer PEI [31] and observed an almost twofold increase of the plateau length.

Surface roughness is another factor that leads to shorter plateau lengths, since geometrical heterogeneity also promotes conductive heterogeneity [31]. Balster et al. studied 40-um-deep corrugations tailored on a SPEEK membrane surface, and observed a noticeable decrease in the plateau length when the lines of the corrugations were parallel to the fluid flow [31]. Rubinstein et al. predicted a shortening of the plateau length if the height of the undulations matches the boundary layer thickness $[34,56]$, which is in the range of 50 to $500 \mu \mathrm{m}$, depending on conditions [57]. On the other hand, Pismenskaya et al. studied the effect of cavities on the membrane surface with a depth of as little as $2 \mu \mathrm{m}$ on the onset of electroconvection and found that the geometry of the cavities gives rise to electric force at cavity's walls where electroconvection is promoted [33]. Although experimental verification has not been performed yet, Rubinstein et al. estimated that a 10\% increase in the surface roughness results in a $30 \%$ decrease of the plateau length [56].

Thus, in view of these findings and discussions, the decrease in surface roughness and elimination of conductive heterogeneities on the membrane surface should provide a wider I-V plateau after coating of the membranes. Indeed, an increase in plateau length was observed for the Fuji A-mono membrane relative to the uncoated version of this membrane (Figure 4.11). The surface roughness (Ra) decreased from 5.8 to $3.7 \mu \mathrm{m}$ (Figure 4.10), which is a decrease of $36 \%$. Although it may not be the only factor that affects electroconvection, the decrease of the surface roughness likely contributed most to the delayed onset of the overlimiting region in the I-V curves.

Surface hydrophobicity/hydrophilicity is a third important parameter that affects the development of electroconvection [33]. As the membrane became more hydrophilic after coating (determined by contact angle measurements; see Table 4.4), the limiting current density and the overlimiting current density at the same potential difference 
diminished [33]. That behavior corresponds to an increase in the plateau length. Improved hydrophilicity of the membrane surface means that there is no significant repulsion of water molecules by the surface, resulting in a more stagnant water flow with fewer hydrodynamic instabilities [33]. As expected the plateau length became broader after the Fuji A membrane was coated (Figure 4.11a).

The I-V behavior of the commercial monovalent-ion-selective ACS and ASV membranes overlapped when a pure $\mathrm{NaCl}$ solution was used as test solution (Figure 4.11a). That indicates that the ionic-transport properties of these membranes are quite similar.

Figure $4.11 \mathrm{~b}$ shows the $\mathrm{I}-\mathrm{V}$ behavior of the membranes in a solution containing also divalent ions, i.e. sulfate. Relative to the plateau lengths for a pure $\mathrm{NaCl}$ solution, slightly broader plateaus were observed for all investigated membranes. This indicates lower transport of sulfate from the diffusive boundary layer to the bulk membrane matrix resulting in concentration polarization at higher potentials. Also, because of slower depletion of the counter ion concentration $\left(\mathrm{Cl}^{-}\right)$, a higher potential was required to obtain a zero counter ion concentration at the membrane-solution interface.

Table 4.5 shows the LCD data for the membranes tested in pure $0.1 \mathrm{M} \mathrm{NaCl}$ and in a mixture of $0.05 \mathrm{M} \mathrm{NaCl}$ and $0.05 \mathrm{M} \mathrm{Na}_{2} \mathrm{SO}_{4}$.

Table 4.5. Limiting current density (LCD) data of test membranes.

\begin{tabular}{lcc}
\hline & \multicolumn{2}{c}{$\mathrm{LCD}\left(\mathrm{mA} / \mathrm{cm}^{2}\right)$} \\
Membrane & $0.1 \mathrm{M} \mathrm{NaCl}$ & $0.05 \mathrm{M} \mathrm{NaCl} /$ \\
& & $0.05 \mathrm{M} \mathrm{Na}_{2} \mathrm{SO}_{4}$ \\
\hline Fuji A & $13.70 \pm 0.01$ & $21.08 \pm 0.53$ \\
AMX & $14.81 \pm 0.00$ & $19.92 \pm 0.00$ \\
Fuji A-mono & $11.36 \pm 0.01$ & $12.79 \pm 0.00$ \\
ACS (mono) & $13.95 \pm 1.01$ & $19.49 \pm 0.49$ \\
ASV (mono) & $13.95 \pm 1.01$ & $19.77 \pm 0.10$ \\
\hline
\end{tabular}

As seen in Table 4.5, LCD values of standard grade membranes (Fuji A and Neosepta AMX) are similar in the $\mathrm{NaCl}$ solution and also in the sulfate-containing solution (higher in the latter). The commercial monovalent-ion-selective membranes (ACS and ASV) also have similar LCD values in both types. All membranes have higher LCD values for the sulfate-containing solution than for the pure $\mathrm{NaCl}$ solution (Table 4.5). This is due to the lower transport rate of sulfate in the membrane as LCD is an 
inverse function of the difference between the counter ion transport numbers in the membrane and in the bulk solution [48].

Since LCD increases with increasing ionic transport inside the membrane, we expected the LCD to become lower after coating; this was indeed the case (Table 4.5). This difference was greater when divalent sulfate ions were used in the solution (Table 4.5), with the Fuji A membrane having the highest and the Fuji A-mono the lowest value. When sulfate ions are used, the Fuji A-mono membrane has repulsive effects towards sulfate and ionic transport inside the membrane is mainly due to the monovalent chloride counter ions. On the other hand, with the standard Fuji A membrane, the ionic transport rate is dependent on both sulfate and chloride; this is lower for sulfate ions due to the lower transport properties compared with chloride.

\subsubsection{Transport numbers}

Another method to determine the monovalent selectivity of membranes is to calculate bulk transport numbers of monovalent ions (e.g. chloride) and divalent ions (e.g. sulfate) based on ionic fluxes (Equation 4.1). We determined the ionic fluxes of sulfate and chloride and calculated transport numbers (Equation 4.3 and Table 4.6)) for each membrane under an applied direct current density held constant at $11.4 \mathrm{~mA} / \mathrm{cm}^{2}$ (a total current of $150 \mathrm{~mA}$ ) which is about $80 \%$ of the limiting current density of the Fuji A membrane (Table 4.5). We then calculated the relative permselectivity $\left(\mathrm{P}_{\mathrm{Cl}}^{\mathrm{SO}_{4}}\right)$ of the divalent ion (sulfate) to monovalent ion (chloride), using the transport number data of Table 4.6. The lower the $\mathrm{P}_{\mathrm{Cl}}^{\mathrm{SO}_{4}}$ value becomes, the better the monovalent-ion selectivity of the considered membrane is.

Table 4.6. Bulk transport numbers for anion exchange membranes.

\begin{tabular}{lccccc}
\hline \multicolumn{1}{c}{ Membrane } & $\begin{array}{c}\mathrm{J}_{\mathrm{Cl}} \\
\left(10^{-8} \mathrm{~mol} /\left(\mathrm{cm}^{2} \mathrm{~s}\right)\right)\end{array}$ & $\begin{array}{c}\mathrm{J}_{\mathrm{SO} 4} \\
\left(10^{-8} \mathrm{~mol} /\left(\mathrm{cm}^{2} \mathrm{~s}\right)\right)\end{array}$ & $\mathrm{t}_{\mathrm{Cl}}$ & $\mathrm{t}_{\mathrm{SO} 4}$ & $\mathrm{P}_{\mathrm{Cl}}^{\mathrm{SO}_{4}}$ \\
\hline Fuji A & $6.15 \pm 0.01$ & $5.32 \pm 0.02$ & 0.519 & 0.449 & 0.841 \\
AMX & $6.56 \pm 0.00$ & $5.58 \pm 0.00$ & 0.553 & 0.471 & 0.832 \\
Fuji A-mono & $6.31 \pm 0.00$ & $4.90 \pm 0.00$ & 0.533 & 0.413 & 0.755 \\
ASV (mono) & $6.88 \pm 0.00$ & $5.18 \pm 0.01$ & 0.581 & 0.438 & 0.730 \\
ACS (mono) & $6.23 \pm 0.00$ & $4.55 \pm 0.00$ & 0.526 & 0.384 & 0.727 \\
\hline
\end{tabular}

J: ionic flux; t: bulk transport number; P: relative permselectivity (monovalent-ion selectivity)

The Fuji A membrane is a standard membrane without any specific monovalent-ion selectivity. Although the chloride and sulfate fluxes of the Fuji A membrane are lower than that of the standard-grade AMX membrane, it is clear that Fuji A membrane is 
similar when the ratio of the ionic fluxes of sulfate and chloride is considered (Table 4.6).

The Fuji A-mono membrane has improved monovalent-ion selectivity with a relative permselectivity $\left(\mathrm{P}_{\mathrm{Cl}}^{\mathrm{SO}_{4}}\right)$ of 0.755 which is lower than that of the original uncoated Fuji A membrane, 0.841. It is also obvious from the flux values that the sulfate flux of the Fuji A-mono membrane was reduced. The negatively charged coating on the membrane repels oppositely charged ions, i.e. sulfate and chloride. This electrostatic repulsion is greater for divalent ions (though also depending on size), which provides a separation due to electrical forces rather than a steric repulsion mechanism based on ion size [44] (such as accomplished by highly crosslinked coatings). In other words, the charged layer affects the permeability of divalent ions by rejecting them more intensively than monovalent ions.

The ACS membrane has the highest monovalent-ion selectivity with the lowest relative permselectivity $\left(\mathrm{P}_{\mathrm{Cl}}^{\mathrm{SO}_{4}}\right)$ value of 0.727 . This membrane has also the lowest sulfate flux of $4.55 \cdot 10^{-8} \mathrm{~mol} /\left(\mathrm{cm}^{2} \mathrm{~s}\right)$. This might be due to the highly cross-linked surface structure as indicated by Saracco et al. that decreases the ion flux of divalent ions [43]. The ASV membrane is another high-performance monovalent-ion-selective membrane available in the market; although the chloride flux of this membrane is the largest, its monovalent-ion selectivity is comparable to that of the ACS membrane (Table 4.6). According to the literature, the monovalent-anion selectivity of the ASV membrane comes from the coating of a highly crosslinked resin on its surface similar to the mechanism of monovalent-ion selectivity of the ACS membrane [44].

As a general trend, we observed that monovalent-ion selectivity increases (i.e. $\mathrm{P}_{\mathrm{Cl}}^{\mathrm{SO}_{4}}$ value decreases) with increasing area resistance (Tables 4.2 and 4.6). However, the ion flux values and the corresponding transport numbers of sulfate do not decrease with increasing area resistance. That could be related to membrane coatings with different degrees of crosslinking resulting in differences in monovalent-ion selectivity. Moreover, only the Fuji A-mono membrane has a relatively high monovalent-ion selectivity with a relatively low area resistance, $1.10 \Omega \cdot \mathrm{cm}^{2}$ (Table 4.2 ). The conductive coating is so thin $(1.5 \mu \mathrm{m})$ that it does not lead to an increase in area resistance.

The Fuji A-mono membrane has an 8\%-reduced sulfate flux (from 5.32 to $4.90 \cdot 10^{-8}$ $\left.\mathrm{mol} /\left(\mathrm{cm}^{2} \mathrm{~s}\right)\right)$ provided by the coating layer. This corresponds to a decrease of the $\mathrm{P}_{\mathrm{Cl}}^{\mathrm{SO}_{4}}$ value of $10 \%$. When the relative permselectivities of the monovalent-ion-selective membrane ACS and the standard AMX membrane are compared, the $\mathrm{P}_{\mathrm{Cl}}^{\mathrm{SO}_{4}}$ value exhibits a decrease of almost $13 \%$. Thus, the monovalent-ion selectivity of the Fuji A- 
mono membrane can be considered in the same order as that of the commercially available ACS membrane.

\subsubsection{Evaluation of antifouling potential}

To evaluate the antifouling potential of the anion exchange membranes after coating, we looked at the transition time, i.e. the time elapsed before the onset of fouling, under constant direct current. Figure 4.12 shows the membrane potential (i.e. potential difference between both sides of the membrane, $\Delta \mathrm{E}$ ) of the original Fuji A membrane and the modified membrane (Fuji A-mono) over time.

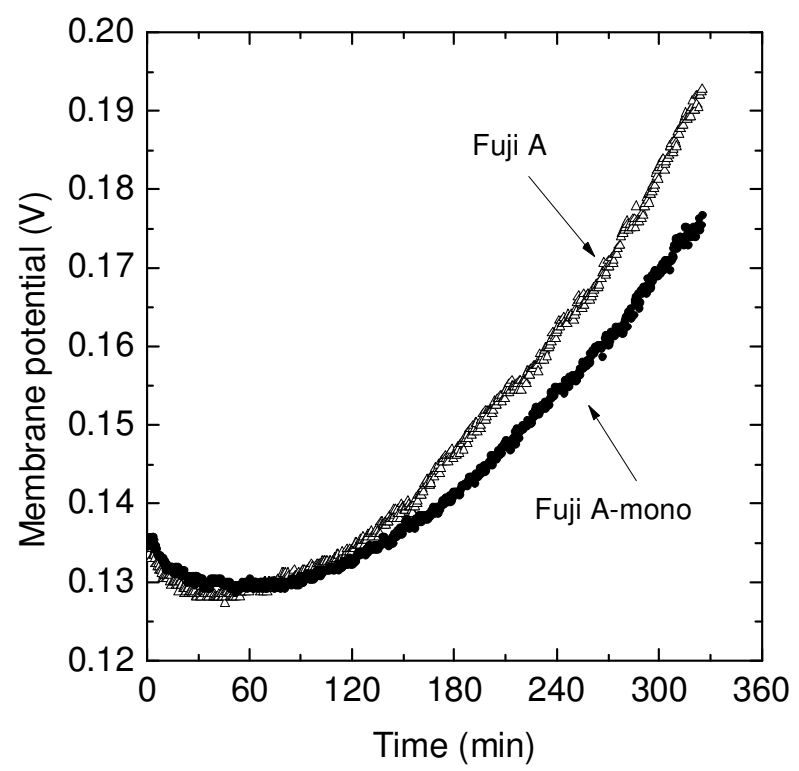

Figure 4.12. Effect of surface coating on antifouling potential of Fuji A membrane. Membrane potential is the potential difference between both sides of membrane as a function of time. The feed solution contained $0.01 \mathrm{M} \mathrm{NaCl}$ and $0.00060 \mathrm{M}$ sodium dodecyl sulfate.

Figure 4.12 shows that, as expected, the Fuji A-mono membrane has a lower tendency for fouling because of its anionic coating and subsequent electrostatic repulsion. The transition time for the modified membrane was found to be 90 min whereas it was 50 min for the original unmodified Fuji A membrane.

Another indication of the fouling tendency of membranes is the slope of membrane potential vs. time after the transition time [10]. Higher slopes indicate that fouling is more probable and severe whereas it is less pronounced when the slope is relatively low, i.e. the increase of membrane potential over time is slow. The slope of membrane potential vs. time curve $(\Delta \mathrm{E} / \mathrm{t})$ also shows that the modified membrane is less prone to fouling as it is less steep compared with the slope of the curve of the original membrane (Figure 4.12). However, the difference between the fouling tendencies of the 
original and the modified membranes does not appear to be large. A possible reason for this behavior may be enhanced adhesion of the foulant to the membrane surface over time because of a reduction in the repulsive effects of the coating after fouling has started. Another reason for the small difference in the fouling tendencies of the original and the modified membrane might be related to the critical micelle concentration CMC (i.e. solubility) of SDS in the solution. It is known from the literature that fouling takes place immediately in electrochemical processes such as electrodialysis when the SDS concentration becomes higher than the CMC because the formation of micelles in the solution promotes fouling [14, 38]. Depending on various analytical techniques, CMC of the SDS solution is mentioned as $1.3-8.3 \mathrm{mM}$ at $25^{\circ} \mathrm{C}$ in the literature [58-59]. We did not measure the CMC of the used solution in this work, but the concentration of SDS may have approximated this value.

In addition to the charge of the membrane surface, also the hydrophilicity determines the antifouling potential of anion exchange membranes. As the contact angle of the Fuji A membranes had decreased significantly (from $63.6^{\circ}$ to around $23^{\circ}$ ) after the surface modification, the membrane hydrophilicity increased resulting in improved antifouling potential (Table 4.4). This is also in good agreement with the work performed by Mulyati et al. in which decrease of transition time was monitored as the contact angle of the used membranes increased [8]. It is clear that the anionic coating we applied to the Fuji A membranes indeed yielded a simultaneous improvement of antifouling potential and monovalent-anion selectivity.

\subsubsection{RED performance}

We compared the RED performance of the coated (Fuji A-mono) anion exchange membranes having specific monovalent-ion selectivity with that of commercial membranes. Specifically, we looked at the gross power densities of the monovalent-ionselective Neosepta ACS and Fuji A-mono membranes and the values of their standard counterparts, the Neosepta AMX and Fuji A membranes, respectively. Two tests were performed using artificial river water with different molar ratios of monovalent to divalent ion $\left(\left[\mathrm{Cl}^{-}\right] /\left[\mathrm{SO}_{4}{ }^{2-}\right]\right)$ of 1.5 and 6 , respectively and a seawater composition of 0.45 $\mathrm{M} \mathrm{NaCl}$ and $0.05 \mathrm{M} \mathrm{Na}_{2} \mathrm{SO}_{4}$. (Figure 4.13). The Neosepta CMX membrane was used as reference cation exchange membrane in the RED stack for each test. 

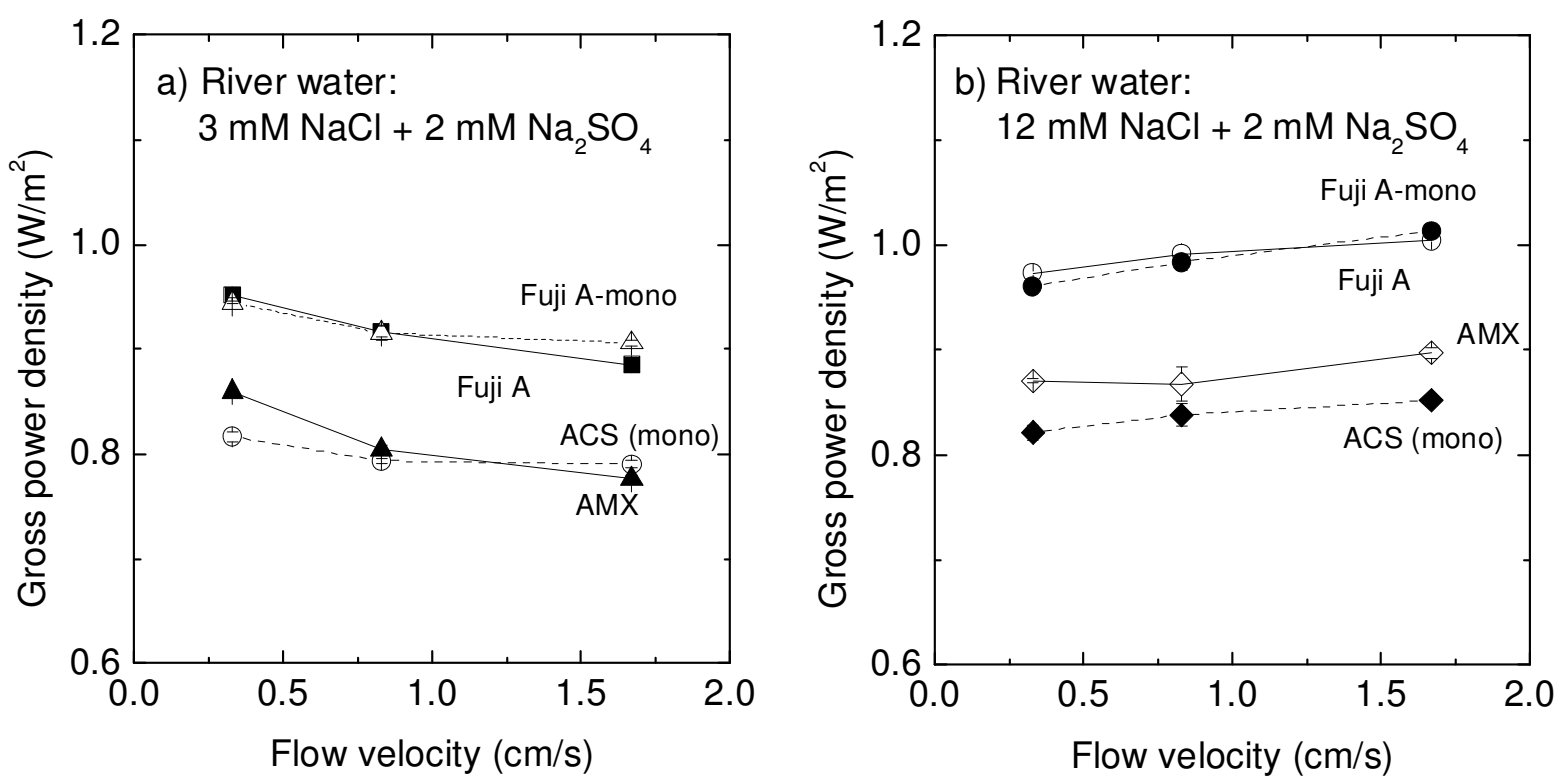

Figure 4.13. RED performance of monovalent-ion-selective anion exchange membranes using river water compositions of (a) $3 \mathrm{mM} \mathrm{NaCl}$ and $2 \mathrm{mM} \mathrm{Na}_{2} \mathrm{SO}_{4}$ and (b) $12 \mathrm{mM} \mathrm{NaCl}$ and $2 \mathrm{mM} \mathrm{Na}_{2} \mathrm{SO}_{4}$. Seawater composition: $0.45 \mathrm{M} \mathrm{NaCl}$ and $0.05 \mathrm{M} \mathrm{Na}_{2} \mathrm{SO}_{4}$.

As can be seen in Figure 4.13, the Fuji A and Fuji A-mono membranes performed better than the ACS and AMX membranes. Regardless of monovalent selectivity, the electrical resistance of these membranes appears to be dominating overall RED performance, i.e. gross power density. The benefit of using Fuji A-mono membranes in RED is that the area resistance did not increase significantly after coating Fuji A membranes due to the low thickness of the conductive coating layer as already mentioned (Table 4.2). Besides, the permselectivity increased very slightly from 89 to 91\%. In conclusion, the use of these Fuji A membranes is advantageous in RED applications, and results in the higher gross power densities.

On the other hand, there is no significant difference between the gross power densities of the monovalent-ion-selective Fuji A-mono membrane and the standard Fuji A membrane. A similar trend is valid for the Neosepta membranes (ACS and AMX); the standard-grade AMX membrane performed better than the monovalent-selective ACS membrane when a relatively low amount of sulfate was used in the artificial river water (Figure 4.13b). In these specific conditions, using monovalent-ion-selective membranes clearly does not lead to better gross power output, although the resistance to fouling has improved.

In Figure 4.13a, the gross power density diminishes when the flow velocity of the feed waters increases. However, this is not the case when the artificial river water has a 
high salt content (Figure 4.13b). The situation in Figure 4.13a can be attributed to the very low conductivity of river water which is rapidly renewed such that an increase of flow velocity creates additional resistance due to the reduced ion transport which is a consequence of low residence time in the RED stack. In Figure 4.13b, the conductivity of the river water is high enough so that the ionic transport is even promoted when the flow velocity is increased. In summary, besides the ionic composition (monovalent or divalent), the conductivity of river water is another important parameter that determines the power density in this case.

The RED performance of the monovalent-selective ACS membrane was worse than that of the conventional AMX membrane; this difference was more pronounced when a relatively low concentration of sulfate was used in the river water (Figure 4.13b). This is a consequence of the higher area resistance of ACS membranes (Table 4.2).

As it depends on many factors such as membrane resistance, apparent permselectivity and the ionic composition of the feed water, the power density of a RED process is certainly not solely determined by monovalent/divalent selectivity of membranes. It is therefore useful to assess RED performance at open-circuit voltage (OCV), in zerocurrent condition. For that purpose, Equations 4.6 and 4.7 can be used to calculate the gross power densities. Table 4.7 shows experimental and OCV-based gross power densities at the highest feed flow velocity $(1.67 \mathrm{~cm} / \mathrm{s})$.

Table 4.7. Gross power density based on experimental data and open-circuit voltage.

\begin{tabular}{lcccc}
\hline \multirow{2}{*}{ Membrane } & \multicolumn{2}{c}{ River water $\mathrm{A}$} & \multicolumn{2}{c}{ River water $\mathrm{B}$} \\
& \multicolumn{2}{c}{$\begin{array}{c}3 \mathrm{mM} \mathrm{NaCl}+2 \\
\mathrm{mM} \mathrm{Na}_{2} \mathrm{SO}_{4}\end{array}$} & $\begin{array}{c}12 \mathrm{mM} \mathrm{NaCl}+2 \\
\mathrm{mM} \mathrm{Na}_{2} \mathrm{SO}_{4}\end{array}$ \\
\cline { 2 - 5 } & $\begin{array}{c}\text { Experimental } \\
\left(\mathrm{W} / \mathrm{m}^{2}\right)\end{array}$ & $\begin{array}{c}\mathrm{OCV} \text { based } \\
\left(\mathrm{W} / \mathrm{m}^{2}\right)\end{array}$ & $\begin{array}{c}\text { Experimental } \\
\left(\mathrm{W} / \mathrm{m}^{2}\right)\end{array}$ & $\begin{array}{c}\text { OCV based } \\
\left(\mathrm{W} / \mathrm{m}^{2}\right)\end{array}$ \\
\hline Fuji A & 0.89 & 1.53 & 1.01 & 1.86 \\
AMX & 0.78 & 1.41 & 0.90 & 1.67 \\
Fuji A-mono & 0.91 & 1.66 & 1.01 & 1.94 \\
ACS & 0.79 & 1.54 & 0.85 & 1.69 \\
\hline
\end{tabular}

In Table 4.7, the RED performance of monovalent-ion-selective membranes is better than of the standard membranes when looking at OCV-based gross power density calculations (zero-current condition); this applies to both types of artificial river water. Although the values of the gross power density are not that distinctive from each other, using OCV values to calculate power density indicates that the use of 
monovalent-selective membranes has some benefits over using their standard counterparts. However, under current-producing condition, these benefits showed to be limited under the current conditions.

Although the presence of multivalent ions is known to have a deteriorating effect on the power density obtainable in RED [5-6], the currently available monovalent ion selective membranes and the ones developed in this work, are not able to overcome this effect yet. The method we developed and presented is a very easy, one-step approach to introduce monovalent ion selectivity on ion exchange membranes. At the same time, it serves to cope with fouling due to its anti-fouling potential, a property that is essential especially in practical applications where real seawater and river water is used. However, the obtained monovalent ion selectivity of the developed and available membranes is probably not sufficiently high yet, and higher values are required to obtain high power density in RED when using real feed waters, which do contain multivalent ions.

\subsection{Conclusions}

This paper studied the preparation and characterization of a monovalent-ion-selective anion exchange membrane specifically designed for RED, using a single-step and relatively fast method that adds a negatively charged layer to the membrane surface by UV irradiation. The developed membrane combines antifouling tendency and monovalent ion selectivity.

The negatively charged coating added antifouling properties to the membrane. Particularly, the coated membrane surface exhibited improved hydrophilicity.

By coating a standard-grade commercial Fuji A membrane, we obtained a monovalention selectivity comparable to that of the commercially available monovalent-selective membranes Neosepta ACS and Selemion ASV. However, the use of such membranes was not found to be impressively effective for obtaining higher gross power densities in RED, however it has benefits in minimising power density losses by rejecting adhering molecules or foulants. 


\subsection{Acknowledgements}

This work was performed within the TTIW cooperation framework of Wetsus, centre of excellence for sustainable water technology (www.wetsus.nl). Wetsus is funded by the Dutch Ministry of Economic Affairs (IOP-TTI), the European Community (European Fund for Regional Development and Seventh Framework Programme), Northern Netherlands Provinces (Peaks in the Delta), the city of Leeuwarden and the Province of Fryslân. The authors would like to thank Alliander, Eneco Energy, Fujifilm, Landustrie, Magneto Special Anodes, A. Hak and MAST Carbon of the research theme "Blue Energy" for productive conversations and financial support.

\subsection{Nomenclature}

$\begin{array}{ll}\text { A } & \text { effective membrane area }\left[\mathrm{cm}^{2}\right] \\ \mathrm{C}_{\mathrm{A}} & \text { concentration of the ion A }\left[\mathrm{mol} / \mathrm{cm}^{3}\right] \\ \mathrm{d}_{\mathrm{c}} & \text { thickness of dilute compartment }[\mathrm{m}] \\ \mathrm{d}_{\mathrm{d}} & \text { thickness of concentrate compartment }[\mathrm{m}] \\ \mathrm{E}_{\mathrm{OCV}} & \text { open-circuit voltage }[\mathrm{V}] \\ \mathrm{F} & \text { Faraday constant }[96485 \mathrm{C} / \mathrm{mol}] \\ \mathrm{I} & \text { total current carried in six-compartment cell }[\mathrm{A}] \\ \mathrm{I}_{\mathrm{A}} & \text { current carried by the ion A }[\mathrm{A}] \\ \mathrm{J}_{\mathrm{A}} & \text { ion flux of the ion A }\left[\mathrm{mol} /\left(\mathrm{cm}^{2} \mathrm{~s}\right)\right] \\ \mathrm{N} & \text { number of membrane cells }[-] \\ \mathrm{P}_{\mathrm{A}_{1}}^{\mathrm{A}_{2}} & \text { relative permselectivity of the membrane between } \mathrm{A}_{2} \text { and } \mathrm{A}_{1}[-] \\ \mathrm{P}_{\text {gross }} & \text { gross power density }\left[\mathrm{W} / \mathrm{m}^{2}\right] \\ \mathrm{P}_{\text {max }} & \text { maximum power output obtained }[\mathrm{W}] \\ \mathrm{R}_{\text {aem }} & \text { anion exchange membrane resistance }\left[\Omega \cdot \mathrm{m}^{2}\right] \\ \mathrm{R}_{\text {cem }} & \text { cation exchange membrane resistance }\left[\Omega \cdot \mathrm{m}^{2}\right] \\ \mathrm{R}_{\text {stack }} & \text { ohmic stack resistance }[\Omega] \\ \mathrm{V} & \text { volume of circulated solution }\left[\mathrm{cm}{ }^{3}\right] \\ \text { Greek symbols } & \\ \kappa_{\mathrm{d}} & \text { conductivity of dilute compartment }[\mathrm{S} / \mathrm{m}] \\ \kappa_{\mathrm{c}} & \text { conductivity of concentrate compartment }[\mathrm{S} / \mathrm{m}]\end{array}$




\subsection{References}

[1] J.W. Post, H.V.M. Hamelers, C.J.N. Buisman, Energy Recovery from Controlled Mixing Salt and Fresh Water with a Reverse Electrodialysis System, Environmental Science \& Technology, 42 (2008) 5785-5790.

[2] J. Kim, S.J. Kim, D.-K. Kim, Energy harvesting from salinity gradient by reverse electrodialysis with anodic alumina nanopores, Energy, 51 (2013) 413-421.

[3] G.L. Wick, Power from salinity gradients, Energy, 3 (1978) 95-100.

[4] D.A. Vermaas, D. Kunteng, M. Saakes, K. Nijmeijer, Fouling in reverse electrodialysis under natural conditions, Water Research, 47 (2013) 1289-1298.

[5] J.W. Post, H.V.M. Hamelers, C.J.N. Buisman, Influence of multivalent ions on power production from mixing salt and fresh water with a reverse electrodialysis system, Journal of Membrane Science, 330 (2009) 65-72.

[6] D.A. Vermaas, M. Saakes, K. Nijmeijer, Influence of multivalent ions on renewable energy generation in reverse electrodialysis, The Journal of Physical Chemistry C (to be submitted), (2013).

[7] H.-J. Lee, S.-H. Moon, S.-P. Tsai, Effects of pulsed electric fields on membrane fouling in electrodialysis of $\mathrm{NaCl}$ solution containing humate, Separation and Purification Technology, 27 (2002) 89-95.

[8] S. Mulyati, R. Takagi, A. Fujii, Y. Ohmukai, H. Matsuyama, Simultaneous improvement of the monovalent anion selectivity and antifouling properties of an anion exchange membrane in an electrodialysis process, using polyelectrolyte multilayer deposition, Journal of Membrane Science, 431 (2013) 113-120.

[9] F. De Körösy, E. Zeigerson, Interaction of permselective membranes and their counter-ions, Desalination, 5 (1968) 185-199.

[10] V.D. Grebenyuk, R.D. Chebotareva, S. Peters, V. Linkov, Surface modification of anion-exchange electrodialysis membranes to enhance anti-fouling characteristics, Desalination, 115 (1998) 313-329.

[11] E. Korngold, F. de Körösy, R. Rahav, M.F. Taboch, Fouling of anionselective membranes in electrodialysis, Desalination, 8 (1970) 195-220.

[12] H.J. Lee, S.H. Moon, S.P. Tsai, Effects of pulsed electric fields on membrane fouling in electrodialysis of $\mathrm{NaC} 1$ solution containing humate, Separation and Purification Technology, 27 (2002) 89-95.

[13] V. Lindstrand, A.S. Jönsson, G. Sundström, Organic fouling of electrodialysis membranes with and without applied voltage, Desalination, 130 (2000) 73-84.

[14] V. Lindstrand, G. Sundström, A.S. Jönsson, Fouling of electrodialysis membranes by organic substances, Desalination, 128 (2000) 91-102.

[15] J. Veerman, M. Saakes, S.J. Metz, G.J. Harmsen, Reverse electrodialysis: Evaluation of suitable electrode systems, Journal of Applied Electrochemistry, 40 (2010) 1461-1474.

[16] T. Gunjima, Y. Sugaya, JP 48-34999, Preparation method of anion exchange membranes having permselectivity between anions, in, Japan, 1973.

[17] R. Yamane, Y. Mizutani, H. Motomura, R. Izuo, Preparation of SO42- nonpermeable anionexchange membrane, J. Electrochem. Soc. Japan, 32 (1964) 277-288.

[18] T. Sata, T. Yamaguchi, K. Matsusaki, Interaction between anionic polyelectrolytes and anion exchange membranes and change in membrane properties, Journal of Membrane Science, 100 (1995) $229-238$. 
[19] T. Sata, K. Mine, K. Matsusaki, Change in transport properties of anion-exchange membranes in the presence of ethylene glycols in electrodialysis, Journal of Colloid and Interface Science, 202 (1998) $348-358$.

[20] T. Sata, Studies on anion exchange membranes having permselectivity for specific anions in electrodialysis - Effect of hydrophilicity of anion exchange membranes on permselectivity of anions, Journal of Membrane Science, 167 (2000) 1-31.

[21] T. Sata, T. Yamaguchi, K. Matsusaki, Effect of hydrophobicity of ion exchange groups of anion exchange membranes on permselectivity between two anions, Journal of Physical Chemistry, 99 (1995) $12875-12882$.

[22] T. Sata, K. Mine, M. Higa, Change in permselectivity between sulfate and chloride ions through anion exchange membrane with hydrophilicity of the membrane, Journal of Membrane Science, 141 (1998) 137-144.

[23] M. Amara, H. Kerdjoudj, Electro-adsorption of polyethyleneimine on the anion exchange membrane: Application to the nitrate removal from loaded solutions, Analytica Chimica Acta, 547 (2005) 50-52.

[24] M. Amara, H. Kerdjoudj, A modified anion-exchange membrane applied to purification of effluent containing different anions. Pre-treatment before desalination, Desalination, 206 (2007) 205-209.

[25] F. Guesmi, C. Hannachi, B. Hamrouni, Selectivity of anion exchange membrane modified with polyethyleneimine, Ionics, 18 (2012) 711-717.

[26] T.K. Dey, R.C. Bindal, S. Prabhakar, P.K. Tewari, Development, Characterization and Performance Evaluation of Positively-Charged Thin Film-Composite Nanofiltration Membrane Containing Fixed Quaternary Ammonium Moieties, Separation Science and Technology, 46 (2011) 933943.

[27] S.U. Hong, R. Malaisamy, M.L. Bruening, Optimization of flux and selectivity in Cl-/SO42separations with multilayer polyelectrolyte membranes, Journal of Membrane Science, 283 (2006) 366372 .

[28] K. Mihara, T. Misumi, H. Miyauchi, Y. Ishida, JP 48-34676, Anion-exchange membranes with excellent permselectivity between anions with the same charge, in, Japan, 1973.

[29] E. Guler, Y. Zhang, M. Saakes, K. Nijmeijer, Tailor-Made Anion-Exchange Membranes for Salinity Gradient Power Generation Using Reverse Electrodialysis, ChemSusChem, 5 (2012) 2262-2270.

[30] P. Długołecki, K. Nymeijer, S. Metz, M. Wessling, Current status of ion exchange membranes for power generation from salinity gradients, Journal of Membrane Science, 319 (2008) 214-222.

[31] J. Balster, M.H. Yildirim, D.F. Stamatialis, R. Ibanez, R.G.H. Lammertink, V. Jordan, M. Wessling, Morphology and microtopology of cation-exchange polymers and the origin of the overlimiting current, Journal of Physical Chemistry B, 111 (2007) 2152-2165.

[32] I. Rubinstein, B. Zaltzman, O. Kedem, Electric fields in and around ion-exchange membranes, Journal of Membrane Science, 125 (1997) 17-21.

[33] N.D. Pismenskaya, V.V. Nikonenko, N.A. Melnik, K.A. Shevtsova, E.I. Belova, G. Pourcelly, D. Cot, L. Dammak, C. Larchet, Evolution with Time of Hydrophobicity and Microrelief of a CationExchange Membrane Surface and Its Impact on Overlimiting Mass Transfer, The Journal of Physical Chemistry B, 116 (2011) 2145-2161.

[34] I. Rubinshtein, B. Zaltzman, J. Pretz, C. Linder, Experimental Verification of the Electroosmotic Mechanism of Overlimiting Conductance Through a Cation Exchange Electrodialysis Membrane, Russian Journal of Electrochemistry, 38 (2002) 853-863. 
[35] G. Chamoulaud, D. Bélanger, Modification of ion-exchange membrane used for separation of protons and metallic cations and characterization of the membrane by current-voltage curves, Journal of Colloid and Interface Science, 281 (2005) 179-187.

[36] G. Pourcelly, Conductivity and selectivity of ion exchange membranes: structure-correlations, Desalination, 147 (2002) 359-361.

[37] A. Elattar, A. Elmidaoui, N. Pismenskaia, C. Gavach, G. Pourcelly, Comparison of transport properties of monovalent anions through anion-exchange membranes, Journal of Membrane Science, 143 (1998) 249-261.

[38] S. Mulyati, R. Takagi, A. Fujii, Y. Ohmukai, T. Maruyama, H. Matsuyama, Improvement of the antifouling potential of an anion exchange membrane by surface modification with a polyelectrolyte for an electrodialysis process, Journal of Membrane Science, 417-418 (2012) 137-143.

[39] www.fujifilmmembranes.com.

[40] H. Antheunis, WO2011073638, Curable compositions and membranes, in, The Netherlands, 2011.

[41] www.tokuyama.co.jp, in.

[42] www.agc.co.jp, in.

[43] G. Saracco, M.C. Zanetti, Ion transport through monovalent-anion-permselective membranes, Industrial \& Engineering Chemistry Research, 33 (1994) 96-101.

[44] H.-Y. Lu, C.-S. Lin, S.-C. Lee, M.-H. Ku, J.-P. Hsu, S. Tseng, S.-H. Lin, Preparation of mineral source water from deep sea water: Reduction of sulfate ion using selemion ASV membrane, AIChE Journal, 57 (2011) 1033-1042.

[45] M. Ulbricht, Advanced functional polymer membranes, Polymer, 47 (2006) 2217-2262.

[46] G. Saracco, Transport properties of monovalent-ion-permselective membranes, Chemical Engineering Science, 52 (1997) 3019-3031.

[47] http://surface.kratos.com, in.

[48] J.J. Krol, M. Wessling, H. Strathmann, Concentration polarization with monopolar ion exchange membranes: current-voltage curves and water dissociation, Journal of Membrane Science, 162 (1999) $145-154$.

[49] P. Długołęcki, A. Gambier, K. Nijmeijer, M. Wessling, Practical Potential of Reverse Electrodialysis As Process for Sustainable Energy Generation, Environmental Science \& Technology, 43 (2009) 68886894.

[50] E. Güler, R. Elizen, D.A. Vermaas, M. Saakes, K. Nijmeijer, Performance-determining membrane properties in reverse electrodialysis, Journal of Membrane Science, 446 (2013) 266-276.

[51] B.V. Crist, Handbook of monochromatic xps data, in, XPS International LLC, 2005.

[52] F. Parvizian, M. Rahimi, S.M. Hosseini, S.S. Madaeni, A.A. Alsairafi, The effect of high frequency ultrasound on diffusion boundary layer resistance in ion-exchange membrane transport, Desalination, 286 (2012) 155-165.

[53] P. Długołecki, B. Anet, S.J. Metz, K. Nijmeijer, M. Wessling, Transport limitations in ion exchange membranes at low salt concentrations, Journal of Membrane Science, 346 (2010) 163-171.

[54] V. Freger, J. Gilron, S. Belfer, TFC polyamide membranes modified by grafting of hydrophilic polymers: an FT-IR/AFM/TEM study, Journal of Membrane Science, 209 (2002) 283-292.

[55] W. Garcia-Vasquez, L. Dammak, C. Larchet, V. Nikonenko, N. Pismenskaya, D. Grande, Evolution of anion-exchange membrane properties in a full scale electrodialysis stack, Journal of Membrane Science. 
[56] I. Rubinstein, B. Zaltzman, Electro-osmotically induced convection at a permselective membrane, Physical Review E - Statistical Physics, Plasmas, Fluids, and Related Interdisciplinary Topics, 62 (2000) 2238-2251.

[57] X.T. Le, P. Viel, D.P. Tran, F. Grisotto, S. Palacin, Surface Homogeneity of Anion Exchange Membranes: A Chronopotentiometric Study in the Overlimiting Current Range, The Journal of Physical Chemistry B, 113 (2009) 5829-5836.

[58] R.M.M. Brito, W.L.C. Vaz, Determination of the critical micelle concentration of surfactants using the fluorescent probe N-phenyl-1-naphthylamine, Analytical Biochemistry, 152 (1986) 250-255.

[59] C.-E. Lin, Determination of critical micelle concentration of surfactants by capillary electrophoresis, Journal of Chromatography A, 1037 (2004) 467-478. 
Chapter 4. 


\section{Micro-structured membranes for reverse electrodialysis}
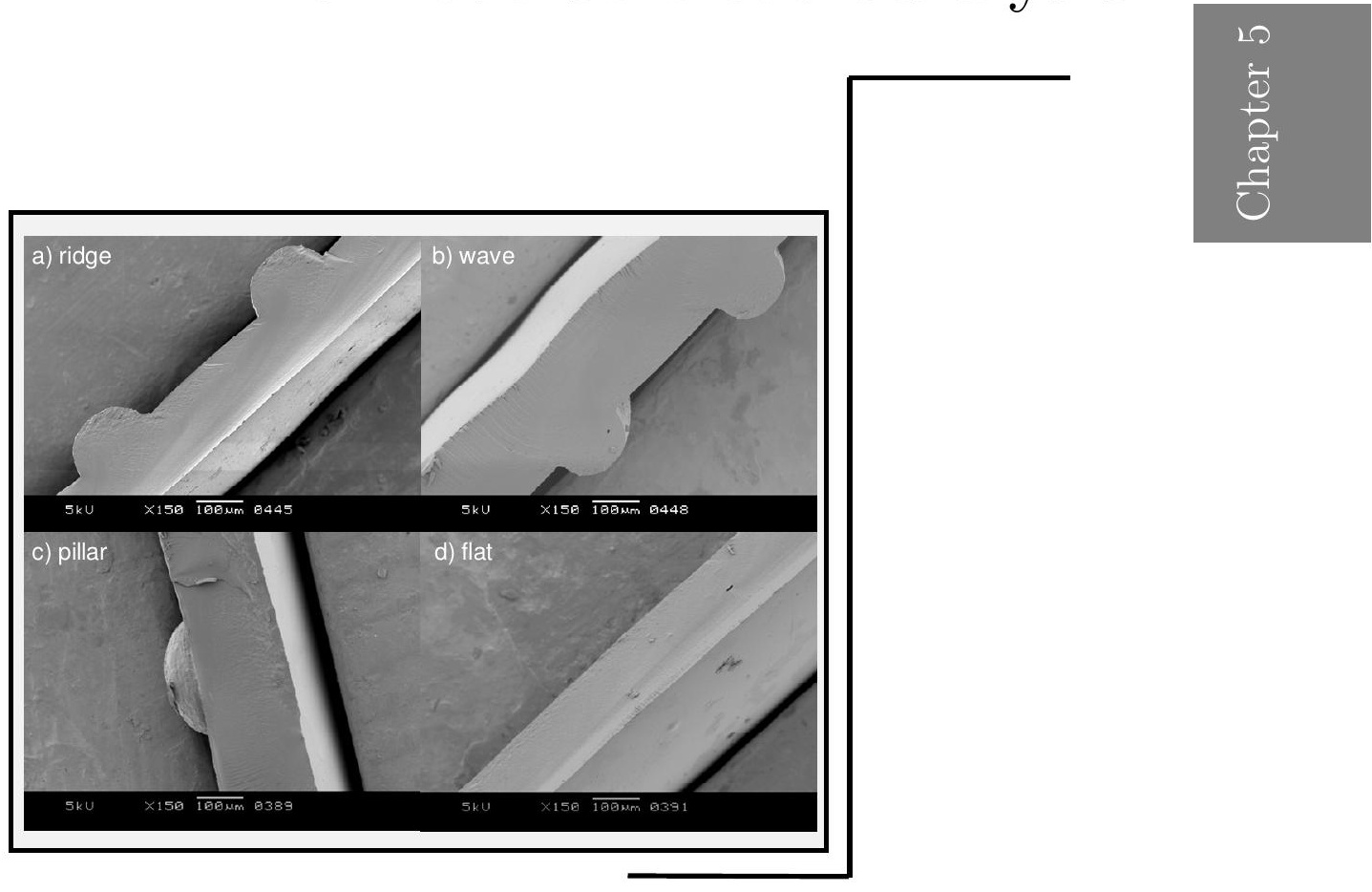

This chapter has been submitted to the Journal of Membrane Science as:

E. Guler, R. Elizen, M. Saakes, K. Nijmeijer, Micro-structured membranes for electricity generation by reverse electrodialysis. Journal of Membrane Science (2013). 


\begin{abstract}
Reverse electrodialysis (RED) is a technology for extracting salinity gradient power by contacting waters with different salinity, i.e. seawater and river water, through ion exchange membranes. Conventionally, non-conductive spacers are used to separate these ion exchange membranes from each other in RED. The power output is hampered by these non-conductive elements which increase the stack resistance. To eliminate the use of these spacers, structured anion exchange membranes with a structure height of $100 \mu \mathrm{m}$ were prepared by casting a polymer solution on stainless steel molds followed by solvent evaporation. These self-standing membranes with straight-ridge, wave and pillar structures as well as similarly prepared flat membranes were installed on the river water side in a RED stack (where electrical resistance is the highest). $38 \%$ higher gross power density and 20\% higher net power density were achieved with the pillar-structured membranes when compared to that of flat membranes with spacers. Further optimization of the structure geometry in combination with the possibility to cast membranes of different chemistries offer a huge potential for further development of homogeneous membranes with the desired electrochemical and physical properties, which could provide high power densities in RED.
\end{abstract}




\subsection{Introduction}

As the amount of fossil fuels is limited and their use has environmental consequences, the development of clean and sustainable forms of energy receives much attention. One of these promising new energy sources is salinity gradient power, which can be harvested from the mixing of two water streams with different salt concentrations (e.g. seawater and river water). The driving force for mixing is the change in the Gibbs free energy that can be converted into electricity via direct ion transport through ionselective membranes [1]. When all river water streams are considered that discharge into the sea, the global potential of salinity gradient power is huge with an estimated potential power of 2.4-2.6 TW [2-3]. Therefore, the importance of technologies that can efficiently harvest salinity gradient energy is growing rapidly.

Several ways of generating energy from salinity gradients have been previously proposed, such as pressure-retarded osmosis (PRO) and reverse electrodialysis (RED) [4-5]. PRO uses an induced fluid flow that occurs when two solutions of different concentrations are placed in contact through a barrier (i.e. membrane) that is permeable to water only, but impermeable to ions [6]. On the other hand, RED uses an ion flow that is induced when seawater and fresh water are brought in contact through ion-selective membranes [6]. Recent studies have concluded that RED is more appropriate for use with seawater and river water, whereas PRO is more favorable for power generation from brines [4].

The principle of RED is well described in the literature [1, 7-9]. A typical RED stack consists of a series of alternating anion exchange membranes and cation exchange membranes (Figure 5.1). Spacers between the membranes separate the membranes, forming narrow compartments for water to flow through. Ions are then transported from the concentrated side (e.g. seawater) to the diluted side (e.g. freshwater), promoted by the salinity gradient. Since the membranes are selective for only specific types of ions (i.e. cation exchange membranes allow the passage of cations, and anion exchange membranes allow the passage of anions), cations migrate to one side and anions migrate to the other side, resulting in a potential difference. Electro-neutrality of the solutions in electrode compartments is maintained through redox reactions at the electrodes. Electrons are transferred from anode to cathode via an external electrical circuit, and this current can be used to power an external energy consumer. 


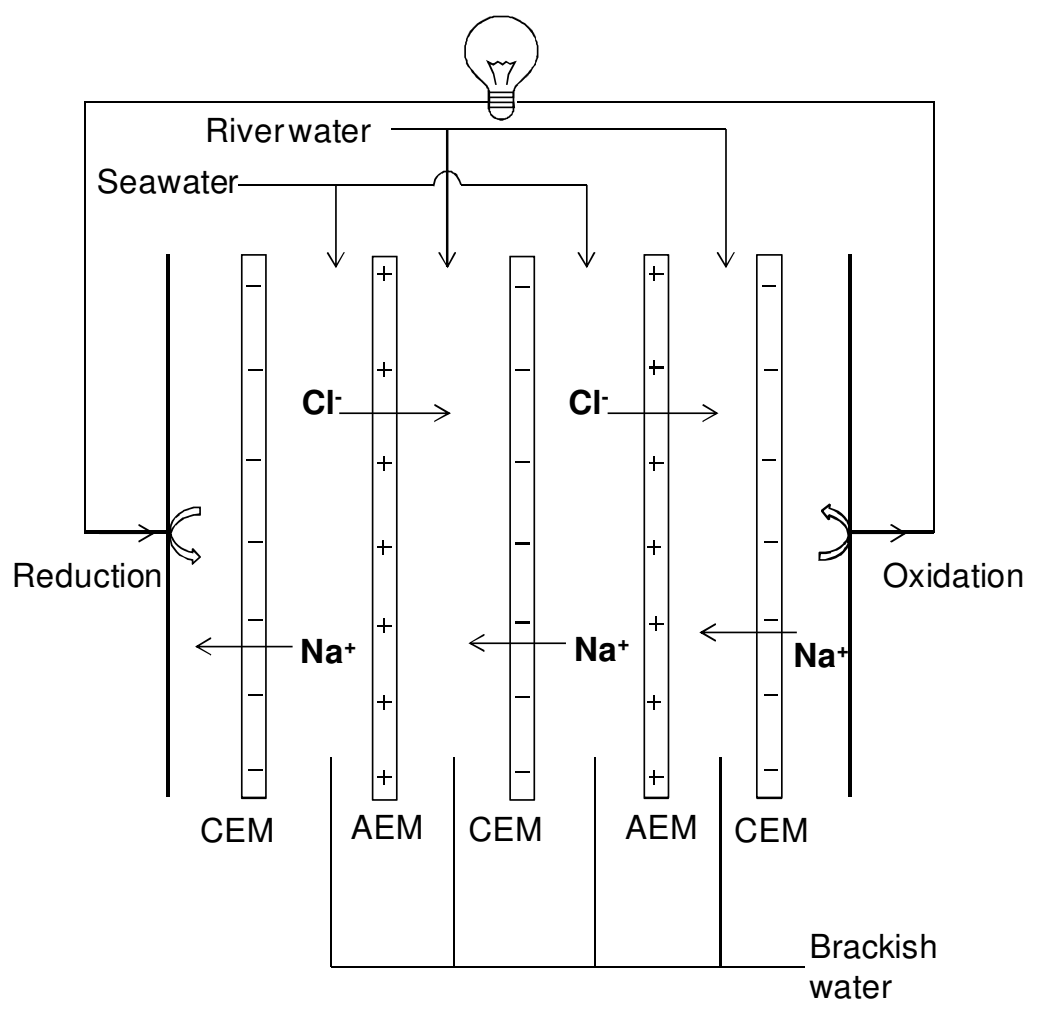

Figure 5.1. Principle of reverse electrodialysis (RED).

It is vital to achieve a high net power density (i.e. gross power density minus required pumping power). To achieve such a high power density, the internal electrical resistance of the stack and the hydraulic friction losses inside the stack should be low. A low electrical resistance of the stack enables the desired ion transfer as it makes the stack more conductive, and low hydraulic friction minimizes the power consumed in pumping the feed waters through the stack [10]. In conventional RED and ED, nonconductive spacers are used to separate the membranes from each other to allow water flow between them. These spacers cover part of the conductive membrane area, resulting in a smaller membrane area available for ion transport and an increased resistance, the so-called spacer shadow effect [11]. Moreover, spacers usually have woven or non-woven structures which are formed by knits (where the spacer filaments meet), causing tortuous flow resulting in additional hydraulic friction. In addition, this undesired flow enables fouling in the spacers, which is the most common problem in many membrane processes [12-13].

One possible remedy to reduce the stack resistance in RED is to use ion-conductive spacers instead of the conventional inert spacers. Długołecki et al. cut Neosepta CMX and Neosepta AMX membranes into spacer-shaped pieces, and used them as spacers, resulting in a power density increase by a factor of 3 relative to when using conventional non-conductive spacers [11]. However, hydraulic friction was not reduced 
as the spacer design of these hand-made spacers used was far from optimal. Another remedy is to use micro-structured membranes (also called profiled or corrugated membranes), which integrate the membrane and spacer functionality. Such membranes provide channels for feed water to flow through and at the same time keep the membranes apart in the stack. Because of their fully conductive character, the stack resistance is significantly reduced and the hydraulic friction remains low because of the open-channel geometry [10].

Although profiled membranes have been used in electrodialysis (ED) in several previous studies [14-16], the first successful application of such membranes in RED was achieved by Vermaas et al., who investigated heterogeneous membranes with straight ridges [10]. A high net power density, $10 \%$ higher than with conventional flat membranes, was obtained; a hot-pressing technique was used to prepare these profiled membranes [10]. Profiled membranes also significantly reduce hydraulic friction, not only in RED [10] but also in ED [15]. Thus, the use of such membranes has become a prerequisite for obtaining high performance in RED.

Micro-structured membranes can be produced by different techniques, such as calendering (roll-pressing) of a thermoplastic ion-exchange film between corrugated rollers at elevated temperature [17], hot pressing of a thermoplastic polymer containing suitable functional groups [10, 17], and casting a solution of an ion-exchange polymer into a mold followed by evaporation of the solvent [18-19]. Hot pressing and calendering are usually advantageous for making membranes that are structured on both sides, but are only applicable for thermoplastics. Most problems in hot pressing (sometimes referred to as hot embossing) occur during the release of the membrane film from the mold, generally related to rupture or deformation of the microstructures [20-21]. Release problems can be reduced when the mold has slightly inclined sidewalls, or when anti-adhesive coatings are used that ease the release of the film from the mold. The dimensions of the mold play a role as well. Moreover, electrochemical properties usually are not always preserved during hot pressing; previous studies showed that electrical resistance increases and permselectivity may decrease when heterogeneous membranes are hot-pressed [10, 22].

To overcome these drawbacks, we propose the use of membrane casting to prepare micro-structured homogeneous anion exchange membranes. This method provides more freedom for preparing a variety of homogeneously dense polymeric membranes with various structures. Casting of structured membranes can be performed using several techniques. One of these methods is 'capillary force induced surface structuring ' in which two layers of the membrane are created in contact with each other [19]. After 
casting and drying of the first layer, a second layer is cast on top of the first and a commercial spacer with the desired structures is placed on top of the second layer. After solvent evaporation and immersion in a water bath, the spacer is removed and a replica of the shape of the spacer has formed on the membrane. Another technique to cast structured membranes involves the use of molds with the desired structures and casting the polymer solution into the mold [23-24]. The phase separation of the solvent/polymer mixture can be performed either with liquid-induced phase separation (i.e. immersing the polymer solution in a nonsolvent bath and removing the solid membrane) or by simply evaporating the solvent followed by rinsing the solid polymer film $[17,20]$. In general, liquid-induced phase separation results in membranes with a certain porosity [24]. With solvent evaporation, dense membranes are created, as required in RED applications [25-26]. Since casting requires no force to form the microstructures, rupturing and deformation of these structures are less likely to happen. In addition, electrochemical and mechanical properties of the membranes can be tailored and preserved depending on the characteristics of the casting solution and reaction conditions. However, it is still a challenge to make membranes that are structured on both sides. The molds contacting both sides of the membranes make it difficult to evaporate the solvent.

A variety of geometrical structures can be created in this way as was shown previously for mostly non-ion exchange materials and other applications (e.g. ultrafiltration, gas separation and electrodialysis). Structures involving continuous ridges, e.g. straight lines or wave-shaped, allow water flow in channel-type ducts $[15,17,24]$. On the other hand, non-continuous structures can be created as pillar shapes with different geometries, such as circular, tear drop, kite (diamond) or star structures [23]. Depending on the number of structures per unit surface area and the dimensions of the structures on the membrane surface, pillar structures generally provide a more open area for water flow due to their high channel-to-structure ratio. Depending on the flow conditions, pillar structures can have undesired effects as well. For instance, stagnant regions occur at the front of the pillars where the flow streamlines separate, and deviate from the overall flow direction. Moreover, recirculation regions can form at the back of the pillars, which is detrimental to efficient ionic transport [23]. Such effects do not occur with structures that consist of continuous ridges; since there are no obstacles to the water flow in the channel, recirculation zones and stagnant regions are not expected to occur in these geometries. However, such structures usually exhibit less mixing and increased boundary layer effects. 
The structural geometry and dimensions of the features on the membranes are critical, as these have direct impact on the mixing of the flows and boundary layer resistances, but also on the hydraulic friction and power consumption by the pumps. The ratio of channel-to-ridge width for water flow is an important parameter and characterizes structured membranes [17]. This parameter provides information about the proportion of conductive region occupied by structures and the volume of the space available for water transport. It is also related to the amount of hydraulic friction that is experienced.

Considering the importance of the structural geometry and dimensions on the performance of RED, in this paper, we investigate the performance of tailor-made micro-structured anion exchange membranes prepared by casting and solvent evaporation for operation in a RED stack. Specifically, we prepare and investigate the performance of three different membrane structures (i.e. ridges, waves and pillars) and compare that with that of flat membranes. We characterize the membranes in terms of their electrochemical properties, flow distribution, resistance and pumping power in the stack and relate that to gross and net power density obtainable in the RED stack.

\subsection{Experimental}

\subsubsection{Materials}

The elastomer polyepichlorohydrin (PECH, EPICHLOMER H, 37 wt\% chlorine content, Daiso Co. Ltd, Japan) was used as the active polymer for the anion exchange membranes. Polyacrylonitrile (H-PAN, $\mathrm{M}_{\mathrm{w}}=200,000 \mathrm{~g} / \mathrm{mol}$, Dolan GmbH, Germany) was chosen as an inert supporting polymer. Dimethyl sulfoxide (DMSO, 99\%, Merck) was used as solvent and a tertiary diamine (DABCO, 98\%, Sigma-Aldrich) was used for amination.

Commercial homogeneous Neosepta CMX cation exchange membranes (Tokuyama Co., Japan) were used as reference membranes for cation exchange in the stack, without any modification. The resistance and permselectivity of these membranes are $2.91 \Omega \cdot \mathrm{cm}^{2}$ and $99.0 \%$, respectively [26].

Sodium chloride (99.5\%, Acros Organics) and sodium sulfate (99\%, Acros Organics) were used for membrane resistance measurements. For RED performance characterization, sodium chloride (technical grade, Boom BV, the Netherlands), potassium hexacyanoferrate(II) (99\%, Boom BV) and potassium hexacyanoferrate(III) (99\%, Boom BV) were used. All chemicals were used without further purification. 


\subsubsection{Preparation of tailor-made anion exchange membranes}

\subsubsection{Preparation of flat membranes}

PECH anion exchange membranes were prepared by a solvent evaporation technique as described in a previous publication [26]. The membrane-forming solution (comprising PECH, PAN, DABCO and the solvent DMSO) was cast onto a glass plate to prepare flat membranes. After thermal curing (for $2 \mathrm{~h}$ at $110^{\circ} \mathrm{C}$ ) and solvent evaporation (for $30 \mathrm{~min}$ at $130^{\circ} \mathrm{C}$ ) in a thermostated oven, the polymer film was soaked in a $0.5 \mathrm{M} \mathrm{NaCl}$ solution to release the membrane from the glass plate. The membranes were then stored in aqueous $\mathrm{NaCl}(0.5 \mathrm{M})$ till further use. PECH membranes were prepared at a blend ratio of 0.208 , which is the mass ratio of $\mathrm{PECH}$ (active polymer providing the ion exchange groups) over PAN (inert polymer providing mechanical stability). The flat membranes had a thickness of $200 \mu \mathrm{m}$ in wet state. The thickness of the membranes was determined with a digital screw micrometer (Mitutoyo 293-240, Mitutoyo Co., Japan).

\subsubsection{Preparation of structured membranes}

The same membrane preparation route as for the preparation of flat membranes was followed to prepare structured membranes The same blend ratio of 0.208 was used. Different than in the preparation of the flat membranes, the membrane-forming solution was cast onto structured stainless steel molds (160 mm x $160 \mathrm{~mm}$ ) to obtain structures integrated on one side of the membrane surface (Figure 5.2). Figure 5.2 shows a schematic top view of a mold, in which the channels are represented by lines. These stainless steel molds were specially designed on demand by Stork Veco BV, Eerbeek, the Netherlands; three different molds having three different patterns (pillars, ridges and waves) were used (Figure 5.3). The central area of the mold (i.e. the area where the straight lines are located, shown in Figure 5.2) contained the structures indicated in Figure 5.3. The ridges and waves had a depth of $100 \mu \mathrm{m}$ and a width of

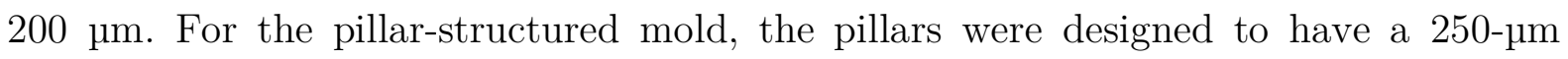
diameter, and an open slit distance of $800 \mu \mathrm{m}$. 

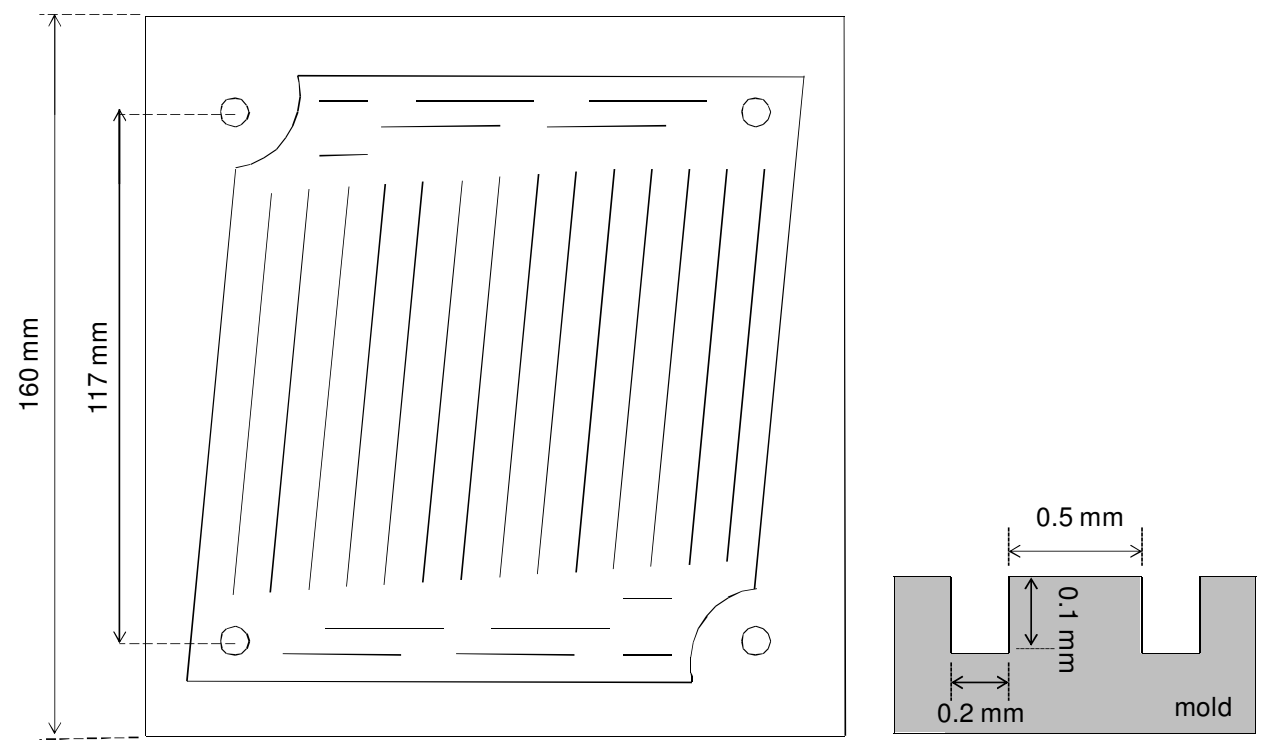

Figure 5.2. Schematic representation of stainless steel molds. Left: top view of the structured mold. Right: cross-section at the center of the mold for ridge structures. (The drawings are not to scale.)

a)
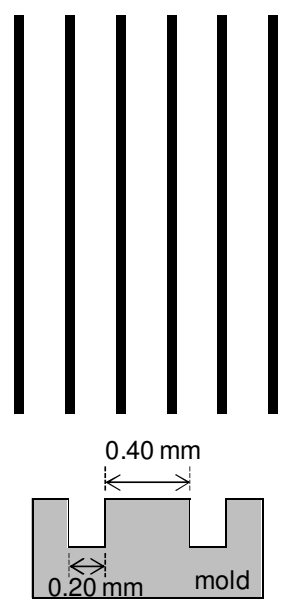

b)
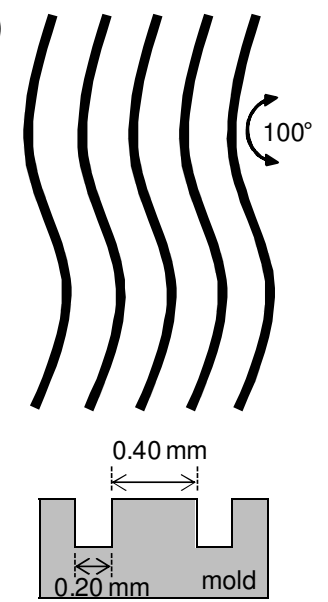
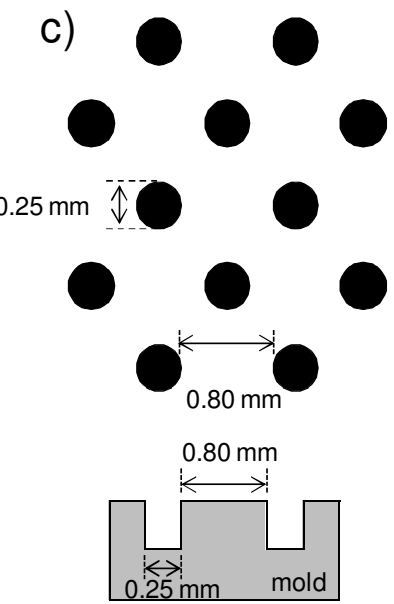

Figure 5.3. Dimensions of mold structures: (a) ridge, (b) wave and (c) pillar.

The membrane-forming solution containing specific amounts of PECH, PAN, DABCO and DMSO were spread over the stainless-steel molds (Figure 5.4), by using a syringe as described earlier [26]. To prevent further evaporation of DABCO during amination, the mold was sealed with a hand-made glass lid. The sealed mold was placed into an oven and heated for $2 \mathrm{~h}$ at $110^{\circ} \mathrm{C}$ under nitrogen atmosphere. After amination and cross-linking (thermal curing), the lid was removed to allow the solvent to evaporate and the temperature was increased to $130^{\circ} \mathrm{C}$ for $30 \mathrm{~min}$. After cooling to room temperature, the mold with the film was immersed in $0.5 \mathrm{M} \mathrm{NaCl}$ solution. After a few minutes, the membrane film was released from the mold by gentle pulling and stored in $0.5 \mathrm{M} \mathrm{NaCl}$ solution until further use. The result was a continuous dense polymer film with structures (i.e. ridge, wave or pillar), a perfect replica of the mold pattern 
(Figure 5.4). The obtained structured membranes had a total thickness of about 300 $\mu \mathrm{m}$ including the structures which were $100 \mu \mathrm{m}$ high (membrane base was $200 \mu \mathrm{m}$ in all cases). The thickness of the continuous film can easily be adapted by changing the volume or concentration of the membrane-forming solution spread on the mold.

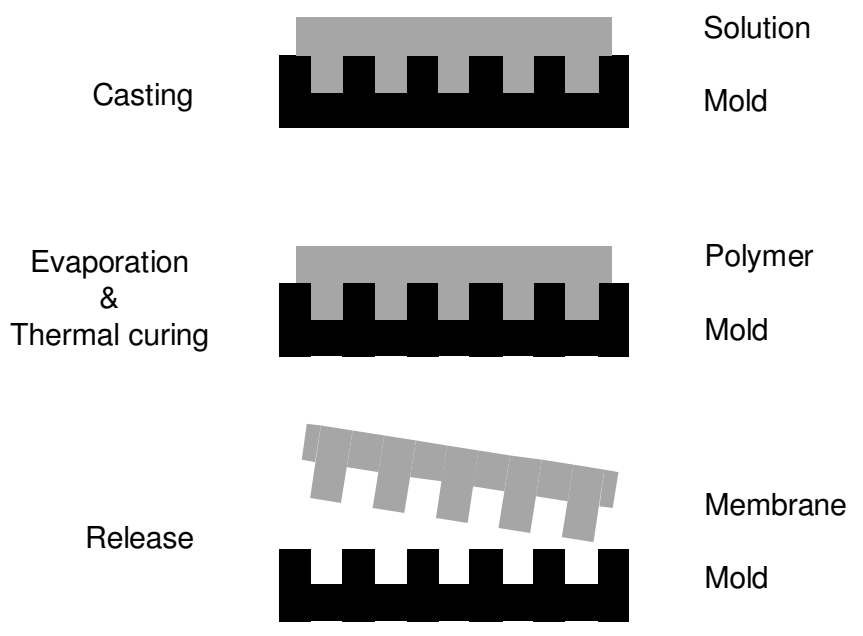

Figure 5.4. Preparation of tailor-made membranes using casting and solvent evaporation.

\subsubsection{Membrane characterization}

\subsubsection{SEM}

To determine the morphology and dimensions of the membranes, a scanning electron microscopy (SEM, JSM 5600LV, JEOL) was used. The membranes were broken in liquid nitrogen and sputter-coated with gold (Balzers Union SCD 040 sputtering device). Images were taken at $5 \mathrm{kV}$.

\subsubsection{Area resistance}

The area resistance $(\mathrm{R})$ is the electrical resistance of the membrane. It is an important parameter determining the energy-generating performance in RED. From an engineering point of view, the unit of membrane resistance is usually referred to as $\Omega \cdot \mathrm{cm}^{2}$ or $\Omega \cdot \mathrm{m}^{2}$. It is usually dependent on the ion exchange capacity and the mobility of the ions within the membrane matrix. Moreover, it is affected by the temperature.

In the work described in this paper, the area resistance of the flat and structured membranes was determined following a previously described procedure [26]. A sixcompartment cell was used with $\mathrm{NaCl}(0.5 \mathrm{M})$ as the test solution and $\mathrm{Na}_{2} \mathrm{SO}_{4}(0.5 \mathrm{M})$ as the electrolyte solution under direct current (DC). With a potentiostat (Ivium Technologies, the Netherlands), the applied current density and voltage were measured 
with the membrane under investigation and without a membrane (blank) to determine the area resistance. The net area resistance was calculated from the difference between the slopes of the current-voltage curves for these two measurements. At least two runs were performed for each membrane. For micro-structured membranes, the central part of the membranes was measured where the structures are located together with the continuous part.

\subsubsection{Permselectivity}

The permselectivity of the membranes is defined as the flux of a specific component relative to the mass flux through the membrane under a given driving force. The permselectivity of an ion exchange membrane is a measure for how well the membrane discriminates between anions (e.g. $\mathrm{Cl}^{-}$) and cations (e.g. $\mathrm{Na}^{+}$).

In this study, permselectivity was determined by using a two-compartment cell as described earlier [26]. Solutions of $0.1 \mathrm{M} \mathrm{NaCl}$ and $0.5 \mathrm{M} \mathrm{NaCl}$ (99.5\%, Acros Organics) were recirculated on each side of the membrane. Two reference calomel electrodes were used to measure the potential over the membrane; the experimental potential was monitored with an external potentiostat. The permselectivity $(\alpha)$ was calculated from the ratio of the experimentally measured potential $\left(\Delta \mathrm{V}_{\text {measured }}\right)$ to the theoretical potential $\left(\Delta \mathrm{V}_{\text {theoretical }}\right)$ for a $100 \%$ permselective membrane:

$\alpha=\frac{\Delta \mathrm{V}_{\text {measured }}}{\Delta \mathrm{V}_{\text {theoretical }}} \times 100 \%$

\subsubsection{RED performance}

\subsubsection{Flow distribution}

To investigate the flow distribution of the structured membranes, we used custommade glass end plates as a stack with a single inlet and outlet for feed water. Only one structured membrane was installed inside this stack without any use of spacers, and the stack was sealed with silicon gaskets (Specialty Silicone Fabricators) to prevent leakage. Black ink (Quink Ink, Parker, USA) was injected to the demineralized water stream of $12 \mathrm{ml} / \mathrm{min}$. We monitored the flow distribution over the structured surface of the membranes with a MotionBLITZ EoSens mini2 high-speed camera (Mikrotron, Germany). A video was recorded at a rate of $93 \mathrm{fps}$. Continuous illumination behind the transparent glass stack was used. The images from the recorded video were captured at several intervals $(0.0 \mathrm{~s}, 0.4 \mathrm{~s}, 0.8 \mathrm{~s}, \ldots, 2.4 \mathrm{~s})$ to record the color patterns 
inside the compartment. Videos are recorded at least two times. Adobe Photoshop CS6 software was used to improve image contrast to enhance the visibility of the ink.

\subsubsection{RED setup}

Figure 5.5 is a schematic representation of the RED stack with structured membranes. It contained $2 \mathrm{Ti}$ electrodes (mesh 1.0, $10 \mathrm{~cm}$ x $10 \mathrm{~cm}$ ) coated with $\mathrm{Ir} / \mathrm{Ru}$ (Magneto Special Anodes B.V., the Netherlands). The electrolyte solution was prepared by dissolving $\mathrm{NaCl}(0.25 \mathrm{M}), \mathrm{K}_{4} \mathrm{Fe}(\mathrm{CN})_{6}(0.05 \mathrm{M})$ and $\mathrm{K}_{3} \mathrm{Fe}(\mathrm{CN})_{6}(0.05 \mathrm{M})$ in Milli-Q water. The electrolyte was circulated through the electrode compartments at a flow rate of $300 \mathrm{ml} / \mathrm{min}$.

This stack contained three flat cation exchange membranes (CEMs) and two structured tailor-made anion exchange membranes (AEMs), alternately stacked (Figure 5.5). To shield the electrode compartments and to prevent leakage of the electrolyte to the feed water and vice versa, cation exchange membranes (Neosepta CMX, Tokuyama Co., Japan) were installed at both ends of the stack. The cell width (i.e. intermembrane distance) was adjusted to $100 \mu \mathrm{m}$; a silicon gasket with the same thickness (Specialty Silicon Fabricators, USA) as the height of the structures on the membranes was installed between two membranes to seal the water compartments. The silicon gasket for the structured side of the membranes was specially designed such that it fitted around the structures. A woven non-conductive spacer (Sefar, Nitex 03-160/53, Switzerland) was used in the seawater compartments where the flat sides of the membranes faced each other. The thickness of the spacer was measured as about $100 \mu \mathrm{m}$ by a digital screw micrometer (Mitutoyo 293-240, Mitutoyo Co., Japan). The complete RED stack was installed inside a thermostated oven (MMM Friocell 222, Germany) to keep the temperature constant at $25^{\circ} \mathrm{C}$. 


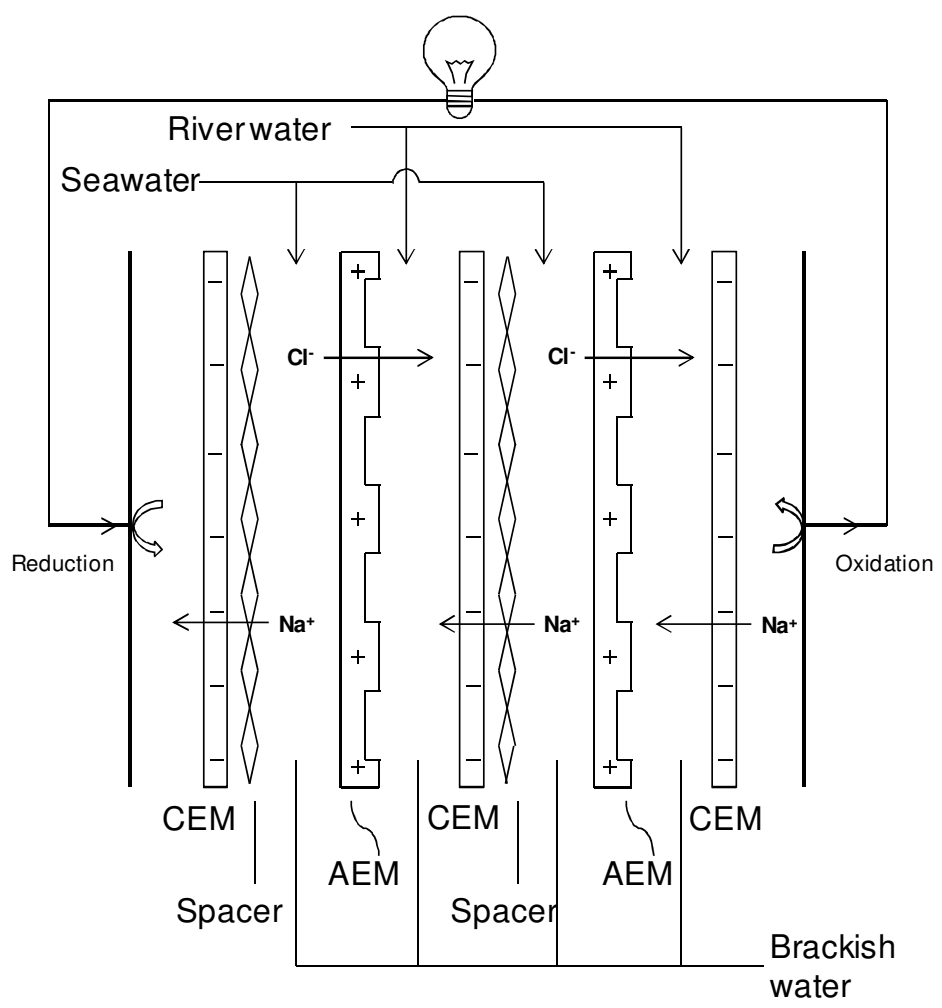

Figure 5.5. Illustration of stack setup with structured anion exchange membranes. Spacers are installed on the seawater side on the non-structured side of the membranes. In reality, spacers and membranes touch each other, but these are somewhat separated in the figure to increase the clarity of the figure.

The river water compartment exhibits a significant amount of resistance in the stack because of its relatively low salt concentration. Since only one side of the membranes was structured, the structured side of the membranes was placed facing the fresh water (i.e. river water) compartment where the use of non-conductive spacers was eliminated.

Artificial river water and seawater were prepared having concentrations of $0.017 \mathrm{M}$ and $0.507 \mathrm{M}$, respectively by dissolving $\mathrm{NaCl}$ in demineralized water. The temperature of the feed solutions was kept constant at $25^{\circ} \mathrm{C}$ using a thermostated water bath (Colora thermostat WK16). The flow rates were adjusted to 2, 5, 8, 15, 30 and 40 $\mathrm{ml} / \mathrm{min}$ by manual peristaltic pumps (Masterflex, Cole Palmer). Corresponding to these flow rates, the Reynolds number was calculated assuming the flow geometry in a wide duct:

$\operatorname{Re}=\frac{\overline{\mathrm{u}} \cdot \mathrm{D}_{\mathrm{h}}}{v}=\frac{\overline{\mathrm{u}} \cdot 2 \mathrm{~d}}{v}=\frac{2 \Phi}{\mathrm{b} \cdot v}$

where $\overline{\mathrm{u}}$ is the average flow velocity $(\mathrm{m} / \mathrm{s}), \mathrm{D}_{\mathrm{h}}$ is the hydraulic diameter $(\mathrm{m})$ and $v$ is the kinematic viscosity of water $\left(8.9 \times 10-7 \mathrm{~m}^{2} / \mathrm{s}\right.$ at $\left.25^{\circ} \mathrm{C}\right)$, d is the height of the flow 
path, $\Phi$ is the flow rate for the feed water per compartment and b is the width of the flow path.

The pressure drop between the inflow and outflow of the feed water compartments was measured with a differential pressure transmitter (Endress+Hauser Deltabar S, Germany).

\subsubsection{Power density}

To determine the generated power density of the RED stack, a 2-cell setup was used, each cell containing one AEM and one CEM, in order to have a better control of leakage inside the stack (Figure 5.5). A potentiostat (Ivium Technologies, Eindhoven, the Netherlands) in chronopotentiometry mode was used. At each flow rate of the feed waters, 20 current steps $\left(0,2,4, \ldots, 40 \mathrm{~A} / \mathrm{m}^{2}\right)$ of 30 seconds each were applied and the corresponding voltages were recorded. All chronopotentiometric measurements were performed at least three times.

The gross power output was calculated as the maximum product of voltage E and current I from the measured voltage-current curves. The gross power output was then corrected by subtracting the power output of a blank run using only one cation exchange membrane in the stack. The power output can then be converted into the gross power density $\left(\mathrm{P}_{\text {gross }}\right)$ by dividing it by the total membrane area $\left(\mathrm{W} / \mathrm{m}^{2}\right)$.

One of the parameters that determines the RED performance is the internal resistance of the stack. It includes the ohmic resistances, $R_{\text {ohmic }}$, and the non-ohmic resistances, $\mathrm{R}_{\text {non-ohmic }}$. The calculation of these resistances are described in more detail in Section 5.3.3.3.

Of the gross power generated by the RED stack, a certain amount is consumed by the pumps to transport the feed waters through the stack. The pumping power per unit membrane area, $\mathrm{P}_{\text {pump }}\left(\mathrm{W} / \mathrm{m}^{2}\right)$ can be calculated as follows [27]:

$\mathrm{P}_{\text {pump }}=\frac{\Delta \mathrm{p}_{\mathrm{r}} \cdot \Phi_{\mathrm{r}}+\Delta \mathrm{p}_{\mathrm{s}} \cdot \Phi_{\mathrm{s}}}{2 \mathrm{~A}}$

where $\Delta \mathrm{p}_{\mathrm{r}}$ and $\Delta \mathrm{p}_{\mathrm{s}}$ are the measured pressure drop in the river water and seawater compartment, respectively $(\mathrm{Pa}), \Phi_{\mathrm{r}}$ and $\Phi_{\mathrm{s}}$ are the discharge of the feed water per river water and seawater compartment, respectively $\left(\mathrm{m}^{3} / \mathrm{s}\right)$, and $\mathrm{A}$ is the area of a single membrane $\left(\mathrm{m}^{2}\right)$, which is the same for both flat and structured membranes having the dimensions of $10 \mathrm{~cm} \times 10 \mathrm{~cm}$. The subscripts, $\mathrm{r}$ and $\mathrm{s}$, represent seawater and river water compartments, respectively. 
Subtracting the pumping power losses (Equation 5.3) from the gross power density $\mathrm{P}_{\text {gross }}$, the net power density can then be calculated as follows:

$\mathrm{P}_{\text {net }}=\mathrm{P}_{\text {gross }}-\mathrm{P}_{\text {pump }}$

\subsection{Results and discussion}

\subsubsection{Membrane preparation}

Casting followed by solvent evaporation was performed to make flat membranes and three types of micro- structured membranes, as described in more detail in Section 5.2 .2 .

The volume of the membrane-forming casting solution was adjusted such that the thickness of the continuous part (i.e. non-structured part) of the structured membranes was the same as that of the flat ones, namely $(200 \mu \mathrm{m})$. The thickness (or height) of the structures on the membranes was designed to be $100 \mu \mathrm{m}$, equal to the thickness of the spacers used for flat membranes. Figure 5.6 shows the approximate dimensions of the flat and structured membranes in wet state using different volumes of casting solution.

Structured membrane

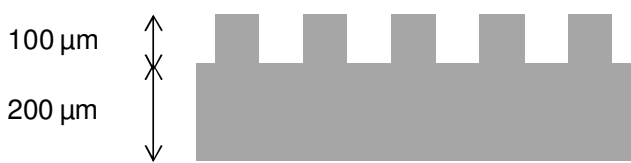

Flat membrane

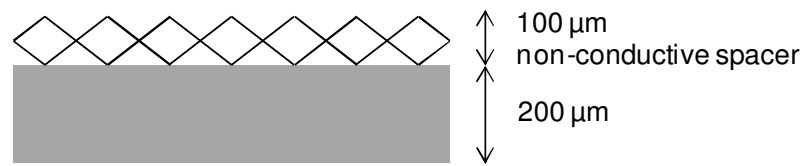

Figure 5.6. Schematic representation of the cross-section of a structured membrane (left) and a flat membrane with spacer (right).

If the flat part of the structured membranes is too thin $(<30 \mu \mathrm{m})$, it is very difficult to remove the membranes from the mold without rupturing the film. In addition, if the thickness is less than $200 \mu \mathrm{m}$, the non-structured continuous part becomes wavy, due to the shrinkage during drying of the membrane film. This might be due to a possible solvent concentration gradient towards the mold substrate during the evaporation [24, 28]. When the continuous part is mostly dry, the ridges may still contain some solvent. Further evaporation of the solvent from these ridges results in further shrinkage and a deformation of the continuous film. 


\subsubsection{Membrane characterization}

\subsubsection{SEM}

SEM pictures of the produced membranes provide insight in the dimensions of the channels and ridges and the membranes' morphology. Figure 5.7 shows images of each of the structured membranes and, at a higher magnification (x2000), of the flat membrane surface. As can be seen, the dimensions of the stainless steel molds were nicely replicated to the polymer films. The dense, non-porous character of the membranes is visible at a higher magnification in Figure $5.7 \mathrm{~d}$.

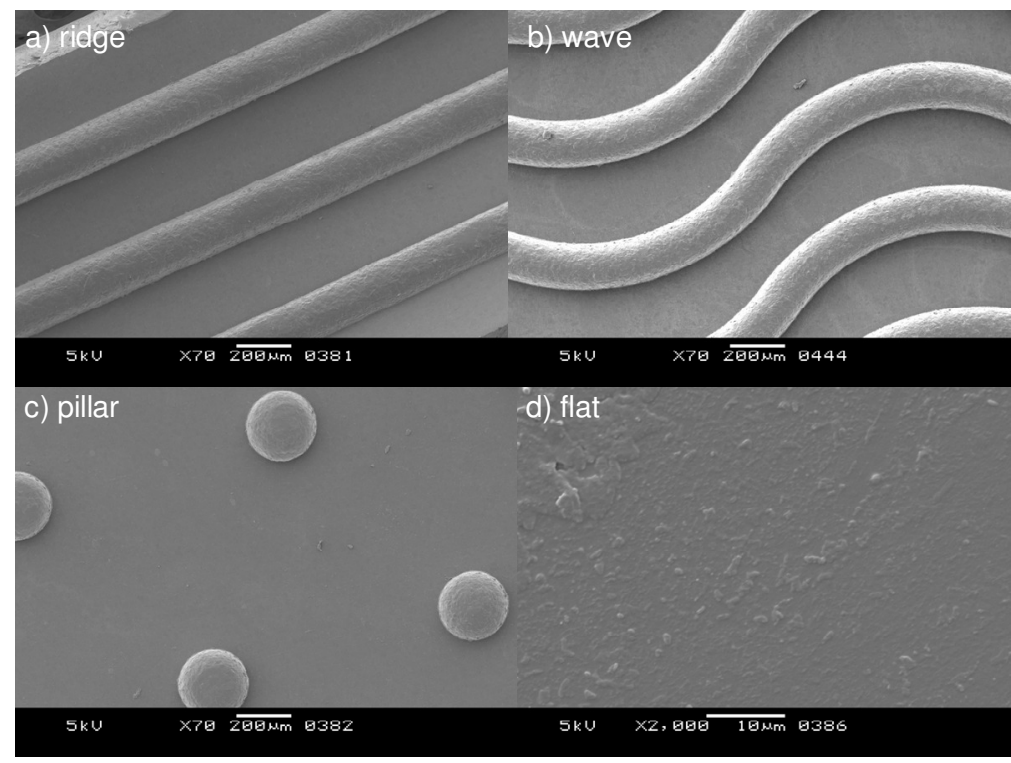

Figure 5.7. Surface morphology of tailor-made membranes: a) ridges b) waves c) pillars and d) flat membrane. Magnification a-c: 70x; Magnification d: 2000x.

To avoid changes in the dimensions of the structures, the membrane films were allowed to dry on the mold in the oven at elevated temperature $\left(130^{\circ} \mathrm{C}\right)$ and subsequently immersed in a $0.5 \mathrm{M} \mathrm{NaCl}$ solution. The films swelled in the salt solution and were then peeled from the molds by gentle pulling. Most swelling occurred parallel to the membrane surface (32 - 45\%) (as determined by optical microscope) rather than perpendicular to the surface (as determined by the digital screw micrometer). 


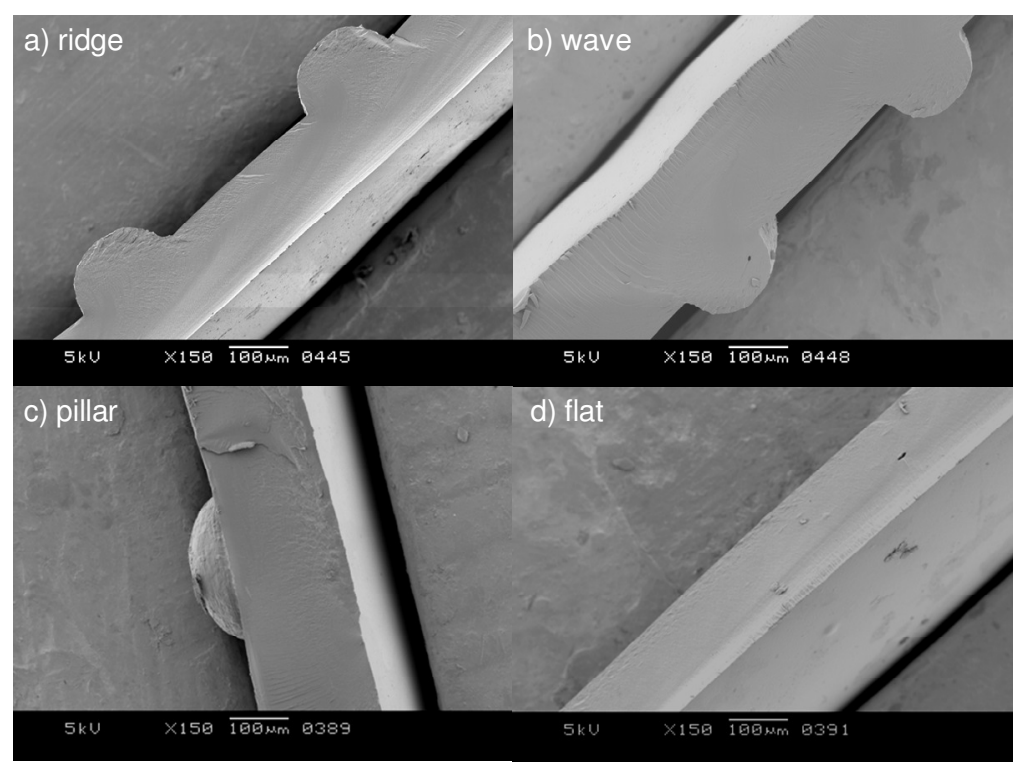

Figure 5.8. Cross-section morphology of tailor-made membranes: a) ridges b) waves c) pillars and d) flat membrane. Magnification: 150x.

Figure 5.8 shows cross-sections of the investigated membranes; as can be seen, dense replicas of the molds were obtained (see also Figure 5.3). Since the continuous flat part of the membrane is thick enough $(200 \mu \mathrm{m})$, the effect of shrinkage was not observed (i.e. no waviness was observed on the flat side of the membranes). The dry thicknesses of the continuous part of the structured membranes were comparable to those of flat membranes although the thickness of the pillar-structured membrane was slightly greater than that of the others (Table 5.1).

\subsubsection{Area resistance and permselectivity}

Table 5.1 shows the membrane properties of the PECH anion exchange membranes prepared in this study.

Table 5.1. Characteristics of anion exchange membranes used in this work.

\begin{tabular}{lccc}
\hline Membrane type & Thickness $^{\mathrm{a}}(\mathrm{\mu m})$ & Area resistance $\left(\Omega \cdot \mathrm{cm}^{2}\right)$ & Permselectivity (\%) \\
\hline Flat & $189 \pm 7$ & $2.55 \pm 0.04$ & $90.5 \pm 0.05$ \\
Ridges & $199 \pm 9$ & $3.16 \pm 0.07$ & $89.6 \pm 0.35$ \\
Waves & $200 \pm 4$ & $2.94 \pm 0.04$ & $89.5 \pm 0.30$ \\
Pillars & $212 \pm 9$ & $3.20 \pm 0.06$ & $90.1 \pm 0.20$ \\
\hline
\end{tabular}

a The thickness is that of the continuous part of the membranes in wet state.

The area resistance of the structured membranes was found to be slightly higher than that of flat membranes (Table 5.1). This is due to the structures on the membrane surface which contribute to the total membrane thickness; area resistance increases 
with increasing membrane thickness [26]. On the other hand, the area resistance of wave-structured membranes was slightly lower than that of ridge-structured and pillarstructured membranes. This could be related to possible differences during thermal curing, such as in the solvent evaporation rate, which might result in slightly different degrees of cross-linking. However, there were no major differences in permselectivity between the membranes.

\subsubsection{RED performance}

\subsubsection{Flow distribution}

Figure 5.9 displays a visualization of the flow distribution along the structured membranes. The images show different sections recorded at different times (see Section 2.4.1). The feed was transported diagonally from the bottom-left opening to the topright opening. The ink was injected via a connection at a very close distance to the opening at the bottom part of the membrane (Figure 5.9). After performing two trials, the images were determined to be representative.

In Figure 5.9, the darker regions represent the ink flow along the membrane surface whereas the lighter regions represent mainly water flow. It can be seen that for the ridge-structured membranes, the ink flow preferred the sides of the active membrane area after the initial injection of the ink (at $0.8 \mathrm{~s}$ ). After some time, the central part of the membrane turned darker, indicating that the ink flow experienced a delay relative to the sides. Some channels may not even have filled with ink at all as the inflow/outflow of the stack was not optimized.

Similar flow behavior was observed for the wave-structured membranes. The flow showed preferential flow paths along the membrane surface, but there was more ink flow in the central part compared with ridge-structured membranes. It resulted in darker central regions at $0.8 \mathrm{~s}$, and again, unfilled channels are observed at the membrane surface (Figure 5.9b). This is related to the fact that the flow design for the waves was apparently not optimal. 


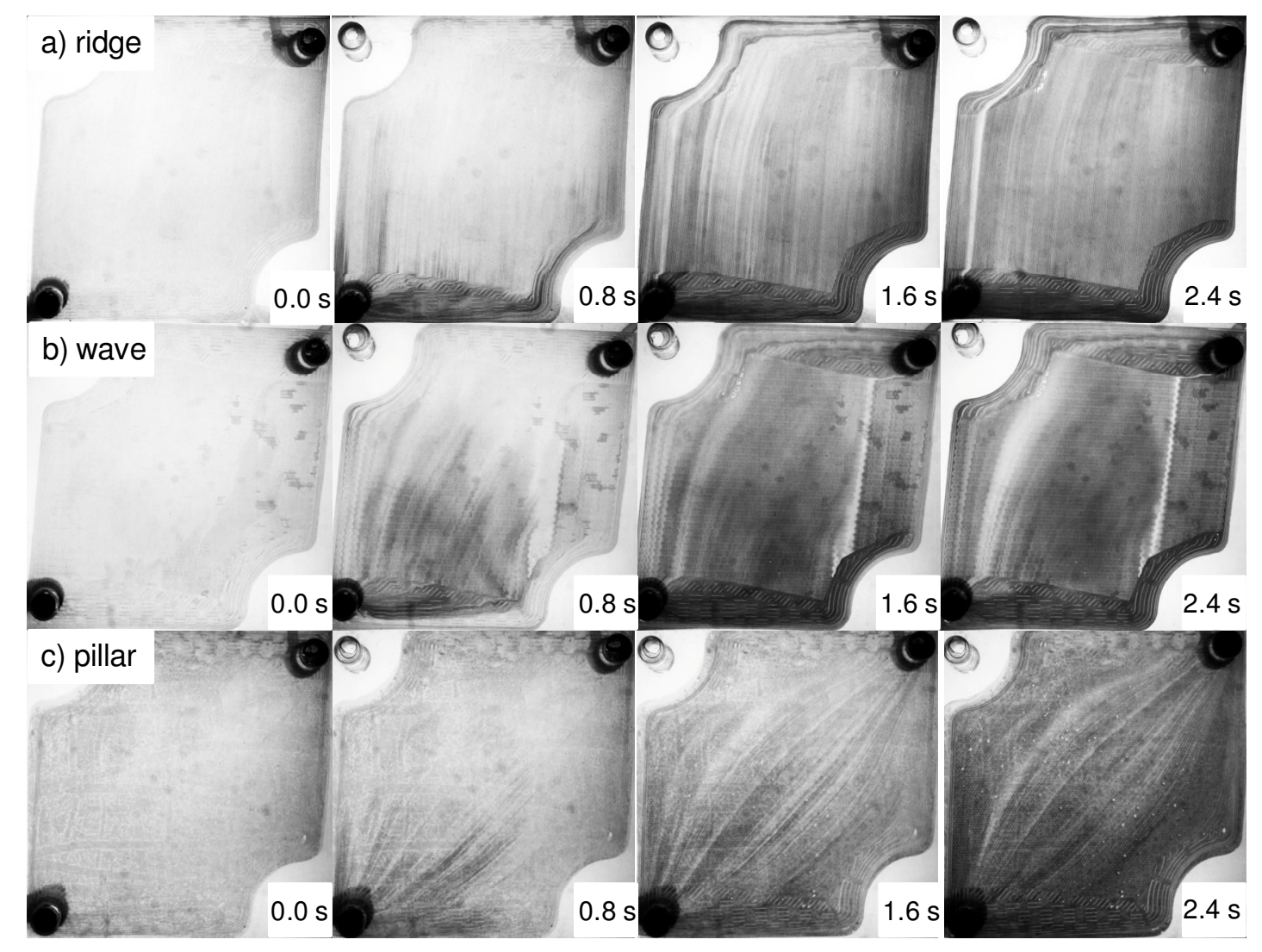

Figure 5.9. Visualization of the flow distribution inside the membrane structures (a) ridge, b) wave and c) pillar), realized by ink-injection in the water stream of $12 \mathrm{ml} / \mathrm{min}$.

On the other hand, the ink distribution showed no preferential local flows for pillarstructured membranes. Since pillar structured membranes have no continuous structures that form channels, the risk of preferential channeling or clogging of the flow by (ink) particles as may have occurred with the ridge and wave structures is less likely. Thus, after the initial ink injection, the flow exhibited an even distribution over the membrane surface and at $2.4 \mathrm{~s}$, the ink was well distributed over the entire membrane area (Figure 5.9c). The results show that the pillar structures allow a more efficient use of the active membrane area compared with when other structured membranes are used. Of course these designs can be further optimized and different structural geometries and dimensions can be chosen. However, that is beyond the scope of this work.

\subsubsection{Gross power density}

Figure 5.10 shows the gross power density of the stacks with structured and flat membranes as a function of the Reynolds number and the corresponding feed flow rates. The graphs represent arithmetic average values. The error bars indicate the 
fluctuations in the measurements. Some error bars are smaller than the symbol size and therefore not visible.

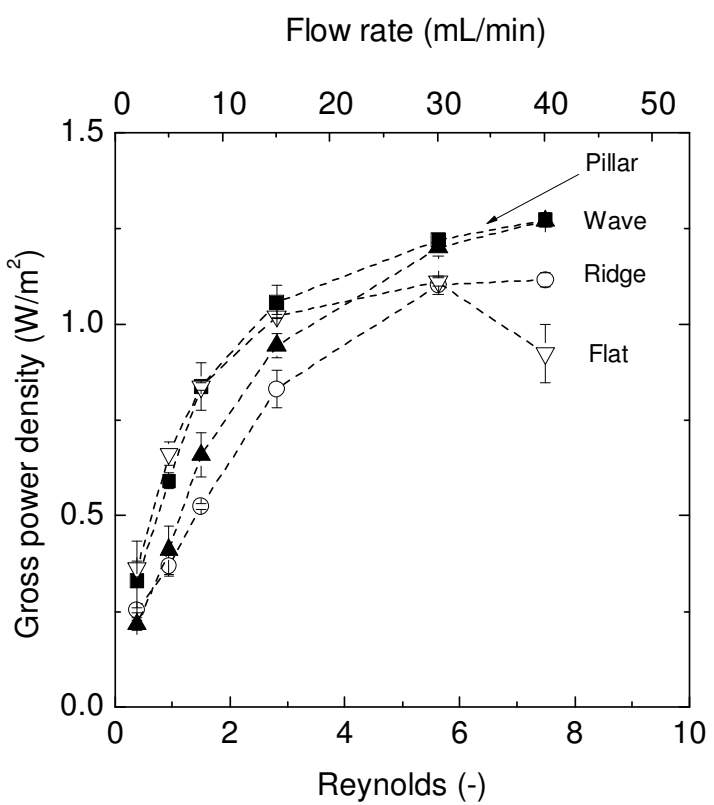

Figure 5.10. Gross power density of the RED stack using tailor-made flat and structured membranes.

In general, the gross power density increases with increasing Reynolds number because of improved mixing and since the ionic transport is promoted, resulting in lower internal resistances at higher flow rates when the feed waters are rapidly renewed (Figure 5.10). At relatively high Reynolds numbers, the structured membranes yielded higher gross power densities than the flat membranes with spacers, whereas flat membranes yield higher gross power densities at lower Reynolds numbers. This observation is in good agreement with a study by Vermaas et al. who only investigated straight-ridge and flat membranes [10]. At lower flow rates, when hydraulic friction is not that significant, spacers cause better mixing than structured membranes resulting in increased driving forces and gross power outputs. Consequently, structured membranes are advantageous to use especially at higher feed flow rates (higher Reynolds numbers).

In our experiments, the membranes with pillar structures exhibited the highest gross power density of $1.3 \mathrm{~W} / \mathrm{m}^{2}$, which is close to the gross power density achieved with membranes with wave structures, both at the highest feed flow rate. This is in agreement with Figure 5.9c that shows that the flow distribution with the pillarstructured membranes was more uniform than with the other structured membranes. In addition, the pillar-structured membranes had a wider slit for the feed waters to flow through compared with the other types of structured membranes (Figure 5.3). 
An interesting observation regarding the stack with flat membranes is that the gross power density increased with increasing Reynolds number and then reached a maximum at a Reynolds number of 6 . Probably, at higher flow rates, the time available for ion exchange is limiting (due to the high flow rate and consequently low residence time. Additionally, some leakage may have occurred in the tests with flat membranes, because of the high pressure drop due to the presence of spacer; the structured membranes with their open-slit geometry experience a lower pressure drop at high Reynolds numbers. For the flat membranes, the error bars are much larger after the maximum (Figure 5.10).

Wave-structured membranes have advantages over straight-ridge-structured membranes. First, relative to straight-ridges, wave structures lead to better mixing of water due to the change in the direction of the flow along the stack. Second, compared with straight ridges, wave structures create longer flow paths in the stack which means that more ions of the feed are utilized for cross-membrane ion transport in the stack due to the longer residence times. This also results in higher fuel efficiency. However, similar to Vermaas et al. [10], we also found that ridge- and wave-structured membranes are less advantageous than flat membranes with spacers at lower Reynolds numbers (lower than 4 and 6, respectively) where the feed flow is relatively low. At these low flow rates, the lack of mixing for wave and ridge structures results in higher boundary layer resistances (thus, high non-ohmic resistances) than for the stack with spacers [10].

Vermaas et al. showed that the ohmic resistance of their stacks was lower with ridgestructured membranes than with flat membranes because the spacer shadow effect was eliminated [10]; this should have led to higher power densities. In our work, we observed a $21 \%$ increase in gross power density with ridge-structured membranes at a Reynolds number of 7.5. However, Vermaas et al. found no significant difference between the gross power densities between the stacks with ridge-structured membranes and flat membranes, at the same Reynolds number (7.5) [10]. Moreover, the gross power density obtained by Vermaas et al. was less than $0.7 \mathrm{~W} / \mathrm{m}^{2}$ whereas we achieved $0.9 \mathrm{~W} / \mathrm{m}^{2}$ at the same Reynolds number. We can attribute this to several factors. Firstly, we used an intermembrane distance of $100 \mu \mathrm{m}$ whereas $200 \mu \mathrm{m}$ was used by Vermaas et al. The effect of intermembrane distance on the gross power density is well described in the literature [29]; a smaller intermembrane distance makes the stack more conductive. Secondly, there is a difference in the electrochemical properties of the membranes. We prepared self-standing anion exchange membranes with relatively low area resistances (Table 5.1; 2.6-3.2 $\Omega \cdot \mathrm{cm}^{2}$ ); these membranes are homogeneous, without 
any non-conductive reinforcement, and are specially designed for RED. Vermaas et al. used heterogeneous membranes with higher area resistances $\left(2.7-5.8 \Omega \cdot \mathrm{cm}^{2}\right)$ [10]. Considering this, even though only the anion exchange membranes were structured in this study and only on one side, we were able to obtain higher gross power densities. The gross power density of the stack with pillar structured membranes $\left(1.3 \mathrm{~W} / \mathrm{m}^{2}\right)$ was the highest, obtained at a Reynolds number of 7.5, which is approximately $38 \%$ more than for the flat membranes at that Reynolds number.

\subsubsection{Resistance}

To investigate this further, we can split the resistances (losses) into an ohmic and a non-ohmic part. The ohmic part includes, e.g. the resistances of the membranes, seawater and river water compartments; whereas the non-ohmic resistances stem from non-linear effects such as concentration polarization, boundary layer effects and mixing.

Vermaas et al. classified non-ohmic resistances (i.e. resistance due to time-dependent voltage changes at constant current) into two subgroups: resistances due to concentration changes along the flow path and the resistances due to boundary layers $[10,30]$. Their study showed that resistances due to concentration changes are significant at low Reynolds numbers and do not exhibit a significant difference whether the stack is built with flat or with ridge-structured membranes. However, different membrane geometries affect these resistances which are influenced by the boundary layer thickness and thus by ionic transport. On the other hand, boundary layer resistances were shown to be significantly reduced when spacers were used in the stack $[10]$.

The total internal resistance of the stack is an important parameter as it determines RED performance. It represents the sum of the ohmic resistances, $R_{\text {ohmic }}$, and the non-

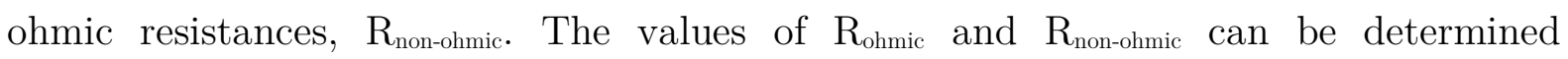
experimentally from chronopotentiometric measurements [29, 31]. The rapid voltage jump when the current is released represents the contribution of the ohmic resistance, whereas the time-dependent voltage change is due to non-ohmic resistances. Figure 5.11 displays $R_{\text {ohmic }}$ and $R_{\text {non-ohmic }}$ for the stacks with flat membranes and those with the different structured membranes. 
Flow rate $(\mathrm{mL} / \mathrm{min})$

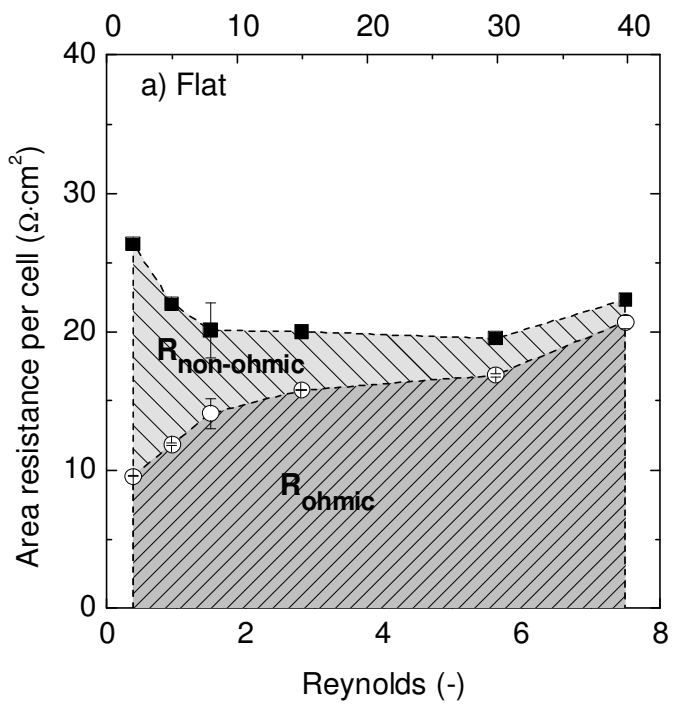

Flow rate $(\mathrm{mL} / \mathrm{min})$

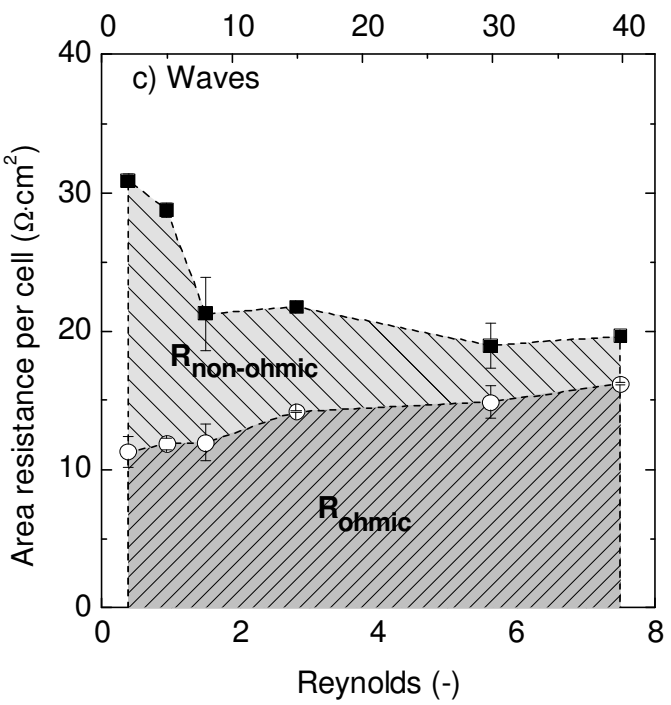

Flow rate $(\mathrm{mL} / \mathrm{min})$

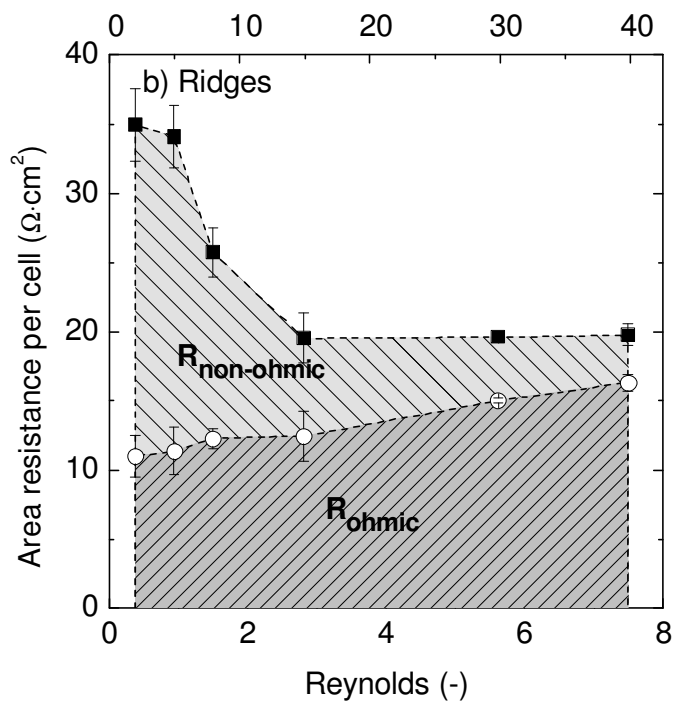

Flow rate $(\mathrm{mL} / \mathrm{min})$

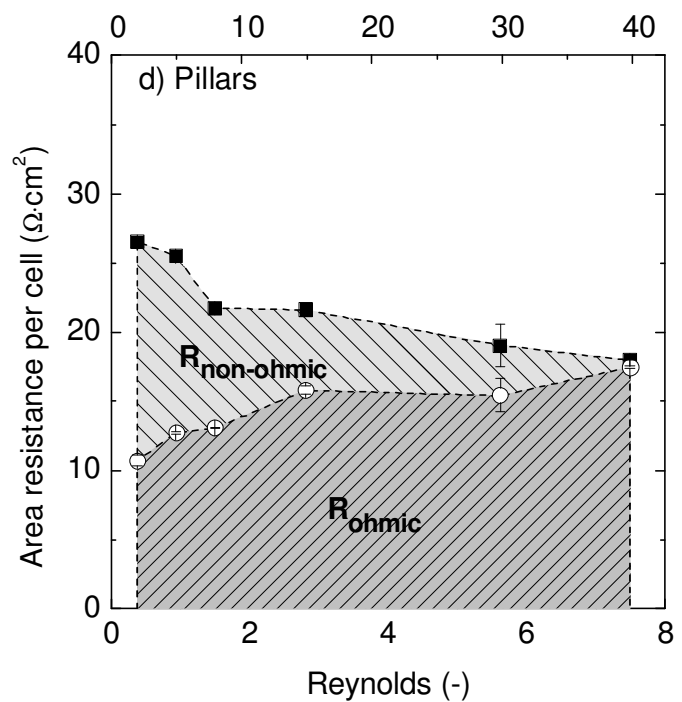

Figure 5.11. Area resistance as a function of the Reynolds number for a) the stack with flat membranes, b-d) the stacks with structured membranes. (b) ridges; c) waves; d) pillars).

Figure 5.11 shows that $R_{\text {ohmic }}$ increased while $R_{\text {non-ohmic }}$ decreased with increasing Reynolds number and flow rate for all stacks. The stacks with structured membranes show significantly lower ohmic resistances because of the elimination of the spacer shadow effect. The ohmic resistance was reduced by 21,22 and $16 \%$ when using membranes with ridges, waves and pillars, respectively, relative to the stack with flat membranes. As we used homogenous membranes with relatively low area resistances (Table 5.1; 2.6-3.2 $\Omega \cdot \mathrm{cm}^{2}$ ), this achieved decrease in $\mathrm{R}_{\text {ohmic }}$ is significant. Vermaas et al. reported a decrease of approximately $30 \%$ of the ohmic resistances in a RED stack in which all the membranes were structured, but had high area resistances (around 2.7- 
$5.8 \Omega \cdot \mathrm{cm}^{2}$ ) [10]. Considering that only one side of our membranes was structured (and only of the anion exchange membranes), the decrease in ohmic resistance can be expected to be even greater when stacks are used with membranes that are structured on both sides.

The decrease of non-ohmic resistances with increasing flow rate is due to better mixing at higher flow rates (i.e. at higher Reynolds numbers). At lower flow rates, $\mathrm{R}_{\text {non-ohmic }}$ is significant compared with $\mathrm{R}_{\text {ohmic }}$ as the low mixing rate results in poor ionic transport for all the stacks. In comparison with the stack with flat membranes, $\mathrm{R}_{\text {non-ohmic }}$ is higher for all stacks with structured membranes, as mixing in the spacered system is much better which results in lower boundary resistances. Vermaas et al. reported similar behavior [10] and observed that boundary layer resistances as well as the resistances due to concentration changes decreased with increasing feed flow rate, both for stacks with flat membranes and with profiled membranes (i.e. straight ridges).

A higher $\mathrm{R}_{\text {non-ohmic }}$ is visible for membranes with straight ridges than for flat membranes and for membranes with wave and pillar structures (Figure 5.11b). This is because there is less mixing in the open channels of straight ridges. Wave structures cause the flow to change direction and follow a zigzag pattern, which promotes mixing (Figure 5.11c). Non-ohmic resistances were found to be the lowest for pillar-structured membranes, and were very low at higher Reynolds numbers (Figure 5.11d). The advantage of the pillar structures is that the flow is more uniform as shown in Figure 5.9, while the pillars still generate mixing as they are obstacles that force the flow to split locally. Optimization of the design and dimensions of the structures to enhance mixing could ultimately result in further increased power outputs.

Overall, the area resistances of the stacks with ridge and wave structures on the membranes were found to be slightly higher than for the other membranes for low Reynolds numbers. For high Reynolds numbers, the values are comparable to that of the stack with flat membranes. The area resistance of the stack with pillar-structured membranes is similar to the area resistance of the stack with flat membranes for low Reynolds numbers, whereas it is the lowest of all for high Reynolds numbers.

\subsubsection{Pumping power}

As the structured membranes are structured on one side only, the stacks with these membranes still contained spacers at the non-structured flat sides of the membranes. In the stack with flat membranes, spacers were used on both sides of the membranes. Spacers cause a large pressure drop due to their structure but also induce a tortuous 
water flow. The greater the pressure drop, the greater the power required to pump the waters through the stack, and the lower the net power density. To calculate the net power density, the used pumping power (power loss) was determined and subtracted from the gross power density.

Figure 5.12a shows the pressure drop on the seawater side of the membranes where $100-\mu m$-thick spacers were used in all cases. As expected, there is no significant difference in pressure drop for the different membrane types since the same intermembrane distance $(100 \mu \mathrm{m})$ and the same flow rates were used, and the structure of the membranes on the seawater side was the same (i.e. flat). Only for Reynolds numbers higher than 4, some differences in pressure drop are observed. This may be due to irregularities in the hydraulic friction at the inflow and outflow of the stack or because the stacks have to be assembled manually.

Figure $5.12 \mathrm{~b}$ shows the pressure drop on the structured side of the membranes (i.e. the river water compartment) where no spacers were used (other than for the flat membranes). The pressure drop for the pillar-structured membranes is approximately 4 times less than for flat membranes with spacers. Stacks with membranes with ridge and wave structures also experienced a lower pressure drop than stacks with flat membranes; the pressure drop for flat membranes is approximately 1.3 times greater than for ridge-structured membranes for a Reynolds number of 7.5. The pressure drop for flat membranes was found to be about 5 times greater than for ridge structured membranes by Vermaas et al. who studied ridge-structured membranes with a channel width of $1.0 \mathrm{~mm}$ and a ridge width of $0.2 \mathrm{~mm}$, i.e. a channel-to-ridge width ratio of 5 . For the ridge-structured and wave-structured membranes we used, this ratio is 2, implying narrower channels for the water flow than in the work by Vermaas et al..

Another parameter affecting the pressure drop is the intermembrane distance (i.e. the spacer thickness in the stacks with flat membranes or the height of the structures in the stack with structured membranes). The smaller the intermembrane distance, the higher the hydraulic friction is and the higher the resulting pressure drop. When comparing our pressure drop (0.76 bar) for an intermembrane distance of $100 \mu \mathrm{m}$ for ridge-structured membranes with the pressure drop measured by Vermaas et al. (0.08 bar) for an intermembrane distance of $200 \mu \mathrm{m}$ [10], the pressure drop is higher for a smaller intermembrane distance, however at these intermembrane distances, the differences are not really large. 

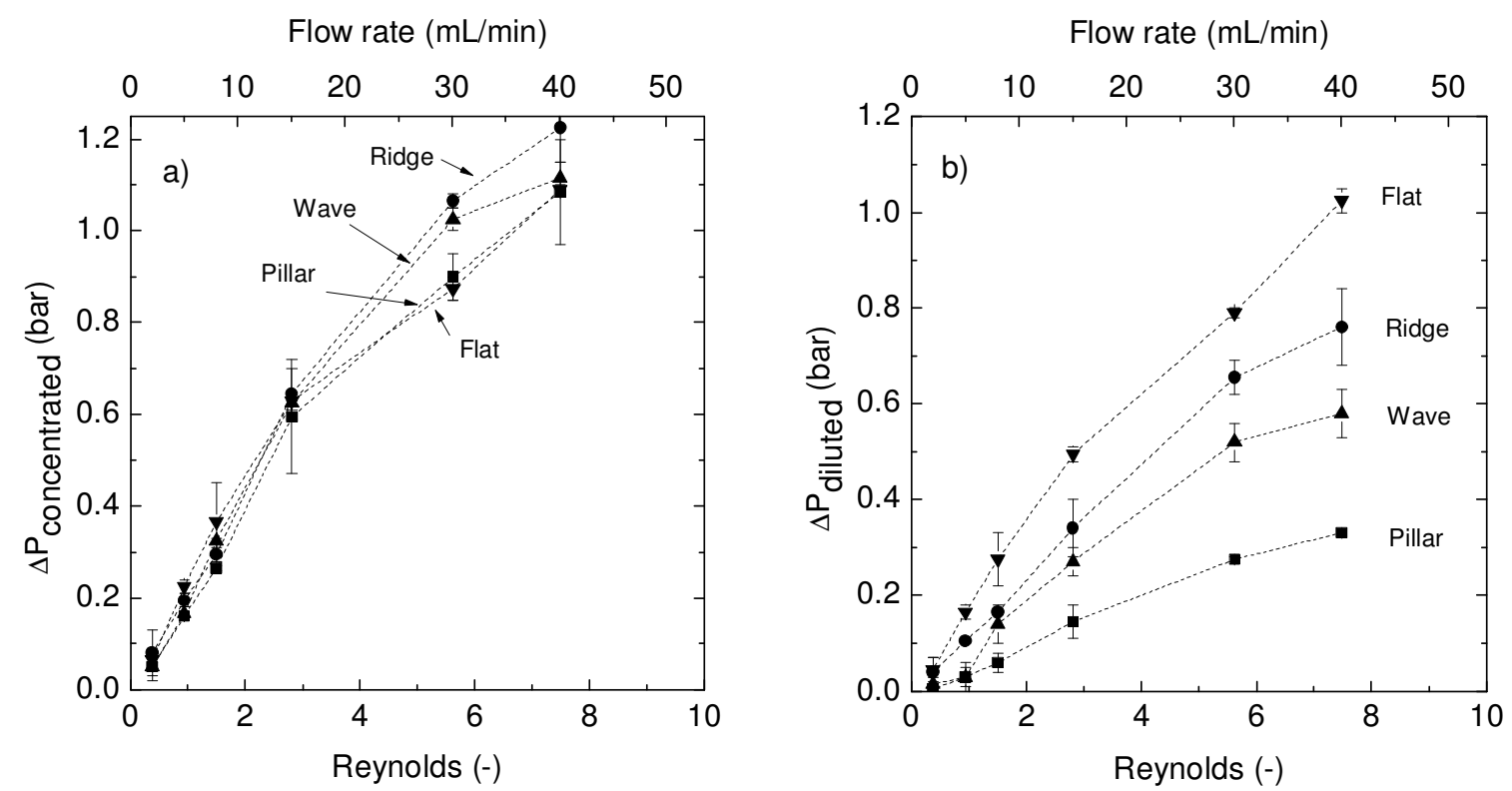

Figure 5.12. Pressure drop in (a) the concentrated (seawater) compartment and (b) in the diluted (river water) compartment.

Figure 5.13 shows the average pressure drops of the feed water compartments. These data are based on the arithmetic mean of the pressure drop on the seawater side and on the river water side. The highest average pressure drop occurred in the stack with flat membranes (Figure 5.13). The stack with pillar-structured membranes exhibited the lowest average pressure drop because of the relatively wider slit for water flow and because there is less hydraulic friction with pillar structures.

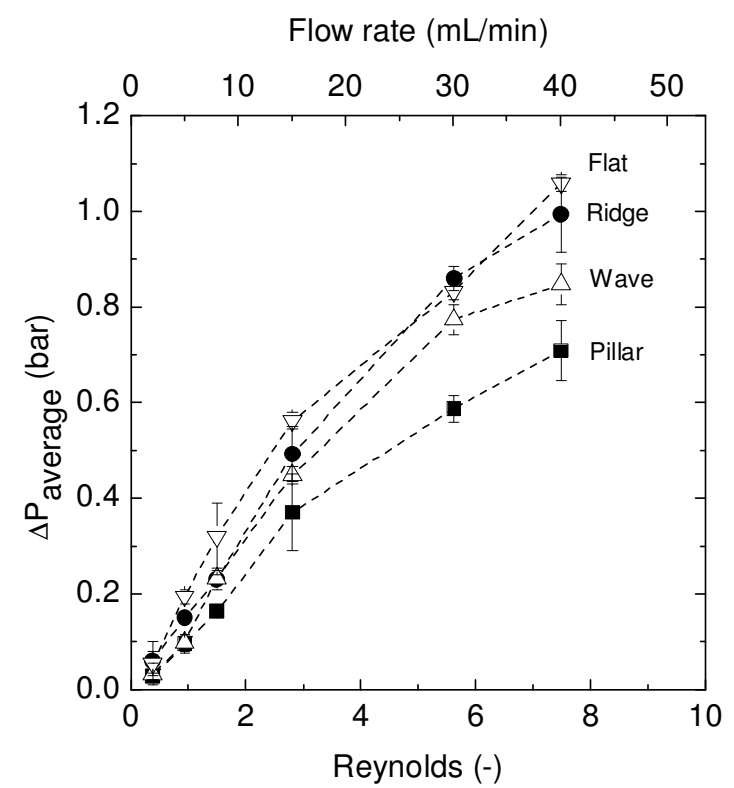

Figure 5.13. Average pressure drop at the seawater and the river water side combined. 


\subsubsection{Net power density}

Using Equation 5.4, we calculated the net power density by subtracting the pumping power from the gross power density (Figure 5.14). The highest achieved net power density was $0.62 \mathrm{~W} / \mathrm{m}^{2}$ with pillar-structured membranes, which incurred the lowest pressure drop. To our knowledge, this value is the highest net power density obtained so far with the use of homogeneous membranes in a RED stack. It was approximately $20 \%$ higher than for the stack with spacers. In Figure 5.14, the peak in net power density shifts towards higher Reynolds numbers for the stack with structured membranes compared to the stack with flat membranes. This is because structured membranes experience lower hydraulic friction (i.e. lower pumping power required), but require higher Reynolds numbers to obtain sufficient mixing. Considering that a positive net power density is still possible at higher Reynolds numbers (i.e. higher flow rates) when using structured membranes (e.g. wave and pillar structured membranes), it will allow one to increase the feed flow further to get higher power densities compared to that of flat membranes.

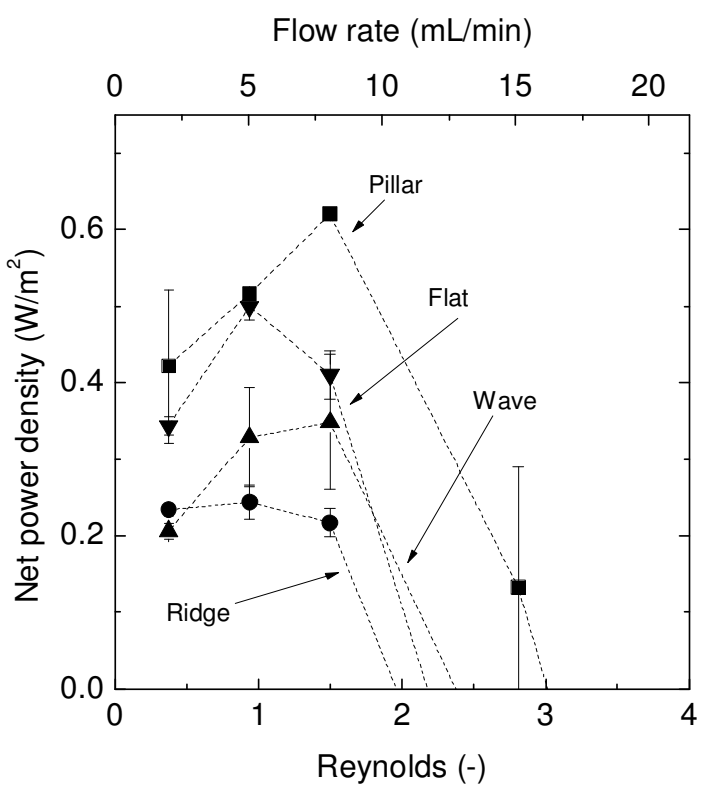

Figure 5.14. Net power density of the RED stacks using tailor-made anion exchange membranes.

Figure 5.14 shows that the use of flat membranes with spacers in a RED stack is still advantageous over using membranes with wave and ridge structures. The average pressure drop in the stack with ridge-structured membranes was very close to the drop in the stack with flat membranes, and at lower flow rates, the stack with flat membranes still outperforms the stacks with wave and ridge structures. Only at a very 
small range of Reynolds numbers, wave-structured membranes provided a higher net power density than flat membranes.

By contrast, Vermaas et al. observed a 10\% higher net power density with ridgestructured membranes relative to flat membranes [10], whereas the use of ridgestructured membranes is not advantageous over flat membranes in our system. This may be attributed to the use of $50 \%$ less high ridges (smaller intermembrane distance) and the lower channel-to-ridge width ratio in our system, all leading to a greater pressure drop and a lower gross power density.

However, the relatively low pressure drop that occurs with structured membranes allows the use of relatively high flow rates of feed waters in small-scale pilot plants where the volume of feed waters is not a limiting factor. Moreover, new designs of structured membranes can be considered such as different geometries to promote mixing at the boundary layers and less high ridges on the membrane surface, which would reduce the intermembrane distance resulting in reduced electrical resistance (but would also cause more hydraulic friction).

\subsection{Conclusions}

In this study, the performance of a reverse electrodialysis (RED) stack was investigated using different structured membranes. The use of such structured membranes eliminate the use of conventional non-conductive spacers. Flat homogeneous anion exchange membranes and three types of structured membranes, i.e. with straight ridges, wave structures and pillars on one side of the membrane were prepared by casting. These membranes showed good electrochemical properties. The pillar-structured membranes performed best in all aspects. The ohmic resistance of the stack with the pillar-structured membranes was around $21 \%$ lower than that of the stack with flat membranes resulting in a $38 \%$ higher gross power density. These values are significantly high since half of the stack still required the use of spacers. The hydraulic friction (i.e. required pumping power) was significantly reduced in the feed compartments where the structured sides of the membranes were used. The required pumping power was the lowest for the stack with pillar-structured membranes, which also provided a more homogeneous flow distribution. The net power density achieved with pillar-structured membranes at only one side was approximately $20 \%$ higher than was achieved with flat membranes and spacers. In addition, the low hydraulic friction allows higher feed water flow rates when structured membranes are used. To the best of our knowledge, this was the first time that self-standing homogeneous membranes 
with specific structures were used in RED. Considering this, further improvements can be foreseen when casting is used to obtain homogeneous structured membranes with optimized structure geometries, the desired electrochemical and physical properties.

\subsection{Acknowledgements}

This work was performed in the TTIW cooperation framework of Wetsus, centre of excellence for sustainable water technology (www.wetsus.nl). Wetsus is funded by the Dutch Ministry of Economic Affairs (IOP-TTI), the European Community (European Fund for Regional Development and Seventh Framework Programme), Northern Netherlands Provinces (Peaks in the Delta), the city of Leeuwarden and the Province of Fryslân. The authors would like to thank Alliander, Eneco Energy, Fuji Film, Landustrie, Magneto Special Anodes, A. Hak and MAST Carbon of the research theme "Blue Energy" for productive conversations and financial support. In addition, the authors thank David Vermaas for fruitful discussions and his assistance in the design of molds.

\subsection{Nomenclature}

$\begin{array}{ll}\mathrm{V}_{\text {measured }} & \text { measured membrane potential }[\mathrm{V}] \\ \mathrm{V}_{\text {theoretical }} & \text { theoretical membrane potential }[\mathrm{V}] \\ \mathrm{Re} & \text { Reynolds number }[-] \\ \mathrm{p}_{\mathrm{r}} & \text { pressure drop on river water side }[\mathrm{Pa}] \\ \mathrm{p}_{\mathrm{s}} & \text { pressure drop on seawater side }[\mathrm{Pa}] \\ \overline{\mathrm{u}} & \text { average flow velocity }[\mathrm{m} / \mathrm{s}] \\ \mathrm{D}_{\mathrm{h}} & \text { hydraulic diameter }[\mathrm{m}] \\ \mathrm{d} & \text { height of flow path }[\mathrm{m}] \\ \mathrm{b} & \text { width of flow path }[\mathrm{m}] \\ \mathrm{P}_{\text {pump }} & \text { pumping power per unit membrane area }\left[\mathrm{W} / \mathrm{m}^{2}\right] \\ \mathrm{P}_{\text {gross }} & \text { gross power density }\left[\mathrm{W} / \mathrm{m}^{2}\right] \\ \mathrm{P}_{\text {net }} & \text { net power density }\left[\mathrm{W} / \mathrm{m}^{2}\right] \\ \mathrm{R}_{\text {ohmic }} & \text { ohmic resistance }\left[\Omega \cdot \mathrm{cm}^{2}\right] \\ \mathrm{R}_{\text {non-ohmic }} & \text { ohmic resistance }\left[\Omega \cdot \mathrm{cm}^{2}\right] \\ \text { Greek symbols } & \\ \alpha & \text { membrane permselectivity }[-] \\ v & \text { kinematic viscosity }\left[\mathrm{m}^{2} / \mathrm{s}\right] \\ \Phi_{\mathrm{r}} & \text { flow rate of river water compartment }\left[\mathrm{m}^{3} / \mathrm{s}\right] \\ \Phi_{\mathrm{s}} & \text { flow rate of seawater compartment }\left[\mathrm{m}^{3} / \mathrm{s}\right]\end{array}$




\subsection{References}

[1] R.E. Pattle, Production of electric power by mixing fresh and salt water in the hydroelectric pile [19], Nature, 174 (1954) 660.

[2] J.N. Weinstein, F.B.J.W. Leitz, Electric power from differences in salinity: the dialytic battery, Science, 191 (1976) 557-559.

[3] G.L. Wick, W.R. Schmitt, PROSPECTS FOR RENEWABLE ENERGY FROM THE SEA, Marine Technology Society Journal, 11 (1977) 16-21.

[4] J.W. Post, J. Veerman, H.V.M. Hamelers, G.J.W. Euverink, S.J. Metz, K. Nymeijer, C.J.N. Buisman, Salinity-gradient power: Evaluation of pressure-retarded osmosis and reverse electrodialysis, Journal of Membrane Science, 288 (2007) 218-230.

[5] G.Z. Ramon, B.J. Feinberg, E.M.V. Hoek, Membrane-based production of salinity-gradient power, Energy and Environmental Science, 4 (2011) 4423-4434.

[6] J. Kim, S.J. Kim, D.-K. Kim, Energy harvesting from salinity gradient by reverse electrodialysis with anodic alumina nanopores, Energy, 51 (2013) 413-421.

[7] J. Veerman, M. Saakes, S.J. Metz, G.J. Harmsen, Reverse electrodialysis: Performance of a stack with 50 cells on the mixing of sea and river water, Journal of Membrane Science, 327 (2009) 136-144.

[8] J.W. Post, H.V.M. Hamelers, C.J.N. Buisman, Energy recovery from controlled mixing salt and fresh water with a reverse electrodialysis system, Environmental Science and Technology, 42 (2008) 57855790.

[9] P. Długołecki, K. Nymeijer, S. Metz, M. Wessling, Current status of ion exchange membranes for power generation from salinity gradients, Journal of Membrane Science, 319 (2008) 214-222.

[10] D.A. Vermaas, M. Saakes, K. Nijmeijer, Power generation using profiled membranes in reverse electrodialysis, Journal of Membrane Science, 385-386 (2011) 234-242.

[11] P. Długołęcki, J. Dą̧browska, K. Nijmeijer, M. Wessling, Ion conductive spacers for increased power generation in reverse electrodialysis, Journal of Membrane Science, 347 (2010) 101-107.

[12] J.S. Vrouwenvelder, D.A. Graf von der Schulenburg, J.C. Kruithof, M.L. Johns, M.C.M. van Loosdrecht, Biofouling of spiral-wound nanofiltration and reverse osmosis membranes: A feed spacer problem, Water Research, 43 (2009) 583-594.

[13] J.W. Post, Blue energy: electricity production from salinity gradients by reverse electrodialysis, in: Environmental Science, Wageningen University, 2009, pp. 222.

[14] V.V. Nikonenko, N.D. Pismenskaya, A.G. Istoshin, V.I. Zabolotsky, A.A. Shudrenko, Description of mass transfer characteristics of ED and EDI apparatuses by using the similarity theory and compartmentation method, Chemical Engineering and Processing: Process Intensification, 47 (2008) 1118-1127.

[15] C. Larchet, V.I. Zabolotsky, N. Pismenskaya, V.V. Nikonenko, A. Tskhay, K. Tastanov, G. Pourcelly, Comparison of different ED stack conceptions when applied for drinking water production from brackish waters, Desalination, 222 (2008) 489-496.

[16] H. Strathmann, Electrodialysis, a mature technology with a multitude of new applications, Desalination, 264 (2010) 268-288.

[17] A. Grabowski, Electromembrane desalination processes for production of low conductivity water, in, Logos-Verl., Berlin, 2010. 
[18] J. Balster, M.H. Yildirim, D.F. Stamatialis, R. Ibanez, R.G.H. Lammertink, V. Jordan, M. Wessling, Morphology and microtopology of cation-exchange polymers and the origin of the overlimiting current, Journal of Physical Chemistry B, 111 (2007) 2152-2165.

[19] J. Balster, D.F. Stamatialis, M. Wessling, Membrane with integrated spacer, Journal of Membrane Science, 360 (2010) 185-189.

[20] L. Vogelaar, Phase separation micro molding, in, University of Twente, Enschede, 2005, pp. 117.

[21] H. Becker, C. Gärtner, Polymer microfabrication methods for microfluidic analytical applications, ELECTROPHORESIS, 21 (2000) 12-26.

[22] V.I. Zabolotskii, S.A. Loza, M.V. Sharafan, Physicochemical Properties of Profiled Heterogeneous Ion-Exchange Membranes, Russ J Electrochem, 41 (2005) 1053-1060.

[23] I.S. Ngene, R.G.H. Lammertink, M. Wessling, W.G.J. Van der Meer, Particle deposition and biofilm formation on microstructured membranes, Journal of Membrane Science, 364 (2010) 43-51.

[24] L. Vogelaar, R.G.H. Lammertink, J.N. Barsema, W. Nijdam, L.A.M. Bolhuis-Versteeg, C.J.M. Van Rijn, M. Wessling, Phase separation micromolding: A new generic approach for microstructuring various materials, Small, 1 (2005) 645-655.

[25] E. Güler, R. Elizen, D.A. Vermaas, M. Saakes, K. Nijmeijer, Performance-determining membrane properties in reverse electrodialysis, Journal of Membrane Science, 446 (2013) 266-276.

[26] E. Guler, Y. Zhang, M. Saakes, K. Nijmeijer, Tailor-Made Anion-Exchange Membranes for Salinity Gradient Power Generation Using Reverse Electrodialysis, ChemSusChem, 5 (2012) 2262-2270.

[27] J. Veerman, M. Saakes, S.J. Metz, G.J. Harmsen, Electrical Power from Sea and River Water by Reverse Electrodialysis: A First Step from the Laboratory to a Real Power Plant, Environmental Science \& Technology, 44 (2010) 9207-9212.

[28] M. Bikel, I.G.M. Pünt, R.G.H. Lammertink, M. Wessling, Shrinkage effects during polymer phase separation on microfabricated molds, Journal of Membrane Science, 347 (2010) 141-149.

[29] D.A. Vermaas, M. Saakes, K. Nijmeijer, Doubled power density from salinity gradients at reduced intermembrane distance, Environmental Science and Technology, 45 (2011) 7089-7095.

[30] D.A. Vermaas, E. Guler, M. Saakes, K. Nijmeijer, Theoretical power density from salinity gradients using reverse electrodialysis, Energy Procedia, 20 (2012) 170-184.

[31] P. Sistat, G. Pourcelly, Chronopotentiometric response of an ion-exchange membrane in the underlimiting current-range. Transport phenomena within the diffusion layers, Journal of Membrane Science, 123 (1997) 121-131. 
Chapter 5. 


\section{General conclusions and outlook}

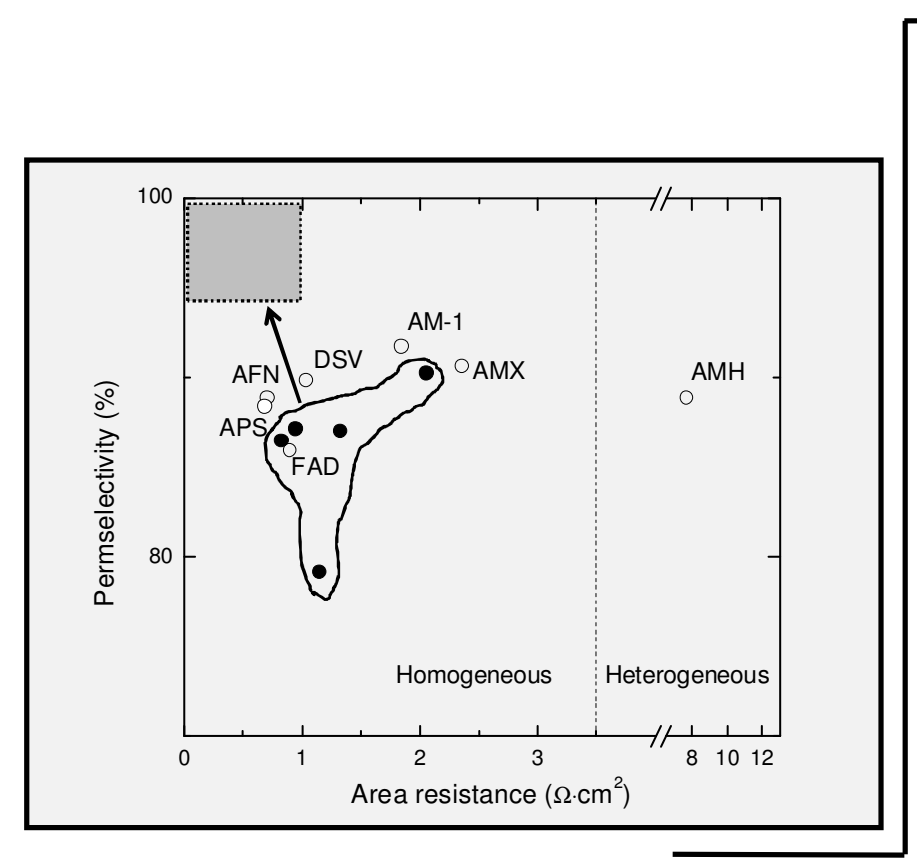




\begin{abstract}
This final chapter summarizes the general conclusions of this research on reverse electrodialysis as a sustainable energy generating technology as discussed in this thesis. The main focus of the research was on the fabrication, characterization and application of anion exchange membranes, as no up-to-date research on membranes specifically designed for RED existed so far. This needs to be addressed in order to understand the potential of RED for a full-scale technology that generates electricity in a sustainable way. This study covers four different approaches: 1) fabrication of tailor-made homogeneous anion exchange membranes, 2) determination of dominating membrane properties in RED performance, 3) fabrication of monovalent ion selective membranes and surface modification, and 4) design and optimization of microstructured membranes. Furthermore, some challenges are discussed and directions for future development of the RED process are suggested.
\end{abstract}




\subsection{General conclusions}

This $\mathrm{PhD}$ thesis investigates the design and optimization of the reverse electrodialysis process, with the main focus on anion exchange membrane fabrication, characterization and application.

In Chapter 2, the fabrication of homogenous anion exchange membranes in a singlestep, environmentally-friendly method using a pre-halogenated polyether, polyepichlorohydrin $(\mathrm{PECH})$ is described. To the best of our knowledge, for the first time tailor-made homogeneous anion exchange membranes were tested in a real RED stack. It was seen that thinner membranes performed better as they had lower area resistances compared to that of relatively thick membranes. Very thin anion exchange membranes with a thickness of $33 \mu \mathrm{m}$ could be fabricated with a very low area resistance of $0.82 \Omega \cdot \mathrm{cm}^{2}$, resulting in the highest power density $\left(1.27 \mathrm{~W} / \mathrm{m}^{2}\right)$.

To optimize the membrane properties such as area resistance and permselectivity, the blending ratio of active polymer PECH to supporting polymer PAN and the relative amount of the aminating agent, $\mathrm{DABCO}$, in the film forming solution (i.e. membrane casting solution) were varied. As the relative amount of PECH increases in the membrane casting solution, the area resistance exhibited a decreasing trend, as there are more functional groups available for amination, which increases the ion-conducting properties. On the other hand, permselectivity decreased with increasing blend ratios. This variation was attributed to the increasing degree of swelling with increasing blend ratio. When the amount of aminating agent was increased in the membrane casting solution, it was observed that, up to a certain amount, permselectivity improved and area resistance decreased due to the simultaneous amination and crosslinking reactions. At higher values of aminating agent, the variation of these parameters was almost independent.

In Chapter 3, in addition to the tailor-made anion exchange membranes designed in Chapter 2, also cation exchange membranes were fabricated to be used in a RED stack. Sulfonated polyether ether ketone (SPEEK) was used to prepare cation exchange membranes without any reinforcement. Solvent evaporation was employed to get a dense membrane structure. Thus, we were able to built the complete stack only with tailor-made ion exchange membranes of which we could tune the properties easily. The performance of the stack with these membranes was later compared to that with commercially available membranes. For that, various RED stacks were built. Model seawater (30 $\mathrm{g} \mathrm{NaCl} / \mathrm{l})$ and river water $(1 \mathrm{~g} \mathrm{NaCl} / \mathrm{l})$ were prepared as feed 
solutions. It was observed that the highest gross power density $\left(1.3 \mathrm{~W} / \mathrm{m}^{2}\right)$ was observed with the stack built with tailor-made membranes relative to the stacks built with commercially available membranes.

For membrane designers, it is crucial to decide which membrane property is performance-determining in a RED process, as that defines the membrane fabrication routes and the ways how to optimize and improve that specific membrane properties. Thus, a sensitivity analysis, so-called 'ANalysis Of VAriance`, ANOVA, was performed to assess the effects and the respective contributions of the parameters (i.e. membrane bulk properties, e.g. area resistance and permselectivity) on the gross power density in a RED system. The results showed that a correlation exists between the membrane resistance and the gross power density, rather than between the permselectivity and the gross power density. A clear inverse correlation between area resistance and power density was found. Consequently, these findings help the membrane designers to draw some conclusions and make adequate strategies to design specific ion exchange membranes for RED.

In Chapter 4, the potential use of monovalent ion selective membranes in a RED system was investigated. When natural seawater and river water are used as feed solutions in RED, the presence of multivalent ions is inevitable. Multivalent ions have a performance declining impact on the ion exchange membranes, i.e. these ions increase the electrical resistance and, in most cases, decrease the permselectivity. Since these membrane properties are the main performance determining factors as determined in Chapter 3, the use of monovalent ion selective membranes that retain multivalent ions is proposed for the RED process. UV irradiation was used to coat anion exchange membranes with a negatively charged moiety (i.e. 2-acryloylamido-2methylpropanesulfonic acid, AMPS, was used as active monomer). Thus, the negatively charged multivalent ions can be retained to some extent through electrical repulsion forces. After modification of the anion exchange membranes, $8 \%$ reduction of sulfate flux was achieved due to the coating layer. That corresponds to a monovalent ion selectivity that can be assumed as good as the commercially available Neosepta ACS membrane. Since the coating layer was negatively charged, it has also a capability to retain negatively charged matter, like organic foulants, e.g. sodium dodecylsulfate (SDS). As expected it was found that a delay in fouling was observed when the membranes were coated. The application of such oppositely charged coating layer thus corresponds to a simultaneous improvement of both the monovalent ion selectivity and the antifouling property of anion exchange membranes. 
Surface properties of the obtained membranes were characterized using e.g. SEM-EDX, XPS, roughness and contact angle measurements. SEM-EDX analyses showed that the thickness of the coating layer was about $1.5 \mu \mathrm{m}$, which can be assumed as very thin. Thus, due to the thin coating layer, the area resistance of the obtained membranes did not increase significantly and standard permselectivity improved very slightly. This makes the use of such membranes advantageous over commercial monovalent ion selective anion exchange membranes (ACS and ASV), which have relatively high area resistances. However, the beneficial use of monovalent ion selective membranes was found to depend on the ionic composition of the river water. The results showed that it would be more beneficial to use such membranes in RED when there is a relatively high content of multivalent ions in the river water.

In Chapter 5, the fabrication of micro-structured membranes is described. The aim of this work was to eliminate the use of non-conductive spacers, which reduce the effective area for ionic transport thus reducing the RED performance. For that purpose, structured anion exchange membranes with integrated flow channels were designed having different surface geometries, i.e. straight ridges, waves or pillars. This was done by casting the membrane forming solution on stainless steel microstructured molds followed by solvent evaporation, which later creates perfect replicas of the molds. This was the first time that homogeneous microstructured ion exchange membranes were tested in a RED stack. As homogeneous membranes usually have lower area resistances than their heterogeneous counterparts, the use of homogeneous membranes is more advantageous. The use of micro-structured membranes was successful such that $38 \%$ higher gross power density was achieved (for the pillarstructured membranes) when compared to that of flat membranes at the same Reynolds numbers. Another very crucial advantage of the use of micro-structured membranes in a RED stack is that the hydraulic friction is significantly lower compared to that of the stack with flat membranes where the use of spacers is required. The knits of the filaments of the spacers behave as obstacles to fluid flow in the feed compartments thus increasing the hydraulic friction. High hydraulic frictions refer to high pumping costs that decrease the net power density and is undesired in a RED system. Consequently for the pillar-structured membranes, next to a higher gross power density, also a $20 \%$ higher net power density was obtained when compared to their flat equivalents. 


\subsection{Outlook}

\subsubsection{Further development of membranes and alternative routes for production}

The highest practical RED power density measured was recently reported by Vermaas et al. as $2.2 \mathrm{~W} / \mathrm{m}^{2}$ using $100 \mathrm{\mu m}$ intermembrane distances [1]. That achievement already meets the desired goal for a commercially attractive RED process [2]. However, there is still room for development of a more economically feasible RED system. Ion exchange membranes are termed as core elements of RED by several authors, and the importance of the ion exchange membranes in RED was already mentioned explicitly [2-4]. However, most research was done for standard ion exchange membranes designed for electrodialysis. Development of specific ion exchange membranes for RED is still not a mature technology and the way to go is still long, broad and undefined.

Further research should focus on development of ion exchange membranes that have especially lower area resistance but also even higher permselectivity. Post et al. indicated already that the membranes for RED should have low area resistance $(<3$ $\Omega \cdot \mathrm{cm}^{2}$ ), and a high permselectivity of $95 \%$ or more [2]. In this work, anion exchange membranes obtained have already very low area resistances $\left(<1 \Omega \cdot \mathrm{cm}^{2}\right)$, which gave excellent performance in RED [5-6]. However, permselectivity of these membranes could still be improved further as we obtained a permselectivity of about 90\% [5-6]. Figure 1 shows a representation of the characteristics of a few current membranes (i.e. permselectivity vs. area resistance), and the final goal (indicated as gray region) for such membranes in order to obtain high performance in RED.

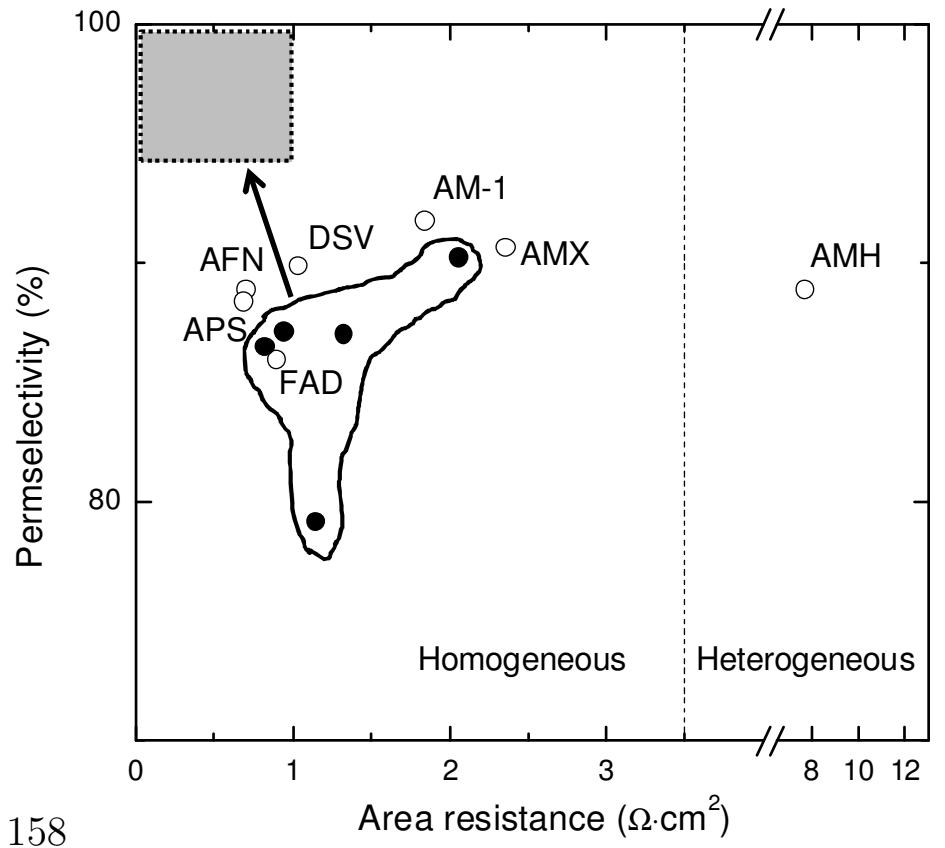

Figure $\quad$ 6.1. Schematic representation of the relation between permselectivity and area resistance of anion exchange membranes ( $\bullet$ tailor-made anion exchange membranes (PECH) obtained in this work; 0 commercially available anion exchange membranes). The final goal is to fabricate membranes that have the properties corresponding to the gray region indicated at the topleft of the graph. 
In this work, we have found that the area resistance of the ion exchange membranes had strong influence on the RED performance, and that the thinner membranes had a significant advantage over relatively thick ones. In that sense, membrane designers should follow that direction. Ion exchange membranes with a homogeneous character without any reinforcement have definitely huge benefits in RED since such membranes usually have low area resistances. Membranes with lower film thickness have also similar benefits in terms of having low area resistances. In this work, we manage to make membranes as thin as about $30 \mu \mathrm{m}$ without any defects, which is already a big step in the development of the RED process [6]. However, there is still possibility to make them thinner with good mechanical and electrochemical properties.

Polyepichlorohydrin $(\mathrm{PECH})$ seems to be a very promising material for the fabrication of RED membranes. Not only because it has the possibility to obtain high ion exchange capacity and good conductive properties, but also because the processing stage to make membranes is a single-step process and environmental friendly (i.e. no use of chloromethyl methylether). Other alternative methods, which can be assumed as promising from an environmental point of view, are bromination and subsequent amination of benzyl containing polymers (e.g. poly(2,6-dimethyl-1,4-phenylene oxide, PPO) [7]; or a vinylpyridine process involving quaternaryamination with iodomethane [8]. However, the fabrication process using these raw materials usually requires a batch-wise process since most methods require thermal treatment for functionalization reactions followed by solvent evaporation. Perhaps that makes these methods less attractive for large-scale membrane production. On the other hand, UV curable monomers, such as monomers with acrylic groups, can also be considered for further research [9]. UV induced processes usually require relatively shorter time scales, thus can be considered better candidates for scale-up production because of the flexibility of the process towards a continuous operation.

Since the operation of ion exchange membranes in RED is in mild conditions (i.e. seawater and river water media), extreme chemical stability is not a priority in designing such membranes. However, to get insight about the lifetime of the membranes, e.g. high temperature stability, durability against oxidation can be tested.

Fouling of membranes is a common problem in all membrane processes. The same issue counts for RED as well. Generally, anion exchange membranes are more sensitive to fouling than cation exchange membranes [10]. Therefore, more attention should be paid to the development of anti-fouling anion exchange membranes. In other membrane processes, the concept of electrostatic repulsion of organic foulants by coating layers integrated on the membrane surface is a widely used technique to 
improve the antifouling potential. However, simultaneous improvement of the monovalent ion selectivity of the membranes should be provided during the fabrication of such membranes. Therefore, new materials (for instance, polyelectrolytes) should be employed as surface modification materials. In addition, membranes are not the only elements that can solely solve the fouling problem in the RED system. Not only antifouling membranes should be taken into account, but also different methods for pretreatment of the feed water before the use in the stack should be extensively investigated to remove fouling and scaling in RED. Hydrodynamic limitations, pumping costs should be carefully evaluated as well.

Of course one of the most crucial bottlenecks is the membrane price. Currently available ion exchange membranes still have high prices $\left(>80 € / \mathrm{m}^{2}\right)$ [11]. Since relatively thinner ion exchange membranes without reinforcement are favorable for RED, the potential of price reduction of such membranes is large for the RED applications due to the low amount of raw materials required compared to that for electrodialysis membranes. Additionally, when successful, RED will be an extremely large scale operation, requiring much larger membrane areas than currently employed in ED or other electromembrane processes. The economy of scale also offers potential for a further significant price reduction.

\subsubsection{Hydrodynamics and stack design}

Hydrodynamic limitations, boundary layer resistances and the spacer-shadow effect in the stack reduce the practical power output in RED. New stack designs, new spacers or structured membrane concepts should be considered for future development of RED.

The stack used in this study is not fully optimized yet. To reduce the pressure drop and to obtain a better flow distribution over the membrane surface, new inflow/outflow designs should be practically implemented. Instead of only one inlet/outlet for each feed water stream (i.e. seawater and river water), multiple inlet designs should be considered. Membrane geometry also plays an important role in the flow pattern of feed solutions. Structured membranes with a channel-wise geometry are a good remedy to reduce the pressure drop (i.e. pumping power), as investigated in this work as well. However, when using such membranes, flow distribution should be carefully taken into account. Instead of continuous ridges (e.g. channels) on the membrane surface, segmented ridges can be designed in such a way that preferential flow is prohibited. Tear-drop shapes on the membrane surface are also a of big interest to make innovative RED membranes because these structures eliminate the dead zones or recirculation zones in the stack and provide a more efficient use of active membrane 
area [12]. Since better mixing together with a lower pressure drop is a vital requirement for high RED performance, geometries such as helical structures, which can simultaneously provide low pressure drop and better mixing, can be considered.

The problem regarding the spacer shadow effect has already been solved by structured membranes [13] and ion conductive spacers [14]. However, more attention should be paid to the river water compartment since the electrical resistance of this compartment is high due the low ionic content and, thus, still dominating the RED performance. As mentioned already, elimination of non-conductive spacers by the replacement of structured membranes is a good solution, however new alternatives can also be considered, such as integration of ion exchange resins in the river water compartment. This will significantly increase the conductivity of this compartment. Of course, optimization of such systems should be carefully investigated.

Smaller stack designs are another alternative for the reduction of pressure drop as the distance between inlet and outlet will be reduced. A reduced pumping power allows smaller intermembrane distances and smaller residence times, which would reduce boundary layer resistances and ohmic stack resistance [15]. These benefits of the smaller stacks (i.e. smaller cell length) would always provide higher net power density. On the other hand, for large scale RED stack production, spiral-wound RED stacks may be considered as in the sense of reverse osmosis membranes. Leakage problem is less likely in spiral-wound systems compared to flat-sheet stack designs where gaskets are needed for sealing. However, this seems still a big challenge. 


\subsection{References}

[1] D.A. Vermaas, M. Saakes, K. Nijmeijer, Doubled power density from salinity gradients at reduced intermembrane distance, Environmental Science and Technology, 45 (2011) 7089-7095.

[2] J.W. Post, C.H. Goeting, J. Valk, S. Goinga, J. Veerman, H.V.M. Hamelers, P.J.F.M. Hack, Towards implementation of reverse electrodialysis for power generation from salinity gradients, Desalination and Water Treatment, 16 (2010) 182-193.

[3] R. Audinos, Electrodialyse inverse. Etude de l'energie electrique obtenue a partir de deux solutions de salinites differentes, Journal of Power Sources, 10 (1983) 203-217.

[4] P. Długołecki, K. Nymeijer, S. Metz, M. Wessling, Current status of ion exchange membranes for power generation from salinity gradients, Journal of Membrane Science, 319 (2008) 214-222.

[5] E. Güler, R. Elizen, D.A. Vermaas, M. Saakes, K. Nijmeijer, Performance-determining membrane properties in reverse electrodialysis, Journal of Membrane Science, 446 (2013) 266-276.

[6] E. Guler, Y. Zhang, M. Saakes, K. Nijmeijer, Tailor-Made Anion-Exchange Membranes for Salinity Gradient Power Generation Using Reverse Electrodialysis, ChemSusChem, 5 (2012) 2262-2270.

[7] Y. Li, T. Xu, Fundamental studies of a new series of anion exchange membranes: Membranes prepared from bromomethylated poly(2,6-dimethyl-1,4-phenylene oxide) and 4-vinylpyridine, Journal of Applied Polymer Science, 114 (2009) 3016-3025.

[8] L. Zongqing, L. Jianwu, Research on elimination of chloromethylation in preparation on anionexchange, Desalination, 56 (1985) 421-430.

[9] R. van Engelen, WO2010082069, Process for preparing membranes, in, the Netherlands, 2010.

[10] E. Korngold, F. de Körösy, R. Rahav, M.F. Taboch, Fouling of anionselective membranes in electrodialysis, Desalination, 8 (1970) 195-220.

[11] M. Turek, B. Bandura, Renewable energy by reverse electrodialysis, Desalination, 205 (2007) 67-74.

[12] I.S. Ngene, R.G.H. Lammertink, M. Wessling, W.G.J. Van der Meer, Particle deposition and biofilm formation on microstructured membranes, Journal of Membrane Science, 364 (2010) 43-51.

[13] D.A. Vermaas, M. Saakes, K. Nijmeijer, Power generation using profiled membranes in reverse electrodialysis, Journal of Membrane Science, 385-386 (2011) 234-242.

[14] P. Długołęcki, J. Dąbrowska, K. Nijmeijer, M. Wessling, Ion conductive spacers for increased power generation in reverse electrodialysis, Journal of Membrane Science, 347 (2010) 101-107.

[15] D.A. Vermaas, E. Guler, M. Saakes, K. Nijmeijer, Theoretical power density from salinity gradients using reverse electrodialysis, Energy Procedia, 20 (2012) 170-184. 


\section{Summary}

Reverse electrodialysis (RED) is a clean, sustainable, and thus a promising and potentially attractive technology for the generation of energy from the mixing of solutions with different salinity. It utilizes the free energy of mixing these solutions (e.g. river water and seawater) to generate power. In RED, a concentrated salt solution and a less concentrated salt solution are brought into contact through ion selective membranes (anion exchange membranes, AEMs, and cation exchange membranes, CEMs) that are alternately patterned in a stack. Anion exchange membranes allow only anions to pass through towards an anode and cation exchange membranes allow only cations to pass through towards a cathode. At the electrodes a redox couple is used to provide the transfer of electrons through an external circuit, thus creating power. The ion exchange membranes are key elements in RED. Especially the study of anion exchange membranes is crucial since the fabrication is complex and limited research has been done specifically for RED. This $\mathrm{PhD}$ thesis investigates the design and development of the RED process, with a special focus on fabrication, characterization and optimization of anion exchange membranes.

Chapter 2 deals with the fabrication of homogeneous anion exchange membranes in a simple, environmentally friendly manner. Different membrane properties and characterization methods are studied and implemented. The directions towards how to tune membrane properties specifically for RED are defined. The results suggest that PECH membranes are good materials for a viable RED process. Very low area resistances with good permselective properties were obtained in a single-step process. In addition, the membrane thickness should be as low as possible to generate high power outputs in RED. With this study, for the first time, it was shown that tailormade anion exchange membranes installed in a RED stack increase the power obtainable from the mixing of seawater and river water.

As a next step, it was investigated which membrane property dominates and how to correlate the membrane properties to the RED performance. To clarify this, Chapter 3 systematically investigates the bulk membrane properties of both a series of commercially available membranes and tailor-made membranes (both anion and cation exchange membranes) and correlates these to experimental RED performance data. The results set directions to decrease the area resistance rather than to improve permselectivity because area resistances of the membranes were found to be the dominant parameter regarding RED performance. This was the first time that a RED stack was constructed with only tailor-made membranes of which the properties could 
be easily tuned. In addition, the performance of such a RED stack exhibited the highest gross power density $\left(1.3 \mathrm{~W} / \mathrm{m}^{2}\right)$ relative to the stacks with commercially available membranes. The results are of high importance as they show the directions towards tailoring ion exchange membranes for RED applications.

In Chapter 4, the practical potential of monovalent ion selective anion exchange membranes is further investigated. As RED in natural conditions requires the use of natural seawater and river water, the presence of multivalent ions in the feed is inevitable. These ions have a decreasing effect on the power output in RED. To prevent this undesired effect, monovalent ion selective membranes were fabricated by using UV irradiation and a standard commercial anion exchange membrane was coated with an additional cation exchange layer, making the membrane monovalent selective. A monovalent selectivity comparable to that of the commercially available monovalent ion selective membranes was achieved. Obtained membranes with their negatively charged coating layer exhibited increased hydrophilicity and sufficient antifouling potential against organic foulants, resulting in minimized power density losses in RED.

Chapter $\mathbf{5}$ is dedicated to the fabrication of micro-structured membranes that eliminate the spacer shadow effect. The spacer shadow effect occurs when nonconductive spacers are used to separate membranes from each other in the RED stack. Because of their non-conductive character, they reduce the effective area of the membranes for ionic transport resulting in low power outputs obtainable in RED. To eliminate the use of these spacers, structured anion exchange membranes having a structure height of $100 \mu \mathrm{m}$ were fabricated by casting a polymer solution on microstructured stainless steel molds followed by solvent evaporation. Self-standing, non-reinforced anion exchange membranes were obtained having straight-ridge, wave or pillar structures. Pillar-structured membranes exhibited a more uniform flow distribution compared to that of other types. $21 \%$ lower ohmic resistance was obtained by the use of pillar-structured membranes compared to the stack with flat membranes. That resulted in $38 \%$ higher gross power density and $20 \%$ higher net power density.

The last part of this thesis, Chapter 6 discusses the future potential of the RED process as a clean, sustainable energy generating technology. It indicates the directions to further optimize, design and develop the process in two main aspects: membrane design and development; and hydrodynamics and stack design. It briefly presents the main insights that were experienced in this $\mathrm{PhD}$ thesis, that need to be addressed to make the RED process a full scale, commercially attractive technology for salinity gradient power generation. 


\section{Samenvatting}

Omgekeerde elektrodialyse (RED) is een schone, duurzame en dus veelbelovende en potentieel aantrekkelijke technologie om energie te genereren uit het mengen van oplossingen met verschillende zoutconcentraties. Het gebruikt de verandering in Gibbs energie die optreedt bij het mengen van oplossingen met verschillende zoutconcentraties (bijv. zee en rivierwater) om elektriciteit op te wekken. Bij RED worden een geconcentreerde en een minder geconcentreerde zoutoplossing met elkaar in contact gebracht door middel van ionselectieve membranen (anionuitwisselingsmembranen (AEM) en kation-uitwisselingsmembranen (CEM)) die alternerend worden gestapeld en zo een stack vormen. Anion-uitwisselingsmembranen laten alleen anionen passeren in de richting van de anode, terwijl kationuitwisselingsmembranen alleen kationen richting de kathode doorlaten. Aan de elektrodes wordt een redoxkoppel gebruikt om het ionentransport om te zetten in elektronentransport, dat vervolgens via een extern circuit gebruikt kan worden. Deze ionuitwisselingsmembranen spelen een essentiële rol in RED. Vooral de studie naar anion-uitwisselingsmembranen is cruciaal omdat de huidige fabricagemethoden complex en belastend zijn en er slechts beperkt onderzoek is gedaan naar de ontwikkeling van deze membranen, zeker voor toepassing in RED. Dit proefschrift onderzoekt het ontwerp en de ontwikkeling van het RED proces, met een speciale focus op fabricage, karakterisatie en optimisatie van anion-uitwisselingsmembranen.

Hoofdstuk 2 beschrijft de fabricage van homogene anion-uitwisselingsmembranen door middel van een eenvoudige, milieuvriendelijke methode. Verschillende membraaneigenschappen en karakterisatiemethoden zijn onderzocht en geïmplementeerd. Er is een richting gedefinieerd om de membranen zo te ontwerpen dat deze geschikt zijn voor RED. De resultaten wijzen erop dat PECH membranen goed zijn voor een haalbaar RED proces. In een éénstapsproces zijn membranen ontwikkeld met een zeer lage weerstand gecombineerd met een hoge permselectiviteit. De membranen moeten zo dun mogelijk zijn, om een zo hoog mogelijk vermogen in RED te genereren. Met deze studie is voor het eerst aangetoond dat de ontwikkeling van membranen specifiek voor RED leidt tot een verhoging van het op te wekken vermogen uit het mengen van zee en rivierwater.

Als volgende stap is onderzocht welke membraaneigenschappen dominant zijn voor en hoe deze gecorreleerd kunnen worden aan de RED prestaties. Hiervoor is in hoofdstuk 3 systematisch onderzocht wat het effect is van verschillende membraaneigenschappen op het opgewekte vermogen in RED voor zowel commercieel verkrijgbare electrodialyse 
membranen als voor speciaal voor RED ontwikkelde membranen (zowel anion- als kation-uitwisselingsmembranen).. De gekozen route voor de bereiding van de membranen maakt het mogelijk de membraaneigenschappen relatief eenvoudig en systematisch te variëren. De resultaten laten zien dat een verlaging van de membraanweerstand een groter effect heeft op de verhoging van het vermogen dan een verlaging van de permselectiviteit., Met name de membraanweerstand is dominant waar het de RED prestaties betreft. In het onderzoek is voor het eerst het vermogen bepaald van een RED-stack geconstrueerd met alleen specifiek voor RED ontwikkelde membranen. Daarbij lieten de prestaties van deze RED-stacks de hoogste waarden zien voor het vermogen $\left(1.3 \mathrm{~W} / \mathrm{m}^{2}\right)$. Dit toont het belang van de ontwikkeling van membranen speciaal voor RED aan.

In hoofdstuk 4 is de praktische potentie van monovalent ion selectieve anionuitwisselingsmembranen onderzocht. Omdat RED in praktische applicaties zee- en rivierwater gebruikt, is het niet te vermijden dat er multivalente ionen in deze type waters aanwezig zijn. Deze ionen hebben een negatief effect op de prestaties in RED en verlagen het vermogen. Om dit ongewilde effect te voorkomen, zijn monovalent selectieve membranen ontwikkeld. Een standaard commercieel anionuitwisselingsmembraan is gecoat met een extra kation-uitwisselingslaagje met behulp van UV-polymerisatie, om zo het membraan monovalent selectief te maken. De zo geintroduceerde monovalente selectiviteit is vergelijkbaar met die van commercieel beschikbare monovalent ionselectieve membranen.. De verkregen membranen met negatief geladen coatingslaag hadden een verhoogd hydrofoob karakter, terwijl de weerstand nauwelijks verhoogd was. Dien ten gevolge hebben deze membranen een verhoogde weerstand tegen membraanvervuiling, terwijl het op te wekken vermogen in RED niet beïnvloed wordt.

Hoofdstuk 5 is gewijd aan de fabricage van micro-gestructureerde membranen met als doel het elimineren van het zogenaamde spacer-schaduw effect. Het spacer schaduweffect treedt op wanneer niet-geleidende spacers worden gebruikt om de membranen in de RED stack van elkaar te scheiden. Door de niet-geleidende eigenschappen verminderen de spacers het membraanoppervlak dat effectief beschikbaar is voor ionentransport, resulterend in een lagere energieopbrengst. Om dit effect te elimineren, zijn de membranen en spacers vervangen door microgestructureerde membranen, die de membraan- en spacer-functionaliteit integrereren. Deze membranen zijn gestructureerde anion-uitwisselingsmembranen met een structuurhoogte van $100 \mu \mathrm{m}$ gefabriceerd door het strijken van een polymeeroplossing op micro gestructureerde roestvrijstalen mallen, gevolgd door verdamping van het 
oplosmiddel. Op deze manier zijn homogene, microgestructureerde anionuitwisselingsmembranen verkregen met rechte kanalen, een golfpatroon of met pilaren. De pilaar-gestructureerde membranen vertoonde de meest uniforme stromingsverdeling. Tevens resulteerde het gebruik van deze membranen in RED in een $21 \%$ lagere Ohmse weerstand, een $38 \%$ hoger bruto vermogen en een $20 \%$ hogere netto energieopwekking.

Het laatste deel van dit proefschrift, hoofdstuk 6, beschrijft het een toekomstvisie op de ontwikkeling van het RED proces als een schone, duurzame energietechnologie. Het presenteert kort de belangrijkste inzichten die zijn beschreven in dit proefschrift. Daarnaast geeft het richting voor verdere optimalisatie van ontwerp en proces met betrekking tot twee hoofdaspecten: membraanontwerp en hydrodynamica en stack ontwerp,met als doel om het RED proces op grote schaal commercieel aantrekkelijk te maken voor het opwekken van energie uit zoutgradiënten. 


\section{About the author}

Enver Güler was born on the $22^{\text {nd }}$ of February, 1984 in Kardzhali, Bulgaria. In 1989, his family immigrated to Turkey. After primary school, he had received the high school diploma with the highest grade from Anibal Anatolian High School in Kocaeli, Turkey, and he started studying chemical engineering in Ege University in Izmir, Turkey. Related to chemical engineering studies, he performed his internships in Bayer Cropscience (in 2005) and Unilever (in 2006) in Kocaeli, Turkey. In the last year of his bachelor studies, he worked on a diploma project based on removal of heavy metals from water by electrodeionization process. In August 2007, he continued working for his Master degree at the same university. His master studies covered desalination by reverse osmosis and boron removal from reverse osmosis permeate. During his master education in 2008, he visited Technion University, Haifa, Israel, to study the effect of halogen based disinfectants on the performance of polyamide reverse osmosis membranes. After a year he successfully completed his MSc at Ege University, Izmir, Turkey. From October 2009 to October 2013 he worked in the Membrane Science and Technology Group at the University of Twente as a PhD student. The project was in close collaboration with Wetsus - water research institute located in Leeuwarden, the Netherlands, and it was focusing on the research topic presented in this dissertation: anion exchange membrane design for reverse electrodialysis. In May 2012 during his $\mathrm{PhD}$, he started working in FujiFilm company as a visiting researcher, and focused on the design of ion exchange membranes for reverse electrodialysis for almost a year. Since October 2013, he works at Wetsus as a Post-Doctoral researcher on selective sodium removal from irrigation water.

\section{Conferences}

October $2009 \quad$ NPS9, Veldhoven, the Netherlands

June 2010 EMS summer school, Bucharest, Romania

October $2010 \quad$ NPS10, Veldhoven, the Netherlands - poster presentation

July $2011 \quad$ NYM13, Enschede, the Netherlands

July 2011 ICOM 2011, Amsterdam, the Netherlands - organizing committee and poster presentation

September 2011 MESA+ meeting, Enschede, the Netherlands - poster presentation 
October $2011 \quad$ NPS11, Arnhem, the Netherlands - oral and poster presentation

April $2012 \quad$ Technoport, Trondheim, Norway - oral presentation

June 2012 Membrane symposium and poster day, Shell technology center, Amsterdam, the Netherlands

September 2012 Euromembrane 2012, London, UK - poster presentation

October 2012 MESA+ meeting, Enschede, the Netherlands - oral and poster presentation

September 2013 MESA+ meeting, Enschede, the Netherlands

\section{Courses}

March $2010 \quad$ Introduction TGS, Enschede, the Netherlands

April $2010 \quad$ Sustainable process, product and system design, Groningen, the Netherlands

February $2011 \quad$ Technical writing and editing, Enschede, the Netherlands

March $2011 \quad$ Professional effectiveness, Enschede, the Netherlands

April $2011 \quad$ Molecular Affinity Separations, Eindhoven, the Netherlands

June $2011 \quad$ Research management, Enschede, the Netherlands

June 2011 Membrane Technology, Enschede, the Netherlands

March $2013 \quad$ Fundamentals and practice of process intensification, Delft, the Netherlands

\section{Publications}

E. Guler, J. Piekacz, D. Ozakdag, W. Kujawski, M. Arda, M. Yuksel, N. Kabay, Influence of the chosen process parameters on the efficiency of seawater desalination: SWRO pilot plant results at Urla Bay seashore, Desalination and Water Treatment, 5 (2009) 167-171.

N. Kabay, E. Güler, M. Bryjak, Boron in seawater and methods for its separation-a review, Desalination, 261 (2010) 212-217. 
H. Koseoglu, B. Harman, N. Yigit, E. Guler, N. Kabay, M. Kitis, The effects of operating conditions on boron removal from geothermal waters by membrane processes, Desalination, 258 (2010) 72-78.

E. Guler, D. Ozakdag, M. Arda, M. Yuksel, N. Kabay, Effect of temperature on seawater desalination-water quality analyses for desalinated seawater for its use as drinking and irrigation water, Environmental geochemistry and health, 32 (2010) 335339.

E. Güler, N. Kabay, M. Yüksel, E. Yavuz, Ü. Yüksel, A comparative study for boron removal from seawater by two types of polyamide thin film composite SWRO membranes, Desalination, 273 (2011) 81-84.

E. Güler, N. Kabay, M. Yüksel, N. Yiğit, M. Kitiş, M. Bryjak, Integrated solution for boron removal from seawater using $\mathrm{RO}$ process and sorption-membrane filtration hybrid method, Journal of Membrane Science, 375 (2011) 249-257.

Ş.G. Öner, N. Kabay, E. Güler, M. Kitiş, M. Yüksel, A comparative study for the removal of boron and silica from geothermal water by cross-flow flat sheet reverse osmosis method, Desalination, 283 (2011) 10-15.

E. Yavuz, E. Güler, G. Sert, Ö. Arar, M. Yüksel, Ü. Yüksel, M. Kitiş, N. Kabay, Removal of boron from geothermal water by RO system-I-Effect of membrane configuration and applied pressure, Desalination, 310 (2012) 130-134.

E. Guler, Y. Zhang, M. Saakes, K. Nijmeijer, Tailor-Made Anion-Exchange Membranes for Salinity Gradient Power Generation Using Reverse Electrodialysis, ChemSusChem, 5 (2012) 2262-2270.

D.A. Vermaas, E. Guler, M. Saakes, K. Nijmeijer, Theoretical power density from salinity gradients using reverse electrodialysis, Energy Procedia, 20 (2012) 170-184.

E. Güler, R. Elizen, D. Vermaas, M. Saakes, K. Nijmeijer, Performance-determining membrane properties in reverse electrodialysis, Journal of Membrane Science, 446 (2013) 266-276.

E. Güler, W. van Baak, M. Saakes, K. Nijmeijer, Monovalent-ion-selective membranes for reverse electrodialysis, Journal of Membrane Science, (2013) submitted manuscript.

E. Güler, R. Elizen, M. Saakes, K. Nijmeijer, Micro-structured membranes for electricity generation by reverse electrodialysis, Journal of Membrane Science, (2013) submitted manuscript. 


\section{Acknowledgements}

It has been four years -very significant four years of my life, since I started my $\mathrm{PhD}$. Now this journey has come to an end and I am happy and proud to be able to complete an important stage of my life with this scientific book in my hands. I would like to express my sincere gratitude to all the people without whom this book would not be possible and my $\mathrm{PhD}$ life would not have a meaning. For those who I forgot, I will owe you a drink and do my best to make you forgive me.

First I owe my deepest gratitude to my daily supervisor and my promotor Prof. Dr. Ir. Kitty Nijmeijer who gave me the opportunity to start this $\mathrm{PhD}$ project. I still remember that morning when you called me very early on the phone to inform I was accepted for the project. I cannot really describe that happiness with words. Kitty, thank you for your trust and continuous encouragement. You always believed in me from the beginning on, and without you, I would not be able to stand here today, with my thesis in my hands.

I wish to thank Dr. Michel Saakes, my supervisor from Wetsus. Thank you for your inspiring ideas, your guidance, support, endless scientific discussions and your valuable corrections in my papers.

I would also like to thank my promotion committee for reading the draft of this thesis, and giving the approval to defend it publicly. I would like to thank Prof. Dr. Nalan Kabay, who was also my MSc supervisor at the Chemical Engineering Department, Ege University, in Turkey. You are the first person who introduced me membranes in the last year of my Bachelor studies more than six years ago. You contributed a lot to my scientific life and I certainly learnt a lot from you, especially how to `stand on my own feet ' and struggle in life and never to give up. Now it is a great honor for me that you agreed to be a member of my PhD graduation committee. Dr. Barbara L. Mojet, Prof. Dr. Johan F.J. Engbersen, Prof. Dr. Luuk C. Rietveld and Dr. Ir. Bert Hamelers, it is an honor for me that you agreed to be part of this special day.

The next person, Prof. Dr. Marek Bryjak from Wroclaw University of Technology is actually the one who had advised me to apply Wetsus for a possible $\mathrm{PhD}$ position. Special thanks for your final push to start this $\mathrm{PhD}$ period, without you, most probably I would not be here today.

I would like to thank all the members of the research theme Blue energy 'The REDarmy soldiers` and CAPMIX researchers. Ir. Maarten van Riet, thanks for being the leader of our theme, and for your ideas and encouragement during our theme meeetings. David, thank you for all the help -always with encouraging mood. I will always remember our endless discussions and your smart ideas. You are a true inventor! Joost, thanks for your valuable contributions to my work and suggestions for my papers. I always admired you because you are a great RED-scientist. Especially important was the close collaboration I had with the FujiFilm company in Tilburg. For almost a year, I had chance to work in a fascinating ‘company atmosphere`. Willem, thanks a lot for creating such an opportunity for me and showing me the world of membrane production in industrial scale. We were a great team with 
Jacko, Bas, Vinod, Harro, Theo and Ronny. Henk and Ingrid, thank you to both of you for the help and guidance whenever I needed in the building. Of course I should thank to analytical and technical supports of Dennis, Willemien, Martin and Rensel. Big thank you to all of you.

Yali, Thijs, Mirjam, Anita and Rianne, the students who contributed a lot to this project; without you I would not be able to finish this thesis. Yali, we designed the first tailor-made membranes for RED together. I will never forget your endless efforts and your friendly character. Now, you are also a PhD student and you are not my student anymore. But I know I have a great friend instead. Big thanks to you! Thijs, thank you for your kindness and efforts. Mirjam, thank you too for your modest character. I hope you are doing fine now. Anita, thanks as well for your efforts and contributions to improve our set-up. We have never managed to make the small stack run, but we learnt a lot from our experiences. And my last student during PhD, Rianne. I owe you a big thank you. We did significant amount of work together and thanks for the Dutch translation of the summary of my thesis. I wish you a great PhD life in Belgium.

Beyond science, of course, a special mention to Greet. You are 'the heart' of MST. I was always impressed and sometimes surprised how you could manage all the paper work and solve all the issues in the group. I am very sure nobody could survive without you there. You always had time for me as well whenever I came to your office to ask help. Thanks a lot to you.

And amazing person, John. I know you hear and feel me now. Sometimes words are not enough to express feelings, but I will try to do so now. I learnt a lot from you. You always put lots of efforts on my set-up and tried to solve all my technical problems. As said a million of thanks is not enough to express my gratitude to you. Thanks a lot for everything.

I want to thank to my office mates in MST as well. First we had an office with Katja, Ikenna and Giri. Katja, thanks for being vegetarian and helping me a lot in my first months of my $\mathrm{PhD}$. And also for coming to office earlier than me every day and for telling me not take Ikenna serious. Ikenna, my first days of my $\mathrm{PhD}$ were very chaotic since I did not get your jokes, but at the end it has always been very nice to share the office together. Giri, thanks for being silent and calm. Later on, Wojtek and Irdham joined us. Wojtek, thank you for being a smart and confident guy all the time, and passing the RPK exam that I failed in Utrecht. Now it is very nice to see that your family is growing, so I should not forget thanks for Joanna and the baby :). Irdham, thanks for eating your lunch in the office and creating an exotic smell in the office. After that, I moved to another office where I shared it with Olga, Kishore and Nazely. Olga, for now, I will only mentioned about you as my officemate. We shared the office(s) for about three years, so you are almost my non-changing officemate during my PhD. Thanks for almost being active for the group events, preparing stukjes for weeks, dancing in the office or doing acrobatic movements in front of Kitty, and always chatting/facebooking/texting to your other friends. Nazely, you are one of the few people that I know who have such a gentle and soft character. Thanks for your positive attitude and smile, your typical Spanish food that you cooked at Olga`s place and for finding a room for me to stay in the city center. Kishore, you stayed in the office for a short time, thanks for your friendship during that period. After a few months, I moved to a new office where I shared the place with Olga, Alhadidi and Harro. Alhadidi (Didi), thanks for being my ‘brother', your 
endless advice about life and later on being my colleague in FujiFilm. Harro, thanks for talking so much, but being very honest and being my ‘fishing buddy`. After Didi left, Ivonne and Anne Corine joined our office. Ivonne, for being silent and very warm to people. Anne Corine, for being the only one who smelled my DMSO solvent in the lab but being a nice friend in the same office during my last days in the group. And Namik, thanks for joining our group at the end, and for the funny conversations in Turkish. During my PhD, I had a great time with all of you, guys. Lots of thanks..

Outside of the office as well, I had great friends in the last four years, who made the working days nicer and with whom I also had nice activities outside the university. Karina, 'because you are amazing`! I am very sure, now, you have the life as you wish. Finally! Wika, my favorite technician. I cannot compensate just by giving thanks to you. You are the first one who taught me how to cast a membrane and how to characterize them. That already makes you special. Thanks a lot. Nicolas, my favorite French friend. Jigar, for being cool with your special movements at the parties. Mayur, for your friendship not only in Enschede but also in Tilburg. You and Tina made me feel better there as well. Marlon, for being a real princess. Jumeng, for being a hard-working Chinese guy. Sandra, Dimitris, Rob, Matthias, Nieck, Lydia, Ineke, Marcel, Erik v.V., Miriam, thanks for the nice talks and moments. Szymon, we have a lot of common hobbies that I realized later on :) like fishing, motorbikes and shooting. Thanks for letting me drive your bike in the campus although I did not have the license. Yusuf, thanks for never joining us in any event, but actually being very friendly and funny. Joris, thanks for knowing almost everything. Vic, for being my peer-review buddy. Kah, for asking me to check for the house for you before you moved to Enschede and for being the author of the most downloaded article in JMS. Salman, you were the first PhD student who has the name on a summer school, so-called Salman School. Sorry for not joining that but I knew it was very cool. Now new summer or winter schools are to be organized. I am sure Erik and Olga will make a perfect organization, and we will have chance to meet again. Jeroen and Beata, thanks for being my 'lunch' friends and for the nice chats during coffee breaks. Additional thanks to Jeroen for taking me to several conferences with his car, and also to the Scheveningen beach where I first got my Dutch sun tan. And Beata thanks for never joining the Wetsus events.

Here I would also like to thank to all my 'Wetsus friends', and especially to the ones who are actually a member of our group MST. Jordi, for joining the Blue energy team, now you and Timon will create a new atmosphere in the theme. Charu, thanks a lot for your neverending smile. I will join once to your meditation session. And Christina, thanks a lot for your friendship as well. Also for being the best photographer I have ever met, but mostly for helping me find a house in Leeuwarden by leaving your place to me. Now I really feel `home`. Thanks a lot.

Now I would like to go back to university again to continue my thanks. Antoine you always surprised me by being very sincere and friendly. The only thing that spoiled the nice moments was that you and Harmen had to give me safety advice in the lab all the time :) And Antoine, I still appreciate your visit to Wetsus every Thursday! Believe me! Harmen besides safety issues, we also did cool stuff together -like going to the Korn concert! I always 
appreciated your friendships, talks and borrels together. Thanks a lot to both of you. Zandrie, for your enthusiasm and interest in my project. Erik Roesink, for joining our group together with Wiebe. Now the group has a new future with a new atmosphere with you. Erik R., thanks a lot for all your help in the lab and always finding a solution to my chemistry problems in the lab. Herman, I heard that you are doing my stukje. I hope not..Instead I would like to thank you for your help about SEM.

Now I wanna thank Erik V., Damon and Krzysztof. I always admired you, guys, because I know I will never manage to be as cool as you. Erik V., with you our borrels were always legendary but lunchgym was a bad-timing for me. Sorry! Krzysztof (I checked again if I wrote your name correctly), thanks for being bald but also for being the most handsome guy in the group. Damon, I should specially thank you because you are special in your own way. You are a great actor, dancer and so many things you do perfectly except your $\mathrm{PhD}$ :) And big thanks for driving me with my stuff all the way to Leeuwarden. I will never forget your help. I would also like to thank Aura, here, for the smoking/coffee breaks, for the lovely friendship. I did not join you once for a beer, sorry for that and I still feel guilty :)

Gerard, I did not forget you. Thanks for being Gerardo and for sending invitations to play football that I have never managed to join. Roland, thanks for sharing the high-speed camera with me during my last experiments of my PhD. Arturo, my Mexican friend! Thank you for running non-stop 2h (maybe even more) and keeping Olga fit.

Next, I could not forget mentioning my housemates. First, my housemates in the university campus: Olga E., Dragana, Alina, Irina and Gabriella, and later on, Tri, Mehmet and Burcu. Thanks a lot, guys, for sharing my first few months in the Netherlands. After that, I moved to Enschede (city center) and had great housemates there too. My French: Martin and Florian; my Italians: Roberto, Vincenzo and Nicola; and my only Romanian (half Hungarian): Csaba. I will never forget all the nice talks in the house although we were busy somehow from time to time.

Luckily, I had also Turkish friends with whom I could enjoy talking my mother tongue. I would like to thank: Zeynep for being my neighbor in the group although it was for a very short time. Elif and Cem for the nice dinner in Zeytin and additional thanks to Elif for asking me to buy cigarettes from Turkey and for smoking. Gulistan for eventually getting the $\mathrm{PhD}$ position in Twente. Bade for all the sharing. Sertan, Ozlem and the baby thanks for the friendship and additional thanks to Sertan for being a fan of Fenerbahce. Muharrem for being the leader of the Turkish community in Twente. Hasan for having a great passion for Turkey. Engin for being the engine and for the nice talks in the coffee breaks. Can Altunlu for asking me to be the official photographer of your defense. Ramazan for your friendship. I will certainly mention Sinem my 'longest-term` Turkish friend in the group. Sinem thanks a lot for your calm and soft character. I am sure one day you will manage to make the best membranes ever. Outside the city Enschede, I would like to thank Selin (my paranymph`s paranymph). Thanks for your visits to Enschede from time to time. And Kadir (my other paranymph`s twin), thanks for your super cool character. You are a real friend. 
Now I think it is time to mention my paranymphs that I feel very lucky that our paths, somehow, crossed in the university. Olga, we have been friends for more than four years. So that already makes you one of the persons that know me the most. First of all, thanks for accepting my offer to be my paranymph. It would not be wrong if I say that I learnt the meaning of friendship from you. Thanks for being with me all the time and for your support whenever I needed you. There are, of course, many to mention but I need at least a whole page for this :) Besides that, thanks for never sharing your food with me, for making me carry your heavy mattresses and washing machine when you moved to Enschede, for dinners, BBQs at your place, for being a great sister to Michelle, for buying Strepsils ${ }^{\circledR}$ for me when I became ill, and coming with me to Waaier to print posters and getting lost in the building. To keep it short thanks for your existence.

My dude Can, my brother. I feel very lucky to have a friend like you. I will never forget our secret, low-level-quality conversations in Turkish, our fifty-times-per-day coffee breaks in the university, drinks at Moly (our favorite Kasteel Rouge) and getting emotional afterwards. Also your efforts to make me more social and your invitations to your place (especially when Laura was away :)). And Laura, thanks for being great complement to Can (You are one of the few persons in the world who have a great beauty on both inside and outside). Can, I have not finished yet! I am really grateful for your phone calls whenever I feel down or complicated. And I will always be grateful for whatever I learnt from you. Cok sagol CANiko.

I would also like to spend special words of thanks for the people who I met in the Ege University in Turkey and with whom I continue (and will forever continue) my friendship: Idil (abla), my sister. Thanks for your warm, heartfelt character. You gave a lot of support to me not only during my Master studies but also during my PhD. You became a great friend to me as years have passed. I hope you will manage to come to my $\mathrm{PhD}$ defense, but if you cannot, I will know your soul will be with me on that day (-). And my brother, Ozgur. I learnt a lot from you. I first did my membrane-related-research experiments with you during the last year of my bachelor studies. Now it is hard to believe how fast the years have passed. I know now you are on a holly duty for your country. Hope you will be safe back home. My golden-hearted friend Sema, the person with whom I appreciated talks and support a lot during my PhD. Still I could not manage to see you even though I came to Tarragona once. Now you are far away again -almost at the North Pole! You should stop moving (:) Thanks a lot. And I should not forget mentioning Guray who visited me several times (in fact the purpose was always work), while I have never visited you in Belgium. I am very happy to have a friend like you.

Last but not least, I would like to give special thanks to my family for being with me all the time in this journey. Canim ablam Ayfer Altinsoy, ailenle birlikte her zaman yanimda oldugunuz icin sana ve ailene sonsuz tesekkurler. Simdi ailemiz buyuyor. Aramiza biri daha katiliyor :) Mutluluk ve saglik hep sizlerle olsun. Canlarim benim. Ve tabii ki canim annem ve babam, Naciye ve Ali Guler. Ikiniz de ‘guzellerin guzelisiniz`. Sizler olmasaydiniz ne bugunlere gelebilirdim, ne de burada bu mutlu gunu yasayabilirdik. Sizleri cok seviyorum. HERSEY ICIN COK TESEKKUR EDERIM. 
